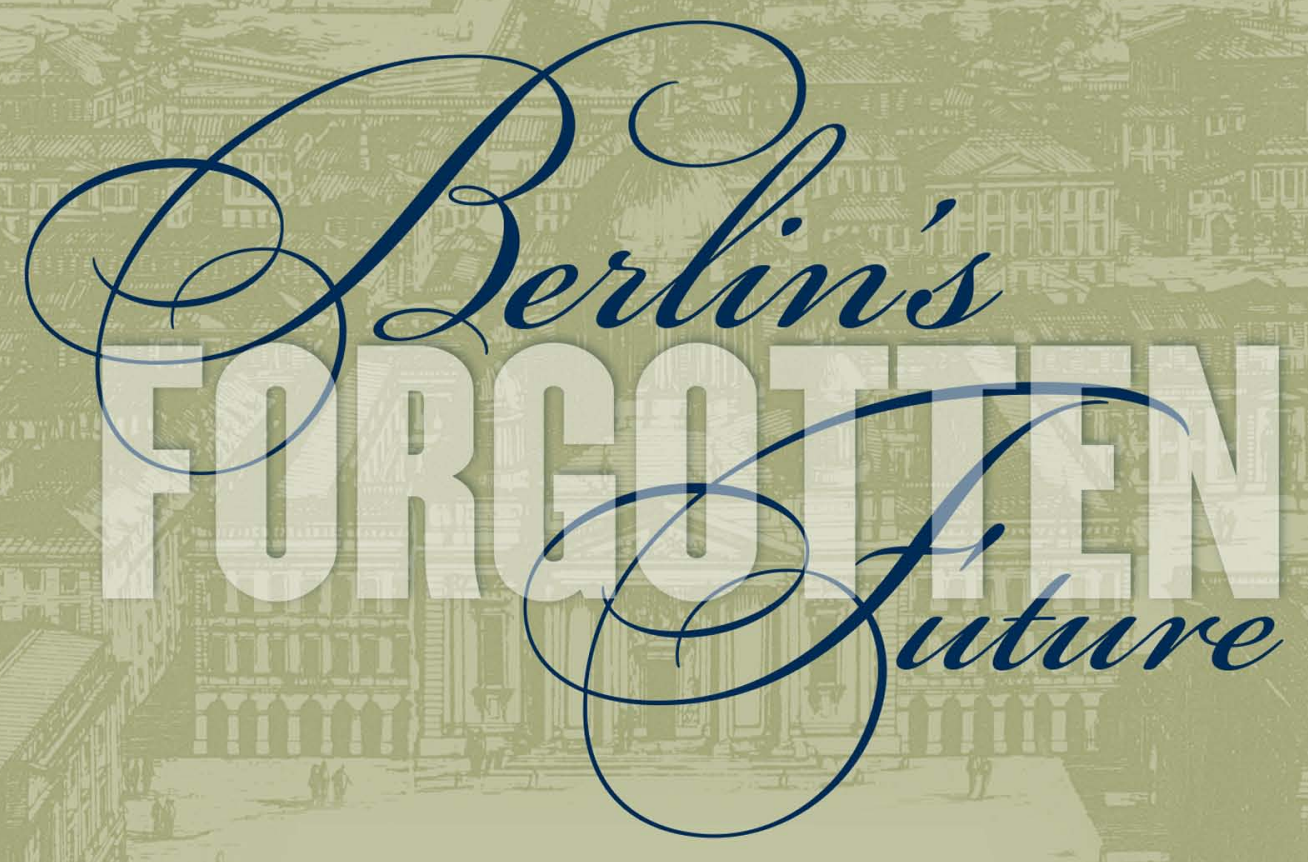

\author{
City, History, \\ and Enlightenment in \\ Eighteenth-Century \\ $\sim$ Germany
}

MATT ERLIN 


Berlin's Forgotten Future 
From 1949 to 2004, UNC Press and the UNC Department of Germanic \& Slavic Languages and Literatures published the UNC Studies in the Germanic Languages and Literatures series. Monographs, anthologies, and critical editions in the series covered an array of topics including medieval and modern literature, theater, linguistics, philology, onomastics, and the history of ideas. Through the generous support of the National Endowment for the Humanities and the Andrew W. Mellon Foundation, books in the series have been reissued in new paperback and open access digital editions. For a complete list of books visit www.uncpress.org. 


\section{Berlin's Forgotten Future}

\section{City, History, and Enlightenment in}

Eighteenth-Century Germany

MATT ERLIN

UNC Studies in the Germanic Languages and Literatures

Number 127 
Copyright (C) 2004

This work is licensed under a Creative Commons CC BY-NC-ND license. To view a copy of the license, visit http://creativecommons. org/licenses.

Suggested citation: Erlin, Matt. Berlin's Forgotten Future: City, History, and Enlightenment in Eighteenth-Century Germany. Chapel Hill: University of North Carolina Press, 2004. DOI: https://doi.org/ 10.5149/9781469657486_Erlin

Library of Congress Cataloging-in-Publication Data

Names: Erlin, Matt.

Title: Berlin's forgotten future : city, history, and enlightenment in eighteenth-century Germany / by Matt Erlin.

Other titles: University of North Carolina studies in the Germanic languages and literatures ; no. 127.

Description: Chapel Hill : University of North Carolina Press, [2004] Series: University of North Carolina Studies in the Germanic Languages and Literatures. Includes bibliographical references and index.

Identifiers: LCCN 2003014104 | ISBN 978-1-4696-1463-2 (pbk: alk. paper) | ISBN 978-1-4696-5748-6 (ebook)

Subjects: Enlightenment - Germany — Berlin. | Berlin

(Germany) - History - 18th century. | Berlin (Germany) Intellectual life.

Classifications: LCC DD866.8 .E75 2004 | DDC 943/.15505 — dc21 


\section{CONTENTS}

Acknowledgments $i x$

Note on the Translations $x i$

1. City, History, Enlightenment 1

2. Fashion, Progress, and the Multiple Futures of Late

Eighteenth-Century Berlin 37

3. Urban Exegesis in the Works of Friedrich Nicolai 64

4. Aesthetic Experience and Urban Enlightenment in G. E. Lessing's Minna von Barnhelm 97

5. Moses Mendelssohn and the Philosophy of the City 132

Conclusion: Metropolis, Hybridity, and Historical Consciousness 166

Notes 177

Works Cited 201

Index 211 



\section{AC K NOW L E D G M E N T S}

Writing a book is both a solitary endeavor and a group effort, and I take great pleasure in acknowledging the numerous individuals and institutions whose support helped make the completion of this project possible. First and foremost among these is my wife, Ebba Segerberg, who has been involved, sometimes reluctantly, in the project since its inception. Without her astute criticism and unflagging moral support, the book never would have been written.

This investigation into eighteenth-century urban culture began as a dissertation at the University of California, Berkeley, and I owe a tremendous debt of gratitude to my mentors there. I am especially indebted to Hinrich Seeba for his extraordinary hermeneutic talents and infectious enthusiasm for the topic, as well as for the extensive and incisive commentary he provided on preliminary versions of the individual chapters. W. Daniel Wilson, Robert C. Holub, and Thomas Kavanagh also provided invaluable suggestions and criticisms of the dissertation manuscript. Brett Wheeler came up with a crucial insight for the Lessing chapter one day over coffee, and he, Eric Ames, and Sara Hall have been sources of encouragement and intellectual inspiration at all stages of the project. While at Berkeley, I received generous summer grants for research in Berlin from both the University of California and the German Academic Exchange Service.

The supportive atmosphere I experienced at Berkeley has been more than matched by my colleagues in the Department of Germanic Languages and Literatures at Washington University. Not only have they offered valuable advice on the project and on the profession in general; incredibly, they have also tried to shelter me from some of the administrative demands of academic life and thereby free up time for me to concentrate on my research. In addition, I have benefited greatly from the knowledge and insights of my colleagues in the Salon, Washington University's eighteenth-century studies working group.

A large number of other friends, colleagues, and family members, too 
many to name, also deserve thanks for their role in making this book possible. At the very least, I would like to single out Michael Werz, John Abromite, and Alexander Košenina as intellectual role models. And I want to thank my parents for providing the kind of encouragement that only parents can.

Finally, I would like to express my gratitude to the UNC Press and especially to Jonathan Hess, editor of the Studies in the Germanic Languages and Literatures, for their interest in the project. My experience with the press has been extremely positive, and it has been a privilege to have a fellow eighteenth-century scholar overseeing the publication process, especially one so knowledgeable. The book has profited significantly from his thoughtful suggestions for improvement. The same can be said with regard to Daniel L. Purdy and the anonymous reader for the press, both of whom offered extremely valuable comments on the manuscript. Last but not least, I would like to thank Brian R. MacDonald for his meticulous copyediting.

An excerpt from Chapter 4 was published previously as "Urban Experience, Aesthetic Experience, and Enlightenment in G. E. Lessing's Minna von Barnhelm," Monatshefte 93, no. 1 (2001): 20-35. Sections of Chapter 5 appeared in "Reluctant Modernism: Moses Mendelssohn's Philosophy of History," Journal of the History of Ideas 63, no. 1 (2002): 83-104. I thank both of these journals for the permission to reprint.

This book is dedicated to my good friend Paul Sagara, with apologies for a previous omission. 
NOTE ON THE TRANSLATIONS

In order to make this study accessible to nonspecialists, I have included English translations of all German materials. In cases where something approaching a standard translation was available, I have made use of it, citing the translation as the source in the notes and the bibliography. In all other cases I have provided my own translations and have provided a reference to the original German source. 

BERLIN'S FORGOTTEN FUTURE 



\section{City, History, Enlightenment}

\section{The Enlightened City}

In his pioneering 1932 study on the philosophy of the Enlightenment, Ernst Cassirer offered one of the first systematic refutations of the widely held conception of the eighteenth century as an "unhistorical age." ${ }^{1}$ The legend of Enlightenment antihistoricism has long since been laid to rest, but the precise character of historical consciousness in this period and its relationship to our current thinking on history continue to provide scholars with a productive area of inquiry. With regard to the German intellectual tradition, something of a consensus has emerged in the past few decades, according to which the latter half of the eighteenth century must be seen as the crucial moment in the evolution of modern historical consciousness. Of particular importance for the establishment of this consensus has been a renewed interest in conceptual history and especially the work of Reinhart Koselleck, whose 1975 essays on "History" and "Progress" in the encyclopedia Geschichtliche Grundbegriffe serve in many respects as the starting point for discussions of the topic. ${ }^{2}$ Koselleck's specific terminological analyses have also been supplemented by the work of a number of other scholars in social, intellectual, and cultural history. Their investigations of the new group of professional historians working in the period as well as of the general public's increasing interest in historical topics provide additional evidence of a paradigm shift in ways of thinking the relationship between past, present, and future. ${ }^{3}$

The current study addresses the question of eighteenth-century historical consciousness from a perspective that has thus far received little attention and that takes its methodological inspiration from the fields of literary and cultural studies. It is my contention that textual representations of the urban experience, in particular those which address the newly minted Prussian capital of Berlin, played a crucial role in the emergence and articulation of new paradigms of historical understanding in this period. Partly as a re- 
sult of more frequent travel to European capitals and partly because of the growth of cities within Germany, urban development came to be recognized by German intellectuals as a historical phenomenon worthy of attention. This recognition lead to a flurry of publications after 1750 on various aspects of city government, on the advantages and (more commonly) disadvantages of big-city life, on the relationship between the country and the city, and on the cultural consequences of Germany's lack of a national capital. At the root of these representations are questions inextricably intertwined with historical thinking - questions regarding the meaning of rapid temporal change, the value of tradition, and the opposition between the supposedly eternal truths of nature and the shifting fashions of the city. What I hope to establish in the pages that follow is that eighteenth-century Berlin, perceived as a site of both progress and regression, as a hub of enlightenment as well as a hideout for obscurantists, raises these historically charged questions even as it defies any attempt to find easy answers. Efforts to provide appropriate textual mediations of urban life, in other words, give rise to precisely the kind of nuanced historical reflection that has recently come to be seen as characteristic for the German Enlightenment.

An investigation of the historical-theoretical implications of eighteenthcentury conceptions of urban space might seem an ill-considered project. After all, the very idea of the enlightened city as it emerged in the period has frequently been viewed as synonymous with an absence of history. At least as far back as Descartes, who uses the example of a rationally planned metropolitan district to illustrate his new epistemology in Discourse on the Method (1637), the ideal city is conceived in opposition to history. The philosopher, it will be remembered, is forced to spend a winter in Germany, where he passes the time reflecting on the nature of perfection. With regard to the city, he comes to the following conclusion: "Again, ancient cities which have gradually grown from mere villages into large towns are usually illproportioned, compared with those orderly towns which planners lay out as they fancy on level ground. Looking at the buildings of the former individually, you will often find as much art in them, if not more, than in those of the latter; but in view of their arrangement - a tall one here, a small one there and the way they make the streets crooked and irregular, you would say it is chance, rather than the will of men using reason, that placed them so." ${ }^{4}$ Like the ideal philosophical system that the author elucidates later in the work, 
the ideal city as depicted here is essentially ahistorical, the eternally valid construct of a single, unified, rational subjectivity.

This Cartesian model remains a powerful force in eighteenth-century Germany, as can be seen in both the writings of professional urban planners and in the numerous reflections on existing cities found in the travel literature from the period. One of the more striking examples of its continued influence is an article by the author Friedrich Wilhelm Taube, a German jurist who held a variety of private and governmental positions in Germany and Austria. His commentary on the relative beauty of various European capitals, "Thoughts on the Beautification of Cities, with a Historical Report on How the Most Distinguished Capitals in Europe Have Been Gradually Improved and Beautified since 1763," appeared in Deutsches Museum in 1776. Taube's conception of urban beauty proves noteworthy for its representative character. The brief descriptions of the various European capitals reveal an ideal based on classicist aesthetic principles of symmetry and balance, principles that fortuitously coincide with the exigencies of good hygiene and the unhindered circulation of both individuals and commodities. Beauty and utility are meant to coexist in perfect harmony. Among his favorite adjectives are not only "beautiful" but also "regular" and "clean," and he criticizes the "tasteless ornaments" that one finds on the houses of merchants and artisans in London. According to Taube, "Nothing makes a city more appealing than large, well-ordered public spaces that are kept clean, are surrounded by attractive houses, and have a fountain in the center, or some other kind of water sculpture, or a garden, or even just a green lawn with a pretty statue." 5

Striking in this context is Taube's obvious distaste for the historical city, something he shares with Descartes. He laments that the old city center of Vienna, like that of Paris and London, has evolved over time and is thus characterized by "a wild chaos of randomly arranged alleyways and houses," shocking the traveler who has arrived there expecting to discover its beauty. ${ }^{6}$ Markedly superior are those cities - he names Karlsruhe, Mannheim, Erlangen, St. Petersburg, and Lisbon - that have been founded or reconstructed more recently and have thus benefited from the advantages of modern urban planning. Taube's zeal for the new gives his article a slightly apocalyptic undertone, an impression that is strengthened by the occasional biblical reference. Often one has the sense that he would prefer to raze entire cities and rebuild them rather than tinker with beautification projects; his 
discussions of the improvements made to Paris after the 1666 fire and Lisbon after the 1755 earthquake are a case in point. As the author notes, with an optimism that suggests an unshakable confidence in divine providence: "To be sure, it is always a sad fate for any city to meet with devastation; however, a better, more orderly reconstruction generally follows thereafter." ${ }^{7}$

Taube's essay presents an image of the ideal city that is central to the urban discourse of the Enlightenment. The emphasis on circulation, cleanliness, order, and symmetry, which combines classical and Renaissance architectural models with a more contemporary interest in social engineering, appears time and again in eighteenth-century representations. ${ }^{8}$ Given the extent to which the ideal of a rationally planned urban space dominates the literature of the period, it is not surprising that this ideal has often been equated with the "enlightened" city as such. ${ }^{9}$ What has too often been ignored, however, and what Taube's article also makes clear, is the fact that the ideal almost always appears together with the opposing urban reality, that it is used as a standard against which to measure the real progress toward its realization. By focusing on only one of the variables in the equation, scholars have often overlooked a crucial element in the eighteenth-century urban imaginary - namely, the extent to which representations of the ahistorical and rationalized ideal city are always intertwined with reflections on historical change and development in the real city. In the case of Taube's article, the title alone serves to indicate the way in which authors insert their representations of the city into longer-term historical narratives. It is possible to discern at least two important and closely related temporal levels in this context. On the one hand, the juxtaposition of the rationally planned new city and the old city center illustrates the sense of a break with the past and a heightened awareness of the historical specificity of the contemporary. At the same time, however, both the representation of the rational city as an only partially realized ideal and the sensitivity to the burden of the past embodied in the city center suggest a sense of historical process.

Thus, in its very renunciation of history, the rationalized cityscape reveals a crucial aspect of the historical-theoretical function of the city in eighteenth-century Germany. The well-ordered city serves as a concrete reminder of the superiority of the modern age, an age whose ability to impose rational order on the built environment marks a qualitative break with the chaos of the past. It also serves as a marker for the march of progress. As we will see, both this recognition of a qualitative difference between past and 
present and the belief in the possibility of progress to which it gives rise have come to be viewed as key elements in the evolution of historical consciousness in the period.

If Descartes's city offers a model of one major interface between eighteenth-century historical consciousness and urban experience, Jean-Jacques Rousseau's depraved metropolis offers another. Here as well, the urban environment becomes a kind of cipher for modernity; indeed, in this case the connection is explicit and undergirded by a historical-philosophical framework of decline. ${ }^{10}$ For Rousseau, the city is the catastrophe of civilization in miniature, a catastrophe exemplified not merely in the built environment but also in the city's institutions and its residents. Large cities are sites of conspicuous consumption, empty diversions, and dangerous perversions. As he writes in the 1758 Letter to M. d'Alembert: "In a big city, full of scheming, idle people without religion or principle, whose imagination, depraved by sloth, inactivity, the love of pleasure, and great needs, engenders only monsters and inspires only crimes; in a big city, where morals and honor are nothing because each, easily hiding his conduct from the public eye, shows himself only by his reputation and is esteemed only for his riches; in a big city, I say, the police can never increase the number of pleasures permitted too much or apply itself too much to making them agreeable in order to deprive individuals of the temptation of seeking more dangerous ones." ${ }^{11}$

Here Rousseau is arguing for the value of the theater in a city like Paris, because, by occupying the residents for two hours a day, it helps to reduce the amount of time spent on even more despicable activities. Similar attacks on modern urban life can be found in other texts, as well. Certainly the most insensitive is his response to Voltaire's poem on the Lisbon earthquake, where he interprets the damage done as evidence of the unnatural character of large cities, but Emile and the Discourse on the Arts and Sciences are also peppered with jabs at the city dweller. ${ }^{12}$ In social terms, Rousseau views city residents as dissimulating degenerates, lacking the physical and moral strength of peoples of antiquity and interested in nothing but corrupt pleasure and their own self-aggrandizement. In economic terms, they appear as parasites who depend on the hard work of those in the country and repay their benefactors with scorn and contempt. ${ }^{13}$

Rousseau's influence on eighteenth-century German letters is pervasive, and his critique of civilization lurks behind much of the German writing on the city in the period. ${ }^{14}$ These essays and articles show little of the en- 
thusiasm for urban modernity that one finds in Taube, but they nonetheless follow Rousseau in positing the city as the crucible of that modernity and thus indicate another point of intersection between urban experience and historical consciousness. In this case the focus is on the seemingly unbridgeable gap between degenerate present and idealized past, an ideal that writers sometimes attach to Greek and Roman antiquity and sometimes push back to the hazy origins of humanity. One finds a compelling example of this perspective, together with its peculiar spatial and temporal displacements, in a 1782 essay entitled "On Conception and Education in Berlin." In keeping with the Grecophilic spirit of the age, the essay begins with a reference to antiquity, as the author asks how the Athenians could have been both beautiful and strong despite their inclination for sensuous pleasures. The reason, he claims, is to be found neither in the Greek climate nor in the Greeks' emphasis on physical exercise, but rather in their ability to harness the formative power of the imagination. The author then shifts his focus to northern Europe, comparing the modern Berliners with the seven-foot-tall warriors who were supposedly their forbears and asking: "How can we have fallen so far? How did we lose the colossal size and enormous strength of our fathers?" 15 His answer takes the form of a quasi-scientific examination of the negative impact of cultural refinement on human physiology, and the institutions of urban life serve as the basis for illustrating his point. In another shift that reveals the imbrication of spatial and temporal frameworks in the period, the author asks his reader to imagine a "Nordic colossus" exposed to the galleries, concerts, or theaters of Berlin. Confronted with the refined art and music of the modern city, the savage would react with total indifference, because his crude sensory apparatus would be unable even to register their subtle pleasures. In the case of the theater, he would react with the wild enthusiasm of one who cannot distinguish illusion from reality. The author's point is not to ridicule the vulgarity of this imaginary visitor to the city. On the contrary, he stresses the extent to which a society and educational system that emphasize art and artifice rather than physical activity leads to degenerate bodies and overwrought nerves, such that even the unborn child is threatened. In the words of the author, "And thus a corrupt and infirm world conceives and educates an even more corrupt and unhealthy posterity." 16

The examples of Descartes, Rousseau, and their German disciples demonstrate that eighteenth-century discussions of the city nearly always en- 
tail reflection, whether implicit or explicit, on historical-theoretical issues. In both Taube and the anonymous article on Berlin, the city as built environment and as institutional nexus becomes an occasion for reflecting on the specificity of the contemporary, a specificity that is positively charged in Taube and negatively charged in the "Education" essay. In light of the rupture that characterizes modernity in these texts, one is tempted to take recourse to Ernst Bloch's now classic notion of "nonsimultaneity" and argue that the eighteenth-century city appears as a site where past and present are spatially coexistent, thereby fostering a sensitivity to historical change. As we will see, this idea is indeed crucial for understanding the eighteenthcentury urban discourse in Germany. The problem with such a notion, however, is that it presupposes a conception of history as a linear totality, a kind of number line onto which the relative positions of various temporal phenomena can be mapped. Yet what makes the late eighteenth century so fascinating in this context is that such a linear, evolutionary understanding of history is only beginning to take shape. The remarkably tenacious conception of the Enlightenment as characterized by a naive belief in human progress (or, in the case of Rousseau, decline) fails to do justice to the complexity of historical consciousness in this period, as does the equally oversimplified notion of a shift from a cyclical to a linear framework for grasping historical change. ${ }^{17}$ There can be no doubt that eighteenth-century thinkers were concerned with the mutability of social and intellectual phenomena; indeed, this recognition was a necessary precondition for the critiques of traditional authority so central to Enlightenment thought. The historiographical implications of this concern, however, whether changes are understood within the framework of an ahistorical Christian theology, a transhistorical natural law, a natural cyclicality, or a linear conception of human progress, vary from individual to individual and situation to situation. To this extent, Cassirer's early evaluation of the period, as a time in which the "conditions of possibility" of history were still under investigation, retains its validity. As Cassirer writes, "The eighteenth-century conception of history is less a finished form with clear outlines than a force exerting its influence in all directions." 18

In eighteenth-century Germany, encounters with the city provide commentators with an opportunity to work out the contours of this multifaceted historical force. To be sure, they do not provide the only opportunity. Concern with the nature and meaning of historical change suffuses discussions 
and representations of a wide-ranging array of eighteenth-century institutions. One obvious and important example is global exploration, which gives rise to the identification of various non-European peoples with the childhood of humankind. ${ }^{19}$ Another is local politics, where concerns regarding changes in the status of peasants and villagers are raised in a thoroughly historical framework of tradition and precedent. ${ }^{20}$ The evolution of eighteenthcentury historical consciousness, in other words, cannot simply be traced by way of a crude causal mechanism back to the urban experience. Nonetheless, the city plays a special role in this evolution, not least because of what can be termed its historical-theoretical complexity.

In discursive terms, this complexity derives from the fact that the eighteenth-century city is temporally overdetermined; it is unusual in the degree to which it gestures simultaneously to past, present, and future. On the one hand, it is linked to the distant past, whether through association with the infamous cities of the Bible, the great urban centers of antiquity, or even the self-governing middle-class cities of Germany's medieval urban renaissance. On the other hand, the city, especially the capital city, also figures prominently in the contemporary cameralist discourse on the organization of the state, according to which it functions as the administrative nucleus of a current unit of political organization. Finally, in its perceived role as cultural center and locus of surplus production, the city intersects with a discourse on sociability, cultural refinement, and luxury that registers the achievements of modernity but simultaneously points to an uncertain future. Each of these discursive axes entails certain assumptions about the larger temporal frameworks into which individual events are embeddedwhether short-, medium-, or long-term, linear, cyclical, or static. ${ }^{21}$ Encounters with the rapid changes taking place in the cities themselves lead to a simultaneous actualization of multiple discursive axes and their corresponding temporal frameworks, and thus challenge both authors and readers to consider more carefully the precise relation between specific events or phenomena and the larger historical narratives into which they might be inserted.

It is the precise character of this process that I want to elucidate in the following pages, through an investigation of urban life and urban institutions as they appear in the works of four leading figures from the Berlin Enlightenment: Friedrich Gedike, Friedrich Nicolai, G. E. Lessing, and Moses Mendelssohn. Each of these individuals had a unique relationship to Berlin, and 
each must be seen as a key contributor to eighteenth-century conceptualizations of metropolitan life. Gedike is best known as coeditor of the Berlinische Monatsschrift, public mouthpiece of the German Enlightenment and occasional forum for eighteenth-century urban advocacy. Nicolai was the overseer of a powerful, Berlin-based publishing empire and a tireless chronicler and defender of city life. Lessing had high hopes for success upon arriving in Prussia's expanding capital in the late 1740s but eventually left Berlin in frustration, in large part because of his failure to secure stable employment. Moses Mendelssohn, finally, came to Berlin from Dessau as a young man and spent the remainder of his life living, working, and writing in the city. He eventually achieved a kind of legendary status, referred to by contemporaries as the "Socrates of Berlin." Analyzing the diverse contributions of these authors reveals some of the individual and generic variation in eighteenthcentury reflections on urban phenomena. At the same time, however, the consideration of multiple text genres - travel writing, cultural criticism, literature, and philosophy - enables the reconstruction of a shared framework for conceptualizing the city and its historical-theoretical significance. It is no coincidence that Berlin became a focal point for such efforts, and I turn shortly to the reasons for its privileged status. In order to map accurately the points of intersection between these representations and eighteenth-century thinking about history, however, it will be necessary to provide a more detailed topography of modern historical consciousness as it has come to be understood in recent scholarship.

\section{Modern Historical Consciousness}

Characterizing epochal shifts in mentality is risky business. In the case of the evolution of what has come to be termed modern historical understanding, the trajectory of development spans at least three hundred years (ca. 1500-1800) and is by no means linear. Furthermore, the very notion of a single, unified "historical consciousness" becomes problematic when one considers the complex interconnections among various areas of intellectual inquiry, including philology, theology, natural science, jurisprudence, and philosophy, each of which was deeply engaged in the eighteenth century with questions of temporal transformation. All of these areas, although they shared certain assumptions about the relationship between past, present, 
and future, retained a certain degree of independence in their articulation of that relationship.

Such qualifications notwithstanding, one can discern a constellation of elements characteristic of a new mode of thinking about history that emerges in Germany in the latter half of the eighteenth century. Before turning to the substance of this paradigm shift in mentality, however, which I have schematized into three basic areas, one should note that it is contemporaneous with two related but distinct developments in the status of historical investigation in Germany. The first is the establishment of history as an independent university discipline, which entails a marked increase in the number of professional historians together with an effort to build a methodological foundation for history as a science. The university in Göttingen emerges in this period as the dominant center of historical research, home to such pioneering scholars as Johann Christoph Gatterer, August Ludwig Schlözer, and Ludwig Timotheus Spittler. ${ }^{22}$ The second development is an intensification of interest in history on the part of the educated middle class. Such a phenomenon is of course difficult to document. Nonetheless, one can chart both an increase in the number of historical treatises written by amateurs and in the number of essays on historical themes - from both amateurs and professionals - appearing in popular journals. Hans Erich Bödeker points out that the percentage of journal articles on historical and political issues in the late eighteenth century was higher than for any other thematic area except entertainment literature. ${ }^{23}$ Indeed, one finds a greater emphasis on history in all of the main media for the dissemination of knowledge in the period, not just journals but also newspapers, travel reports, letters (fictitious and otherwise), and lexica. $^{24}$

The precise nature of the relationship between these two developments has been the subject of some scholarly discussion, though without any conclusive results. In a 1986 essay entitled "Historical Interest in the Eighteenth Century," for example, Rudolf Vierhaus claims that the work of professional historians had only limited impact on the evolution of a modern historical understanding among the educated middle class. He writes: "It was less the reading of historical works than the interest in one's own present, the rising demand for political enlightenment, and the growing criticism of existing conditions that directed their [the middle class's] attention to history." ${ }^{25}$ At the same time, however, he notes a convergence in the latter half of the century between the aims of professional historians and the interests of the gen- 
eral reading public. For both groups, history was seen as a source of useful knowledge in the service of enlightenment. ${ }^{26}$ The picture is complicated further by the rise in the late eighteenth century of various philosophies of history (Geschichtsphilosophie), a phenomenon that is certainly indebted to the achievements of Enlightenment historiography, even if its main proponents were philosophers and literati (Herder, Kant, Lessing, Schiller, Hegel, and the early romantics). Although he recognizes the continuities between the guiding principles of eighteenth-century historians and those of the various Geschichtsphilosophen, Vierhaus here again emphasizes the "real-historical process," the personal experience of rapid change, as the driving force behind the attempts to construct historical metanarratives. ${ }^{27}$

Vierhaus's claim that professional historians had only limited direct impact on popular historical interest in the eighteenth century is well taken, but it is important to recognize the wide circulation in the period of certain key assumptions regarding the nature and significance of historical change. Professional historians, after all, experienced the same "real-historical process" as the educated public, even if disciplinary exigencies molded the form and scope of the investigations in which this experience was articulated. Indeed, the very notion of two separate strands of historical discourse is problematic in a period in which history as an autonomous university discipline was still establishing itself. Although one can distinguish a growing number of university historians who are intensely occupied with questions of historical methodology in the late eighteenth century, one also finds a great deal of exchange with scholars and intellectuals from other backgrounds. As the twentieth-century historian Horst Walter Blanke points out, one must include among the important historians of the German Enlightenment not only the Göttingen professors Gatterer, Schlözer, and Spittler but also Friedrich Nicolai, the jurist Justus Möser, the theologian Johann Martin Chladenius, the philosopher Jacob Wegelin, and the Swiss philosopher and essayist Isaac Iselin, not to mention more renowned figures such as Winckelmann, Schiller, Kant, and Herder. ${ }^{28}$ As a consequence of the dynamism and the relatively unified (that is, nonatomized) character of the literary public sphere, these individuals were all in dialogue with one another, a fact that becomes apparent when one peruses the titles and authors of journal articles from the period on topics like "Writing History" (Geschichtsschreibung) or "Historical Instruction" (Geschichtsunterricht). For Blanke, the public character of the disciplinary discussion was one of the most striking character- 
istics of Enlightenment historiography, which he describes as achieving "an astonishing level of discursivity, one that is simply unimaginable from our current perspective." 29

My intent in thematizing this problematic here is to provide a rough methodological framework for my own analysis. Vierhaus's opposition between theoretical treatises written by eighteenth-century historians and the widespread personal experience of rapid change actually instantiates an ongoing controversy regarding the social content of intellectual and conceptual history. Since its emergence in the mid-1970s, conceptual history in particular, at least as practiced in the Geschichtliche Grundbegriffe, has been criticized for its sometimes insufficient attention to the specific socialhistorical contexts in which concepts originate and are used. ${ }^{30}$ With regard to the question of historical consciousness, the error lies in believing that methodological treatises or essays on Geschichtsphilosophie are an adequate source of information on historical consciousness in the period. Opposing the focus on elite culture - the Gipfelwanderung - that allegedly characterizes some examples of conceptual history, social historians have stressed the need to evaluate a wider range of sources as well as to engage in other kinds of analysis to get behind textual representations to the level of "social reality." 31

The very notion of an extratextual social reality might seem problematic to scholars in literary and cultural studies. Nonetheless, the basic objection to an overemphasis on canonical texts is certainly valid. In practice, however, historians interested in the social determinants of historical consciousness in eighteenth-century Germany often simply expand the source material to include lesser-known authors. The focus remains on explicitly historiographical texts, sometimes supplemented with statistical evidence on the increased historical interest among members of the middle class. There is no reason to denigrate this approach, which constitutes a necessary foundation for understanding historical consciousness in the period. Once the general outlines of the theoretical discussion have been established, however, it can be extremely productive to investigate how historical-theoretical paradigms are actualized in other kinds of texts, particularly those dealing with contemporary phenomena. If, as Vierhaus claims, it was the "interest in one's own present" that engendered the middle-class fascination with historical topics, then certainly important insights into the complexity of eighteenth-century historical consciousness can be gleaned from texts that 
attempt to come to terms with this dynamic present. Indeed, I would argue that in such texts, rather than those that are ostensibly historiographic or even historical, temporal structures become manifest in the most interesting fashion, as authors attempt to place current events into longer-term historical frameworks. In this context, a hermeneutic analysis that seeks to uncover the implicit temporalities that structure city texts can serve as a kind of cross-reference to more explicitly historical-theoretical writings. An evaluation of representations of the city and of urban phenomena can provide insights into the nature of historical consciousness that are both more substantive than those gleaned from statistical data and less reified than what one finds in historical-theoretical treatises.

Moreover, even though such an analysis remains at the level of textual representation, it can nonetheless shed light on the social determinants of historical consciousness by illuminating the way in which historicaltheoretical paradigms are confirmed or called into question on the basis of the quotidian experience. Textual mediations of the eighteenth-century city serve as more than mere instances for the unreflected application of historical-theoretical models developed elsewhere; they also contribute to the development, refinement, or abandonment of these models. In their attempt to come to terms with an evolving present, city texts constitute an important medium for working out the meanings of those very concepts that become central to the eighteenth-century understanding of historical change, from "causality" to "progress" to "civilization." These concepts are not fixed units of theoretical analysis in the period; they are in a process of articulation. The eighteenth-century is clearly characterized by a universal sense of historical transition, but the conceptual frameworks used to understand and theorize this transition must be constantly renegotiated in an ongoing confrontation with contemporary phenomena. As a site of rapid change, the city in general, and the unusually dynamic capital city of Berlin in particular, plays a critical role in this process. The full significance of this role, however, can only be appreciated once a baseline for the analysis has been established through a review of some of the more explicit theoretical reflections from the period.

I

The most significant and the most complex aspect of the new mode of historical understanding that emerges in the eighteenth century is a tran- 
sition from what can be termed an atemporal conception of history to a notion of history as development. ${ }^{32}$ The former conception, which posits a fundamental equality between past and present, is characteristic of the essentially static temporal framework of traditional Christianity. Time as a variable plays no significant role in the evaluation of specific historical occurrences. Instead, these occurrences are seen as iterable examples of certain ideal types of behavior, to be measured against a divine and immutable ethical norm. Although certain events may be interpreted as marking the stages in an inevitable march toward the Last Judgment, the stages themselves are not characterized by any substantive differences in human mentality or forms of interaction. Coincident with the gradual process of secularization that characterizes early modern Europe, however, one can discern a growing sense of the importance of historical process and historical specificity for understanding the past. Koselleck describes the change as a "temporalization" (Verzeitlichung) of history. This temporalization entails a recognition of the qualitative uniqueness of different periods and thus lays the foundation for a belief in the possibility of substantive historical change. ${ }^{33}$

Another way to think about this development is in terms of a shift from an exemplary to a genetic way of thinking about both the past itself and about the relationship between past, present, and future. ${ }^{34}$ The philosopher Gottlob David Hartmann, in a Herder-inspired article entitled "On the Ideal of a History" (1774), offers the following characterization: "History comprises a series of events, whereby one event is always linked to another, as with the rings of a long chain, and each must partly determine those that follow. An event initially in the past, connected with one in the present, necessarily engenders the future event." 35 If, prior to the eighteenth century, past events were considered primarily in terms of their value as timeless models for present behavior (stories from the Bible or from antiquity offer the most obvious examples), over the course of the century the focus shifts to their origins as well as to their originary function - their role in giving rise to a certain historical trajectory in which the present must be located. The relationship between past, present, and future, in other words, is conceived of in evolutionary and causal terms.

This transition finds concrete expression in the emergence of the German term Geschichte as a collective singular in the final third of the century. Whereas prior to this point, Geschichte was generally found in the plural 
(Geschichten) and referred either to specific, iterable past events or their representation, the term eventually comes to denote the totality of past events and their perceived interrelatedness. History is viewed as a unified force, an agent that has the capacity to shape human will and identity. As Koselleck puts it, "this linguistic concentration into a single concept after about 1770 must not be underestimated. In the ensuing period, after the events of the French Revolution, history itself becomes a subject upon which is bestowed the divine epithet of omnipotence, absolute justice, or holiness." ${ }^{36}$ The goal of writing about history shifts accordingly from the establishment of accurate chronologies or the compilation of case studies demonstrating ideal types and situations to the construction of narratives that foster an understanding of how the past came into existence and how it relates to the present. Friedrich Schiller, in his 1789 inaugural lecture on universal history, distinguishes between an arbitrary "aggregate" of past events and a coherent historical "system." The Berlin popular philosopher Johann Jakob Engel contrasts the "unpragmatic" historian, who merely presents us a series of snapshots from Cromwell's biography, with the "pragmatic" historian, who is able to construct a causal narrative from these snapshots. ${ }^{37}$ Although he was by no means at the cutting edge of the historiographical debate in the eighteenth century, even the king of Prussia reveals an awareness of this new understanding of the historian's task. In his 1780 essay On German Literature, Friedrich II writes, "I permit myself the freedom to ask them [the historians], if the study of chronology is truly the most useful subject of history? ... if it is such a grave error to forget . . . the time of day when the Golden Bull was published, whether it was at six o'clock in the morning or at four o'clock in the afternoon? . . . It is not that I want to excuse those historians who commit anachronisms; I would, however, judge small oversights of this kind with greater leniency than some far more serious mistakes, such as that of narrating events in a confusing fashion, or failing to establish cause and effect clearly, failing to follow any method whatsoever, lingering too long over insignificant details and hurrying past the important things." ${ }^{38}$

On a rhetorical level, one of the consequences of this new conception of historical writing is a convergence of history and literary narrative, as historians begin to pay greater attention to questions of narrative coherence as well as to the relationship between the general and the particular. ${ }^{39}$ Engel, for example, addresses the historian's task within the context of a more general 
discussion of poetics. In terms of historical understanding, a more important consequence of the new evolutionary model is that the perceived alterity of the past gives rise to the conception of an open future, of the future as a realm of possibility. In the words of Peter Hanns Reill: "The more historical analysis could show that the present evolved from something that was qualitatively different, the more one could believe that a new set of social relations could be forged from those in existence." ${ }^{40}$ The temporal differentiation of past, present, and future creates the conditions of possibility for a belief in progress, whether on the grand scale of the Geschichtsphilosophie formulated by Lessing, Kant, Schiller, and Hegel or in the more practical terms of the numerous German Aufklärer engaged in projects of social reform.

As I already intimated, this conception of history as an evolving totality also has important implications for the venerable topos of historia magistra vitae, the idea that "history teaches life." While a belief in the didactic value of history remains central in the eighteenth century, a transformation in the nature of this belief begins to take shape. History is no longer viewed solely as a reservoir of experiences from which one can select exempla appropriate to a given contemporary situation. Such a conception of the value of history can only exist when past, present, and future are perceived as essentially identical. ${ }^{41}$ The new conception of learning from history, as Jürgen Habermas explains, entails the recognition of and the attempt to understand one's own historical embeddedness. ${ }^{42}$ The ultimate lesson of history, in other words, is to think historically, to realize that a given historical moment has a unique horizon of possibility and thus requires a historically adequate standard of evaluation. Johann Gottfried Herder is the best-known representative of such historical sensitivity in the period, having once remarked, for example, on how foolish it would be to tear "a single Egyptian virtue out of the country, the age and the youth of the human spirit and measure it with the yardstick of another age!" ${ }^{43}$ Although Herder is certainly unique in the degree of his appreciation of historical and cultural diversity, one can adduce numerous German intellectuals from the late eighteenth century who insist on the need for historically sensitive judgments. Nicolai, for example, asserts at one point in his monumental Description of a Journey through Germany and Switzerland in the Year 1781 (1783-96) that the houses in Augsburg cannot be compared with "the temples of Greece or Rome's Capitol." On the contrary, "one must compare them with other burghers' houses from the century in which they were built." ${ }^{4}$ 
II

Closely linked to the emergence of a genetic model of historical understanding in the late eighteenth century is a heightened awareness of the significance of perspective in historical representation. To the extent that history constitutes a singular totality, it necessarily transcends the scope of any given account of events. This space that opens up between history and its representation has a variety of philosophical implications, the most important of which is the recognition of a plurality of perspectives on past events, each of which may have a claim to partial validity. Koselleck has characterized the emergence of this notion as a shift away from a premodern ideal of suprapartisanship, a shift inspired by a recognition of the necessarily subjective nature of all historical representation. ${ }^{45}$ Although eighteenth-century historians continue to strive for an unembellished presentation of the "naked truth," an aim that had been part of their disciplinary identity since antiquity, one finds an increasing recognition of the difficulty of fulfilling this task. ${ }^{46}$ Not only are the sources of historical information, whether texts or eyewitnesses, influenced by personal interests and social position, but historians themselves are vulnerable to subjective distortions of the truth. ${ }^{47}$

Such developments are, of course, never linear or unidirectional; nonetheless, in this case a decisive break with earlier models can be traced to the work of Johann Martin Chladenius, a professor of theology and literature in Erlangen. In two main works, the Introduction to the Correct Interpretation of Rational Lectures and Writings (1742) and the General Science of History (1752), Chladenius develops a concept of historical perspectivism according to which any individual account of historical events is necessarily determined by position and thus has only relative validity. Whereas the past itself retains an objective existence, representations of the past are shaped by various subjective and extrasubjective factors. As Chladenius writes, "History is one; however, the conceptions of it are numerous and manifold." 48

This positionality also applies to the historian himself, who is forced by the very act of representing the past to make selections, attribute relative significance, and develop appropriate metaphors and concepts, each of which entails an act of interpretation that in turn reflects personal interests. ${ }^{49}$ As Koselleck points out, however, Chladenius's new historical epistemology leads not to a sense of despair among historians but rather to a sense of liberation. No longer simply a medium for the conveyance of historical truth, the historian now takes on an active role in "creating" that 
truth through analysis and interpretation. ${ }^{50}$ Again one can discern a blurring of the boundaries between writing history and writing literature, as historians become more concerned with causal plausibility and the creation of coherent narratives.

Chladenius's idea of a historical Sehepunckt (point of view) was rapidly adopted by eighteenth-century historians, among whom one finds a marked increase in the frequency of synonymous terms such as Standort or Standpunkt..$^{51}$ In 1768, for example, the historian Johann Christoph Gatterer published a programmatic essay entitled "A Treatise on the Position and the Point of View of the Historian, or, the German Livy." Here he demands a reflection on the epistemological conditions of historical truth, because "nation, epoch, religion, custom, and the other things that determine the position and the point of view of the historian have a noticeable influence on his selection of events." ${ }^{52}$ In the latter half of the eighteenth century, a further evolution in the understanding of historical perspectivism occurs. Chladenius operates in an essentially spatial framework. Although, in his opinion, individual accounts of the past vary and are thus imperfect, history itself, the historical truth behind the representation, remains static and noncontradictory. The best approximation to this truth is to be achieved through an examination of sources, preferably eyewitnesses to the event. Over the course of the century, however, the understanding of historical perspectivism, like the understanding of history itself, becomes increasingly temporalized. ${ }^{53}$ Not only does one's point of view depend on social position and interests; it also depends on one's position within the historical totality. As a consequence of this recognition, the eyewitness loses his privileged status as a source of historical information, as the conception begins to take shape that those who experience a given historical moment are actually at a disadvantage in terms of understanding its significance. ${ }^{54} \mathrm{~A}$ statement made in 1781 by the historian Gottlieb Jakob Planck summarizes the new mind-set: "Every great event is always shrouded in fog for those upon whom it has a direct impact, and this fog dissipates only gradually; often several generations make hardly any difference." ${ }^{55}$ This new attitude is, of course, linked to the broader conception of history as an evolving totality in which past, present, and future are seen as qualitatively different. Previous events appear with greater clarity as time passes and their relative position within the general course of historical development becomes more easily discernible. Surprisingly, perhaps, Koselleck insists on the imbrication of a tem- 
poralized historical perspectivism and eighteenth-century philosophies of progress. The recognition of others' as well as one's own historical situatedness does not necessarily lead to historical relativism; it can also foster belief in a continuous demolition of prejudice and an ever increasing knowledge of the course of human history. ${ }^{56}$

III

If the first shift discussed concerns the perceived nature of temporal change and the second concerns its representation, the third reflects a new conception of the social function of this representation. Friedrich Nicolai provides a concise formulation of the new view in an 1806 treatise on the history of the Freemasons and the Rosicrucians. Here he writes: "History carries the torch that guides enlightenment." ${ }^{57}$ In the eighteenth century, historical investigation becomes part and parcel of a wide-ranging program of middleclass emancipation. ${ }^{58}$ This emancipatory intent has several implications for the kinds of historical writing that dominate in the period. First, the study of the past becomes a means to challenge the political and social status quo. Both courtly historiography and traditional Christian historiography had been (and often continued to be throughout the eighteenth century) affirmative in nature. Christian historians used past events as a means to validate the teachings of the Bible; court historians, to legitimate or valorize a particular regent or lineage. Over the course of the eighteenth century, however, historical writing, increasingly dominated by middle-class intellectuals, becomes a tool of social criticism..$^{59}$ Investigations into the Christian past reveal the historical variability of its dogma, just as political history challenges the supposedly unlimited authority of the territorial princes. In his History of Osnabrück (1768), for example, Justus Möser concludes that the princes had originally been the elected representatives of the landowners and thus could not claim an unassailable right to rule. ${ }^{60}$

These critical investigations, whatever their theoretical consequences, were not intentionally relativistic, and they usually aimed at cautious reform rather than any radical transformation of society. In the religious sphere, progressive theologians conceived critical Bible scholarship and the historicization of contemporary dogma as a means to uncover the truth of Christianity that underlay its historically specific manifestations. ${ }^{61}$ Lessing's own reflections on religion can be viewed within this context. Political and social history, for its part, rarely called into question the paternalistic and monar- 
chical foundations of German political organization. Nonetheless, the role of critical historical studies in justifying and inspiring attempts at social reform should not be underestimated.

A second consequence of the middle-class character of eighteenthcentury historical writing was a thematic expansion and reorientation. The historical challenge to existing power structures entailed a simultaneous affirmation of the values of the upwardly mobile middle class. Historical investigations played an important role in the self-affirmation of an emerging group of nonnoble elites, often by deemphasizing the historical significance of war and diplomacy in favor of those spheres of activity in which the middle class loomed large. For the first time, for example, economic culture becomes an object of historical investigation, as in August Ludwig Schlözer's Attempt at a General History of Trade and Navigation in Ancient Times (1760) and in lecture courses like Leonhard Johann Karl Justi's "The History of Commerce, Public Policy and Finance" (1755-56) and Johann Friedrich Reitemeier's "The History of the European Trading Companies in East India" (1781-82). ${ }^{62}$ One also finds works on the history of technology and inventions, of various artisanal occupations, and of the cultural significance of tobacco, to name just a few areas of interest. ${ }^{63}$

The shift away from high politics toward social and cultural investigations is closely linked to the period's belief in the didactic function of history, inasmuch as these were the areas with the most immediate utility for middleclass readers. The orientation of historical knowledge toward the practice of everyday life is central to the period, and various authors stress the need to make the past relevant to the contemporary reader. This relevance, however, is something that must be established through an explication of the link between past and present, rather than being derived from the timeless moral lesson that one can distill from a given historical occurrence as explicated through the topos of historia magistra vitae. While it is clear that the present drives the interest in the past in the eighteenth century, the two temporal dimensions are not only linked in the sense that the great figures from the past model appropriate behavior or that the lessons of certain historical situations can be memorized for their future application. Rather, inasmuch as the present evolves out of the past, the lessons to be learned concern the trajectory of development and the potential for improvements. Enlightenment historiography, in other words, is oriented toward the future. At least among the more progressive authors, the goal of historical education is not 
to hammer home a selection of moral wisdom by way of historical example but rather to cultivate the critical faculties of the learner so that he can participate in the creation of that future. ${ }^{64}$

The thematic reorientation in eighteenth-century history can also be linked to its critical agenda. In emphasizing those activities in which the middle class has the highest level of participation, it implicitly relativizes the role of the ruling nobility in the course of historical development. ${ }^{65}$ The shift in focus, however, is by no means perceived in terms of group interests. What appears from a late twentieth-century perspective as a refocusing on the concerns of a different class was conceived and articulated in the late eighteenth century as a universalist project. This universalist agenda constitutes a third consequence of the middle-class basis of historiography in this period. As is the case with the Enlightenment intellectuals more generally, eighteenth-century historians are interested in transcending particularism and hence stress the historical role of humans as such rather than any particular estate. ${ }^{66}$ The emphasis on a universal humankind as the subject of history, which can be seen as part of a more general anthropological turn in the period, finds its most pronounced expression in the increasingly popular genre of universal history (Universalgeschichte) as well as in the more explicitly teleological Geschichtsphilosophie. Friedrich Schiller describes the task of universal history in his inaugural lecture on the topic: "What states did man pass through before he rose from that extreme to this extreme, from the state of the isolated cave dweller - to that of the sharp-witted thinker, the cultivated man of the world - universal world history offers an answer to this question." ${ }^{67}$ But more limited investigations also reflect this emphasis on the universally human, to the extent that an event's impact on humankind becomes the criterion for evaluating its historical significance. As the philosopher Thomas Abbt remarks in a 1760 article entitled "On the Different Uses of Ancient History": "Perhaps one may be so bold as to assert that only those events which concern the entire human race, or each person in particular, deserve the attention of an intelligent reader." 68

Histories of the whole of humanity have a long tradition in Christian Europe, but eighteenth-century universal history eventually detaches itself from the Christian model, eliminating once and for all the notion of four successive world empires followed by the Last Judgment. Intellectuals were by no means antireligious, as various analyses of the peaceful coexistence of the Enlightenment and religiosity in Germany have made clear. ${ }^{69}$ None- 
theless, world-historical narratives in the period become largely secularized. Divine intervention no longer constitutes a valid factor in historical explanation; the meaning of historical events must be derived from the events themselves. In this secularized context, the human being as such becomes the subject of history in another sense as well, namely, as the source of historical progress. As Hans Erich Bödeker remarks, "Increasingly, human beings learned to view themselves as the condition for and the motive force behind all change." ${ }^{70}$ History comes to be viewed as something that is made by humans, ideally on the basis of the universal faculty of reason.

At the same time, however, writers of history also become more attuned to the complexity of causal relationships, recognizing both the role of the irrational and of supraindividual factors in shaping the course of human development. Significant in the latter case is not only the interest in natural factors (natural disasters, climate, geography) but also the struggle to understand the meaning of social phenomena that operate above the level of individual control. Despite a relatively high level of optimism regarding the potential of social engineering, one can discern in the period a degree of anxiety vis-à-vis social processes that seem to have acquired the status of a second nature. Long-term population fluctuations, patterns of economic crisis, and especially the seemingly ceaseless growth of luxury production all are phenomena that challenge attempts at simple causal explanation, operating according to a seemingly inscrutable, immanent logic. The historicaltheoretical implications of this growing awareness of large-scale social processes have received little attention in the scholarship, despite the apparent affinity between the inexorable linearity of some of these processes and that of theories of human development. In this context in particular, the city, as the site where these processes appear in their most acute form, plays a crucial role.

IV

The three elements of historical understanding that I have introduced here in ideal-typical form are not intended as an exhaustive characterization of historical consciousness in eighteenth-century Germany. Not only do other shifts occur that have not been mentioned, but those which have been addressed are by no means universal. Because the period is one of transition, it is not surprising that older conceptual models continue to hold sway alongside newer ones. Thus, even as the foundation for its validity is 
hollowed out, the topos of history teaching life remains widespread in the eighteenth century (as it does today), often coexisting in a single text with a sensitivity to historical difference. In On German Literature, for example, Friedrich II acknowledges on the one hand the existence of a "taste of the times," but he also adopts a transhistorical standpoint in referring to the "one hundred examples" that history can provide to illustrate the causes for the rise and fall of states. ${ }^{71}$

Nonetheless, the evolutionary and causal model of historical understanding, the awareness of historical perspective, and the link between history and middle-class emancipation represent three key moments in the historicaltheoretical force field of the period. Taken together they describe a plane of historical-theoretical discourse, offering a starting point for an attempt to graph the line of intersection between this plane and the one constituted by the discourse on the city. By investigating this line of intersection as it appears in the works of the Berlin Aufklärer, I hope to provide some insight into the role played by everyday experience in the evolution and articulation of the new understanding of history. Texts addressing urban life and urban phenomena certainly do not provide a transparent representation of Vierhaus's "real-historical process" - the impact of social reality on eighteenthcentury historical consciousness - but they can at least gesture to the role of material conditions. As I mentioned, the thrust of this impact would seem to be in the form of a challenge to overly simplistic theoretical models. If, for example, one can accept as representative Schiller's claim that the discovery of "primitive" peoples convinced the Europeans of their advanced position on the timeline of human development, the domestic urban experience tended to complicate such naive linearity. The challenge was raised on an obvious and concrete level through the presence of various disenfranchised groups, from prostitutes to day laborers and indigents. Whereas the discussion of these individuals in texts often gives rise to reflections on imminent social disintegration, the marginalized and disadvantaged urban Jewish communities are often perceived as a case of arrested historical development and thereby linked to the distant past. The aggregation of such groups in the city creates a sense of nonsimultaneity both more palpable and more problematic than that perceived as existing between Europeans and the inhabitants of distant islands.

The urban context, at least for those who care to think seriously about it, also presents more abstract challenges to historical thought. As the site of a 
confrontation between social and natural processes, where the borders between the two often blur, the city forces intellectuals to consider the historical significance of these processes, to attempt to situate them within emerging models of historical development. Of most immediate concern is the question of how to interpret the rapid growth of the cities themselves, a quasi-natural process that seems to indicate growing prosperity even as it demonstrates the limited ability of humankind to shape its own destiny. But other historically charged concerns arise as well. What, for example, is one to make of the seemingly endless succession of new fashions that appear in the city? How does one reconcile the project of individual self-cultivation, perceived as closely linked to urban forms of sociability, with conceptual models of the gradual development of the species as a whole? Can the detachment from traditional mechanisms of social control that characterizes big-city life open up possibilities for human progress or does it merely lead to degeneracy? These are the questions raised and reflected upon in the works of Gedike, Nicolai, Lessing, and Mendelssohn, as well as in other essays on the city written in the period. Admittedly, all of these representations of the urban environment are pretextualized to varying degrees by literary and rhetorical convention, but it is precisely in the interface between convention and narrative content that the subjective experience of urban life, together with its historical-theoretical implications, becomes apparent.

\section{The Case of Berlin}

Berlin's central role in these discussions is no coincidence. Eighteenthcentury considerations of urban life, to the extent that they deal with Germany at all, find it impossible to ignore this city. The interest in Berlin is not surprising, because the city was, in several important respects, unusual in the German-speaking world. Part of its uniqueness has to do with sheer size. In the period after 1750, only Berlin, Hamburg, and Vienna could boast more than 100,000 residents. ${ }^{72}$ These three cities were thus at least twice the size of the next largest group of cities, most of which had between 30,000 and 50,000 residents. ${ }^{73}$ The emergence of an entirely new category of Großstadt in central Europe was recognized by contemporaries as a historical novelty and led, particularly in the case of Berlin, to comparisons with London and Paris and to discussions of the dangers of urban sprawl. Friedrich Gedike, 
for example, whose anonymous letters "On Berlin" are the focus of the next chapter, attempts to counter the charge that Berlin, like Paris and London, has become too populous in proportion to its geographic extension. ${ }^{74}$

Even within the aforementioned triumvirate of large German cities, however, Berlin again stands out due to the rapidity of its growth. The comparison with Hamburg is particularly revealing. Hamburg's population remained relatively constant between 1650 and 1800 , hovering between 70,000 and 75,000 until the latter half of the eighteenth century, when it increased to 100,000 . The population of Berlin, in contrast, jumped from 12,000 in 1650 to 55,000 in 1700 , and then nearly tripled to 150 , 000 by $1800 .{ }^{75}$ Much of this growth came from immigration, not only of economic refugees from the Brandenburg countryside but also of groups from other German states and other nations. ${ }^{76}$ Berlin was thus a singularly cosmopolitan city for the period, home to Huguenots and Bohemians as well as an unusually wealthy and prominent Jewish community, and this diversity comes up repeatedly in the descriptions from the travel literature. Within German-speaking lands, only Vienna was comparable in this regard. Already in 1752 the city's rapid expansion had led the Berlin theologian and demographer Johann Peter Süßmilch to investigate its causes in a work entitled A Treatise on the Rapid Growth of the Royal Residence Berlin. ${ }^{77}$ As discussed in the following chapter, Süßmilch's treatise does not merely register this growth but also attempts to place Berlin's expansion within the context of a more general historical narrative, revealing a peculiar hybrid of Christian and secular historical models in the process.

While one cannot draw definite conclusions about the subjective experience of urban life from population statistics alone, the essays, travelogues, and fictional texts that address Berlin make it clear that these changes gave rise to an increased sense of the dynamism of the city. This pervasive sense of rapid transformation, more than anything else, underlies eighteenthcentury Berlin's uniqueness as an impetus for reflection on historical change. This is not to deny the importance of other major German or European cities as focal points for the articulation and mediation of historical consciousness. On the contrary, the discussion of Descartes, Rousseau, and their German disciples at the beginning of the chapter was intended to demonstrate the general historical-theoretical significance of the city in eighteenthcentury Europe, a significance that often becomes most visible in comparisons among cities, either across different time periods, different territories, 
or both. A more comprehensive understanding of the role of the city in the formation of eighteenth-century historical consciousness would require an analysis of several major European cities, paying special attention to the way in which temporal structures are actualized within the specific discursive traditions associated with each. With regard to the German-speaking world, eighteenth-century Vienna no doubt deserves special attention, because it shares some of the characteristics that made Berlin unique in the period: rapid growth, a diverse population, and an association, at least after 1780, with the forward-looking policies of "enlightened" absolutism. ${ }^{78}$ And the various textual mediations of the major foreign metropolises, especially Paris, London, and Rome, could certainly be mined for their historicaltheoretical content as well. Nonetheless, the unparalleled dynamism of Berlin does provide some justification for focusing on this city, especially within the context of the German Enlightenment. Commentators perceive eighteenth-century Berlin as an arriviste on the urban scene. Unlike Hamburg, it has no connection to the medieval traditions of the free imperial city. ${ }^{79} \mathrm{Un}$ like Vienna, it is not the capital of an empire with links to antiquity, nor is it suffused with the faded glory of that antiquity like Rome. And unlike Paris or London, which were already vibrant cultural, economic, and political centers with more than 500,000 residents in the seventeenth-century, Berlin's evolution into a major European capital only becomes apparent after 1750. Indeed, a number of late eighteenth-century writers on Berlin occupy themselves precisely with the question of whether the city has in fact "arrived" and what this arrival means for its future. Later, Berlin's lack of tradition ossifies into something of a cliché. ${ }^{80}$ In the eighteenth century, however, Berlin's conspicuous modernity challenges commentators to find appropriate temporal models with which to interpret recent changes in the city and to delve into its murky past to determine exactly how it did evolve into its present state. Perhaps paradoxically, then, it is precisely the lack of preexisting historical narrative into which to insert Berlin that makes it a focal point with regard to historical consciousness.

Demographic movements provide only part of the story in this context. The rapid growth of Berlin in the eighteenth century, together with the tensions (and opportunities) that accompanied it, must be viewed within the context of profound, longer-term changes in the very nature of the city as a social and political entity that were occurring in Germany at the time. The early modern period was long considered by subsequent historians to be an 
epoch of urban decline, in which the inexorable rise of the territorial princes gradually eroded the status of what were conceived of as the powerful, independent, and largely bourgeois trading cities of the Middle Ages. Already anticipated by late eighteenth-century critics of German absolutism like Justus Möser, this attitude became particularly prevalent among liberal historians of the nineteenth century, who viewed the emergence of the absolutist state as a fatal detour from the path toward a liberal-democratic constitutional state that had been anticipated in the self-governing medieval German city. ${ }^{81}$

An increased interest in the relationship between the city and larger political and economic structures in the past few decades, however, has resulted in a shift in perspective. ${ }^{82}$ Historians now recognize the period as one of radical reorientation rather than decline, in which the majority of cities lose their status as self-contained political entities and begin to function as nodes in the administrative, economic, and political networks of the emergent territorial states. Particularly in the case of the provincial capitals, one finds a gradual integration of the city into an expansive web of social, cultural, economic, and political relationships, in which it functions as a kind of nucleus. In other words, city and state become increasingly interconnected, a development that finds its concrete illustration in the demolition of the defensive city walls that occurs regularly in this period as well as in their replacement, especially in Brandenburg-Prussia, by customs control points. ${ }^{83}$ Contemporaries were well aware of the connection between city and state, especially in the case of Berlin, where the rise of territorial power and the increasing status of the city went hand in hand. Friedrich Gedike makes this connection explicit in one of the first letters in his collection, where he remarks: "In short, Berlin is the emblem of the Prussian monarchy, where more or less everything useful and entertaining has been crowded together with the aim of satisfying only itself." ${ }^{84}$

The simple precision of this particular statement is somewhat misleading, however, because other passages in the text suggest the indeterminate status of the city in this transitional period. Whereas in this remark Berlin is represented as the state in microcosm, in other passages it appears as an independent entity that can best be understood within the framework of the "big city." This oscillation corresponds to an inconsistency in the author's discussion of the residents themselves: the "Berliners" are sometimes treated as an urban population, sometimes as an independent people with its own "national" character, and sometimes as identical with the "Brandenburgers." 
In these three categorizations of the city residents, which also appear in other descriptions of the city, one can discern three strands of urban discourse that converge in discussions of Berlin and indicate some of the conceptual challenges the city presented to commentators. The notion of the Berliners as a people unto itself hearkens back to the traditional concept of the city as an autonomous, self-governing community of individuals bound together by a common culture and, more important, by a common set of legal rights. This general understanding of the city still predominates in Zedler's Universallexicon, where the author of the entry on "city" places a heavy emphasis on cultural and especially legal autonomy. He refers to the residents' "unity of temperament in their external way of life and comportment," as well as to the fact that they live "according to a single set of rights and laws." ${ }^{85}$ In contrast, the conflation of Berlin and Brandenburg that one also finds in Gedike gestures to the centralization and consolidation taking place in his own day and suggests that the state, rather than the city per se, has become the new frame of reference. Finally, his comments on the Berliners as big-city dwellers points to a metropolitan future that has already arrived, where the big city constitutes an independent entity with characteristics that transcend state boundaries. ${ }^{86}$

A tension between past, present, and future thus informs even the most basic elements in descriptions of Berlin, and this tension points back to the historical-philosophical complexity that was mentioned earlier. An awareness of this tension, however, should not distract us from the fact that writings on eighteenth-century Berlin generally emphasize the city's forward momentum. When one considers the changes taking place in the wake of Prussia's rise to power, this emphasis is hardly surprising. While the consolidation of the power of the territorial states can be linked to urban decline in the case of certain previously powerful trading centers - Augsburg and Nuremberg are two striking examples - it also laid the foundation for the meteoric rise of the capital or court cities (Residenzstädte). In the cases of Berlin and, to a certain extent, Vienna, this rise meant the appearance of an entirely new category of city, with a population, degree of social diversity, and level of political and economic complexity that had been hitherto unknown in central Europe. ${ }^{87}$ The powerful presence of the state in these cities was in no way indicative of a lack in dynamism. On the contrary, in the words of the twentieth-century urban historian Etienne François, it is "remarkable to see how, after 1650, the capital cities take the place of the free 
cities and the traditional trading centers as the privileged sites of economic, social, and cultural innovation." ${ }^{88}$

Berlin, a city whose sovereigns were actively engaged in raising it to the status of a first-tier European capital, was at the forefront of this development. Here, as elsewhere, the aforementioned reorientation had farreaching social consequences. To address them in any detail would require a separate study. For the purposes of my analysis, it will suffice to point out that changes in administrative, political, and economic organization, like the demographic shifts with which they were inextricably intertwined, contributed to a sense of instability (if viewed negatively) and opportunity (if viewed positively) among city residents. That the latter was also the case can be seen in the pull exerted by the city on an emerging cultural elite, Lessing included, as well in the stream of artisans, shopkeepers, and domestic servants who came to the city in the hope of finding employment. ${ }^{89}$ Old centers of urban decision making such as the magistracy and the guilds saw their power erode, either through a restriction of their sphere of influence, as in the case of the Prussian Trade Guild Law (Handwerksordnung) of 1733, or through their incorporation into a more comprehensive state apparatus, as in the case of Friedrich Wilhelm I's various efforts to centralize and reform the state administration in the first part of the century. ${ }^{90}$

What has to be remembered is that these attempts at consolidation, even if they ultimately resulted in an ossified, authoritarian bureaucracy, functioned at the outset as a dynamic element in urban life. Although a social order grounded in estate-based corporatism continued to predominate in Prussia until at least the early nineteenth century, these changes in administration helped to weaken its hold. ${ }^{91}$ As Christoph Dipper writes with regard to the rise of a professional bureaucracy, "after the middle of the eighteenth century, Prussia was the territory in which the specialized qualification of future state officials had become most detached from the methods of selection that were typical of an estate-based society." ${ }^{92}$ And it was, of course, in the capital city, the center of Prussian administration, where the impact of this dissolution was most palpable. The concentration of state offices in Berlin created unprecedented opportunities for upward social mobility for a new, university-educated segment of the middle class. ${ }^{93}$

Another crucial component of Berlin's dynamism as it is conceived by eighteenth-century commentators is the city's reputation for tolerance. Although scholars of the period have long since cast a critical eye toward the 
Berlin Enlightenment under Friedrich II, mapping out its limits and revealing its often illusory character, there can be no doubt that contemporaries viewed the city as unique in terms of the intellectual latitude granted to its residents. This latitude was most obvious in the religious sphere, where the politically inspired immigration policies of the Hohenzollerns had led to a religious heterogeneity that undermined the church's ability to speak with a single, unified voice. General religious tolerance, together with public scandals, including Friedrich II's decision to grant asylum to the French materialist philosopher La Mettrie, led to a widespread stereotype of Berlin as a bastion of atheistic thought. As Goethe remarks to his sister in a letter from 1766, "I think there is now no other place in Europe as godless as the residence of the Prussian king." ${ }^{94}$ Yet despite the powerful association of Berlin and religious freedom, critical discussion was by no means limited to the religious sphere. To be sure, certain subjects were taboo. The fundamental legitimacy of monarchical rule, for example, was rarely called into question; it was primarily addressed, as in the case of Kant's essay on enlightenment, in order to affirm its superiority to other forms of political organization. ${ }^{95}$ However, it would be inaccurate to reduce the Berlin Enlightenment to the freedom to criticize religion. Encouraged by the relative lenience of Friedrich II toward the press and caught up in the general politicization of public discourse that took place in Germany in the 1780s, intellectuals debated numerous issues of city and state government, from school reform to agricultural policy. ${ }^{96}$

Even in the economic sphere, with regard to which it has become clear that state intervention and the militarization of the economy in Prussia hindered the natural emergence of an entrepreneurial class, one must recognize the extent to which Berlin was perceived as a place where radical changes were taking place. ${ }^{97}$ Friedrich Nicolai, who built a small family press into a highly profitable and influential publishing empire, can be taken as evidence of the opportunities available in the city. Also significant in this regard are the aforementioned Trade Guild Law of 1733; the establishment and expansion of wool, silk, and porcelain manufacturing facilities in the city, with which Moses Mendelssohn was involved for most of his life; and the financial crisis and profound redistribution of wealth that followed the end of the Seven Years' War. ${ }^{98}$

My intent here is not to valorize absolutism in eighteenth-century Prussia but rather to counter the assumption that eighteenth-century Berlin, 
because of its status as a court city with a strong state presence, was characterized by inertia. On the contrary, as Deborah Hertz has argued, it was precisely this presence that powered Berlin's rapid growth and fostered its heterogeneous social structure. Administrative expansion created a need for new bureaucrats, mercantilist policies generated new opportunities for Jewish and gentile merchants and financiers, and the powerful court drew in aspiring courtiers. These individuals attracted a supporting cast of artisans, clerks, tutors, and servants in turn..$^{99}$ Berlin's sizable intelligentsia was yet another definable group of residents, albeit one whose members sometimes served equal time in other occupations. As these various social groupings indicate, eighteenth-century Berlin was something of a hybrid: part court city, part state capital, and part bustling metropolis. ${ }^{100}$ The tensions that arise between these various identities are reflected in the works under consideration here and contribute to the perception of Berlin's dynamism in this period. The city's hybrid personality, in other words, is a key aspect of its modernity. As the nucleus of an evolving political unit that anticipated the modern nation-state in many respects, Berlin functioned as a space where the social consequences of various incipient processes of modernization bureaucratization, secularization, the erosion of tradition, and the spread of rationalized forms of production and distribution - made themselves felt with particular intensity. To be sure, these processes competed with powerful conservative tendencies in the policies of the Hohenzollerns, as can be seen, for example, in their resolute commitment to maintaining the social privileges of the nobility. Often, however, such tendencies ended up contributing to the vitality and heterogeneity of the city. If the Prussian monarchy had not been so concerned with the welfare of the landed nobility, for example, it would not have created the attractive positions in the military and civil service that brought them to Berlin and encouraged them to mix with the middle-class elites. ${ }^{101}$

\section{Conclusion}

This brief description demonstrates the plausibility of a link between urban experience and the evolution of historical consciousness in eighteenth-century Germany. The various debates and discussions about city life in general and Berlin in particular are not explicitly framed as histori- 
cal investigations, but virtually all of them have significant implications for historical-theoretical reflection. Changes in the city induce commentators to situate them within a by now largely secularized conception of human history, either as examples of regression, progress, or some other temporal category. Berlin's rapid growth and rise to prominence elicit comparisons with its own earlier incarnations as well as with other European cities, comparisons that entail reflection on the current and future consequences of what are understood as "modern" developments. Even the notion of the big city itself, despite the persistent application of biblical and classical stereotypes in descriptions of urban space and urban life, comes to be articulated less and less in terms of an interchangeable constellation of timeless characteristics applicable to any empirical city. Instead, the focus shifts to a more inductive understanding of a given urban environment-here Berlin - as the product of a unique process of historical development.

The best examples of this shift in focus can be found in the works of Nicolai and Gedike, two enthusiastic Berlin residents. It is by no means universal, however, as becomes clear from an essay by one of the most resolutely negative commentators on big-city life in eighteenth-century Germany, the cameralist Johann Heinrich Gottlob von Justi. In 1764 Justi published a text entitled "The Big City Considered in Various Aspects, Especially with Regard to the Best Methods of Taxation and the Means to Ensure a Reasonable Price for Foodstuffs." Justi has nothing good to say about the big city. In language reminiscent of Rousseau but with a more pronounced economic emphasis, he describes it as "a glutton who drives up the price of food, a gourmet that wastes the country's money, a woman of leisure who flirts with manufacturing and industry only to steal them away from the diligent residents of the provinces, the corruptor of healthy commerce, and in general a weak, overly pampered creature who is thrown in to the most dangerous state of health and the most terrible convulsions by the smallest draft of fresh air." 102

Justi's essay is clearly concerned with contemporary urban growth, but his language suggests that this characterization applies to large cities throughout history. At least he makes no explicit, qualitative distinction between the big cities of the past and those of his own epoch. Even in this ahistorical approach, however, the big city becomes an occasion for addressing the specificity of the contemporary. The lack of sufficient employment in big cities gives rise to residents with time on their hands, and this leisure has 
political implications. The modern state, according to Justi, has no need for idle citizens like those of Greek and Roman antiquity, who assemble in the marketplace, discuss the affairs of state, criticize the actions of their generals, and attempt to govern themselves. In a slightly more progressive moment, Justi also distinguishes between the "ancient times," in which the glory of a ruler was paramount and derived to a large degree from the glory of his capital city, and the more enlightened present, in which the health of the state as a whole has become a central concern. ${ }^{103}$

In addition to providing another illustration of the link between urban and historical discourse in the period, Justi's treatise points to a secondary justification for this study. The prevalence of such negative representations of the big city, together with the valorization of nature and country life in much of the literature from the period, has led to a widespread perception of eighteenth-century German intellectuals as antiurban. With regard to eighteenth-century German literature, Erich Kleinschmidt has spoken of a "refusal" on the part of authors to pay serious attention to the city as a motif, something he attributes to their ambivalence regarding the often stifling living conditions in their own hometowns. ${ }^{104}$ And Conrad Wiedemann, in the foreword to a volume of essays on the experience of German authors and artists in foreign metropolises, speaks of a displacement of the urban ideal, to the extent that it is made explicit, onto the foreign city. Rome, Paris, and London, though often viewed with suspicion and even contempt by German travelers, simultaneously function as the embodiment of a freedom seen as diametrically opposed to German provincialism. As a result, according to Wiedemann, the various journeys to these cities take on existential significance for the individual, generating conflicts between the desire for individual liberation and the need for a sense of national identity. ${ }^{105}$

Wiedemann demonstrates the complexity of German attitudes toward the most famous foreign metropolises, but a similar complexity also characterizes representations of the urban experience in Germany, whether they occur in the form of general discussions of big-city life or in evaluations of specific German cities. It is true that the existential moment tends to be lacking in such representations. Nonetheless, the broader claim that eighteenthcentury authors and intellectuals failed to take an interest in the emancipatory potential of domestic urban life becomes less convincing when one shifts attention away from canonical literary texts and stops basing evaluations on a concept of metropolitan literature derived from the postindustrial 
period. ${ }^{106}$ Even the valorizations of country life used as evidence of German antiurbanism appear in a different light when placed against the backdrop of eighteenth-century worries that big cities were growing too quickly and sucking the life out of the countryside. Already in the 1760 s Justi writes that "a big city simply appeals too strongly to the human desire for opulence and excess to not have a constant stream of new residents." ${ }^{107}$ Thirty years later Christian Garve published an essay entitled, "Fragments on the Investigation of the Decline of the Small Cities, Its Causes, and the Means with Which to Remedy It" (1793). Here the author links the apparent deterioration of Germany's smaller cities to the otherwise beneficial growth of the capital cities. ${ }^{108}$ Even an urban advocate like Gedike warns that "the strange notion that people often have regarding the luster of the capital city is the reason that everything tends to be packed in so tightly there." 109 In the context of such expressions of concern, valorizations like those found in Johann Georg Schlosser's 1771 Moral Catechism for Country Folk ("I cannot even begin to tell you of the trials of life in the city") or even Hölty's 1775 poem "Country Life" ("Most blessed man who has fled from the city!") begin to look like defensive posturing. ${ }^{110}$ Particularly in the case of Schlosser and a number of other nonfiction texts, the glorification of country life is clearly a reaction to an already existing and allegedly dangerous fascination with the city among certain segments of the population. ${ }^{111}$ Moreover, as the general thrust of Gedike's and Garve's essays demonstrates, one does not have to look far to find explicitly positive testimony as well, even if class-based concerns sometimes temper the enthusiasm of these urban commentators.

In the case of the Berlin Enlightenment in particular, one can discern a high degree of civic pride and a cautious but conscious effort to cultivate an urban culture worthy of a European capital. In addition, despite the long shadow cast over the city by Friedrich II, this effort is often conceived as independent of, though rarely in opposition to, the court. Indeed, as I hope to demonstrate, the urban experience is viewed by Berlin intellectuals as a crucial, if problematic, aspect of their progressive agendas. One must recognize, in other words, that the Berlin Enlightenment was not merely headquartered in the capital city but was in important ways an urban phenomenon, which acquired its specific contours and self-understanding through a confrontation with the challenges of an urban modernity.

To these challenges, together with their historical-theoretical implica- 
tions, we now turn. Before doing so, however, it should be noted that the analysis in the book has been structured to progress from the explicit to the implicit. Chapter 2 focuses on the reception of Berlin in the travel literature of the period, delineating the specific urban phenomena that interested commentators as well as the historical-theoretical implications of their responses to these phenomena. At one end of the spectrum are readings that associate Berlin's rapid change with the impermanent and ambivalent mutations of fashion. At the other end are the Berlin letters of Friedrich Gedike, which emphasize a more grounded, gradual form of change viewed as characteristic of progress. Gedike's letters demonstrate the historical-theoretical complexity at the root of eighteenth-century representations of the city, and this notion serves as a structuring principle for all of the remaining analyses in the book. Chapter 3 considers the manifestations of this complexity in the work of Friedrich Nicolai, especially as it relates to questions of historical causality. The focus remains on actual representations of the city, but the chapter progresses from an analysis of the author's historicalstatistical volume on Berlin and Potsdam to an interpretation of the depiction of Berlin in his novel Sebaldus Nothanker. The aim is to identify conceptual analogies between the novel and the nonfiction texts in order to demonstrate key continuities and variations in the treatment of urban phenomena across Nicolai's oeuvre. The explicit reflections on city life discussed in the initial three chapters are intended to provide a foundation for the more interpretive readings in Chapters 4 and 5. Chapter 4 takes the eighteenth-century conception of the big city as a site of liberation and autonomy as the starting point for an analysis of G. E. Lessing's Berlin comedy Minna von Barnhelm. Here the analysis emphasizes the way in which the urban setting informs the drama on a deeper level, motivating both its narrative trajectory and its perspectival structure. Finally, Chapter 5 attempts to demonstrate the extent to which Moses Mendelssohn's theory of sociability, though by no means consciously conceived as an "urban" philosophy, nonetheless resonates powerfully with both the urban writings of his contemporaries and with his own experience in eighteenth-century Berlin. In particular, the dialectic of sociability that becomes a central theme in Mendelssohn's late work and that serves as the foundation for an incipient theory of modernity, appears heavily indebted to the urban discourse of the period. It is hoped that the engagement with both explicit and implicit re- 
flections on urban phenomena will not only make the central thesis of this study more compelling but that it will also give some sense of how significantly urban life impacted key facets of eighteenth-century German culture, even if this impact sometimes left its traces only beneath the surface of the text. 


\section{Fashion, Progress, and the Multiple Futures of Late Eighteenth-Century Berlin}

\section{Introduction}

Perhaps the most compelling testimony to Berlin's dynamism in the late eighteenth century is the sheer volume of articles and travel reports devoted to describing it. Authors writing toward the end of the century already cast themselves as critical revisionists of earlier reports; by 1785 the large number of publications even seems to have led to a sense of market saturation. In the prologue to a book from that year entitled Candid Observations on Berlin, Leipzig, Prague, for example, the author engages in a fictionalized dialogue with his publisher and is told that "there is already far too much about Berlin; we can leave Berlin out." ${ }^{1}$ He responds by insisting that much of what has appeared to date is untrue, and that his firsthand experience of Berlin has allowed him to provide the real story. The irony of this claim is that large passages from the Candid Observations are copied almost verbatim from Nicolai and Gedike and merely given a different, overwhelmingly negative spin. Such insulting combinations of plagiarism and disparagement were prevalent enough in the 1780 os for editors of Berlinische Monatschrift to issue a counteroffensive. In 1785 the journal published an article entitled "A Comment on the Numerous Anti-Berlin Texts in Our Day." ${ }^{2}$ Here the author of the Candid Observations and other participants in the alleged slur campaign against the city are taken to task for their misrepresentations and questionable motivations.

As the controversy surrounding Berlin in the 1780 os reveals, the city's rapid rise to prominence elicited reactions from both insiders and outsiders attempting to make sense of its growth. Much of the discussion consists of standard fare to be found in any late eighteenth-century travelogue. Considering the dramatic gap between Berlin and more venerable European me- 
tropolises in terms of size and cultural impact, it is somewhat surprising that one finds so little variation among these cities as regards their representation in the German travel literature. Nonetheless, while German travel writers clearly recognize that Berlin is not Paris or London, they have no difficulty considering all three within a common framework of metropolitan life, as the multiple comparisons among them make clear. ${ }^{3}$ Of interest in all cases are topics like public hygiene, the attractiveness of public buildings, the character of city residents, and the number and quality of political, educational, religious, and cultural institutions. Within these categories, a number of specific topics also appear with regularity in texts about Berlin: the deplorable condition of the streets, the disproportionate influence of French culture, the strong military presence, the outspokenness of city residents, the beauty of the Tiergarten, the large number of prostitutes, the relaxed atmosphere of the social clubs, and the problems of poverty and begging. What really distinguishes the descriptions of Berlin in such reports, however, is the underlying sense that the city is in a state of flux, that its institutions, policies, and even concrete structures have been established recently and face an uncertain future.

Attitudes toward the city range from enthusiasm to repulsion. Although virtually every commentator, in keeping with the rhetoric of the period, insists on his impartial status, and although virtually everyone finds something to like about Berlin, one can discern a fairly clear split in opinion between Berlin residents and writers from outside the city. The real advocates of Prussia's new metropolis are proud residents like Gedike and Nicolai. The outsiders, in contrast, often seem intent upon taking the Berliners down a peg. A 1787 article from the Teutscher Merkur, to give one example, suggests that much of Berlin's fame derives from the provincialism of German travel writers, who have no experience of foreign cities with which to compare it. Casting himself in the role of the true cosmopolitan, the author writes: "And so a German who has never made it over the Alps or past the Rhine must necessarily be amazed at the number of large, new . . . buildings that he finds in Berlin. The mere fact of this amazement, however, no matter how many people have expressed it, does not qualify Berlin for the title of the most beautiful city in the world." ${ }^{4}$ The opposition between the pro- and anti-Berlin camps is significant, because it often corresponds to a split in the underlying conceptual frameworks employed to understand the city's 
recent history. In competition are two basic models for interpreting temporal change, both of which are central to Enlightenment conceptions of urban experience and to Enlightenment historical consciousness more generally. At one end of the spectrum is a notion of rapid and directionless fluctuation whose only long-term significance is to indicate the capriciousness of human activity. Eighteenth-century authors tend to identify this type of change with the ambivalent mutations of fashion (Mode), which in texts from the period are often interpreted through the lens of an older Christian vanitas discourse. At the other end is progress narrowly understood, conceived by commentators as gradual evolutionary change according to an organic model of development. The controversy over Berlin as a historical phenomenon is largely played out in the space created by these opposing conceptual frameworks. Berlin's recent growth and current status, in other words, are interpreted through some combination of the categories of fashion and organic progress. Moreover, the force field generated by this opposition also impels writers to consider the connection between causality and temporality that plays such a crucial role in the evolution of historical understanding in the period.

\section{The History of Fashion}

Modefieber, Modeleichtsinn, Modegespräch, Modeliteratur - the proliferation of these and other compounds in eighteenth-century Germany gives some indication of the period's interest in fashion and related topics. ${ }^{5}$ In contemporary German studies, a growing recognition of this interest and of fashion's role in the self-definition of an emergent middle class has resulted in a number of important scholarly investigations. Most significantly, Daniel Purdy has traced the way in which the new nonnoble elites come to incorporate fashion and consumer consumption into a complex project of identity formation around the turn of the century. ${ }^{6}$ Rejecting the ostentatious display of wealth they associated with the ancien régime, this group both reframed the discussion of fashion to emphasize utility and linked fashion to the expression of individual subjectivity. As Purdy puts it, "Clothes were no longer signs of privilege granted to individuals to confirm class membership but were clues to individual identity." ${ }^{7}$ Rather than a mere marker of member- 
ship in a particular estate, in other words, fashion becomes in this period a means of situating oneself and others within the constellation of abstract values that constitute a new discourse of subjectivity. ${ }^{8}$

Purdy offers an exemplary demonstration of fashion's crucial contribution to the evolution of the modern subject. In eighteenth-century Germany, however, fashion also functions as a historical-theoretical category, one that figures prominently in efforts to conceptualize modernity more generally. This aspect of fashion remains largely unexplored in the scholarship on the topic. ${ }^{9}$ In order to grasp better this temporal function as well as fashion's specific significance for the convergence of historical consciousness and urban experience in the period, a brief overview of the general eighteenth-century discourse on the subject is in order. A number of the central elements of this discourse can be found in the 1739 article on fashion from Johann Heinrich Zedler's Universallexicon. Written in the early phase of the German Enlightenment, the article contains a characteristic appeal to reason within a framework of conservative Christianity and unquestioning acceptance of the existing social hierarchy. As a document from the period just prior to the shift that Purdy delineates in his study, the article can be seen as something of a transitional piece. It already incorporates the emphasis on naturalness, utility, and balance found in the latter part of the century, but it also includes a healthy dose of anxiety regarding threats to the estate-based social hierarchy. Purdy rightly associates this anxiety with a critique of fashion and luxury that has its roots in Roman antiquity, but, as we will see, it continues to play a significant role well into the 1780 s, especially in reflections on bigcity life. ${ }^{10}$

According to the author of the article, the idea of fashion applies not just to clothing but to the distinctive character of a wide variety of objects (furniture, coaches, buildings, and manufactures) and practices (forms of speech, compliments, and ceremonies) of a given people at a given time. Fashions allegedly have their origins in the innate human desire for change and variety, a desire that is particularly strong, the author notes, among Germany's fickle Gallic neighbors. The author makes a good show of taking a balanced approach to his subject matter, even suggesting at the end of the article that some silly but harmless fashions should be adopted for reasons of personal advancement. Despite such magnanimous gestures, however, and despite the claim that certain fashions may comply with the dictates of reason and thus improve our lives, his general thrust is to associate fashion with cor- 
ruption and decline. He contrasts fashion with the more gradual and lasting changes that characterize "habits," "customs," and "observances." Unlike these, fashion overwhelms countries like a natural disaster: "Like a raging torrent, a new fashion floods an entire land in a moment's time and, like a virulent epidemic, infects most of those people who come into contact with it." ${ }^{11}$ He goes on to denounce the new fashions in religion as the work of Satan, to condemn the unnatural excesses of contemporary culinary fashions, and to lament the misguided (and allegedly self-destructive) attempts of the lower classes to imitate the fashions of the powerful.

One can discern in this article at least three elements that are characteristic of the eighteenth-century German discussion of fashion. The first is the association of fashion with the unnatural, with a corruption of both the appropriate hierarchy of individual faculties and the social hierarchy. This unnatural aspect of fashion is most apparent in the examples of fashionable excess given by the author. He refers at one point to the deplorable aversion to healthy red cheeks among women, an aversion that has led some extremists to apply makeup in an effort to enhance their pallor. Later in the article, he remarks that the current taste for exotic foods has become so extreme that soon new dishes will have to be fetched from the moon and other planets. Such complaints may seem fairly innocuous, but the socially conservative implications of this position become more evident in the author's discussion of the poor. In this context, he criticizes those who attempt to imitate the fashions of their superiors and thereby escape the restrictions of their naturally ordained social station. Here it is not fashion per se that is unnatural but rather the adoption of fashions by those who lack the financial resources to maintain them. As a result of their foolishness, the author claims, many of modest means have been reduced to beggary. But wealthy and ambitious nonnobles are likewise advised to remember their station. Even if they are able to match or exceed the expenditures of their social superiors, the author explains, they will always lack that certain je ne sais quoi that ultimately legitimates the power of the powerful.

These criticisms point to a second important and related component of the discourse on fashion, namely, its association with a split between interior and exterior, essence and appearance. Fashion is the quintessential category of the exterior, and the anxiety that permeates this article as well as other eighteenth-century discussions of fashion stems from a fear that this superficial exterior may become detached from, or veil, or even deform a more 
essential interior. Hence the author's concern that "our Germans are becoming half French," 12 and his contempt for those nonnobles who think that the conspicuous display of wealth will make them equal to those of a higher station. He writes: "It leads rather to exasperation and grief when they are similar to those of higher station in outward appearance, and are also possessed of the desire to truly be and to have the power of those whom they resemble, but nonetheless receive from neither the lower classes, and even less from their equals or those more high-born, the status, the titles, and the other expressions of honor that they wish for themselves." 13 The consequence of such behavior is a kind of exile from the social order, inasmuch as none of the social strata treats them with the respect that they had hoped to attain.

At other points in the article the detachment of appearance and essence caused by fashion is framed as a more general disintegration of the harmonious totality of one's existence. The "reasonable" life, according to the author, is characterized by the unity of its component parts. Participation in various fashions, however, often creates a situation in which extravagance in one area of life is paired with privation in another. In the author's own words: "Does it not strike one as highly peculiar when some women try to keep pace with the noblest ladies as regards their clothing and their coffee service, and yet resemble the most miserable tradesmen's wives when it comes to their food or their lodgings, indeed, are forced into this situation as a result of their poverty and humble station." ${ }^{14}$ Here the "essence" corrupted by fashion is implied rather than named explicitly; it derives from the aggregate of life practices appropriate to a given social stratum. In both of the examples given here, however, the adoption of a fashion appears as a merely external transformation that threatens to destroy the integrity of individual and social life.

As a historical-theoretical category, fashion in this article operates in terms of deviations from a norm. The balance that it threatens possesses an a priori validity grounded in some notion of its "naturalness." In the context of the developments in eighteenth-century historical consciousness I discussed previously, fashion can be seen as a kind of holdover from what Reinhart Koselleck might have called an atemporal view of history. The ebb and flow of fashions reveals nothing more than the oscillation of humanity between virtue and vice; it testifies to the ephemerality of human creations. The various religious pronouncements of the author lend support to this 
view. Such an interpretation of fashion in the article, however, requires a qualification. In the first place, the author's condemnation of fashion is based on largely secular arguments. Transgressions related to fashion are transgressions against nature, rather than against an explicitly divine order, although the former most likely presumes the latter. Furthermore, the criticism of these transgressions is usually couched in aesthetic and utilitarian terms: either one destroys the harmony and balance of one's life, or is made to look ridiculous, or is reduced to poverty, or incurs the wrath of one's fellow man. Thus, if criticisms of the empty temporality of fashion evoke an orthodox Christianity in which there is nothing new under the sun, they are nonetheless modern to the extent that existential concerns are subordinated to questions of social utility and good taste.

More significant, the historically meaningless mutations of fashion are linked by way of opposition to a more recognizably modern historicaltheoretical paradigm, that of gradual progress. The temporality of fashion, in other words, does not apply to the totality of human activity, as it would in an (admittedly oversimplified) orthodox Christian framework. Instead it appears as the antithesis of truly meaningful historical change and thus as a means of differentiation. This opposition constitutes the third important element in eighteenth-century discussions of the topic. Criticisms of fashionable superficiality are leveled with an alternative in mind, albeit one that makes only a brief appearance in the encyclopedia article. According to the author, to the extent that some fashions have their basis in virtue and reason, they contribute to the general, long-term improvement of humanity. He writes: "Our ancestors were not able to see and invent everything good and useful all at once and thus had to leave some tasks to be accomplished in our times." ${ }^{15}$ He goes on to explain how the achievements of the present generation will be taken up and perfected in turn by those born later. These few lines offer a compact, popular formulation of the notion of a gradual, stadial historical development that has come to be so closely associated with the Enlightenment and that Koselleck and others describe in terms of a temporalization. Just as the present has evolved out of the past to become a distinct period, so the future will differ from the present in ways that cannot be foreseen.

The author's remarks in this passage contain a number of interesting ambiguities, such as the historical vagueness of the terms "forefathers" and "descendants" and the indeterminate extension of the pronoun "our." More- 
over, he appears to contradict himself near the end of the article when he claims that "the world is becoming more rather than less wicked." 16 What matters most in this context, however, is the presence in the text of two opposing frameworks for understanding historical change. Although the author also calls the positive, more lasting developments Moden, his very definition of the category as characterized by ephemerality and the absence of any clear causality would seem to rule out their inclusion. At most, they can be considered fashions only until they are recognized as contributing to the long-term improvement of humanity, at which point they become part of a linear historical narrative. As Purdy points out, this was precisely the way in which later commentators like Christian Garve and Friedrich Bertuch viewed fashion. By definition, Mode was a catchall category for those social phenomena that were not yet epistemologically (or, I would argue, historically) anchored. In Garve's words, "Objects without firm guidelines are left to the rule of Mode." ${ }^{17}$ To the extent that certain fashions reveal themselves to be socially valuable, however, they cease to be fashions altogether and are instead viewed as examples of progress. ${ }^{18}$

\section{Fashion and the Metropolis}

In eighteenth-century Germany, then, the category of fashion can be read as shorthand for a certain kind of temporal change, one opposed to changes subsumed under the conceptual framework of progress. If we return now to the question of the city, it becomes clear that this same opposition plays a crucial role in representations of urban life, especially those concerned with Berlin and its rapid rise to prominence. Undoubtedly the most comprehensive of these is the series of twenty-eight letters published by Friedrich Gedike in the Berlinische Monatsschrift between 1783 and 1785. Gedike was a longtime resident of the city, having arrived in Berlin in the 1770 s after studying theology and ancient languages in Frankfurt an der Oder. He is most often remembered for his role as coeditor of the Monatsschrift, which he published together with Johann Erich Biester between 1783 and 1791. In this capacity he distinguished himself as a prominent spokesman of the Berlin Enlightenment and was actively engaged, though sometimes under the veil of anonymity, in contemporary debates on a variety of social, cultural, and political topics. He also held a number of civil service positions in Ber- 
lin, serving first as rector of the Friedrich-Werder-Gymnasium and later as Oberkonsistorialrat (church council member), and as Oberschulrat (school council member) and founding member of the Oberschulkollegium (school advisory board).

Gedike's letters on Berlin, published in the first issues of a journal that was ostensibly established to further the spread of enlightened thinking in Germany, reveal the extent to which the controversy about enlightenment that arises in the 1780 s is simultaneously a debate about the advantages and disadvantages of modern urbanism. In Gedike's text, the defense of enlightenment against its detractors is inseparable from a defense of Berlin. To give just one example, his discussion of living conditions in the city, where most of the residents rent rather than own, suggests that this state of affairs fosters, or at least reflects, the high degree of tolerance in the city: "The wealthiest merchants, the most respected officers of the king, even the high chancellor of the Prussian kingdom and other ministers and generals live in rented rooms in large houses, and their neighbors are often manufacturers and tradesmen." ${ }^{19}$ In mounting their defense, Gedike's letters also offer a unique perspective on the historical-theoretical significance of the urban experience in eighteenth-century Germany. To understand this uniqueness, however, it is necessary first to step back and address more generally the extent to which fashion, in its broadest application, comes to be associated in the period with the metropolis and with Berlin in particular. Probably the best-known expressions of this connection come from non-German sources. In book 7 of Montesquieu's Spirit of the Laws, the author addresses the topics of fashion, luxury, and sumptuary laws and remarks: "In proportion to the populousness of towns, the inhabitants are filled with notions of vanity and actuated by an ambition of distinguishing themselves by trifles." In the same passage, he quotes a sentence from Mandeville's Fable of the Bees, where that author describes the "large and populous cities" in which residents "wear clothes above their rank" in order to increase their status. ${ }^{20}$

The evidence indicates that the basic elements of a critique of fashion and luxury as a threat to social order were well established in eighteenth-century Europe. Both of these comments reflect the same concern with an excessive and deceptive emphasis on the exterior that one finds in the article from the Universallexicon. It is interesting to note that Montesquieu's 1748 discussion already gestures toward the voluntary renunciation of luxury that Purdy sees as characteristic of the late eighteenth- and early nineteenth-century 
German middle class. He explains that ostentatious displays of luxury are anathema to republican sentiment but essential to successful monarchies and despotic states. ${ }^{21}$ Whereas both Montesquieu and Mandeville link fashion explicitly to the big city, however, there is no mention of the city in the encyclopedia. There are, of course, a variety of ways to explain this absence, but one possibility is that a real consciousness of fashion as a metropolitan phenomenon only emerged when the metropolis itself became an object of interest in Germany, in the latter part of the century.

By the 1780 s, at any rate, the situation has clearly changed. A brief but telling confirmation of this point can be found in a 1783 article by Johann Friedrich Zöllner entitled "A Contribution to a Characterization of the Big City and the Big-City Dweller.” Zöllner's essay offers a remarkably sophisticated, if rather skeptical characterization of the modern metropolis. The extent to which his reflections anticipate those of twentieth-century authors, especially Georg Simmel, is uncanny; in the current context, however, the importance of Zöllner's text lies in its association of various aspects of big-city life with the category of fashion, conceived in the broadest possible sense. In the context of a discussion of the rapid pace of urban life, for example, the author claims: "One fashionable conversation squeezes out another. Every day there is something new to relate. . . And so after four weeks one rarely hears a word about a topic that had earlier set the whole world talking." 22 One could adduce numerous other passages from the essay where the city appears as the locus of fashion, both in the narrow sense of fashionable objects and in the more general sense of a concern with appearance and the external. This particular example is significant, however, because it also articulates the connection between fashion and rapid but empty temporal change that informed the encyclopedia article on the topic.

Zöllner's "Contribution" addresses the big city as such, but he was in fact a Berlin resident, and it is hardly coincidental that his essay appeared in the same year that Friedrich Gedike began to publish his letters and in the same general period in which the controversy over Berlin becomes acute. Other contributions to the Berlin literature address additional manifestations of fashion as they are specific to the city, often employing language and argumentation that bear a striking similarity to that of the Universallexicon. Concern with the threat to the social hierarchy posed by fashion, for example, emerges in discussions of the Tiergarten, where the author of the aforementioned Candid Observations on Berlin, Leipzig, Prague sees "a 
large number of people whose magnificent clothing indicates a high station, but all of whom are of middling or even low birth." ${ }^{23}$ The author of another report, entitled "Little Excursions through Germany, in Letters from a Hypochondriac to Doctor K.," makes an identical observation. He writes: "You should come to one of the local Sunday promenades here sometimeI'll as good as bet you won't be able to distinguish the merchant's errand boy from the chamberlain, the tailor from the privy councillor, or the barber from his customers." ${ }^{24}$ Later in the text he relates an anecdote about his own barber, who finds it beneath his station to sit in a four-groschen seat at the theater. Interspersed with these observations is the same paternalistic concern with self-destruction found in the encyclopedia. According to the author, the various attempts to live as well as one dresses have led to an epidemic of bankruptcies. ${ }^{25}$

Berlin, however, is not merely a place in which the dreaded addiction to fashion, or Modesucht, runs rampant. Often the city itself-its representative structures, its institutions, and its inhabitants - seems to embody fashion's empty superficiality. For the author of the "Little Excursions," for example, the opposition between interior and exterior that informed the article in the Universallexicon offers a key to understanding the city as a whole. He claims that the Berlin residents are much like their houses, characterized by "splendor on the outside and deprivation within." ${ }^{26}$ At another point, he relates to the reader his feeling that the city was built to impress the visitor, and that its grandeur is something of a facade. Stepping off the beaten path, one is confronted with "wood huts, a single story high, occupied by half-naked men and women." ${ }^{27}$ Even the magnificence of many of the public buildings fails to hold up to careful scrutiny. Everywhere one looks, according to the author of the "Letters from a Traveler in Berlin," one finds evidence of shoddy workmanship resulting from the hurried pace of construction. The result is that he finds it impossible "to have a feeling of stability and permanence when looking at such an edifice." ${ }^{28}$ In this particular report, the sense of transitoriness extends to other urban institutions as well. The opera is but a shadow of its former self, the various manufactories are going bankrupt at an alarming rate, and the arts have never really managed to get off the ground. It is probably no coincidence that the author ends his review by lamenting Moses Mendelssohn's untimely death, a remark that suggests that even the city's intellectual prowess - something all of the travel writers concedemay be on the wane. 
One cannot know to what degree these authors are even attempting to describe their actual reactions to the city. Recent research on German travel literature suggests that by the end of the eighteenth century one could expect to find a high degree of conventionality and repetition in many examples of the genre. ${ }^{29}$ In the case of the Berlin texts, the remarkable proximity of their arguments to those contained in the Universallexicon would seem to indicate a strong pretextualization by an already existing discourse on fashion. The strength of this connection between fashion and the city, however, is precisely the point, because it indicates one way in which the city serves as a case study in historical transformation. In these travel reports, the rapid changes occurring in Berlin, both in its appearance and institutions, are subsumed under a historical-theoretical framework that generally seeks to deny their long-term significance. Although the city has much to commend it, the basic impression one has upon reading their reports is that Berlin's fame will not last, because it does not rest upon a solid foundation. In a striking parallel to one of the status-seeking individuals in the Universallexicon article, Berlin as a whole is characterized by a lack of unity among its various parts, a divergence of appearance and essence that bodes ill for its future.

Even in the critical representations of Berlin contained in these travel reports, however, the historical-theoretical significance of the city transcends the fashion paradigm. Berlin is also acknowledged as a center of science and culture, and as a place that testifies to the spread of enlightened social policy. ${ }^{30}$ Indeed, one often finds among these authors the presupposition that a metropolis like Berlin should actually be a center of cultivation, of the best that contemporary Europe has to offer. Criticisms are leveled from a position of purportedly disappointed expectations. The author of the Candid Observations, for example, expresses his dismay on finding, "in the midst of the flourishing arts and sciences ... the most conspicuous traces of barbarism and raw nature." ${ }^{31}$ As the particular choice of vocabulary here makes clear, such comments presuppose an axis of historical development - the same axis one finds in the writings of eighteenth-century historians. Its two end points are barbarism and cultivation, as represented by the "isolated cave dweller" and the "cultivated man of the world" described in Schiller's previously mentioned lecture on world history.

For all of these authors, the big city represents the culmination of a longterm process of historical development; it embodies the achievements of the "civilized" societies of Europe that distinguish the continent from other 
parts of the world and from its own past. The theologian Johann Peter Süßmilch offers a more elaborate articulation of this idea in a 1749 statistical treatise on Berlin's recent expansion. After a statistical demonstration of the city's growth and current population on the basis of new construction and death rates, Süßmilch takes a moment to consider Berlin's fate from a global-historical perspective. He ponders the decline of the great cities of antiquity-Tyre, Carthage, Rome - and the rise of European capitals like London, Paris, and Amsterdam. In reaction to the apparent migration of cultivation from east to west he asks: "And what is the immediate cause of all these transformations, which we can only view as miraculous?" His answer: "It is science and commerce." 32

Süßmilich's remarks contain a number of elements that resurface in other representations of eighteenth-century Berlin. All of the capitals he mentions, including Berlin, appear as states in microcosm. The prosperity of the metropolis testifies to the level of development of a given nation. Accompanying this national framework, however, one also finds a historical-theoretical link between the city and civilization more broadly understood. The capital city concentrates within itself the achievements of cultivated peoples. A once barbaric Europe has become, in Süßmilch's words, "the seat of the sciences, the arts, morality, merchantry and riches," 33 and its capital cities offer the most convincing demonstration of this cultivation. Moreover, to the extent that "science" and "commerce" are the sources of Europe's new prosperity, the metropolis also functions as the motor for further progress, inasmuch as it serves as the hub for these activities. In the case of Berlin, Süßmilch points specifically to the arrival of the industrious French Huguenots and to Friedrich Wilhelm's manufacturing and trade policies as the wellspring of the city's success.

Süßmilch's discussion thus positions Berlin's growth within a larger narrative of linear historical development, one that begins with the nomadic barbarism of the "uncultivated Britons, Celts, Belgians and other Germans" ${ }^{34}$ and culminates in the wealth, commerce, and cultivated refinement that define metropolitan life in eighteenth-century Europe. To the extent that the travel reports also evaluate Berlin from a similar perspective, it becomes clear that fashion is only part of the story. If, as the locus of fashion, Berlin appears to confirm an atemporal conception of human history as indeterminate ebb and flow, as a center of wealth and commerce it also testifies to the march of progress. To complicate matters further, there is an addi- 
tional aspect of the city reflected in these texts that proves significant for eighteenth-century conceptions of history. Berlin not only appears in the travel literature as the home of Schiller's "cultivated man of the world"; it is also the habitat of the "isolated cave dweller," or at least of his next of kin, if we are to believe the description of the "half-naked men and women" living in dilapidated shacks. From this perspective as well, the city is linked to a conception of progress but by way of a determinate negation. The city, to put it briefly, presents itself as a historical-theoretical puzzle. The troubling juxtaposition of past, present, and future, of barbarism and civilization, elicits expressions of concern and at the same time challenges visitors to find explanatory frameworks to account for it.

\section{Berlin between Past and Future: \\ Friedrich Gedike's Letters On Berlin}

Representations of this juxtaposition demonstrate that Berlin is perceived as more temporally complex than the fashion paradigm alone would indicate. This temporal complexity receives limited articulation in the travel reports, but it plays a central role in Friedrich Gedike's letters on the city. To be sure, Gedike's own discussion owes much to the conventions of travel literature. On the surface, the basic conceptual framework of the letters, even the epistolary format itself appears little different from that of the texts discussed previously. Gedike also espouses his commitment to the ideals of nonpartisanship and outspokenness, a commitment he tries to render more convincing by writing under the assumed identity of a visitor to the city from Munich. He then goes on to address the external appearance of Berlin, the character of its political, religious, and educational institutions, and the moral qualities of its inhabitants. Unlike the travel reports, however, Gedike's letters are written by an enthusiastic local concerned both with defending Berlin against misrepresentations and with advancing a reformist social agenda. They consequently offer a far less formulaic and much more detailed picture of life in Berlin than the average travelogue.

As is the case with the travel literature, Gedike's letters are not overtly historical in their approach. Instead, they treat the city on a phenomenological level, as a static, spatial entity to be understood through a process of critical observation. Nonetheless, one finds embedded in Gedike's investiga- 
tions representations of urban phenomena that raise questions regarding the sources, mechanisms, and directionality of historical change. The analysis of his letters thus also helps to substantiate one of the central methodological claims of this study, namely, that valuable theoretical insights into the nature of historical consciousness in this period can be distilled out of literary and philosophical texts that do not have an explicitly historical focus. Inasmuch as the late eighteenth-century conception of history focuses on the derivation of the present from its past as well as on the possible futures embedded in that present, it is often in texts that address the contemporary situation that one finds the most interesting articulations of the relationship between these temporal categories.

In this context, the most significant aspect of Gedike's letters, and their most substantive departure from the fashion paradigm that predominates in the travel reports, lies in their thematization of the multiple modes of temporality that characterize the urban environment. Like his less enthusiastic contemporaries, Gedike is struck by the rapidity of change in Berlin, as his fictional correspondent's very first statement about the city reveals: "I find that Berlin has changed dramatically in the ten years during which I have been absent." ${ }^{35}$ Whereas other authors tend to interpret this dynamism as an indicator of the fragility of Berlin's prosperity, however, Gedike is careful to place it within a more comprehensive historical context. His first letter goes on to reach deep into the past, addressing the historical nonsimultaneity revealed by Berlin's architecture and describing the traces of medieval origins that can be found in the crooked, narrow alleys and the remaining bits of old walls and buildings. Gedike's remarks in this context reveal an interesting contrast to the decidedly negative representation of the older city we saw in F. W. Taube's article on urban beautification. Taube follows Descartes in his disdain for the chaos and asymmetry of those cities or parts of cities that evolved naturally prior to the advent of rational urban planning. Although Gedike shares Taube's preference for the regularity and beauty of the newer neighborhoods, he simultaneously extols the juxtaposition of the old and the new as a pleasant antidote to visual monotony: "Naturally, the differences among the ten sections of this expansive city are very great. But precisely these differences - between the most ancient and the most recent times, the humble and the magnificent, between ignorance and culture . . . are very pleasant in a city as a whole, particularly one this large, since they prevent monotony and here create an almost unbelievable degree of 
variety." ${ }^{36}$ Even the royal palace, which was in great need of repair at the time and which Gedike adduces as an example of nonsimultaneity in microcosm, is considered "instructive," if not "pleasant." Thus one finds in Gedike an endorsement of the new, rationally planned neighborhoods together with an ability to appreciate the unique aesthetic qualities and pedagogical potential of the city's historical spaces. The value of these spaces, moreover, appears to reside in their ability to cultivate an appreciation of historical evolution understood as progress. The visitor learns from the monuments of the past to appreciate the present.

Gedike's brief description of the city topography in this section offers an alternative to the subtext of instability common in the travel literature on the city. Although he shares many of the same concerns as his contemporaries regarding the pace of growth in the city, these concerns are woven into a more complex dialectic of permanence and change. The initial description of the city can be seen as an attempt to establish Berlin's historical roots and thereby create a sense of durability. The author continues in this same vein in the ensuing description of the historical expansion of the city. Here one can discern an underlying framework of linear progress through a series of predetermined stages, a model that is crucial to historical consciousness in the period and that reappears in Nicolai's Berlin writings and in numerous other late eighteenth-century representations of historical processes. In the author's description, the chaos of the original city gives rise to the simple utilitarianism of the Friedrichswerder, built by the Great Elector one hundred years earlier, when "one had to think more of utility than of beauty." 37 The symmetry and linearity of the Neustadt (also known as the Dorotheenstadt) and Friedrichsstadt indicate a higher degree of reflection, thus revealing their more recent origins under the careful supervision of Friedrich Wilhelm I. Gedike then goes on to emphasize the active participation of the Berlin residents, whose independent industriousness was the primary impetus for the gradual expansion of this urban core by the four suburbs. Finally, he turns to the more ornamental building projects of the most recent period - "a collection of large, beautiful houses" - and the various public buildings commissioned by Friedrich II, as well as the many beautiful public and private gardens that grace the city. ${ }^{38}$

Gedike's description represents the cityscape as concrete evidence of a historical evolution, one that suggests a progression on two fronts. It indicates a movement from basic to more refined needs as well as from absolute 
monarchical control to cooperation between the monarch and the citizens. Friedrich II, often viewed by his middle-class subjects as one of their own, serves as a kind of culmination of this development. In direct contrast to the disjunction and disunity characteristic of the discourse on fashion, here the contemporary city appears as the end point of a process of organic growth, not one that has been hurried along to the neglect of foundations, but a process that has advanced naturally from a concern with basic structures to a celebration of ornamental detail.

Some pieces to the puzzle, however, present Gedike with a challenge. The recently constructed barracks, for example, cannot be easily inserted into the framework of beautiful ornamentation that has allegedly crowned Berlin's development. Instead, they are granted a certain sublimity, described as "simply enormous" and treated as a kind of technical marvel: "Thus the barracks for the Third Artillery Regiment ... is four stories tall, has fifty-five windows and two entrances along its width on one side (which takes up an entire street) and twenty-one windows on the other side." ${ }^{39}$ In addition, the "splendor-loving, extravagant" Friedrich I seems to represent an anomaly in the narrative of gradual development. Fortunately, however, the execution of his plan for the Neustadt and the Friedrichstadt fell to the "more orderly, more careful monarch" Friedrich Wilhelm I.

The linear historical progression that finds expression in Gedike's description of Berlin offers perhaps the most immediately apparent link between the urban experience and late eighteenth-century historical discourse. Here we find the city as the product of a long-term historical evolution, a product whose very appearance bears testimony to the specific character of various periods. Moreover, although Gedike does not go into any detail in this regard, the description suggests a causal coherence or natural pattern underlying developments in the city, one that transcends the idiosyncrasies of the individual monarchs, though they still function as the main motors of positive change. Even in this function they seem to be waning in importance, however, if one takes into account the subtle subtext of autonomy that informs this description. Gedike's emphasis on the "independent industry of the citizens" as the source of recent expansion suggests that the Berliners have evolved along with their city and are now in a position to take at least partial control of their destiny - to emerge, so to speak, from their state of self-incurred immaturity. This motif reappears at various points in the letters, as when Gedike, in a criticism of the most recent construction 
in the city, states his objection to "all hasty improvements that come from above," ${ }^{40}$ or when he celebrates the positive impact of the king's tolerance on the citizens. Indeed, the entire dynamic of big-city life, the diversity of experience and the exposure to a diverse population, is seen to encourage self-reliance and toleration. Gedike presents Berlin as a kind of laboratory of enlightenment, and in doing so he implicitly links it to a narrative of universal human development. This notion of the city as a universalizing space, as a site that fosters the realization of human potential, will reappear in the works of Nicolai, Lessing, and Mendelssohn.

If Gedike's Berlin testifies to the positive consequences of enlightenment, however, it also points to what eighteenth-century commentators saw as its limits. The long-term narrative of linear progress articulated in the city topography represents only one temporally significant aspect of the urban space as it is depicted in this text, and this narrative appears to be called into question by a variety of other phenomena. Most obvious are the alltoo-prevalent reminders of the supposedly modern city's unfinished character: cramped and unattractive public buildings, swamplike roads, and dilapidated bridges, not to mention such retrograde practices as emptying the chamber pots directly onto the streets. Criticisms of these and similar shortcomings are not only to be found in various travel reports on Berlin; they belong to the standard repertoire of eighteenth-century travel literature in general, and Gedike includes them liberally in his own text.

More unique is Gedike's lengthy discussion of the Berlin Jews, cast in his description as a people arrested in an early stage of human development. To Gedike's credit, he places the blame for this state of affairs on the oppressive conditions under which the community has been forced to live and offers sharp criticism of current injustices: the special taxes, the restriction to certain professions, even the uniquely Prussian practice of forcing Jews to purchase a fixed amount of porcelain at regular intervals. More dubiously, he adduces prominent members of the Berlin community like Benjamin Veitel Ephraim, Marcus Herz, and Moses Mendelssohn, along with the "exceptional" Jews of the Middle Ages, as proof of the integrity of an original Jewish national character that has remained strong even for centuries in an atmosphere of superstition and brutishness. Gedike borrows the bulk of his argumentation from fellow Berliner Christian Wilhelm Dohm, whose 1781 treatise "On the Civic Improvement of the Jews" inaugurated the political debate on Jewish emancipation in Germany. ${ }^{41}$ As is the case with Dohm, Gedike's 
position is progressive in an eighteenth-century context, but his reflections are nonetheless marked by a residual anti-Jewish bias and a condescending paternalism. Gedike more or less accepts popular Jewish stereotypes as objectively true - Jews are on the balance deceptive and uncivilized - and then proceeds to explain them on the basis of historical oppression. He actually takes a less liberal stance than Dohm on a number of issues; for example, he has little to say about the need for immediate equal rights and much to say about the need for additional education. Gedike also takes a harder line on the question of religious reform. He shares Dohm's suspicion of Talmudic and Rabbinic Judaism, a suspicion held by many of the Aufklärer, but whereas Dohm believes that rights will naturally lead to reform, Gedike appears to make citizenship contingent upon it. Whereas the "Abrahamitic" Jews must be welcome in all states, he argues, the "Mosaic" Jews will have to abandon their "useless rituals," and the "Talmudic" Jews are simply unacceptable. As he puts it, "no one can really hold it against a person if he completely refuses to accept the Talmudic or Rabbinic [Jews]." 42

With regard to historical consciousness, the Berlin Jewish community appears in Gedike's letters as a case study in human evolution. In many respects the Berlin Jews assume the role of "primitives" living within the city walls, but primitives who are in the midst of a process of civilization. He describes the Jews in general as "turned wild and immoral, to be sure" and compares them - favorably - with the Moors, the Americans, the Gypsies, and the Wends. ${ }^{43}$ To refer to them as primitives does not tell the full story, however. As the expression "turned wild" (verwildert) suggests, the Jews are not represented in Rousseauean terms, as an innocent but noble race whose development has been halted at an early stage. According to Gedike's description, their current state, in which "millions of members have almost become less than human," reflects a deformation of the natural process of human evolution, the result of centuries-long discrimination from without and religious intolerance from within. ${ }^{44}$ These years of oppression are the cause of the extreme difficulties faced by the Jews in their attempts to cultivate themselves, especially, according to Gedike, in the absence of a supportive government.

Rather than bearing witness to the childhood of mankind, as various commentators claimed in regard to the "savages" discovered during the great sea voyages, the Jews provide human testimony to what Schiller calls the "barbaric remnants" that have been carried over into the present. ${ }^{45}$ In 
Gedike's text, this notion of barbarism operates on two levels and reveals the ambiguity of his own position: both the behavior of the majority of the Jews themselves and their continued mistreatment at the hands of a supposedly enlightened government are abhorrent. On both levels, the Berlin Jews serve as human reminder of the uneven progress of enlightenment in the city, a living example of the simultaneity of the nonsimultaneous. ${ }^{46}$

Here as well, however, recent developments suggest an imminent breakthrough to a new historical stage. Gedike writes: "The current generation of Jews in Berlin truly marks a new era in the recent history of this people and would certainly deserve a thorough description and consideration of its origins [Ursachen]." ${ }^{47}$ After privileging the city as a point of historical condensation in this remark, Gedike then goes on to make a more direct connection between the urban context and what he perceives as the spread of enlightenment among members of the community. Surprisingly perhaps, he does not link this spread to the unique social and educational opportunities in the city that he thematized in previous letters, but rather to a happy coincidence of wealth and progressive thinking. He writes: "The general spread of culture and greater open-mindedness has been much aided by the fact that so many rich Jews are also enlightened." 48

Gedike's interest in an elucidation of the reasons for this supposed breakthrough in the current generation of Jews - he calls for a consideration of its "origins"- demonstrates his indebtedness to eighteenth-century historiography. The causal relationships in his own discussion, however, appear a bit muddled. It is unclear, for example, whether wealth has actually facilitated enlightenment or whether it has simply increased the authority of individuals who were already enlightened. On the one hand, by referring in a later sentence to a general human tendency to equate wisdom with wealth, he suggests that the open-mindedness of these prominent Jews was merely a fortunate coincidence. He also remarks, however, that the sons of these wealthy individuals were freethinking even if their fathers were not, suggesting at least a long-term causal link between wealth and a liberal attitude. He then appears to undercut his own argument by stressing the crucial role of Mendelssohn, who was both brilliant and highly influential in spite of his modest means. Such confusion notwithstanding, by coupling the concentration of wealth, which is repeatedly associated with metropolitan life in the period, and the historical progress of the Jews as a nation, Gedike both thematizes the role of the urban dynamic as a motor of positive change and reveals the 
extent to which urban phenomena inspired reflection on the mechanisms of historical causality.

Like other urban factors seen as contributing to historical improvements, however, the concentration of wealth in the city has a negative side, one that directs the reader's attention away from an unmastered past to an uncertain future. The discussion of the Berlin Jewish community offers a compelling indication of Gedike's concern that Berlin's prosperity may not be as lasting as his initial depiction of the city's evolution suggested. In Gedike's text, then, the Berlin Jews not only serve as a case study in retarded evolution and the progress that characterizes his own age but also reveal the danger posed by that very progress. According to Gedike, all wealthy and enlightened nations are at risk of succumbing to the temptations of luxury, and the Jews are no exception: "All of the sensuous pleasures, all of the luxuries of the capital city, all of the foolish fashions - often one sees the children of Israel lining up here to enjoy them as well." ${ }^{49}$ The author's comments in this context can actually be traced back to specific, historically documented changes occurring in the Berlin Jewish community at this time. As Steven M. Lowenstein has shown, a rapid increase in the wealth of prominent Berlin Jewish families during and after the Seven Years' War did indeed lead to life-style changes, and these changes evoked interest and sometimes concern among Jewish and non-Jewish residents of the city. ${ }^{50}$ Gedike's reference to the "luxuries of the capital city," however, also reveals a more general presupposition of a link between opulent excess and the metropolis. Reflections on luxury figure into virtually every representation of urban life in late eighteenth-century Germany. A concentration of luxury goods and of those who have the leisure to enjoy them constitutes one of the defining characteristics of the big city, one closely connected to the discussion of fashion and frequently condemned as a source of depravity. Johann Heinrich Gottlieb von Justi goes so far as to claim that opulence is both the mother and child of the metropolis. Betraying a German bias in his identification of the big city with the court city, he writes: "The opulence and extravagance of the idle courtesans and other wealthy people from the country who follow the court gradually increase the size of an originally modest court city; and precisely this confluence of a large number of idle people, who can think of no better way to while away their ever-so-tiresome leisure hours than to visit one another, honor each other with dinners, and display their splendor to one another, gives rise to opulence. Nothing is as contagious as opulence." ${ }^{51}$ The 
ultimate consequence, according to Justi, is not only a continuous stream of immigrants from the countryside with misguided notions of the urban high life, but also an unchecked rise in the cost of living, as individuals attempt to finance their own extravagance simply by increasing the prices of the goods they produce.

In the case of Gedike's letters, the concern with an increasing interest in luxury and fashion in the city is inseparable from questions regarding the direction of historical development. As we have seen, the author prefaces his paternalistic criticisms of Jewish excess with the assertion that luxury constitutes a threat to all "enlightened and affluent [begütert] nations." 52 As with the reference in the Candid Observations to traces of barbarism in the midst of the highest levels of civilization, Gedike's brief characterization must also be seen as resting upon a particular conception of human evolution. His reference to knowledge ("enlightened") and commerce ("affluent") similarly hearkens back to Süßmilch's analysis and suggests that he too views these as the motors propelling humankind forward. As with both of these other commentators on Berlin, then, Gedike's comments rest upon the notion of a linear trajectory of historical development toward ever increasing levels of comfort and refinement.

As we saw in the discussion of Gedike's first letter, a variant of this narrative, one that emphasizes organic growth, finds its way into the author's description of the urban topography. There the implication was that Berlin's prosperity had resulted from a natural evolution and could thus be expected to endure. The discussion surrounding the Berlin Jews, however, indicates his concern that Berlin's prosperity may not be as lasting as his initial depiction suggested. In fact, a similar anxiety can already be discerned in Süßmilch's text, but the more theologically minded Süßmilch is happy to leave the fate of Berlin in God's hands. According to the author: "For the righteous ruler of the earth, it is just as easy to reduce the most glorious cities, countries, and peoples to pitiful dust, and even to reduce them to nothing, as it is easy for him to raise up the lowly and neglected." 53 All one can do is live a good Christian life and pray for the best. Gedike's letters, in contrast, are characterized by a higher degree of secularization and conceptual sophistication. They adumbrate the contours of an emerging dialectic of modernity, according to which the very progress of civilization gives rise to forces that threaten to undermine it. The concerns expressed in this context bring us back to the fashion paradigm that dominates the travel literature, 
with its emphasis on disunity and the detachment of interior and exterior. Gedike, too, laments the apparent rise of a superficial concern with externalities, and he often couches his criticisms in similar terms. Underlying his fears, however, one finds the outlines of a historical-theoretical model whose linear structure points beyond the seemingly erratic ebb and flow seen to characterize the movements of fashion in other texts.

This model becomes apparent in the convergence of the alleged dangers associated with fashion, represented in familiar terms as a disintegration of organicity, with another aspect of the city's temporal complexity. While gradual changes in the city topography may foster reflection on long-term historical developments, the unhealthy obsession with luxury and fashion that characterizes contemporary big-city life is linked to a troubling experience of temporal acceleration. In contrast to the reassuring linear narrative of continuing progress, this acceleration destabilizes the present and calls the future into question.

Gedike's first mention of this acceleration is to be found in his discussion of the large number of foreigners in Berlin, where he claims that this urban diversity has "brought to fruition prematurely what would otherwise have been a more gradual but therefore more stable enlightenment driven from within." ${ }^{44}$ This notion resurfaces in Gedike's discussion of luxury and the Berlin Jews, when he laments the possibility that this newfound prosperity might be too much too soon, that it could actually deform a more natural and gradual process of national development. He writes: "Woe to us, should this mildew destroy all the hopeful blossoms before they have borne fruit." ${ }^{55}$ In both of these remarks, the city is associated with an unnatural acceleration of natural growth, one whose consequence is a distorted and unstable version of what would have resulted from a more gradual development. As I tried to point out earlier, this basic idea of a disjuncture between interior and exterior also undergirds the negative travel reports on the city. It also appears in Zöllner's "Contribution," where the author associates the big city with a kind of premature aging process. He writes: "In the big city the youth can speak of a thousand things - both good and badwhich have never even reached the ears of a man who has grown old in a small town." ${ }^{56}$ Of course, as Gedike's metaphor in particular makes clear, the alleged unnaturalness of the city is itself understood within an organic framework. Opulent Berlin is the site of a "mildew," and the contaminated growths that it draws forth threaten to prevent the maturation of the healthy 
fruit. A similarly paradoxical relationship between the natural and the unnatural characterizes the representation of the big city in Justi's essay as well. Given the obviously negative consequences of a large city on the state as a whole as well as on the quality of the lives of its inhabitants, it strikes Justi as the most unnatural phenomenon imaginable. As he puts it, "nothing is so unnatural as to see one hundred thousand people living together in a place from which hardly two thousand could earn their living." ${ }^{57}$ The mechanism through which a large city comes into being, however, exhibits all the inevitability and causal consistency of natural processes, and the big city itself is described as an organ within the body of the state: an improperly functioning stomach.

From the standpoint of historical consciousness, these authors' remarks on the temporal acceleration that characterizes the city are significant in their suggestion of a perceived discrepancy between what can be termed individual and social time-scales. As we have seen, the sophistication and complexity of contemporary urban society come to be understood in the eighteenth-century as the culmination of a long-term evolution from nomadic barbarism to settled cultivation and refinement. Premature exposure to this society, however, threatens to disrupt what is viewed as the natural, healthy course of individual development. Zöllner, for example, indicates that the advancements in human sensibility and sociability made possible by the big city, such as a heightened aesthetic sensitivity and more liberal forms of human interaction, threaten to degenerate into indolent sensualism and insolence if they are experienced by individuals who have not yet acquired the level of personal maturity necessary to incorporate them into a balanced life. It is necessary to recognize the conservative moment in these remarks, a point to which I return in my discussion of Lessing. Zöllner and Gedike are especially concerned with destabilizing effects of big-city life on marginalized groups, either the "common man" or the Berlin Jews. Whatever dubious politics lurks behind their arguments, however, it is nonetheless noteworthy that the big city appears in their texts as a space in which the development of the individual and the evolution of society as a whole appear to be out of step. This relationship between the aims of individual self-cultivation on the one hand and the evolution of society as a whole on the other plays a central role in discussions of historical progress in the period, most memorably in the works of Rousseau, but also, as we will see later, in Moses Mendelssohn's late essays. 
Gedike's Berlin thus not only harbors elements from an unmastered, preEnlightenment past; it also gestures in the direction of multiple futures. The temptations of fashion are not merely a problem for Berlin's newly wealthy Jewish community. Gedike also refers to the various fashionable religious sects that have gained a foothold in Berlin in recent years, from the Sociétés mystiques to the atheists, claiming that German "thoroughness" has fallen victim to a French "weakness for fashions." And in the final letter of the collection he also reproaches those Berlin women who place fashion above utility: "It is more often the case that members of the female sex want to shine through fashionable and elegant attire; and they clearly go too far to do so, at the expense, namely, of durability, inner goodness and the acquisition of more necessary articles of clothing." ${ }^{8}$ The increasing obsession with fashion, luxury, and sensuous pleasure that Gedike discerns in Berlin suggests a different, more disconcerting temporal trajectory than the one indicated by his earlier discussion of the city's gradual evolution.

As became apparent in the article from the Universallexicon, fashion's rapid mutations confront the observer with a model of temporal change whose historical character is ambiguous; the question arises as to how these apparently surface-level changes are to be integrated into a larger historical narrative. In terms of its immanent temporal structure, fashion fits into neither a linear nor a truly cyclical framework. Its transformations do not appear to be governed by any discernible causal laws, as is indicated by Zöllner's assertion that one "fashionable conversation" simply "squeezes out" another. Fashion's association with mere appearance and with human vanity in these texts links it to a conception of an empty, meaningless time characterized by a certain frenzied activity but detached from any framework of substantive historical progress. In Gedike's letters, however, the growing interest in fashion and luxury goods he discerns in Berlin, as well as the temporal acceleration associated with it, is clearly viewed as an indicator of social decline. By its very definition, fashion would appear to be insubstantial and thus outside of history understood as progress. In late eighteenth-century Berlin, however, this insubstantiality threatens to become dominant, thereby displacing a more meaningful process of historical development. Thus, along with the satisfaction that accompanies Berlin's entry into the major league of European cities and an optimism that stems from improvements in the quality of life of its inhabitants, Gedike's essay also reveals a fear that developments might spiral out of control. He 
expresses this fear at the end of his letters, where, after once again praising the industriousness and good sense of the Berliners, he refers to the unfortunate fact that "luxury," "gambling fever," "gluttony," and "sensuality" are "becoming more and more widespread." ${ }^{59}$

The temporal acceleration that characterizes Berlin appears as part of a dialectic of progress, a dialectic that at times seems to be a direct result of the urban dynamic and at other times seems simply to find its most concentrated articulation in the big city. Certain aspects of Gedike's critique are identical to those found in the encyclopedia and elsewhere. He too resorts to a moralizing condemnation of the weakness and vanity that define human nature. But his letters also suggest that these troubling phenomena must be understood as a function of metropolitan life, which is itself seen in the context of a long-term cultural evolution. Those very historical accomplishments that have made possible a more humane and comfortable life for the city's residents also threaten to corrupt the values that made these achievements possible in the first place. Gedike's fears are reminiscent of Rousseau's criticisms of modern decadence, criticisms that lurk behind many of the German discussions of urban life in the period. In contrast to the seemingly inexorable narrative of decline found in Rousseau's Discourse on Inequality, however, Gedike's attitude toward the future is one of uncertainty. One could argue that the confrontation with recent developments in Berlin forces Gedike to negotiate between two frameworks for understanding luxury consumption, each of which entails a different historical trajectory for the city and the state. On the one hand, his concerns intersect with a tradition that associates conspicuous displays of wealth with corruption and decline, especially with the decline of the Roman Empire. On the other hand, he has clearly been influenced by an emerging liberalist discourse, according to which luxury consumption is an indicator of economic growth and cultural refinement. ${ }^{60}$ The crucial point is that the adoption of either framework involves situating contemporary Berlin within a more comprehensive historical context. Gedike's ultimate response is vacillation. Tellingly, he follows his comments on the insidious rise of urban vices with the question: "Who knows how it will look in fifty years here in this regard!" ${ }^{61}$

The sense of an open future that Koselleck adduces as a key element of late eighteenth-century historical consciousness appears here as a function of the temporal complexity of the urban context. As the locus of multiple, seemingly contradictory phenomena, coterminous indicators of advance- 
ment, stasis, and decline, the city would seem to challenge any naive belief in either progress or regress. Gedike's Berlin constitutes a present whose origins can and must be traced in order to understand it, but which nonetheless contains elements that prevent it from being reduced to the past. In other words, past experience is essential and yet inadequate for grasping the city, inasmuch as it also belongs to a future that has not yet arrived. Berlin can be neither subsumed under an ahistorical concept of urban depravity nor incorporated into an inexorably linear narrative. Gedike's attitude toward the future oscillates between confident optimism regarding the possibility of continued reform and a kind of secularized apocalypticism. His pessimism becomes most apparent at the end of the letters, where, in what would seem to be an open admission of the fragility of Berlin's prosperity, he expresses the fear that the "stream of time" will wash away "the excellent teachings and even more powerful example of their [the Berliners] currently enlightened citizens." ${ }^{62}$ Gedike's Berlin both confirms and complicates a belief in history as evolution explicable in terms of causal relationships. It testifies to the distinctness of past, present, and future as well as to their interconnectedness, and it challenges the observer to think through the causal mechanisms that underlie this interconnectedness, to derive from the city's present both the influence of its past and the shape of things to come. 


\section{Urban Exegesis in the Works of Friedrich Nicolai}

\section{Introduction}

The emergence of the city as a powerful metonymic figure for modernity in late nineteenth- and early twentieth-century German culture has been well documented. Wilhelminian and Weimar Berlin in particular, most memorably theorized by authors like Walter Benjamin, Siegfried Kracauer, and Georg Simmel, comes to be viewed as an embodiment of the flux and discontinuity that characterize modern life. ${ }^{1}$ The protean Prussian metropolis confronted residents with formidable perceptual and conceptual challenges, eliciting new forms of textual representation in response, from Jacob van Hoddis's "telegram style" in his 1911 poem "End of the World" to the literary montage of Alfred Döblin's 1929 Berlin Alexanderplatz. Moreover, as recent investigations have demonstrated, it was not only the works of high modernism that attempted to assimilate this new urban experience and offer new approaches to "reading" the city. On a more quotidian level, newspapers made use of many of the same techniques - montage, the disruption of narrative continuity, the emphasis on chance and innovation-thereby reinforcing on a mass scale the perception of the city as a heterogeneous, ever changing spectacle. ${ }^{2}$

The singularity of the early twentieth century in the history of urban experience is undeniable. Especially in the case of Berlin, the perception of city life as constantly rewriting itself had an obvious material basis. Not only did the city's population quintuple between 1848 and 1905; the built environment underwent rapid and repeated change as a result of industrialization and the explosion of consumer culture. ${ }^{3}$ The innumerable interpretations that this upheaval elicited, however, have tended to overshadow earlier confrontations with urban modernity, and the reflections that occur in the context of the German Enlightenment offer a case in point. As a consideration of Friedrich Gedike's letters and the wider Berlin debate to 
which they were a contribution reveals, at least some of the key elements of the twentieth-century urban discourse can already be found in eighteenthcentury commentaries on the city. Here as well the city is perceived as a site of change and disorientation, sometimes interpreted as a source of emancipation and sometimes as a harbinger of social collapse. These texts also indicate the extent to which eighteenth-century Berlin, like its twentiethcentury counterpart, becomes entwined with the period's understanding of its own historical specificity. In all of the writings inspired by Berlin, from Süßmilch's explicitly historical analysis, to Gedike's review of the Berliners and their institutions, to Justi's and Zöllner's more general critiques of bigcity life, the representation of the city becomes a search for the present, an attempt to discern historical continuities and ruptures as well as find signposts to the future.

There are, of course, crucial differences. Early twentieth-century Berlin, at least as captured in the newspapers, philosophical essays, and modernist literature of the period, becomes a cipher for the state of permanent transition seen to define the age. In the words of the historian Peter Fritzsche, "that urban experience of extreme impermanence, which has its origin in the last century and which we have come to associate with modernity, profoundly unsettled everyday life." ${ }^{4}$ In a modern metropolis that is continually reinventing itself, the past loses its function as an explanatory model. History can no longer be seen as the unfolding narrative described by traditional philosophies of progress; the planes of historical time begin to collapse into what Fredric Jameson has termed a "perpetual present." ${ }^{5}$ Whether expressed in the relentless cyclicality of mythic time that informs Georg Heym's 1911 poem "The God of the City," or in the obliteration of historical difference revealed by the passing of Kracauer's Linden Arcade in 1930, the city in this period calls forth an attitude that is perhaps best described as posthistorical. ${ }^{6}$

In late eighteenth-century Berlin, the relation between the city and history is more variegated, like eighteenth-century historical consciousness itself. Rather than an object of critique, here the notion of history as linear improvement is just beginning to take shape, and it represents one of several possible frameworks for understanding urban developments. A sense of transitoriness and acceleration also begins to make itself felt, but it too constitutes only one facet of the urban experience, and it is often characterized with the help of older Christian models for understanding temporal change. Berlin testifies in some representations to a radical break with the past, in 
others to an evolution that both supersedes and preserves that past, and in still others to an inability to escape it. Attempts by eighteenth-century authors to situate Berlin between past and future reveal the interface between the city and the temporalization of history occurring in the period. Berlin occasions reflections on the alterity of earlier epochs and the possible direction of future developments. The temporal complexity of the city, however, does not only foster a sensitivity to historical difference; it also inspires commentators to seek explanations for that difference. Berlin bears witness to the possibility of substantive historical change, and it raises questions regarding the mechanisms of that change. The city's significance for the evolution of historical consciousness in the period, in other words, also includes its role as a testing ground for alternative models of historical causality.

No single individual devoted more effort to documenting and explicating eighteenth-century Berlin's changing historical countenance than Friedrich Nicolai. Known to his contemporaries as an influential publicist, novelist, philosopher, and amateur historian, Nicolai was long remembered primarily as the laughingstock of the late eighteenth-century German intellectual elite. His distinguished list of detractors includes not only Goethe and Schiller, but also Kant, Fichte, and the early romantics, with whom the aging champion of enlightenment engaged in a series of vicious attacks and counterattacks. Nicolai had himself been a member of the cultural vanguard with Lessing and Moses Mendelssohn in the 1750 s and 176os, but a resistance to cultural innovation in his later years led to increasingly hostile confrontations with opponents and a declining influence on German cultural life.

Since the 1974 publication of Horst Möller's exhaustive effort to situate Nicolai and his work within its historical context, there has been both an increase in scholarly interest in Nicolai and a clear trend toward a more balanced view of his achievements. ${ }^{7}$ Concomitant with these developments, one also finds an expansion of the field of inquiry beyond his literary works to include his activities as publisher, editor, historian, cultural critic, and public intellectual. ${ }^{8}$ Nicolai's relationship to Berlin and to the emerging discourse on metropolitan life in the period, however, has been largely neglected. ${ }^{9}$ And yet, while the value of his many rambling pronouncements on aesthetic and philosophical matters may be open to debate, his contribution to the establishment of Berlin's reputation as a major European capital city is beyond question. Reflections on the advantages of city life in general, and on the appeal of Berlin in particular, pepper his works. Erich Kleinschmidt, de- 
spite his basic argument concerning the disregard for the city in eighteenthcentury German literature, acknowledges the "new urbanity" conveyed by Nicolai's representation of Berlin in the novel The Life and Opinions of Herr Magister Sebaldus Nothanker (1773-76).$^{10}$ It was Nicolai's early critical and editorial projects, however, especially the pioneering Letters on the Current State of the Fine Sciences in Germany (1755) and the more famous Letters concerning the Most Recent Literature (1759-65), which he wrote together with Lessing, Mendelssohn, and Thomas Abbt, that helped put Berlin on the European cultural map. In addition, he wrote and published three editions of a mammoth historical and statistical volume entitled Description of the Royal Court Cities Berlin and Potsdam, as a result of which Berlin became one of the most extensively documented cities in all of Europe. Berlin as an actual city may have struggled to compete with venerable European metropolises like Paris or London, but thanks to Nicolai's efforts, Berlin as text was certainly no less awe-inspiring. ${ }^{11}$

One finds in Nicolai's works little of the self-conscious reflection on the city that characterizes twentieth-century representations. Nonetheless, a careful reading reveals that his depictions of Berlin present the city as an epistemological problem, one that is inextricably intertwined with an incipient discourse on modernity. His works suggest that "reading Berlin," to borrow a phrase from Fritzsche, presented a challenge long before 1900. Nicolai's attempts to address this challenge led him to reflect not only upon the mechanisms that have given rise to Berlin's present and will determine its future, but also upon the urban experience itself as a causal factor driving historical developments.

\section{Capital Improvements}

Nicolai's earliest remarks on urban culture do not address Berlin specifically but focus instead on the advantages of a capital city more generally. ${ }^{12}$ In his early critical works, the urban experience occupies a central position in an ongoing discussion of the contours of German modernity, where it is unequivocally linked to progress in the cultural sphere. More precisely, he links the lack of an authentic urban experience to a lack of progress. In his first major work, the Letters on the Current State of the Fine Sciences in Germany, Nicolai attempts to explain Germany's failure to realize its full potential as 
a literary nation. Among other causes, the author adduces the absence of a national capital as a reason why Germany has failed to match the cultural achievements of its European neighbors. ${ }^{13}$ Lamenting the absence of a German metropolis comparable with Paris or London, he writes: "In Paris, in London one finds the seat of judgment of wit for the entire country. There one decides the quality of poems according to the praise they receive in the social clubs, in the coffeehouses, in the chambers of men of taste. Germany is far too expansive, and is ruled by far too many different sovereigns for one city to be able to determine the taste of the others." 14 The context of this particular quotation is a discussion of the best means to improve German letters, which, despite the partially successful efforts of Gottsched and Bodmer and Breitinger, remain in a rather sorry state. According to Nicolai, relentless, nonpartisan criticism offers the only means to cultivate good taste among artists and their public and help German literature achieve international acclaim. His comments in the letter make it apparent, however, that critical publications are but an imperfect substitute for the unmediated personal and intellectual exchange that would take place in an actual capital city. In the preceding passage, his references to the "social clubs," "coffeehouses," and "chambers" suggest a natural and spontaneous form of sociability that Germany, because of its political and geographical fragmentation, can only reproduce on a textual level.

Criticism, in other words, creates a kind of virtual public sphere. The basic structure Nicolai has in mind here is a more limited version of the public use of reason that Kant so strongly endorses in his essay on enlightenment, written some twenty years later. Whereas Kant finds the detachment of this sphere from everyday life indispensable, however, Nicolai remains more ambivalent. The opposition between a textualized publicity and the genuine social interaction that characterizes city life is a recurring theme in his writings, and his position on the issue seems to shift back and forth. His own publishing projects, especially his long-running review journal, the Allgemeine Deutsche Bibliothek, can themselves be seen as textual surrogates for the absent metropolis. And in some respects, the textual public sphere appears easier to manage than the real one. One of the characters in Sebaldus Nothanker comments, for example, on how much more quickly new ideas about religion have found their way into literature than into the consciousness of the average Berliner: "The change has been more rapid and more general in the writings that appear than in the hearts and minds of the 
city residents." ${ }^{15}$ At the same time, however, Nicolai gives the impression that the textual public sphere can itself fall victim to the same provincialism that characterizes German cultural life more generally. Also in Sebaldus Nothanker, the tradesman Hieronymous offers a scathing critique of "the authors' estate" in Germany, a group of 20,000 who take an interest only in one another, ignoring the remaining 20 million speakers of German. ${ }^{16}$

Whatever his later equivocations, Nicolai's position at this early stage in his career is quite clear. His remarks indicate that the virtual city is decidedly inferior to the real thing. According to the author, German particularism has an unmistakably negative impact on the development of the arts. The sentiments expressed in this letter place Nicolai squarely within the framework of an Enlightenment aesthetics that attempts to reconcile the belief in timeless, universal standards of good taste with a desire for cultural specificity. He yearns for a national culture that is both uniform, adhering to universally valid standards of aesthetic excellence, and unique, representing German particularities rather than blindly submitting to the prescriptions of French neoclassicism. Nicolai refers regularly in his early writings to a uniquely German national character, but he differs from later eighteenthcentury thinkers like Herder, Möser, and to a certain extent Goethe, for whom intra-German cultural diversity constitutes a major strength of the nation. ${ }^{17}$ Precisely this diversity is the problem for Nicolai. As becomes clear in the remainder of the letter, the absence of the centralizing influence of a real German metropolis makes it all too easy for small-town artists to form self-indulgent literary cliques ("cabals of good friends"), whose relative autonomy enables them to perpetuate bad habits and bad taste. In opposition to the provincial and university towns where such "cabals" originate, the big city allows for the development of a more objective perspective on the world and is thus linked to an Enlightenment project of overcoming particularism. Although Nicolai never goes into the mechanism through which the urban experience fosters this objectivity, the implication of his discussion is that both the intensity and the variety of social intercourse in the city encourage a sensitivity to the universal rather than the particular.

This connection is made more explicit in Nicolai's contributions to the Letters concerning the Most Recent Literature, which he published together with Lessing, Moses Mendelssohn, and Thomas Abbt between 1759 and 1765 . One of the key items on the agenda in these letters is the improvement of German drama. As Nicolai laments in the two-hundredth letter of the collec- 
tion, employing one of the root metaphors of the Enlightenment, the German stage still finds itself in a state of childhood. Regarding drama's coming of age, he writes: "And when will it emerge from childhood? One is tempted to say: never! As long as Germany is still made up of different territories, each with its own capital city, which feel no obligation to align themselves with the others as regards customs, taste, and language; not until the prince in at least one of these capital cities, to which Germany has conceded a certain superiority as regards taste and language, sees to it that a public German stage is erected, not merely one at his court, and makes a special effort to protect it." ${ }^{18}$ Here one sees that the shortcomings of German drama cannot be entirely explained by the absence of a capital city. Nicolai also mentions the lack of commitment on the part of the territorial princes, and he goes on in the letter to list inadequate financial incentives and an insufficiently educated public as further obstacles to improvement. Nonetheless, the quotation makes it clear that the lack of a central cultural authority represents a crucial piece in the puzzle.

If the previous letter focused more on the implications of German provincialism for the general cultivation of good taste, here the function of the city in fostering artistic talent comes to the fore. Lacking exposure to an urban environment that brings together individuals from diverse backgrounds and estates, German artists can produce works of only limited, local interest. As Nicolai writes: "A person who intends to restrict himself to the small number of ideas that a university or a provincial city has to offer can never write successfully for the stage." 19 Variations of this criticism appear repeatedly in Nicolai's contributions to these letters, as he takes German authors to task for their inability to draw characters with universal appeal, for their reliance on imitation, and for their eagerness to praise one another, all of which he attributes to a lack of exposure to "the world."

This association of the metropolis with exposure to a multiplicity of ideas and experiences proves central to the writings of Nicolai's contemporaries as well, and it reminds us again that certain twentieth-century urban obsessions have an eighteenth-century prehistory. Zöllner, to give one example, already characterizes the big city in psychophysiological terms evocative of Georg Simmel, as a site of heightened sensory activity. He refers to the confrontation with a "wealth of concepts" that distinguishes metropolitan from small-town experience, and continues: "The mind is stimulated in innumerable ways and is ceaselessly nourished with new concepts." ${ }^{20}$ Writing 
two decades after Nicolai, in the period in which Berlin becomes the subject of increasing criticism, Zöllner also shares some of the ambivalence of twentieth-century commentators toward this stimulus overload. He writes, "It is, on the other hand, more difficult in large cities to develop the ability to focus on an object, the capacity for concentrated attention, the unique character of independent thought." ${ }^{21}$ Thus, while the surplus of concepts in the city may lead to a more polished and sophisticated exterior, as Zöllner argues earlier in the essay, it threatens to hollow out the interior - to hinder one's ability to concentrate, even to thwart one's ability to think for oneself.

Nicolai's later writings share some of Zöllner's concerns, but in his early phase he remains resolutely optimistic. The capital city is closely linked to the cultural aims of the German Enlightenment. It is the site of a cosmopolitanism and an unmediated social intercourse that offers the most effective training ground for the cultivation of good taste and artistic talent. One should recognize in this context that Nicolai explicitly laments the lack of a capital city, not just the lack of a capital. In other words, he couples the problem of German provincialism with the lack of an authentic, cosmopolitan urban culture, rather than merely with the lack of a dominant court. The two are certainly related, and Nicolai was generally very favorably inclined toward Friedrich II. But here he specifically posits the city as an independent entity, rather than the court, as the wellspring of cultural advances.

Nicolai's celebration of urban culture in these texts thus also reveals the city's importance for the self-understanding of a politically weak but culturally ambitious German middle class. Through its connection to the theater and to the literary public, the city is for Nicolai a quintessentially middleclass space. Given the powerful presence of the territorial princes in many German cities in this period, especially in Berlin, it is interesting to note Nicolai's emphasis on the noncourtly elements of the urban environment. Despite his reference to the role of the princes in the Letters concerning the Most Recent Literature, he makes a clear distinction between a courtly and a truly public (öffentlich) theater. In addition, the "world" or "big world" that he often invokes in his criticism of contemporary German literature is not equated with aristocratic high society, as is often the case in other works from the period. Instead, it has the broader connotation of an urban civil society, which includes but is in no way limited to the nobility. Nicolai conceives the urban space as a universalizing space, both because of its diversity and because of the possibilities it presents for human interaction. As the only 
possible site of a genuine public sphere, he opposes it not only to the court but also to the provincial town and the university, all three of which are seen to foster particularism.

From a historical-theoretical perspective, the most significant implication of this perception is that the capital city, as the embodiment of a cultural refinement with allegedly universal validity, appears as the end point of a narrative of progress. Nicolai's arguments in both texts presuppose a linear march of progress toward cultivation, a march that culminates in a flourishing urban culture and whose stadial character is indicated by the analogy to the ages of man. Although Nicolai focuses exclusively on the sphere of culture, and although he speaks in the subjunctive mode, his remarks bear a notable similarity to those made by fellow Berliner Süßmilch at about the same time. For Süßmilch as well the vitality of the capital offers the most compelling evidence for the overall level of national cultivation. Moreover, as is also the case with Süßmilch, Nicolai's capital city does not merely testify to the march of progress, serving as the site where achievements can best be measured and interpreted. It is also its precondition. Nicolai, in other words, understands urban experience as a causal factor in a linear model of historical evolution. The capital city is the only place where an enlightened humanity can find its voice, a German voice, to be sure, but one that everyone is nonetheless able to understand.

As indicated in the introductory chapter, an increasingly sophisticated approach to the question of historical causation constitutes one important element in an evolving eighteenth-century historical consciousness. In the words of Hans Erich Bödeker, "[the] linking of temporality and causality is the truly seminal historical-logical innovation of the Enlightenment." ${ }^{22}$ The changes occurring in this arena are quite complicated, and they overlap with developments in other areas, from the emphasis on induction and empiricism in philosophy to the interest in psychological motivation in literature. Peter Hanns Reill has addressed the complexities of this topic as it pertains to the pioneering work of the Göttingen circle of historians. His argument differs from Bödeker's in that he emphasizes the Enlightenment historians' turn away from purely mechanistic models of causality to develop more advanced theories of the interaction of material and "spiritual" factors. The crucial point for both authors, however, is that conceptions of causation become more refined in the period. The explanation of historical developments exclusively on the basis of divine providence, the will of great 
men, or blind chance are no longer considered adequate. ${ }^{23}$ None of these models disappear; they remain especially prevalent in more popular historical literature. They are, however, increasingly accompanied or even replaced by explanations that place greater emphasis on material factors, such as social, economic, and environmental structure, and on the interaction of these factors with intangibles like national character, the spirit of the times, or individual genius. ${ }^{24}$

For Nicolai, himself an amateur historian of some renown, the effort to utilize appropriate models of historical causation is inseparable from his interest in the city as an object of historical inquiry and in the historical consequences of urban experience. It is the latter topic that comes to the fore in the excerpts cited earlier. In arguing for the existence of a capital city as a condition of enlightenment, Nicolai reveals his sensitivity to the impact of social structure on historical developments. To a certain extent, the same argument can be made for Süßmilch, inasmuch as he traces the prosperity of Brandenburg back to developments in trade and the sciences, both of which are concentrated in the capital city. In contrast to Süßmilch, however, who ultimately takes recourse to providence as the source of prosperity, Nicolai's notion of the causes of progress, at least of cultural progress, is fully secularized. In addition, his explicit detachment of improvements from the actions of the monarch underscores the role of the urban experience itself as a force for positive change.

Nicolai's praise of the capital city in these early critical texts offers one example of how urban experience emerges as a causal category in eighteenthcentury thinking about history. Unlike his peers among the professional historians, whose interest lay primarily in explaining the causes of past events, Nicolai addresses the material conditions of future progress. His remarks nonetheless reveal a similar recognition of the importance of material factors in shaping the course of history. In his later works, Nicolai continues to investigate the causal connections between history and urban experience. The straightforward correspondence between progress and the capital city that one finds in these early texts, however, increasingly gives way to a more nuanced consideration of the urban space as both a facilitator of and a hindrance to social improvements. Inasmuch as this shift in focus coincides with rapid change and expansion in Berlin, one wonders whether Nicolai's own urban experience encouraged a more sophisticated approach to the topic. While this question cannot be answered with certainty, one can discern in 
these later writings a powerful awareness of the historical-theoretical ambiguities that characterize the author's home city, both in its role as a site and as a source of historical progress.

\section{Reading Berlin, 1786}

In April 1786, some thirty years after the appearance of the Letters concerning the Most Recent Literature, Friedrich Nicolai published the third edition of his already famous reference work on Berlin, the Description of the Royal Court Cities Berlin and Potsdam and All of the Objects of Interest Found Therein. The first fruits of his ambitious effort to catalog and categorize the city had appeared in 1769-a single volume designed primarily, according to the author, to provide relevant information to the foreign visitor interested in the sights of Berlin and Potsdam. By 1786 the work had burgeoned into a three-volume colossus containing a quantity of information that was unmatched for any other German city. Part encyclopedia, part topography, and part guidebook, the topics covered in the twelve chapters and three appendixes ranged from city population, governmental institutions, and local manufactures to cultural activities, coffeehouses, and postal rates.

In reading through the preface to the third edition, however, one has the impression that the increase in scope brought with it a heightened sense of the difficulty inherent in any attempt to offer an exhaustive representation of the city. The need for three thoroughly revised editions of the work within a period of less than twenty years itself testifies to this difficulty, just as it testifies to the rapidity with which changes were occurring in the city. Nicolai already reflects on this state of affairs in justifying the initial revision of 1779 with the claim: "Moreover, the current state of Berlin had changed much since the appearance of the previous edition." ${ }^{25}$ By the time of the second revision, the pace of change appears to have accelerated, calling into question the very possibility of a definitive reference work on the city. In the preface to the third edition, actually more of a captatio benevolentia than an introduction to the contents of the volume, Nicolai emphasizes the indescribable effort demanded by such a survey and excuses himself for unavoidable "minor flaws" that resulted from either a lack of accurate information or from his inability to incorporate information that only became available while the book was in print. He goes on in a footnote to comment on the "in- 
describable number of small things that change daily in such a large city." ${ }^{26}$ The various inserts with last-minute corrections and additions heighten the sense of the provisional character of even such a comprehensive survey. By the same token, however, the very existence of the work points to the perceived need for a textual mediation of Berlin's urban complexity, the belief that such a dynamic city could only be navigated with the help of a guide.

The experience of temporal acceleration that leaves its traces in the Berlin book offers, on a limited scale, an early example of the impermanence that comes to define later conceptions of the metropolis. In addition, although Nicolai's book had nowhere near the mass circulation of the newspapers that became so central in early twentieth-century Berlin, its paradigmatic status suggests that it too helped mediate and mitigate the disorientation of modern urban experience. Indeed, the production of the work seems to have served as a kind of exercise in metropolitan identity formation, bringing together a diverse group of individuals to participate in the construction of a "word city" adequate to the real city of Berlin. ${ }^{27}$ The list of more than seventy contributors to the survey - "patriots from all estates" - resembles a who's who of late eighteenth-century Berlin and Potsdam, from the ministers Baron von Zedlitz and Herr von Möllendorf to the royal librarian Johann Erich Biester and the Oberkonsistorialrat (church council member) Gedike. ${ }^{28}$ For Nicolai, the textual city contained in the Berlin book became upon completion an important element in the real city's self-understanding, providing evidence of the Berliner's civic commitment. He writes: "I must pay my home city the tribute of saying that in no other city has there ever been such widespread enthusiasm about supporting a communal project of this kind." ${ }^{29}$ His comments in the preface thus suggest a resolution of the tension between city and text found in his earlier writings, inasmuch as the two appear to have been collapsed into a single entity. The textualized Berlin becomes a part of the city itself, not just a source of pride for the residents but also proof of its actual stature.

If the production of the Berlin book helped to bring the Berliners together, however, the image of the urban environment that appears in the work is hardly unified. As with early twentieth-century representations of the metropolis, Berlin seems to consist here of a seemingly haphazard juxtaposition of disparate elements. Nicolai himself, in thanking Biester for his editorial assistance, refers to the "so indescribably different kinds of things" that constitute the text. ${ }^{30}$ Admittedly, one can discern a kind of structure in 
the arrangement of the various chapters. Nicolai appears to progress from what he perceives as the fundamental to the more incidental, beginning with geography, population, and administration before moving on to industry and manufacture and then finishing with science, education, culture, and leisure. The range of topics and their treatment also correspond to the framework of interests characteristic of the emergent middle class, with the emphasis placed squarely on factual knowledge and practical utility. ${ }^{31}$ Nonetheless, the survey as a whole makes a decidedly disjunct impression, an impression reinforced by the layout of the individual pages, which often combine copious footnotes, multiple typefaces, and inserted lists or tables. The author offers no explicit discussion of the organizational principle of the work, and there is little or no attempt to draw connections among the contents of individual chapters. The organization of the Description suggests an urban environment composed of discrete units, whose relation to any coherent totality remains unclear. Reading Berlin in 1786, as in 1900, meant perusing a series of urban "snapshots," which, when placed side by side, did not add up to a coherent narrative.

Eighteenth-century Berlin is not pure montage, however. A red thread runs through Nicolai's otherwise fragmented work and ties it together - the thread of history. The past appears as the only possible source of a knowledge beyond that of naked facts. In other words, historical knowledge offers the only epistemological alternative to pure positivistic description. Not only does Nicolai's survey begin with a historical essay on the city; the individual sections, to the extent that they are more than mere lists of names and figures, invariably present Berlin in terms of the historical development of its institutions. The evolution of the municipal court, to give just one example, is traced from the granting of initial rights by Markgraf Woldemar in 1317 to the naming of war councillor and mayor Buchholz as director in 1781.

There is nothing especially unique about Nicolai's decision to document the history of Berlin; city chronicles in Germany have a tradition that dates back to the Middle Ages, and many of these were influenced in turn by the rhetorical theory of antiquity, according to which a treatment of city origins constituted a necessary component of any city encomium. ${ }^{32}$ What these early chronicles lack, however, at least those which appear before the advent of humanism, is a consciousness of the depth of history. The record 
of city history is not viewed in a context of development but one of stasis, as a mere sequence of events with neither originary nor predictive significance. The city itself comes into existence through the act of foundation, and it achieves through that act an unchanging identity and an unassailable legitimacy within the divine order. ${ }^{33}$

Nicolai's Description, in contrast, emphasizes not continuity but the radical transformations that have shaped and reshaped the city since it came into existence in the twelfth century. His very insistence on this date of origin is conceived in opposition to the claims of earlier chroniclers, at least one of whom, he writes, attempted to trace Berlin's foundation back to Arminius. If Nicolai clearly recognizes the historicity of Berlin, however, it is by no means clear that he has a comprehensive conceptual model for explaining the causes of these changes or their overall pattern. In other words, the epistemological complexity that defines Berlin on a synchronic level in his survey holds on a diachronic level as well. His introductory essay suggests competing and seemingly contradictory frameworks for understanding both the sources and the meaning of historical developments. One finds elements of a philosophy of progress as well as of cyclical patterns; moreover, in both cases, it appears that historical change can stem from either the will of individual rulers or from larger, more objective processes.

The general framework of the essay is clearly indebted to a notion of progress and to an individualistic model of historical causation, as becomes especially apparent in the section dealing with the period after the Thirty Years' War. Nicolai speaks in this context of the "nearly unbelievable changes" that have transformed Berlin over the past 130 years. He paints a grim picture of Berlin and Cölln in 1648, replete with "wretched houses and shacks," "an overgrown thicket" in the place of the current Lustgarten, garbage in the streets, and pigs rooting around in canals clogged with waste. ${ }^{34}$ Not surprisingly, given Nicolai's strong endorsement of "enlightened" despotism, he stresses the elector Friedrich Wilhelm's crucial role in improving the situation. ${ }^{35}$ Despite this deference to the Hohenzollerns, however, Nicolai treats mostly those activities of the monarchs that fit within the framework of his middle-class concerns. Berlin as a site of military battles receives scant attention, and when war is discussed, he focuses on the negative financial, legal, and social consequences rather than the glorious deeds of the participants. Neither is there any discussion of diplomacy or courtly 
intrigue. ${ }^{36}$ Rather, Nicolai points to Friedrich Wilhelm's and his successors' well-conceived public-works projects as the source of Berlin's increasing prosperity, from paving the streets to placing lanterns in front of the houses.

If Nicolai's indifference toward high politics and diplomacy reveals his distance from the tradition of courtly historians, the total absence of any mention of divine intervention, or even divine inspiration, also distinguishes his essay from conventional Christian historiography. Revealing his distance from Süßmilch, one of his primary sources, Nicolai's essay places him squarely within the framework of a secularized Enlightenment that views mankind as the object of history and man as the motor of positive historical change. As was the case in Gedike's letters, the growth of Berlin itself testifies to the possibility of such change. The introductory essay ends with the Berlin of the present, a flourishing city of 146,647 residents, 6,664 houses, and 6,178 manufacturing stools, a city whose perceived preeminence offers the only possible justification for the hundreds of pages of meticulous documentation that follow.

Berlin's historical march toward prosperity is only part of the story, however. In general, Nicolai's attitude toward the course of history was less optimistic than that of those philosophically inclined contemporaries who insisted on the steady and irreversible improvement of humankind. His skepticism derives in part from an unwavering commitment to induction, to investigating empirical historical data rather than constructing a philosophy of history based, for example, on an a priori conception of humans as rational beings. ${ }^{37}$ The content of the Berlin book suggests that his historical interest in the city itself, perceived as the locus of multiple models of temporal change, might also have been a source of his resistance to such teleological thinking. Nicolai's engagement with the complexities of the city's history leads him to acknowledge competing frameworks of both historical development and historical causation. In his overview essay, for example, he clearly recognizes that the city has gone through phases of growth and decay. Moreover, his methodological division of city history on the basis of the reign of specific monarchs, inspired no doubt by the positive impact of the Hohenzollerns in the more recent past, entails a temporal horizon defined by cyclicality rather than linearity. Because it measures the dimensions of historical time by the succession of generations, his approach retains, at least as a potential, a cyclical structure that is absent from consistent philosophies of historical progress. ${ }^{38}$ 
As I mentioned, Nicolai's periodization also indicates a conception of historical causation that emphasizes the role of individual will. In a territorial capital and court city like Berlin, such an emphasis is understandable. Virtually all of the texts from the period that deal specifically with Berlin link the city closely to its sovereigns. But Nicolai's introductory essay also demonstrates his awareness of the historical interplay between individual will and more objective, structural processes. Historical cycles, for example, also figure into his argumentation on a supraindividual level, both here and elsewhere in the volume, through references to such periodic phenomena as wars, famines, and epidemics that disrupt the city's growth. And other passages reveal that Nicolai clearly recognizes the significance of units of historical time that transcend the individual life-span. His discussion of Berlin's early development, for example, places it within the context of the more general growth in German cities that occurs in the fourteenth century, an acknowledgment of the local impact of large-scale historical developments. In this case as well, Nicolai's description implies a cyclical framework, inasmuch as it addresses a period of conflict in Berlin and Cölln that ends with the loss of their autonomy in the mid-fifteenth century.

Even if these cyclical elements in Nicolai's introductory narrative call the inevitability of progress into question, however, the book as a whole still gives the impression of forward momentum. In part this is due to Nicolai's relentlessly chronological approach, his exhaustive documentation of the founding, expansion, and improvement of Berlin's innumerable institutions. This sense of momentum is also strengthened by his interest in general trends - his discussion of the city's population in the first chapter of the book, for example, which owes much to the earlier work of Süßmilch. ${ }^{39}$ While the number of inhabitants has varied significantly since the twelfth century, the long-term trend, according to Nicolai, has been one of "general increase," with a notable acceleration in the past hundred years. For Nicolai, the growth in population is a reflection of increased prosperity, as it presupposes a level of economic activity capable of supporting additional inhabitants.

Nicolai's demographic interests are also significant with regard to the question of causation, as they provide another indication of his awareness of the role of supraindividual processes in shaping the course of history and of the city as a condensation point for these processes. In a sense, this awareness manifests itself even in his introductory discussion of the Hohenzollerns, 
where his presentation suggests that the more recent positive changes in the cityscape have followed an immanent logic, independent of the will of any individual ruler. He describes the activities of the various monarchs largely as a continuation of the projects of their predecessors rather than an expression of their own idiosyncrasies, with the trajectory of city development progressing from an initial focus on basic sanitation and housing to the numerous beautification projects of Friedrich II. Again one is reminded of Gedike, who represented contemporary Berlin as the culmination of a multigenerational historical process, a physical testament to an organic, evolutionary relationship between past and present.

Thus, whereas Nicolai's early criticisms of German letters present the capital city as a causal factor in historical development, his Berlin book investigates the mechanisms behind the evolution of the city itself. The city appears here as a site where various categories of causal explanation - politics, economics, geography, psychology, even a logic of organic development similar to that found in Gedike-fuse, intersect, and collide. In the application of these categories, moreover, Nicolai suggests conclusions, sometimes contradictory, about the larger patterns and directionality of historical change. The crucial point in this context is not that Nicolai represents the cutting edge of eighteenth-century thinking about historical causation but rather that his engagement with questions of causation is triggered by an interest in the city. A sense of Berlin's dynamism and a pride in its achievements drive him to consider the events that have made these achievements possible. In the process, he sifts through and relates to his readers some of the multifarious factors that shape historical developments. The city serves as both the source of and a focal point for a popular historical interest that seeks to elucidate its own present through an investigation of its origins. Nicolai makes this goal explicit, when, after his rather lengthy discussion of Berlin's history to the mid-fifteenth century, he stresses the importance of this period for understanding the more recent past: "I have described these events at some length because the documents to which I had access allowed me to distinguish them clearly from one another, because they have never been completely and accurately described before, and because they led to a most important change in the constitution of both cities, which had the greatest influence on the period that followed." ${ }^{40} \mathrm{He}$ had already made a similar point in the 1779 revision of the survey, where he defends his decision to expand the historical scope of the work with the following claim: 
"Part of my new plan was to include more history in the revised edition, because much that is present today really cannot be understood without a knowledge of its previous state, and because the astonishing expansion of Berlin (which was so insignificant one hundred thirty years ago and has now achieved such grandeur) simply cannot be discussed without constant reference to the city's history." ${ }^{41}$ In many respects, Nicolai's Berlin survey offers a textbook example of the contours of popular historical consciousness in late eighteenth-century Germany. The author's acknowledgment of the radically different character of earlier epochs, his interest in evolution and causality, his critical stance toward earlier historians and enthusiasm for archival research, and his focus on middle-class concerns all reveal his participation the paradigm shift I sketched out in the first chapter. ${ }^{42}$ It also demonstrates the extent to which contemporary Berlin provides the impetus for an articulation of all these elements.

Even if urban experience clearly motivated Nicolai's historical interest, however, and even if his investigations of Berlin allowed him to refine his own historiography, the question remains whether he himself was conscious of the city's unique role in the eighteenth century's evolving hermeneutics of historicity. The Berlin book contains no real methodological reflection, and Nicolai, always averse to any activity that might be construed as empty speculation, never wrote a theoretical treatise on the link between the city and history. One does, however, find evidence of an awareness of the city's unique historical-theoretical status in his most popular literary work, the novel The Life and Opinions of Herr Magister Sebaldus Nothanker. It is also possible to discern in this work a convergence of the two main aspects of the city's historical-theoretical significance that materialize in Nicolai's other writings: its function as a motor of historical development and as a site for the interplay of categories of causal explanation.

\section{Urban Enlightenment: Sebaldus Nothanker in Berlin}

Published between 1773 and 1776 - in the years prior to his first major revision of the Berlin book - Sebaldus Nothanker was Nicolai's only major literary success. It proved extremely popular with the German reading public, selling more than twelve thousand copies in four editions at home and many more in translations abroad. Nicolai conceived the novel as a continuation 
of a 1764 work by Mortiz August von Thümmel, a mock epic entitled Wilhelmine, or the Married Pedant. Sebaldus Nothanker begins where Wilhelmine leaves off, with the marriage of the learned country pastor Sebaldus to the ducal chambermaid Wilhelmine. After a somewhat rocky start, the protagonist and his wife settle into a life of simple country pleasures, until Sebaldus's antidogmatic religious views lead a hyperorthodox superior to drive him from his office and his home. In the chaos that follows, he loses both his wife and one of his two daughters to illness. With the help of the wealthy bookseller Hieronymus, he manages to find his remaining daughter Mariane a position as companion to a noblewoman, but Sebaldus himself finds it impossible to stay out of trouble, despite his kindheartedness and humble disposition. Only after a long series of setbacks and misadventures is he reunited with Mariane, at which point a lucky lottery ticket allows him to purchase a small piece of property and end his peregrinations.

The primary target of Nicolai's tale is religious intolerance in all its guises, but the novel also addresses a wide range of contemporary cultural phenomena, from literary sentimentalism to the shortcomings of the German publishing industry. That the novel resonates on a general level with an Enlightenment interest in history already becomes clear in the preface, where the narrator criticizes the author of Wilhelmine for inconsistencies in chronology and explicitly aligns himself with contemporary historians. With regard to the city more specifically, the work proves remarkable for a lengthy and detailed depiction of late eighteenth-century Berlin in book 4, a depiction that speaks to the interconnection of history and the urban context on a number of levels. Indeed, this interconnection comes to the fore even before the protagonist actually enters the city. After his coach is ambushed by bandits, Sebaldus wanders along a country road in search of the way to Berlin, where he had been headed to find employment. He meets and enters into a discussion with an enthusiastic Pietist, who warns him that the city is a breeding ground for all forms of corruption and depravity: "Selfishness and deceit have taken control there, vices are given free reign, inhumanity has reached new heights, all Christian love has been extinguished." ${ }^{3}$ Significantly, Sebaldus counters this claim with a reference to historical developments in the city. He remarks: "Is it possible for a state that contains only this sort of citizen to become prosperous in a short time? And yet I have been assured that the Prussian state has become very prosperous in just the 
period of living memory [seit Menschengedenken] - Berlin in particular is said to have noticeably increased its prosperity in the past thirty years." 44

This clash between Sebaldus and the Pietist involves more than two opposing perspectives on Berlin. More fundamentally, it also entails opposing conceptions of temporal change, with the city-presented in characteristic fashion as the state in microcosm - serving as the basis for their confrontation. Here Nicolai makes explicit what was only implicit in the Berlin book, namely, the city as an epistemological problem. Under consideration are two models for comprehending its nature, one that dismisses history as irrelevant and one that views history as the foundation of accurate knowledge. The Pietist's condemnation of Berlin operates within an essentially atemporal framework. Taking his inspiration from a long-standing cliché of urban decadence, he judges Berlin in terms of its deviation from an immutable standard of Christian morality. His comments suggest adherence to a traditional Christian conception of history based on a notion of homogeneous time, where no qualitative difference exists between the biblical world and the present. ${ }^{45}$ According to such a model, individual historical phenomena, rather than being indicative of any substantive development, represent manifestations of an eternal battle between cosmic forces of good and evil. Historical flux proves insignificant in comparison to the eternal truths of Christianity, as is made clear in the Pietist's response to Sebaldus's objection: "What does the temporal have to do with the heavenly?" 46 This fundamental equivalence of past and present is underscored in the following chapter, when the Pietist describes Berlin as a reincarnation of the infamous biblical cities of Sodom and Gomorrah. Confronted with Berliners enjoying a Sunday afternoon in the park, he cries: "Oh city . . you who are like Sodom and Gomorrah, how soon God will rain his fire and brimstone upon you!" 47

In contrast, Sebaldus posits the prime importance of history for an adequate understanding of the city. His approach, in other words, is genetic, in opposition to the exemplary thinking of the Pietist. To grasp the nature of contemporary Berlin, one must turn not to timeless biblical representations of urban corruption, but rather to the recent past. By the same token, the microcosmic capital city provides the central piece of evidence for measuring the significance of recent historical developments. Given the context, Sebaldus's attribution of meaningfulness to the period defined by living 
memory can perhaps also be seen as a jab at the unworldly character of Christian historiography, according to which the history of mankind was divided into four world empires, with the last of these usually thought to have begun at Christ's death. ${ }^{48}$

Berlin thus serves as the test case for a confrontation between a speculative (in the sense of nonempirical) and an inductive, historicist epistemology, and it also bears witness to the possibility of progress. Nicolai frames the encounter as a clash between two world views. At this point in the novel, Sebaldus serves as Nicolai's mouthpiece, espousing a commonsense empiricism that seeks to base its judgments on the concrete experience of social life. The Pietist, in contrast, embodies the rigidly deductive mentality of religious orthodoxy. His apprehension of the environment is predetermined by an unquestioning acceptance of certain invariable postulates about human nature and human society, one of which is the identification of the metropolis with depravity.

The denial of history entailed by this identification was anathema to Nicolai, and he uses Sebaldus and Berlin to demonstrate the reality of substantive historical change. Nevertheless, it would be a mistake to view Sebaldus's remarks on the city's prosperity as indicating a belief in any sort of general human progress. If the events of the novel take place more or less in the period of its publication, the reference to "the past thirty years" points to a familiar link between the rise of Berlin and Prussia and the reign of Friedrich II, who had ascended to the throne in 1740. As in the Berlin book, Nicolai seems to be revealing his political sympathies as well as his tendency to conceive history within a cyclical framework of generations. Even as Sebaldus's remark gestures toward the role of the regent in Berlin's increased prosperity, however, the absence of any direct reference suggests a reluctance to identify its source with the will of an individual monarch. This was indeed Nicolai's own view, as can be gleaned from his numerous historical essays, from the Berlin book, and, most important, from an earlier passage in Sebaldus Nothanker. ${ }^{49}$ In this passage, the narrator describes the importance of Sebaldus's friend Hieronymous in helping his homeland to flourish and chastises those commentators who fail to recognize the true sources of positive historical change: "It has long since become the rule of all those who investigate political and financial matters not to mention the minor circumstances that are generally the true causes of the events, but rather the obvious circumstances, which generally do not provide the true 
causes." ${ }^{50}$ He then goes on to criticize a recent essay in the royal newssheet that mistakenly attributes the country's increased prosperity to the "benevolent foresight" of the prince, who had in reality wasted his time on the hunt and his mistress.

The precise historiographical implications of Sebaldus's comments on Berlin thus remain ambiguous. Although he represents Berlin in terms of a linear temporal movement, as both a site of substantive historical change and as a phenomenon best understood in historical terms, it is unclear whether the prosperity of Berlin constitutes a localized cyclical upswing or results from a long-term historical process. What is clear is that this initial discussion of Berlin presents the city in terms of a theoretical opposition between historical development and stasis, thereby introducing it as a focal point for an investigation into the meaning of temporal change. The exposition of this theme takes place in the following chapters of book 4 of the novel, where the unique relationship between history and the city appears in several variations.

In at least one passage from this section, however, the author not only detaches the city from a framework of historical development but also casts this absence of history in a positive light. Arriving together by way of Spandau, Sebaldus and his Pietist companion make their way to the Tiergarten, already Berlin's main tourist attraction in the eighteenth century. ${ }^{51}$ Sebaldus, indifferent to the architectural splendor of the palace, feasts his eyes instead upon the long line of lush chestnut trees to be found in the royal garden. The narrator goes on to foreground the natural beauty to be found in the city, providing a lengthy and detailed description of the enormous variety of foliage - elm, oak, birch, acacia, pine, poplar, and linden trees - that surrounds the visitors. Berlin's "naturalness" figured prominently in contemporary eulogies of the city, helping to defend its charm against more established capitals like Paris and Vienna. In this passage, the link to nature manifests itself on a temporal level as well. When the pair reaches the area next to a group of tent cafés, which were popular with walkers in the period, the narrator refers explicitly to the day of the week and the time (Sunday, three o'clock) as the basis for a detailed description of the activities of those present and absent from the park. He writes: "At around three o'clock in the afternoon they finally came to the area next to the tents, which, because it was Sunday, was filled with a throng of walkers. To be sure, the fashionable six o'clock hour had not yet arrived, when the beautiful world joins the circle in order 
to see, and to be seen.... In short, it was three o'clock and thus little was to be seen of the beautiful world; on the other hand, the spot was teeming with the cheerful sons of the earth, who on Sunday completely forget all of the troubles of the week and who, on their walks and over their modest refreshments, take heartfelt pleasure in each other and their lives." ${ }^{52}$ In contrast to the initial conversation between Sebaldus and the Pietist described earlier, here the emphasis is on recurrence rather than development-the scene replays itself every Sunday at the same time. This representation, with its idealized view of a simple life in harmony with nature, owes much to pastoral conventions. But in this case the rural idyll has been transported into the urban space. In addition, through the explicit reference to its temporal coordinates, the narrator also links the idyll to a particular form of temporal experience. It is not merely the unselfconsciousness and lack of artifice that make the so-called sons of the earth appealing, but also their connection to the rhythms of nature. Thus, although the development of the city as a whole is best described as linear, its inner temporal structure appears to be cyclical. This organic cyclicality, which contrasts markedly with Sebaldus's own denaturalized experience of time as he wanders from station to station in the novel, appears in the scene as part of the city's appeal.

An idealized celebration of the simplicity and authenticity that characterizes lower-class life is an established motif in eighteenth-century German literature. ${ }^{53}$ In this case, however, the object of idealization is not the peasant farmer or villager but the urban tradesman. Even more important, Nicolai frames his depiction in such a way as to foreground the temporal structure of this life as a key component of its allure. Nicolai was not alone in acknowledging this allure. Fellow Berliner Karl Philipp Moritz offers a similar perspective in the novel Anton Reiser, which appeared a little more than a decade after Sebaldus Nothanker. In his description of Anton's arrival in Braunschweig to begin an apprenticeship with a hatmaker, Moritz remarks on the joy experienced by the tradesman in anticipation of the Sunday holiday. In Moritz's description, the entire life of the tradesman appears as a series of concentric circles of time, beginning with the recurring cycle of meals in a given day, followed by the cycle of days in the week, and culminating in the annual cycle of religious holidays. Concluding his discourse, Moritz writes: "In accordance with an infinitely good and wise arrangement of things, even the tedious, monotonous life of the laborer has its phases and periods, whereby a certain cadence and harmony are introduced into it. 
These allow it to pass unnoticed without having caused its possessor boredom." ${ }^{54}$ As in Sebaldus Nothanker, Moritz's protagonist is excluded from this reassuring cyclicality, in this case as a result of his desire for individual progress, for linearity: "But through his romantic ideas Anton was simply not in step with this cadence." ${ }^{55}$ He dreams instead of attending the nearby Latin school in order to develop his intellectual faculties.

The celebration of cyclicality that one finds in both Nicolai and Moritz is open to a variety of readings, but it seems plausible to view it as a localized reaction to the temporalization of history occurring in the period. On an individual level, the detachment of past, present, and future that marks this temporalization is linked to a disintegration of experience as a stable and coherent totality. ${ }^{56}$ The recognition of the alterity of the past and the openness of the future creates the possibility of progress, but it also threatens to obliterate the value of experience as a basis for orienting oneself in the world. When the past is no longer normatively binding for the present, that present must find its models and its legitimacy elsewhere. This dilemma is arguably the fundamental dilemma of modernity, and it forms the basis for numerous eighteenth-century theoretical debates about the value of tradition, including the enlightenment debate of the 178 os. It must also be remembered, however, that this same dilemma was mirrored in individual biographies, especially those of an emergent group of middle-class intellectuals who felt increasingly alienated from their own pasts.

The lives of both Nicolai's and Moritz's protagonists are circumscribed by an uncertain future and a past to which they cannot return. Within this framework, the stable cyclicality of artisanal life appears as an appealing alternative. Nicolai's decision to thematize this cyclicality at the beginning of the Berlin section in the novel provides another example of the city's temporal complexity, linking it to eighteenth-century historical consciousness by way of a determinate negation. Here he seems to be presenting the city as a refuge from modernity rather than its embodiment. Like so many other representations of the urban experience, however, this apparently nostalgic depiction is not as straightforward as it first appears. As can be seen in the reference to "the fashionable six o'clock hour," the activities of the "beautiful world" are just as dependent upon a cyclical temporal framework as those of the lower classes. The difference is that in their case, this cyclicality indicates an adherence to social convention that exists in tension with "natural" behavior. Rather than enjoying a sunny afternoon in the park, they are 
indoors, either preparing for their "coffee visits" or sitting around tables, indulging themselves with fine wines and overly rich food.

Berlin's urban cycles thus reflect both the concrete, natural time of the tradesman and the purely conventional time of the affluent. Because both are characterized by recurrence, the overall impact of Nicolai's depiction is to extract the city from a framework of historical development and lend it an atmosphere of timelessness. The entire passage appears in the text as a sort of genre painting, and from this perspective perhaps even the reference to the fashionable classes helps to depict the city as a reassuringly stable and familiar world in microcosm. Against the backdrop of widespread hostility to urban life and a growing suspicion of Berlin in particular, the passage might be read as a defensive gesture by a committed metropolitan. The city, in other words, is by no means as chaotic as its detractors are claiming. Whatever the reasons for its inclusion, however, this particular perspective on Berlin plays only a minor role in Nicolai's urban narrative. The static interlude quickly gives way to a renewed emphasis on the city as a site of both personal and sociohistorical transformation.

Sebaldus adjusts fairly quickly to big-city life, at least once he has been disabused of the provincial naivete that led him to think he could survive by teaching philosophy. In his characterization of this process, Nicolai offers an interesting twist on the city-country opposition so common in later urban narratives, a twist that hearkens back to his earlier critical works and reflects the peculiarity of German conditions in the late eighteenth century. Although he is in many respects a quintessential country bumpkin, Sebaldus's lack of aptitude for city life proves to be less a function of his rural origins than his impractical bookishness. As we saw earlier, the natural and the urban manage to coexist peacefully in Berlin. The real opposition here appears to be between city and university. Sebaldus's first friend and benefactor in Berlin, after revealing that he has no knowledge of the philosophers Crusius or Wüstemann, offers the following reflection on the role of knowledge in the city: "I have already noticed on several occasions that people who are considered quite famous at the university are totally unknown in Berlin. I really do not think you will make your fortune with philosophy in Berlin. Here goodwill and patronage, the ability to bow deeply and wait patiently are often more helpful than the best system." ${ }^{57}$ Here, then, the urban experience is linked not to the overcoming of backwoods ignorance but to an overcoming of the ivory-tower abstraction seen to characterize eighteenth- 
century university philosophy. The inferiority of philosophical systems visà-vis real-world experience was certainly one of Nicolai's favorite themes; the satirization of these systems becomes something of an obsession in later novels. It was also a conviction held by numerous other intellectuals in late eighteenth-century Germany-Goethe, Schiller, and the representatives of the Storm and Stress movement are the most obvious examples.

Although criticisms of impractical bookishness are widespread in the period, however, it is important to consider the different ways in which such criticisms are framed, the different alternatives presented, and their evolution over the course of the century. ${ }^{58}$ Nicolai's novel distinguishes itself in this context in that it explicitly posits the city, rather than nature, as the locus of a more authentic mode of experience. For Nicolai, the antidote to rationalistic pedantry is to be found in the sociability of city life, not in a liberating encounter with the natural world. The best-known example of the second possibility is probably the opening scene of Goethe's Faust, where the frustrated protagonist fantasizes about escaping his "dungeon" to bathe in the moonlight, freed at last from "book-learning's fog and stew" (Wissensqualm). That Nicolai's more intersubjective alternative was also endorsed by his fellow Berliners becomes evident when one examines journal essays on Berlin written in approximately the same period. A similar opposition between the city and scholastic pedantry is constructed by Gedike in his letters. Here Gedike stresses the advantages of Berlin's lack of a university, claiming that knowledge is consequently more practically oriented and spread more widely among the various estates. He writes: "True knowledge, that which is useful to humanity, can never realize its value when it is the possession of only a few learned men." 59

As the novel makes clear, Sebaldus's particular philosophical interests tend toward the speculative. His pet project is a commentary on the biblical story of the apocalypse, an undertaking that is by no means value-neutral from a historical-theoretical perspective. It associates him with the same traditionally Christian conception of history that characterized his Pietist interlocutor. Sebaldus's arrival in Berlin, however, is explicitly framed as a departure from his preoccupation with this specific topic and with speculative philosophy more generally, as he is forced to turn to more practical concerns. As his host informs him, "My dear friend, the apocalypse has an even worse reputation in Berlin than philosophy." ${ }^{60}$ Sebaldus's stay in the city involves what can be termed an urban enlightenment, in the course of 
which abstract theories and opinions based on hearsay are challenged by way of immediate empirical evidence. Moreover, one key element of this enlightenment appears to be a better understanding of the nature of historical transformation. This topic, which marked the entrance of the protagonist into Berlin, reappears in a later section of the novel that focuses on the city as a center of religious freedom.

Now employed as a music teacher, Sebaldus makes the acquaintance of a certain Herr F., an erstwhile private tutor living on a pension provided by his previous employer. After hearing Sebaldus's life story, Herr F. relates his own unfortunate encounters with religious intolerance. Sebaldus responds by praising the open-mindedness of the city: "Certainly ... that is the great advantage that one enjoys in Berlin. This is the true land of freedom, where every man may speak his mind, where no one is denounced as a heretic, where Christian love and enlightenment (Erleuchtung) are present in equal measure." ${ }^{61}$ Whereas Sebaldus's initial association of Berlin with positive historical change focused on the question of material prosperity, here he couples the city with advancements on an intellectual level. In this passage, a connection is made between the urban context and the goal of freedom from prejudice, suggesting a link between the city and the general progress of humanity that hearkens back to the optimism of Nicolai's early writings. An analysis of the discussion that follows, however, suggests that the "urban" character of Berlin actually hinders rather than facilitates this progress. Herr F. is quick to point out to Sebaldus that the religious enlightenment he associates with the city has developed unevenly. Noting that progress in thought is registered far more quickly in the literature than in the minds of the inhabitants, he remarks that the religious views of many Berliners have not changed in forty years. In a description best characterized as a topography of tolerance, Herr F. then goes on to discuss discrepancies in the relative dogmatism of various Berlin neighborhoods. The city proper and the Berlin suburbs are among the most orthodox, whereas one finds freethinkers in Cölln and in the area around the palace. The Herrnhüter congregate around the Hospital Church of Saint Gertraut, and various species of "enthusiasts," including the Pietists, can be found in Friedrichsstadt. Significantly, this topography reveals a clear correlation between tolerance and proximity to the court. As Herr F. says, "The nearness of the court probably also contributes to the fact that the people here are more freethinking." ${ }^{2}$ In other words, enlightenment radiates outward from the center, rather than 
arising from pockets of autonomy made possible by the heterogeneity of the city. On the contrary, it is this very heterogeneity that allows such enclaves of orthodoxy to exist.

Here again Nicolai reveals his endorsement of the political status quo. Freedom from prejudice and a belief in the value of religious tolerance seem to be the possession of a limited number of intellectual elites, including, of course, the king himself. With regard to the urban environment, the implication of this passage is that the city as an independent entity constitutes a threat to the spread of enlightened ideas. The very autonomy of the urban space, the fact that its complexity permits the existence of independent subcultures, prevents a uniform distribution of knowledge. Berlin would actually be much more tolerant if it were simply an appendage of the court. Nicolai's argument parallels the more general arguments he made against German particularism in his earlier critical writings, but he appears to have changed his tune regarding the city as a universalizing space. Now the dangerous heterogeneity previously seen to characterize the nation as a whole is contained within the city itself.

Thus, although the passage initially situates Berlin within the framework of a linear progress, this linearity is problematized on two levels. By tracing improvements back to a small group of intellectuals, Nicolai again reveals his distance from more optimistic philosophers like Kant, who tends to see progress as both irreversible and operating behind the backs of individuals. More important, he posits the urban space itself as a hindrance to progress. This spatialization of time in the city, however, even as it complicates the idea of the city as the embodiment of progress, serves to reinforce the notion of the city's significance for historical consciousness in the period. Nicolai represents the heterogeneity of the urban environment as a material obstacle to the dissemination of new ideas, indicating his recognition of the inadequacy of purely idealist theories of historical change. In this respect, he comes near to those professional historians who sought to develop new theories of historical causation in order to provide an adequate account of the complex interconnections between mental and material factors. ${ }^{63}$ The entire discussion is framed, in a manner parallel to the initial discussion between Sebaldus and the Pietist, as a confrontation between two epistemological strategies. In this case, however, the protagonist appears as the representative of an ahistorical speculation, inasmuch as he bases his claims on a naive deduction from mere hearsay. Herr F., in contrast, insists that they look to 
the material world for empirical evidence of change. Moreover, in depicting Berlin as the locus of uneven intellectual development, Herr F. also presents the city as the place where historical transitions can be most easily discerned.

The self-consciousness with which Nicolai uses the city as an occasion for such disputes suggests that he did indeed recognize its historical-theoretical significance. A final passage from Sebaldus Nothanker offers the most compelling evidence for this claim, and it also links Berlin explicitly to the question of historical causation. Nicolai establishes this link via a discussion of the familiar topic of fashion, but his approach involves a striking departure from the kind of treatment we saw in Zedler's Universallexicon. Mentioned briefly in the Tiergarten passage, both in the narrator's reference to the "fashionable" time of day and his remark on the people dressed "according to the newest fashion," fashion becomes the focus of a conversation between Herr F. and Sebaldus that occurs toward the end of the protagonist's sojourn in the city. Tellingly, the discussion centers around a manuscript entitled Historical Essays on Berlin, again linking the epistemology of the city to a historicist methodology. At issue is one particular essay, "The History of the Hats and Robes of the Berlin Clergy," which addresses the reciprocal relationship between modifications in Protestant doctrine and changes in the attire of the Berlin clergy. Here again, the city appears as the privileged object of historical analysis, not least because its diversity allows for insight into the interactions among different social networks. The essay points out, for example, the impact of courtly fashions on those of the clergy, leading sometimes to imitation and sometimes to attempts at differentiation. It also appears that the urban environment fosters a unique form of historical semiotics, one sensitive to detail and to the imbrication of intellectual and social phenomena. Whereas the country pastor Sebaldus mistakenly claims that all clerical robes look the same, his more savvy urban companion points out the minor but significant variations. ${ }^{64}$

Changes in clerical attire serve as the basis for a debate between Sebaldus and Herr F. over the significance of fashion as an object of historical investigation. Against the backdrop of a largely negative association of fashion with excessive luxury in the period, Nicolai's presentation here appears as a rather radical departure from the mainstream. In an age where, as we have seen, many depicted fashion as a threat to the divine order, Nicolai's decision to use representatives of that order to illustrate his points can only be seen as subversive. In a sense, the passage challenges the very definition 
of fashion, inasmuch as it calls into question the assumed opposition between shifts in fashion and meaningful historical change. At stake is the role of fashion in understanding church history, and, on a more basic level, the question as to what kinds of developments actually deserve to be characterized as historical. The essay under discussion (and, by implication, Herr F.) posits a dialectical relationship between modifications in attire and substantive theological developments. Not only can one infer changes in doctrine from a new style of coat; changes in doctrine can pass unnoticed when the manner of dress remains the same. The essay even points out, albeit not without some irony, the role played by fashion in disciplining the body. The Pietist priests allegedly wrapped their long robes around themselves in such a way that even "those among them who were not thoughtful by nature had to adopt a thoughtful bearing." ${ }^{65}$ Sebaldus, in contrast to his interlocutor, insists upon the essential irrelevance of external appearances. In his opinion, "the signified is fundamental, the sign arbitrary." 66

In conflict here are two different semiotic models that can be seen as corresponding, at least in some respects, to the two eighteenth-century frameworks for conceptualizing fashion that Daniel Purdy discusses in The Tyranny of Elegance. For Sebaldus, a style of dress serves merely as a marker for membership in a particular estate - in this case, that one is a member of the clergy. The details of that style are arbitrary and unimportant. According to the essay and Herr F., however, these details provide subtle but crucial clues to the more specific intellectual identity of the wearer. The essay's reference to the restricted movements of the priests also reflects the increasing tendency in the latter part of the century to view fashions in terms of their relation to the body ${ }^{67}$ In its treatment of religious fashion, Nicolai's novel thus indicates yet another eighteenth-century arena in which the complex and evolving conceptions of the relationship between fashion and identity were being negotiated. Indeed, his self-conscious juxtaposition of these opposing frameworks suggests that Nicolai in fact recognized the emergence of a new discourse on fashion in the period.

These two semiotic models, however, also correspond to two models for understanding the relationship between depth and surface in history. According to the first, these two levels are inextricably intertwined. Religious fashions not only provide clues to the intellectual identity of their wearers but can also serve to distinguish them from their predecessors. And changes in fashion, or the lack thereof, can actually facilitate more substantive intel- 
lectual transformations. Even such apparently superficial phenomena as hats and wigs must therefore be taken into account if one wishes to understand the causes of historical developments. Sebaldus, in contrast, although he acknowledges the variability of these things, feels that epiphenomena such as fashion are irrelevant to an evaluation of the inner values that determine real human progress. This conflict, which is in essence a conflict over the relative weight of material and spiritual factors in driving historical change, is left unresolved. Sebaldus does have the last word, and the passage suggests a general trend away from external symbols of authority. Nonetheless, the examples indicate that changes of fashion can be reflective of significant historical shifts, and Sebaldus admits that such externalities, once they have been deemed important, can become a source of serious dispute, even civil war. Here again we find evidence of Nicolai's materialism in questions of historical causation. It is noteworthy in this context that Nicolai himself pursued this line of inquiry in an 1801 historical study entitled On the Use of False Hair and Wigs in Ancient and More Recent Times. The real significance of the discussion, however, lies in the fact that shifting fashion, a phenomenon closely linked to metropolitan life, provides the occasion for a confrontation between two paradigms for understanding the sources and mechanisms of historical change.

\section{Conclusion}

Nicolai's efforts to "read Berlin" bear witness to the importance of the late eighteenth century in the genealogy of modern urbanism. Like his twentieth-century counterparts, Nicolai recognized the epistemological challenge presented by the emerging metropolis and attempted to address this challenge with varying strategies of textual mediation. His fascination with the city reveals the extent to which the more recent and much more conspicuous Berlin discourse was anticipated in the context of an earlier encounter with modern urban phenomena. In attempting to understand the historical-theoretical significance of eighteenth-century Berlin, however, one should not simply reduce the city to an emblem of modernity, at least not of the modernity thematized in later representations. In these depictions, Berlin most often figures as the site of an accelerated and ateleological mode of experience, a mode characterized by Walter Benjamin in 
terms of the shocks of Erlebnis rather than the more narrative structure of Erfahrung. For Benjamin, the shocks of modern urban life threaten to eliminate altogether the possibility of individual experience as a coherent narrative, reducing it instead to series of discrete and unrelated events. ${ }^{68}$

Aspects of this phenomenon are certainly prefigured in Nicolai's Berlin. In Nicolai's writings on the city, however, as in Gedike's letters, eighteenthcentury Berlin proves most interesting as a site of multiple modes of temporality, a site where modernity starts to become conscious of its own contours. The city offers evidence of real progress, but it is just as much home to "natural" and arbitrary temporal cycles, and to the indeterminate temporality of fashion. In Sebaldus Nothanker and, more implicitly, in the Berlin book, Nicolai repeatedly presents the city as a place that both fosters an awareness of historical transformations and causes the observer to consider the mechanisms driving those transformations.

The city also appears as one of the motors of transformation. The insertion of the city into a trajectory of progress is most clearly articulated in Nicolai's early critical writings, but it continues to inform Sebaldus Nothanker as well. Although the novel challenges any naive identification of urban experience and enlightenment through its emphasis on the uneven distribution of knowledge in the city, Berlin is nonetheless depicted as a place where the struggle against prejudice and superstition has made significant inroads. It also functions as a space of enlightenment for Sebaldus himself. Although one cannot discern any real development of his character over the course of the novel, he is nonetheless forced to reconsider and revise his opinions on a variety of topics while in the city. The same claim holds for the reader as well, who participates vicariously in Sebaldus's discussions and debates. The primary subject of these discussions and debates, moreover, is the nature of contemporary Berlin, its origins in the recent past, its current level of enlightenment, and its uncertain future. In the novel, in other words, urban enlightenment is to a large degree an enlightenment about the historicity of the city.

Berlin's function as a space of enlightenment in Nicolai's novel not only reinforces the link between the city and eighteenth-century historical consciousness; it also offers a corrective to the image of eighteenth-century German intellectuals as antiurban. Erich Kleinschmidt is right that much of canonical eighteenth-century German literature ignores the city, and that those works set in urban contexts often emphasize their restrictive atmo- 
sphere. As soon as one turns to Berlin and incorporates nonfictional sources, however, it becomes clear that there was a lively interest in the problems and prospects of big-city life among Germans in the period. The "new urbanity" that Kleinschmidt detects in Sebaldus Nothanker involves more than a mere acknowledgment of the city as a valid literary motif. A careful reading of the Berlin passage in the novel, especially against the backdrop of Nicolai's broader commitment to urbanism, reveals that he associated the city with the development of a universal perspective of enlightened humanity. Far from "a repressive, restrictive existential shell," the city appears here as a site of liberation - a view articulated not just by Nicolai, but also by Gedike, Zöllner, Lessing, and Mendelssohn, with varying degrees of enthusiasm. ${ }^{69}$ Indeed, with regard to the question of historical progress, the problem with Berlin seems to stem from an excess of freedom rather than its restriction. The perceived ambivalence of urban emancipation is visible in Nicolai's topography of tolerance, where freedom from the grip of authority appears as the freedom to be intolerant. In this context as well, we are brought back to questions of history and historical consciousness, inasmuch as this freedom is evaluated against an idea of enlightenment conceived as a socialhistorical, not just an individual, intellectual development. Concern with the ambivalent social consequences of liberation also suffuses Gedike's letters, and it constitutes one of the motivations behind Mendelssohn's later philosophy. Lessing, however, offers the most intriguing investigation of this ambivalence as it pertains to the city, revealing in the process its inextricability from efforts to ground a modernity that can no longer seek its legitimacy in the past. 


\section{Aesthetic Experience and Urban Enlightenment in G. E. Lessing's Minna von Barnhelm}

\section{Introduction}

In contrast to Nicolai, a cursory review of Lessing's comments on Berlin yields little to suggest a connection between urban culture and enlightened modernity. Although the author spent more than a decade living in the city, he was by no means its most enthusiastic advocate. His correspondence is peppered with criticisms of Berlin and its residents, the most dramatic being an often quoted letter to Nicolai himself from August 25, 1769. Here Lessing dismisses Berlin's alleged intellectual freedom as illusory and memorably decries Prussia as "the most slavish country in Europe." ${ }^{1}$ If there is any association between the city and history here, it would seem to be in the form of a testimony to historical regression. The ease with which he slips in this letter from a discussion of Berlin to a discussion of Prussia implies a near equivalence between the two. Berlin appears as a mere appendage of the absolutist state, an embodiment of the obsolete value system against which Lessing directed so much of his critical energy. He links the dominance of the monarch in this context to the preservation of a backward-looking political status quo, one in which the reason employed by the sovereign is of a purely instrumental variety. Indeed, Lessing's comments suggest that the religious freedom Nicolai praises so highly in fact represents an attempt to defuse the critical energies of the Berliners through redirection into a sphere that poses no threat to state power. In Lessing's opinion, “it consists in nothing more than the freedom to bring to market as many absurd arguments against religion as one likes. And any honest man must quickly become ashamed of making use of this freedom." ${ }^{2}$ He then goes on to point out that an attempt to apply this intellectual freedom to topics like political injustice or exploitation would quickly reveal its limits. Implicit in his observations is an ar- 
gument on the compensatory role of culture, an argument that has figured in the works of critical German intellectuals ranging from Heine to Marx to the members of the Frankfurt School. With regard to our investigation of the urban context in particular, they suggest that Lessing views Berlin not as a center of emancipation but rather as a bastion of servility, of Unmündigkeit.

Lessing's relationship to Berlin and to Friedrich II was complex and variable, however. It can hardly be grasped on the basis of a single letter, especially one written at a time when the recent closure of the Hamburg National Theater and the questionable future of a publishing joint venture with Johann Joachim Christoph Bode may have caused him to regret his decision to leave Berlin in 1767. At the time he was considering a move to Vienna, and his letter is in part a response to Nicolai's negative remarks on that city. Moreover, the emphasis on Berlin's regressive character actually reinforces the notion that urban life in this period fostered a greater sensitivity to historical change and played a significant role in the articulation of new paradigms for thinking about that change. The very fact that a discussion of enlightenment centers on a comparison between Vienna and Berlin - and here it is significant that the conflation of state and capital in the letter is by no means complete - it reminds us that the city constituted one of the key categories on the basis of which an evolving understanding of modernity was articulated.

In this particular context, it appears that Berlin fosters such an understanding mainly negatively, serving as an indicator of the gap between ideal and reality. The Marxist scholar Paul Rilla has presented a more generalized version of this argument in his 1959 Lessing biography, Lessing and His Age. According to Rilla, it was the exposure to the exaggerated courtliness of Berlin culture that inspired Lessing to champion a literature in the service of progressive middle-class values. He writes: "In Berlin Lessing was able to see with his own eyes how the new ideas lost their meaning as soon as they were forced into the service of courtly entertainment." ${ }^{3}$ Rilla is certainly right to point out Lessing's awareness of the limits of enlightenment in the city. His own inability to secure stable employment there taught him the hypocrisy of Berlin's self-characterization as an "Athens on the Spree." ${ }^{4}$ Still, to view his conception of Berlin solely in terms of regression is to ignore the crucial role the city played in his own intellectual, artistic, and personal development. For the young Lessing at least, Berlin clearly belonged to the future rather than the past. That Germany's first professional author of any stand- 
ing chose to begin his career in this newly minted metropolis testifies to its importance in the emergence of innovative, market-based forms of literary culture in the eighteenth century.

The positive function of big-city life for Lessing, however, extends beyond its role as the backdrop for his literary debut. As an analysis of his Berlin comedy Minna von Barnhelm reveals, Lessing conceives the urban experience as inextricably intertwined with an Enlightenment project of fostering tolerance and overcoming particularism. The city appears in the play as the site of a promising though problematic liberation, one that evokes hopes and fears identical to those thematized in the works of Gedike, Zöllner, and Nicolai. Lessing's depiction of urban autonomy, moreover, together with the perspectivism to which this autonomy gives rise, also points to the city's historical-theoretical significance in the period. The representation of urban experience in the play is linked to an endorsement of a historicist epistemology, while the city itself serves as the focal point for a historical reflection that emphasizes the role of perspective in understanding the past.

\section{Urban Autonomy and Its Limits}

In comparison with Lessing's previous dramatic works, Minna von Barnhelm is unique not only in being set in Germany's most self-consciously modern city but also in the frequency with which Lessing alludes to specific elements of the urban environment. Scholars have tended to ignore this aspect of the work, focusing instead on its generic innovations vis-à-vis Lessing's earlier comedies of type or on the seemingly inexhaustible theme of Tellheim's honor. Those few who have addressed the Berlin context, such as Joachim Dyck, place the primary emphasis on Lessing's critical portrayal of life in the city after the Seven Years' War. ${ }^{5}$ Dyck draws attention, for example, to Lessing's satirization of the Prussian use of innkeepers as political informants as well as of the financial crisis that followed Friedrich II's coinage policy during the war. He could have also mentioned the French lieutenant Riccaut, whose dubious morals and broken German must have resonated with a public wary of a disproportionate French influence in the city. ${ }^{6}$ When one keeps the urban context in mind, even seemingly minor elements take on a new significance. The innkeeper's remark to Just regarding the "accursed neighbor's" recently constructed fire walls, for example, evokes 
the contemporary criticism of Berlin's uncontrolled building practices. ${ }^{7}$ And Just's plan to turn the innkeeper's daughter into a "whore" would have been nowhere more easy to carry out than in eighteenth-century Berlin, where the abundance of brothels was a source of uneasy fascination for residents and visitors alike. Considering the prevalence of such allusions to the city, it is hardly surprising that Gedike mentions the play in his letters, following his praise with the parenthetical remark, "and that belongs to Berlin!" 8

Recognizing the specificity of Lessing's references to Berlin and Prussia is, as Dyck points out, crucial to understanding his satiric brilliance as well as the play's unusual position within the largely neoclassical context of eighteenth-century German drama. Equally significant, however, is the influence on the play of a more general eighteenth-century urban discourse, one that sometimes runs parallel to and sometimes intertwines with the discussion of Berlin per se. Although the play's basic adherence to the three unities means that the action is limited to a single location (an inn), the big-city context becomes clear through a variety of explicit and implicit references. The most obvious examples are the maid-in-waiting Franziska's remark on the ceaseless noise of "these awful big cities" and the exchange in act 1 between the soldiers Just and Werner:

JUST: Well, if it isn't Werner! Hello, Werner. Welcome to the city.

WERNER: Damned village! I can't get used to it again. ${ }^{9}$

Less apparent but also significant are the play's various allusions to late eighteenth-century urban culture. After his falling out with the innkeeper in act 1 , for example, Tellheim retires to a nearby coffeehouse. In a meeting that occurs shortly thereafter, Werner teases Just for not reading the newspapers. In act 3, Minna discusses her plans to go sightseeing at three o'clock, which was in fact a preferred hour for tours of Berlin. ${ }^{10}$ And Minna's uncle, the Graf von Bruchsal, exclaims upon his arrival at the end of the play: "But what's this girl? You've only been here twenty-four hours, and you've already made some acquaintances and are beginning to entertain?" ${ }^{11}$ His comment reflects the eighteenth-century association of the city and spontaneous, unrestricted forms of sociability, an association that also informs the texts of Nicolai, Gedike, Zöllner, and various travel reports on Berlin. Even the play's obsession with financial matters, which has its specific referent in the financial catastrophe that followed the war, can be linked on a more general level to the city as the locus of the money economy. 
The focus of the analysis that follows is the role of this urban setting in the resolution of the drama's central conflict, namely, Major von Tellheim's perceived inability to marry Minna as a result of a blow to his honor. Tellheim, a former officer in the Prussian army, finds himself not only wounded and discharged from service at the end of what is now known as the Seven Years' War but also accused of corruption in connection with the collection of the war contributions made by the state of Saxony. In light of this state of affairs, Tellheim believes, apparently with good reason, that a union with his fiancée is no longer possible. ${ }^{12}$ It is only after Minna deceives him into thinking that she has been disinherited by her uncle that he experiences a change of heart and recommits himself to their marriage.

A careful reading of the play reveals that the conditions of possibility for Tellheim's change of heart are closely linked to the urban context in which this transformation occurs. In order to grasp this linkage, however, it is first necessary to recognize the extent to which the city in general, and Berlin in particular, is depicted in eighteenth-century discussions as a site of detachment, of liberation from existing social conventions and norms. This liberation is often viewed in negative terms, as Friedrich Gedike makes clear in the following example from his letters on the city: "Admittedly, the extraordinary number of foreigners has damaged the originality of the national character. It has brought to fruition prematurely what would otherwise have been a more gradual, but therefore more stable enlightenment driven from within. It has also given rise to the revolting chaos of the lower rabble, which is without fatherland, faith, morals, or principles, as well as to the unnatural contrast between virtue and depravity, culture and barbarism, which one finds here in the highest degree." 13

Gedike offers no explanation of the exact mechanism through which the diversity of the city results in a premature "enlightenment," and it is difficult to know exactly what he means. Despite the reference to the purity of the "national character," he cannot be condemning specific elements of a particular foreign culture, such as France, because he uses the term "foreigners" to describe both the French and individuals coming to Berlin from other German states - he mentions Braunschweig, Hanover, Mecklenburg, Saxony, Westphalia, Swabia, and the Palatinate. The fictitious author of the letters himself, also referred to as a foreigner (Fremder), allegedly comes from Munich. It is thus not a question of already "enlightened" immigrants coming to the city and corrupting the innocent locals with their newfangled 
knowledge and customs. Instead, he seems to be making an argument about the urban dynamic itself. It would appear that the conglomeration of rootless individuals in the city, detached as they are from the moderating influence of the long-standing social hierarchies found in their home environments, "unnaturally" accelerates the maturation process, which in turn fosters a lack of respect for the authority of tradition. Gedike's use of organic metaphors in this context - "brought to fruition prematurely" - connects this tradition, embodied in the concepts of "national character," "fatherland," "faith," and "morals," to the natural, God-given order. To Gedike's credit, he goes on to claim that the high percentage of nonnative Berliners in the city has a positive impact overall, but it is clear from this passage that the liberating effect of urban life is viewed as a threat to social stability.

A similar argument is made by Friedrich Zöllner in his "Contribution to the Characterization of the Big City and the Big-City Dweller." Like Gedike, he discusses the enlightening impact of city life, especially on the lower classes, and here again the experience of urban diversity leads to a weakening of traditional social power structures. According to the author, "there exists a certain metropolitan outspokenness [Freimütigkeit], which manifests itself not only in intercourse with strangers, but also and especially in the manner of behavior toward those more highborn." ${ }^{14}$ This outspokenness arises in part as a result of the regular exposure to and interaction with new individuals, such that one becomes accustomed to discerning the general in the particular, to recognizing the universally human beneath any surface. As a consequence, "rank, title, costume make no particularly powerful impression on the big-city dweller." ${ }^{15}$ As with Gedike, Zöllner's arguments suggest that the unique dynamic of urban life, characterized as it is by constant exposure to the new and the different, poses a challenge to established social hierarchies. Within the context of the Enlightenment's emphasis on the autonomous use of reason, one might expect this demystification visà-vis external manifestations of power to be celebrated. As is the case with Gedike, however, the author here warns against the potentially destabilizing effects of this lack of respect for authority. He writes: "In direct contrast [to life in the small town], this metropolitan outspokenness very easily degenerates in the case of the common man into insolence and a complete lack of restraint." ${ }^{16}$ Unlike Gedike's more positive view of Berlin, here a good part of the essay resonates with fear of the threat posed by the urban dynamic to the established social order: vicious rumors spread unchecked, acquiring 
the status of certainty as they pass from mouth to mouth. Even worse, because of the sheer numbers involved, the original source of the untruth can never be uncovered. Moreover, the big city gives rise to an entire class of individuals, the idlers (Müssiggänger), whose lack of sufficient productive employment leads them to fill their empty hours with all sorts of depravity.

Much of this critique rests on the venerable stereotype of the city as a breeding ground for vice, a stereotype with biblical origins but one that owes much of its eighteenth-century popularity to Rousseau. We have also seen that similar criticisms figure prominently in the Pietist's description of Berlin in Sebaldus Nothanker. What I want to focus on in this context, however, are the structural conditions that allegedly give rise to this depravity. Both of the preceding essays imply a concept of the city as a kind of nonregulated space, where one is detached from traditional mechanisms of social control. In the city, in contrast to the rural towns, the institutions through which this control is exercised - the family, the church, the local government-have only limited penetration. As Zollner puts it, "the smaller the city, the more everything is done according to the rules! . . . the bigger the city, the fewer the rules!" 17 Again one is reminded of Sebaldus Nothanker, where the complexity of the city is also represented as a source of autonomy. There as well this autonomy is perceived in negative terms, to the extent that urban heterogeneity hinders the unimpeded spread of enlightenment emanating from the court of Friedrich II.

These essays suggest that the structure of city life and of the city itself grant the individual an unusual degree of independence. Of course, Georg Simmel makes precisely the same claim over a century later in his essay "The Metropolis and Mental Life" (1903). According to Simmel, in the modern metropolis the individual experiences "a kind and a degree of personal freedom to which there is simply no analogy in other circumstances." ${ }^{18}$ Gedike and Zöllner would undoubtedly agree. In the case of the "common man" in the eighteenth century, however, this autonomy creates a potentially dangerous situation, inasmuch as he has not yet reached the level of maturity necessary to use his freedom wisely. His external autonomy, in other words, which derives from the unique character of sociability in the metropolis and from the fact that its spaces and practices lie beyond the reach of societal control, is perceived as out of step with his inner development.

In Minna von Barnhelm, written some twenty years prior to the texts by Gedike and Zöllner, Lessing appears to be working with a similar under- 
standing of the urban context. The fact that his drama offers a literary instantiation of these ideas long before they are articulated in nonfiction texts underscores the importance of literary works for understanding the evolution of conceptions of the city in this period. ${ }^{19}$ Admittedly, Lessing's relationship to the later discourse reveals a number of important shifts and inversions. Minna and Tellheim certainly do not belong to the same social stratum as the "common man," yet for them as well the city functions as a kind of identity threshold. While in the city they too are "rootless," in a state of social suspended animation outside of the framework of those institutional contexts (here primarily the family, the military and the court) that have until now been their primary sources of subjectivity. The indeterminacy that characterizes the city can be seen to crystallize in the space of the inn, itself a site of transition and impermanence, defined by its very detachment from the normal routines of everyday life..$^{20}$

As a space of coincidence, chance encounters, and conflict resolution, the inn has a long tradition as a dramatic motif, a tradition that testifies to an enduring belief in the emancipatory effects of travel. The theme of travel figures prominently in Minna von Barnhelm as well, as we will see; however, it is important to recognize the extent to which Lessing represents the inn as an element of the urban context rather than as a wholly independent location. Except for Minna and Franziska, the participants in the encounters that take place in the inn are all residents of the city, even if only temporary ones, rather than travelers in the narrower sense. Furthermore, as I discussed earlier, the figures themselves make repeated reference to various urban institutions. Given the extent to which the inn is explicitly anchored in its urban setting, it makes sense to view the frequent visits, chance encounters, and informal conversations that occur there within the context of an emerging model of a spontaneous urban sociability. In other words, the nonregulated space of the inn can be understood as emblematic of the nonregulated character of the city itself. In the play, Lessing makes explicit reference to attempts on the part of the state to eliminate this independence by enlisting the innkeepers as informants. As the innkeeper remarks to his new guests shortly after their arrival, "we landlords are directed not to put up any stranger, no matter what his social class or sex, for more than twenty-four hours without handing in a report to the proper authority as to his name, his home address, character, the business which brings him here, the proposed duration of his visit, etc., etc." ${ }^{21}$ The reference to this practice, how- 
ever, which was common in late eighteenth-century Prussia, only serves to underscore the sense that the potential anonymity of the city posed a threat to social control.

In the case of Tellheim, a sense of disconnectedness has been forced upon him as a result of his discharge and the ensuing accusation of corruption. His unquestionable adherence to principle notwithstanding, he has a surprising amount in common with the marginalized rabble described in Gedike's essay. During his sojourn in the city he too is without productive employment, though certainly not as a result of laziness or immorality. Moreover, that he also finds himself "without fatherland" becomes clear at the end of act 4, when Minna makes a reference to Shakespeare's Othello. Tellheim, struck by the parallel to his own situation and in a temporary state of distraction, asks: "Oh yes! But tell me madam, how did the Moor enter Venetian service? Had he no fatherland? Why did he sell his strength and his blood to a foreign country?" 22 Finally, when one considers the cynical fatalism suggested by his laughter in this same scene- "the terrible laughter of the misanthrope" - his faith seems tenuous at best.

These references reveal the depth of Tellheim's psychological crisis, the loss of orientation triggered by the conflict between his societal obligations and his love for Minna. The crucial point here is that Lessing presents this crisis in such a way as to indicate its imbrication with the urban location where it occurs. After losing his room at the inn, which was already a space of impermanence and can itself be viewed as reflective of his psychic instability, Tellheim temporarily joins the rootless urban masses. The intensification of his psychological crisis, which begins with the arrival of Minna in the city, thus corresponds to his spatial displacement. At the risk of being anachronistic, one can argue that Tellheim finds himself in an "existential" situation, estranged from his previous subjectivity yet unwilling to renounce the principles on the basis of which it was constructed. And it is the city, itself a space of detachment and indeterminacy, that constitutes the most appropriate structural context for his crisis.

In Minna's case, the situation appears in a more positive light, but she too experiences the city in terms of a detachment. Following an accident with the coach, as we learn at the beginning of act 2, her uncle has decided to send her ahead to Berlin with her maid-in-waiting. Like Tellheim then, Minna finds herself in a state of newfound autonomy; she has been liberated - at least temporarily - from the external control of the patriarchal order repre- 
sented by her guardian. Considering the general eighteenth-century trend toward a female subjectivity defined in private and familial rather than public terms, it is striking that when Minna enters the city, she occupies none of the traditional gender roles. She comes to Berlin as neither mother, wife, nor daughter. Minna makes her independence clear in her response to the innkeeper's inquiries into her business in the city. She asserts, "I'm just here to look after my own affairs." 23

An unaccompanied, unmarried female traveler would have been extremely rare in late eighteenth-century Germany, and it seems plausible to view Minna's self-confident independence as an early reflection of what scholars have come to recognize as the emancipatory moment of travel, especially for women. ${ }^{24}$ This inflection of the travel motif, however, is inextricable from the urban space that serves as her destination. One can hardly imagine the kind of independence claimed by Minna existing anywhere but in a large city. It may be that Lessing is here again incorporating motifs from the contemporary discourse on Berlin into his work. In at least one journal article from the period, "Letter from a Traveler to the Warden of LB" (1779), the emancipated state of women in Berlin merits significant attention. Here the author remarks with admiration that in the coffeehouse he visited, "three women of the best reputation" enjoyed their coffee unaccompanied without causing the least disturbance. He then goes on to adduce this occurrence as proof of the liberal atmosphere of the city: "so you can conclude for yourself from this how free the way of life is here, without causing any offense to good manners or decorum." ${ }^{25}$

Admittedly, Lessing depicts Minna as hesitant to accept the full responsibility of her autonomy. She decides to postpone answering all of the innkeeper's questions until the arrival of her uncle. Moreover, the notion of the city as a site of liberation appears to be weakened by the very nature of this questioning, designed as it is to fix and classify her identity in terms of status and origins: "Fräulein von Barnhelm coming from her estates in Thuringia ..." ${ }^{26}$ One can, however, view this interrogation from a different perspective. The questions, which serve to mark Minna's entry into Berlin, simultaneously mark her distance from those origins. In other words, they reinforce the sense that she is not at home, that she finds herself in a temporary state of self-imposed exile. Again the city is represented as a site of detachment, as a space of otherness and nonidentity. Through her responses to the questions Minna externalizes her own subjectivity and confronts it as 
an outsider. Indeed, her evasion of the innkeeper's inquiries regarding her business in Berlin not only indicates a surprising level of worldliness for a young woman; it also suggests a heightened degree of self-consciousness, as she is forced to consider the wider political implications of her personal plans. In this respect, the scene offers one of several examples of a kind of self-estrangement and subsequent change in perspective that arises through social interaction in the city. The significance of this particular case lies in its explicit connection to the urban context, suggesting that the process is linked to the city itself.

Both characters thus experience the city in terms of a unique state of freedom, one that they confront with no small degree of apprehension. Both have been thrown back upon themselves, detached from any external determination of their behavior, whether by individual or institutional forces. Such a conception of the city is not without literary models in the eighteenth century. It figures in popular tales of seduction and elopement, in which the city serves as the preferred, indeed the only, hiding place for transgressive couples. In Minna von Barnhelm, however, rather than depicting Berlin simply as a site of deviance or as the source of a threat to the social order, Lessing presents it as providing the spatial-geographical prerequisite for an important reevaluation of previously held assumptions. Nowhere is this more striking than in the case of Minna's pretended disinheritance, which leads to a confrontation with Tellheim, which in turn gives rise to the change of heart mentioned earlier.

I should note at this point that the significance of Tellheim's transformation has been a source of enormous controversy in the secondary literature on the play. While earlier analyses tended to frame his change of position in terms of the renunciation of a feudal concept of honor, some more recent interpretations have pointed out that his rediscovered obligation to marry Minna is just as much a question of honor as his previous refusal. ${ }^{27}$ In both instances, so the argument runs, his position represents a predictable and reasonable response to external circumstances. Thus Tellheim cannot really be said to have changed as a result of Minna's deception. Hans-Georg Werner makes the following observation in this regard: "What does the intrigue accomplish? Certainly not a transformation of Tellheim's character, an 'improvement' of his principles. For Tellheim simply behaves as expected, but he is thereby able to demonstrate to the public his capacity for love and his capacity for action." ${ }^{28}$ Such an interpretation oversimplifies the situation. 
Most importantly, it ignores Tellheim's own account of his transformation, which he describes as follows: "What has happened to me? My soul is newly inspired. My own misfortune cast me down, made me angry, shortsighted, shy, indolent. Her misfortune raises me up again. I look around again as a free man and feel the strength and the will to undertake everything for her. . . Why am I waiting?" 29 In Tellheim's opinion at least, a change has occurred, one that he presents here in terms of a self-alienation that has allowed him to recognize his previous self-absorption and has renewed his faith in the possibility of action. To be sure, this reassertion of his commitment to Minna is also a matter of honor, but there has been an important shift in the emotional motivations driving his behavior. Rather than the "stifled rage" he describes later in act 5, it is now his love for Minna, reawakened by an experience of sympathy, that determines his conduct.

This emotional transformation does not mean that honor as principle has been displaced by something else, but it does reveal to what extent his single-minded obsession with honor reflects a severe imbalance in his emotional economy. ${ }^{30}$ In this regard, Minna is right when she describes him as one of those men "who can fix their eyes on nothing but the ghost of their honor and who steel themselves against any other feeling!" 31 His behavior is characterized by emotional rigidity, coupled with an a priori rejection of the validity of any perspective on his dilemma other than his own. In refusing to marry Minna, he may be acting in her own best interest, but his need to be in complete control of the situation ends up denying her any right to participate in the determination of their mutual fate. In their conversation in act 4, for example, he shows a remarkable insensitivity toward his fiancée, dismissing all of her arguments as the product of "blind tenderness" and insisting on his irrefutable decision-making authority: "[B]ut since I still have some sense left, listen, madame, to the firm resolve which I have made and from which nothing in the world shall shake me." ${ }^{32}$ Minna's intrigue both reawakens Tellheim's sense of compassion and forces him to acknowledge his own dependence upon her.

Thus one can accept the claim made by Peter Michelsen and others that Tellheim's change of heart entails no fundamental change in principle, and that the honor that grounds his refusal forms the very basis of civil society in eighteenth-century Germany, and still acknowledge that his emotional architecture undergoes a radical change for the better as a result of Minna's actions. Michelsen himself, who has written the most compelling critique of 
class-based interpretations of the play, agrees that Minna's intrigue, through its activation of his capacity for pity, has a reformative effect on Tellheim. As he observes, "[The intrigue] does not change the circumstances, but it has a regenerative impact on him through the activation of sentiment; he regains his belief in the possibility of a positive outcome." ${ }^{33}$

Taking recourse to the vocabulary of the Enlightenment, I would argue that the autonomous space of the city has allowed Tellheim to regain his own autonomy. Whereas he had been forced by the accusation against him into a position of passive resistance to an external authority, Minna's intrigue reawakens his belief in the possibility of independent action, however desperate that action may be. Significantly, however, the autonomy achieved here results not from rational deliberation along Kantian lines but from an aesthetic experience. Tellheim's transformation is occasioned by Minna's role play, staged by Lessing as a drama within the drama, complete with the maidin-waiting Franziska as critical audience. Thus, I would argue that the liberation that characterizes the city has important implications not only for our understanding of the play but also for our understanding of Lessing's aesthetic theory.

The link between Tellheim's change of heart and Lessing's theory of drama becomes clear in the protagonist's description of his transformation: "Vexation and stifled rage had clouded my whole soul. Love itself in the fullest splendor of good fortune could not dispel the gloom. But love sent her daughter, Pity, who being more familiar with the blackness of pain, dispelled the clouds and opened my whole soul once again to impressions of tenderness." ${ }^{34}$ The pity or compassion (Mitleid) that has reawakened his will to live is crucial to Lessing's understanding of the social function of tragedy. In the context of the Correspondence on Tragedy, written together with Mendelssohn and Nicolai in 1756 and 1757, Lessing develops an affective ethics in which he posits the ability to feel sympathy as the basis of humane behavior. Inverting traditional interpretations of the Aristotelian notion of catharsis, Lessing claims that tragedy "should expand our capacity to feel pity." ${ }^{35}$ Such an expansion is precisely the result of Minna's role play. In Minna von Barnhelm, then, Lessing has staged a mock tragedy (Minna's pretended disinheritance) within the larger comedic framework; moreover, the cathartic effect of this tragedy makes the positive outcome of the comedy possible.

Lessing presents the possibility of staging this drama as a function of the nonregulated urban space. Minna's ability to stage her deception derives 
from the state of freedom in which she finds herself. It is hard to imagine how she could have carried off her pretended disinheritance in the presence of her uncle. It is also hard to imagine a similar deception taking place in any of the other locations in which Tellheim and Minna might have confronted one another, whether in the private sphere of the family estate or the public forum of courtly society. Behavior in both cases would have been to a large degree pre-scripted. Even if the familial sphere comes to be viewed in the eighteenth century as the privileged locus of emotional authenticity and spontaneity, a development reflected in Lessing's own works, it nonetheless possesses its own set of behavioral norms. The city, however, appears to constitute a uniquely neutral space.

Taking this important connection between the nonregulated nature of urban space and Minna's freedom to stage her role play into account, we can make the following observation on the work: the structural autonomy created by the urban environment serves as the backdrop for a dramatic performance (Minna's) that in turn results in Tellheim's embracing of a subjectivity defined by its capacity for sympathy and love. Lessing's play thus allegorizes the aesthetic theory upon which it is based, according to which aesthetic experience leads to moral improvement through the cultivation of a crucial emotional capacity. Moreover, because this experience as presented within the play presupposes Minna's autonomy, Lessing would seem to be making an implicit argument for the autonomy of the aesthetic, and, even more important, to be linking this autonomy to the structural conditions that obtain in the city. In other words, the rise of autonomous art as a moral force intertwines with the rise of the city as an independent entity, one distinct from both the court and the emerging sphere of middle-class intimacy.

In a sense, Lessing's play suggests a reversal of the relationship between public and private sphere often attributed to the eighteenth century in general and to Lessing in particular. Rather than endorsing what Wolfgang Albrecht has described as a "private humanity" that serves as the "essential precondition for bringing about a more humane and reasonable public or society in general," ${ }^{36}$ Minna von Barnhelm posits a transformative "public" encounter as the foundation for the domestic bliss that finally appears on the horizon with the arrival of Minna's uncle, the Graf von Bruchsal. This is not to say that the opposition between a privately grounded, natural humanity and the selfishness and artificiality of courtly life does not figure into Les- 
sing's works; one need only think of the stark contrast between the court and the home in his tragedy Emilia Galotti. In the present context, however, Lessing does not link humanization with the private sphere of the family, at least not directly. On the contrary, the process takes place in a quasi-public space - that of the inn. Moreover, Lessing foregrounds the public character of the setting in numerous ways, from the constant coming and going of the various actors to the presence of Franziska as a critical audience for Minna's role play in act 5 . Act 2 even underscores this publicness through a subtle instance of comic self-reflexiveness, when, in response to Tellheim's reluctance to speak his mind in the presence of the innkeeper, Minna comments: "What a lot of fuss! Why shouldn't the whole world hear what we have to say to one another." ${ }^{37}$

Admittedly, such a reading of the play constitutes a bit of an oversimplification. In the first place, the relation between public and private in the work is more complex and dialectical than is indicated by the hierarchy offered here. The "public" encounter between Tellheim and Minna not only presupposes the existence of a humane domestic sphere from which Minna emerges; it is also driven by love, the quintessential concern of middle-class intimacy. Moreover, the play ends with an apparent reinsertion of the two main characters into the private-familial sphere. After Minna's uncle arrives and the confusion has been sorted out, the future that appears most likely is the one described by Tellheim earlier in act 5, lived out in the "most peaceful, pleasing, and delightful corner, which has all that is needed for a true paradise except a loving couple." ${ }^{38}$ Nonetheless, it does seem that the city serves in the play as a kind of third space, neither private, in the sense of the intimate familial sphere, nor public, in the sense of the courtly "big world" that Tellheim denigrates in his dialogue with Minna at the end of act 5. Furthermore, through the self-referentiality suggested by Minna's role play, Lessing links this third space to a particular kind of aesthetic experience, made possible through the autonomy of the urban setting and linked to the stimulation of humane sentiment.

What complicates the situation even more is the fact that the aesthetic imperative embodied by Minna appears in a decidedly ambivalent light. Having successfully stimulated Tellheim's sense of sympathy through her pretended loss at the end of act 4, she then proceeds to carry the ruse too far. Even after Tellheim has received the royal dispatch restoring his fortune and reputation, Minna refuses to abandon her deception, claiming that now 
her poverty and diminished reputation make a union impossible. From the perspective of the aesthetic defamiliarization mentioned earlier, it is interesting to note that Minna's argumentation in this scene involves an at times word-for-word repetition of Tellheim's previous grounds for being unable to marry her. She thus forces him to consider familiar material from a different perspective, but here the result is not a reevaluation of a previously held position. On the contrary, her intrigue nearly spins out of control, when, as a result of a chance combination of circumstances involving their engagement rings, Tellheim mistakenly comes to the conclusion that she has come to the city with the intention of breaking off their engagement. Lessing cuts this drama short, however, allowing the two to be rescued by Minna's uncle, the Graf von Bruchsal, whose arrival forces a hasty resolution of the matter.

Thus the results of what I would call the play's experiment in Mündigkeit are ambiguous. Whereas, on the one hand, the autonomy made possible by the city constitutes the structural precondition for a self-estrangement that can open up new perspectives and create new possibilities for action, this same autonomy also creates the possibility of an immature subjectivity run wild. Temporarily emancipated from the restraining influence of her uncle, Minna nearly destroys the hope of domestic bliss that she has come to the city to regain. This subnarrative in the play is well suited to a gendered reading, according to which the transformative power of the feminine is first represented as a necessary stimulus to change and then reinscribed within a patriarchal order, as Minna willingly renounces her independence and prepares to reenter the domestic sphere as wife and daughter. Returning to the scene in which she confronts Tellheim with his own arguments, we can view this act as the ultimate female transgression, in the sense that Minna here appropriates a cold, uncompromising, and characteristically masculine rigorism. What could pass for exaggerated adherence to principle in Tellheim's case appears as "unnatural" behavior on the part of Minna. In presenting this scene, Lessing clearly frames the confrontation in terms of gender. In response to Minna's taunting question, "Surely you don't dare deny your own words when they come from my lips?" Tellheim responds by accusing her of sophistry and asking rhetorically: "Will the weaker sex be dishonored by everything which is unsuited to the stronger?" 39

From this perspective, it seems that Lessing does indeed share some of the apprehension expressed by his contemporaries in the essays on city life discussed earlier. It would appear that gender-based standards for behav- 
ior serve as a "natural" limit beyond which the autonomy made possible by the urban context ceases to be productive and instead becomes a threat to stability. As we saw in the essays by Gedike and Zöllner, it was precisely this potential for emancipation taken to an "unnatural" extreme, albeit presented in terms of class rather than gender, that constituted the danger posed to the social order by the nonregulated space of the city. As a site of detachment from established systems of social control, the city creates the conditions of possibility for overcoming particularism and social convention, even for one's elevation to the enlightened perspective of "pure humanity." This path of liberation, however, can quickly turn into a slippery slope. In the absence of the restraining influence of the "natural" authority of the patriarchal family - here embodied by the Graf - it threatens to degenerate into a destructive chaos.

\section{The View from Berlin}

The progressive potential of the urban experience in Minna von Barnhelm derives from its function as a catalyst of emancipation, both from one's own past and, in the best case scenario, from the prejudices that are associated with it. In itself, however, this emancipation represents only half of the model of an urban enlightenment that takes shape in the play. The learning process for which it prepares the individual depends on exposure to new ideas that can replace those abandoned as obsolete. In the play, these new ideas are not acquired through access to some fixed body of knowledge with allegedly timeless validity; they are generated through spontaneous social intercourse. The numerous moments of insight that are depicted in Minna von Barnhelm result from an immediate encounter with new perspectives, in which characters come face to face with the limitations of their own subject positions and progress to a higher level of understanding. The centrality of such confrontations suggests another connection between the play and eighteenth-century conceptions of the metropolis. Eighteenth-century texts on city life repeatedly stress the salutary impact of the exposure to new and opposing perspectives as a means of achieving truth. Because of its multiperspectivity, in other words, the city comes to be viewed as a privileged site for the intersubjective generation of truth through a productive confrontation of ideas. To the extent that an identical epistemological ideal is operative 
in Minna von Barnhelm, it raises the possibility that the play's urban roots extend even more deeply than the discussion of the plot has suggested.

Scholars have repeatedly adduced the perspectivism of Minna von Barnhelm as a key component of the play's break with the young Lessing's more formulaic comedies of type. Walter Hinck, for example, has remarked on the "differentiated social structure" reflected in the dramatis personae, seeing in the complex representation of social reality a distinguishing characteristic that separates the play from an earlier comedic tradition. ${ }^{40}$ Others have called attention to the diversity of moral perspectives presented by these socially diverse characters, each of whom occupies the position of authority at some point in the drama without ever becoming the unquestioned representative of a morally superior point of view. So, for example, Minna's reflections in act 4, scene 3, reveal the callousness of Franziska's treatment of Riccaut, but, by the same token, Franziska correctly calls Minna's own moral credibility into question when she points out the "self-love" at the root of her plot to deceive Tellheim. Hans Georg Werner writes in this regard: "Every character, to the extent that he or she is proven right, relativizes the others' claims to authority: Minna Tellheim just as much as Tellheim Minna. This also holds for the remaining characters: Just-Tellheim, Just-Werner, JustFranziska, Franziska-Minna, Franziska-Just, Franziska-Werner, TellheimWerner." ${ }^{41}$ One could adduce numerous specific examples to support this claim. In a similar vein, Georg Lukàcs describes the "up and down of moral right and wrong" as the play's compositional principle, seeing in its nonhierarchical, contrapuntal structure a parallel to the music of Mozart. ${ }^{42}$

The author's decision to grant moral authority to a wide range of individuals from varying social classes certainly constitutes one of the central social achievements of Minna von Barnhelm, and, as Hans Georg Werner points out, it was by no means uncontroversial at the time. ${ }^{43}$ Lessing's foregrounding of the collisions between opposing viewpoints in the play, however, together with the ever shifting locus of authority, also entails an epistemological argument. Time and again, Minna von Barnhelm both reveals the degree to which perception is conditioned by subject position and demonstrates the necessity of viewing events from a variety of angles. At times the subjective nature of perception is made explicit, as when Franziska points out Minna's predisposition to see everything through the lens of her relationship to Tellheim. When, in response to a comment by Franziska, Minna claims that the former's remark "has a lot to do with my Tellheim," Franziska 
responds with the query: "Do you ever come across anything that doesn't have some connection with him?" ${ }^{44}$ And later, in the much discussed Riccaut scene, Minna explicitly constructs an interpretation of the Chevalier's behavior that stands in direct opposition to the negative - and admittedly more plausible-interpretation offered by her maid-in-waiting. Here the word choice makes the question of perspective all the more apparent. Minna claims: "My dear girl, you have such sympathy for good people, but when are you going to learn to put up with the bad ones? After all, they are people too ... and often not nearly such bad people as they seem to be. You simply have to find their good side." ${ }^{45}$

Undoubtedly, the controversy surrounding Riccaut in the literature on Minna von Barnhelm, a controversy already apparent in the initial reviews of the play, is due in part to the fact that Lessing preempts a definitive reading by offering a variety of interpretations through his own characters, none of which receives clear confirmation. The obvious disdain with which Tellheim speaks of Riccaut in act 4, scene 6, would seem to confirm Franziska's negative reading of his character, and yet Tellheim's information is later revealed as only partially accurate. While he is correct in questioning Riccaut's claim to have information from an important minister, he is wrong to doubt the accuracy of his message. Riccaut remains an enigmatic figure; his real motives for visiting Tellheim are never revealed. His significance for the play is also open to interpretation, but one of his functions is certainly to reinforce the notion that individual perceptions are necessarily perspectival and thus imperfect. Neither Franziska, nor Minna, nor Tellheim is really incorrect in his or her judgment of Riccaut; it is simply that none of them has the full story.

Of course, the question of perspective figures prominently in a whole range of eighteenth-century discussions, from more narrow art-historical debates over the use of perspective in Greek painting, to broader philosophical considerations related to such key Enlightenment concepts as prejudice and particularism. ${ }^{46}$ With regard to Lessing in particular, an emphasis on multiple perspectives and the concomitant need for a dynamic, dialectical approach to epistemological problems has come to be viewed by many as the author's intellectual signature. ${ }^{47}$ Indeed, the relentlessly dialectical quality of Lessing's thought was already thematized in the eighteenth century by his friend Friedrich Nicolai, who describes the author's intellectual character in precisely these terms: "Lessing, when he was in Berlin, often served 
as the third in our philosophical discussions, and he made them even more lively. This was because it was his custom in arguments either to adopt the weakest position, or else, whenever anyone presented the pro, to immediately, and with remarkable perceptiveness, search for the contra. . . . This tendency in Lessing was not the result of a love of contradiction, but rather an attempt to develop more clear and definite concepts by considering them from several different sides; because he was convinced, as we all were, that in the realm of philosophical speculation the truth once found is not as valuable as the exercise of the mind in the attempt to find it." ${ }^{48}$ In light of the significance of perspectivism for both the period in general and Lessing in particular, any attempt to link the specific manifestation of this phenomenon in Minna von Barnhelm to the play's urban setting calls for a degree of caution. Upon reading through essays from the period on Berlin and on the big city in general, however, one is struck both by the centrality of this concept to representations of urban life and by the parallels to Lessing's work. One wonders whether the play's own structure, with its implicit admonition to transcend the limits of what Volker Nölle has termed our "subjectively colored seeing," cannot in fact be read as an urban moment. ${ }^{49}$ Considered within the framework of the eighteenth-century urban discourse, which repeatedly stresses the city's perspectival character, both the play's dialectical composition and its complex representation of social reality appear in a new light.

Circumstantial evidence for this interpretation is easy to find. One of the earliest expressions of interest in the city as a site of progressive perspectivalism appears in Nicolai's contributions to the Letters concerning the Most Recent Literature. Here, it will be remembered, Nicolai argues that the coming of age of German drama presupposes the centralizing influence of a capital city. For Nicolai, the cosmopolitan character of the metropolis, the exposure to new ideas and new viewpoints, enables the playwright to overcome his own subjective limitations and produce works with universal rather than merely regional appeal. According to his argument, anyone who has been exposed only to those ideas available in a provincial city or a university town can never be a successful author. Nicolai's representation of the city as a universalizing space is grounded in a conception of the perspectival character of big-city life: only through the immediate exposure to the multiplicity of perspectives available in the metropolis can the dramatist grasp the diversity of human experience and reproduce it in his works. 
Within this context, it is interesting to note that the cosmopolitan, universal quality of Minna von Barnhelm constitutes a central focus in contemporary reviews of the play. The author of a 1767 review from the Berlinische Priviligierte Zeitung, for example, writes: "One can see that this comedy comes to us from the world and not from the study." 50 Another reviewer remarks that the play differs from its predecessors in that "it has more of the tone of polite society." ${ }^{51}$ Yet another praises Lessing for his perfect mastery of "the different ways of speaking of the higher and lower estates." 52 Finally, in a 1768 letter to Johann Wilhelm Ludwig Gleim, the Berlin poet Anna Luise Karsch describes Lessing's unique achievement with Minna von Barnhelm as follows: "Before him no German author had been successful in instilling both the noblemen and the common people, the learned and the laymen with such enthusiasm and pleasing them so thoroughly." ${ }^{53}$ In all of these reviews, the emphasis is on Lessing's ability to represent and appeal to "the world" in its entirety, on his ability to draw precisely those universally appealing characters that Nicolai, in his early critical writings, had linked to the diversity of the metropolitan experience. To be sure, this universalism is articulated in national terms. Even before Goethe's famous claim in Poetry and Truth that the work perfectly captures "the substance of the North German nation," contemporary reviewers already described the characters as "completely German" and the play itself as "a true original, in which everything is German." ${ }^{54}$ As Nicolai maintains in his early writings, however, it is precisely this authentic national character, which appeals to all Germans regardless of their regional affiliations, that finds expression in the culture of the capital city. ${ }^{55}$

In its advocacy of a metropolitan dramaturgy, then, Nicolai's opposition between provincial pedantry and the universalism of the big city would seem to have particular relevance for Minna von Barnhelm. Nonetheless, it offers only one example of a widespread eighteenth-century association of the city with the exposure to diversity and a corresponding expansion of personal horizons. In the case of Berlin, even descriptions of its outward appearance play up the city's multiple, often incongruous identities. Eighteenthcentury commentators stress Berlin's architectural (and social) oppositions, contrasting the "beautiful, wide streets" characteristic of the Friedrichstadt to the "miserable alleys" and "miserable, ramshackle houses" that confront those arriving through the Hamburger, Silesian, and Kottbusser gates. ${ }^{56}$ Indeed, one of the recurring motifs in these representations is an emphasis 
on the radically different impression one receives of Berlin, depending on the gate through which one enters the city. Some writers view these incongruities as part of Berlin's appeal: "It is interesting to find everything together in this city, from the royal palace to the peasant's barn. Berlin is capital city, royal residence, manufacturing center, trading city, provincial city, village, and farm - all together within a single city wall. If one no longer wishes to hear the thunder of the coaches, he can leave the city center and hear the rattle of the wool, silk, and linen looms. If he tires of this noise as well, then he can go to the Weidendamm and feast his eyes on the fresh green of a meadow." 57

More significantly for our purposes, the multifarious character of the city also manifests itself in the daily life of its residents, who, if we are to believe the reports, find themselves in an environment characterized by an unusual level of interaction among the various social classes. Particularly in Berlin's many societies and clubs, one finds "the most colorful mixture of all the estates, without stiff ceremony, without any order of rank." 58 According to Gedike, it is precisely the resulting mixture of viewpoints that prevents one from falling victim to intellectual rigidity: "Only in this way is it possible to avoid narrowness and pedantry; one learns to consider a thing from several points of view and hears the most diverse judgments of it." 59 Whereas Gedike associates this experience of enlightenment with a process of rational discussion and debate, other representations of the city stress a more nonreflective, aesthetic version of this intersubjective learning process. As we saw in Zöllner's "Contribution," for example, the dynamism of big-city life - the constant exposure to the foreign and the new, the mixing of classes - necessarily leads to both a greater tolerance for diversity and the ability to discern patterns within this diversity, to recognize "man in all his forms and ornaments." ${ }^{60}$ Here as well the exposure to multiple perspectives in the city makes possible the achievement of a higher perspective. Moreover, the same urban dynamic that fosters this ability also leads to a recognition of the shortcomings of one's own position and a desire for selftransformation, albeit one that arouses the author's suspicion. According to Zöllner, "everything intersects in a hundred different ways; one can neither remain what one is, nor can one become the same as another." ${ }^{61}$ Perhaps Zöllner's recognition of Lessing's interest in these very same phenomena motivates his earlier remark in the essay: "Whoever reads Shakespeare's, Molière's, Lessing's plays, even without having heard a single syllable about 
the lives of these men, knows one circumstance of their lives for certain: that they breathed the air of some large city." ${ }^{62}$

His admiration for Lessing notwithstanding, Zöllner views the dynamism of the city partly within the framework of a Rousseau-inspired critique of civilization. The social mobility of the urban environment constitutes a threat to the "natural" social order; the pace of city life hinders serious intellectual work; and the predominance of the human over the natural interferes with authentic religious sentiment. Nonetheless, Nicolai's, Zöllner's, and Gedike's texts all focus on the city as a place where truth is generated intersubjectively through a productive confrontation between multiple perspectives. As I have tried to demonstrate, this same epistemological model drives the plot in Minna von Barnhelm, suggesting that the perspectival composition of the play can be seen as a kind of sedimentation of its urban content. Not only does the drama unfold in Berlin; its basic compositional principle would seem to be indebted to an urban model of human interaction.

An investigation of the interrelationship between perspectivism and the function of money in Minna von Barnhelm lends support to this interpretation of the play. Even if one remains at the level of the plot, an urban reading of the play's obsession with financial matters certainly seems plausible. Not only has the city been understood generally as the seat of the money economy; the documented significance of Berlin's role in the financial crisis following the Seven Years' War also indicates a historically specific connection. ${ }^{63}$ The centrality of money to the work has been noted by virtually all commentators; as Hinrich C. Seeba writes, "Nowhere else do individual sums of money - deposited and released, advanced and repaid, play as much of a role as they do here." ${ }^{4}$ And Joachim Dyck describes money as "the actual social subject" of the work. ${ }^{65}$ Opinions on how to interpret this state of affairs, however, have been radically divergent. Whereas many have seen Lessing's treatment of money in both Minna von Barnhelm and elsewhere (especially in Nathan the Wise) as a critique of the emerging, exchange-based bourgeois society, others have seen in it an affirmation of that same society. ${ }^{66}$ What interests me at present, however, is less the implication of money's ubiquitous presence for the play's socially critical content than the way in which financial concerns structure the drama or, more precisely, the relation between money and the compositional principle of perspectivism that I discussed earlier. 
The impact of money as represented in the play is ambiguous, even paradoxical. For Minna and Tellheim, it functions simultaneously as the catalyst and the inhibitor of love. In the case of the innkeeper financial concerns are paramount, leading him to view human beings solely as objects of rational calculation. For Werner, money serves as a means for the expression of true friendship. What is common to virtually all representations of money in the play, however, is that it serves as the medium for an articulation of subjectivity. This is not to say that money itself has the power to mold subjectivity ${ }^{67}$ On the contrary, Lessing seems intent on demonstrating the inability of money to change a person's basic nature. ${ }^{68}$ Tellheim, for example, despite his extreme poverty, refuses to accept repayment from Marloff's widow (or anyone else, for that matter). Nonetheless, the strengths and limitations of a character's subject position, both in terms of temporary fluctuations of passion and fundamental personality traits, are revealed almost exclusively through his or her relation to money. In other words, the money economy, a quintessentially urban phenomenon, functions in the play as the vehicle of characterization, and thus as the vehicle of perspectivism. Tellheim's generous character, as well as his intellectual inflexibility, is illustrated through his relationship to money. Minna's irrational exuberance upon hearing that Tellheim is nearby is manifested in an attempt to give away money. Just's boorishness as well as his loyalty become clear in his refusal to accept a bribe from Franziska. Both Werner's recklessness and his capacity for real friendship reveal themselves in his decision to sell his newly acquired property. Along the same lines, money (or lack thereof) serves as the primary motor for the productive confrontations between perspectives that occur in the play: Minna's claim of poverty and its subsequent effect on Tellheim are only the most obvious examples.

The city, then, serves in the play as the locus of circulation and exchange, both of individuals and of money; indeed, the two appear intimately related. Rather than a source of "indifference to genuine individuality," however, as Georg Simmel claims in regard to the twentieth-century metropolis, here circulation actually enables the articulation of subjectivities and thereby fosters the recognition of diverse perspectives, both within the fictional world of the work and vis-à-vis the reading or viewing public. In Minna von Barnhelm, the urban environment can be seen as a kind of spatial metaphor for an epistemological imperative, one that posits the constant exposure to new, often contradictory viewpoints as the only source of truth. At the same time, 
the choice of metaphor would seem to have its basis in the actual understanding of the dynamics of late eighteenth-century urban life.

\section{Perspectivism and Historicity}

This epistemological imperative implicit in the play's perspectivism returns us, finally, to the relationship between city and history. Minna von Barnhelm speaks to this relationship on a variety of levels, but the most fundamental connection arises from the play's depiction of sociability as a source of knowledge. By repeatedly relativizing the truth claims of individual figures, Minna von Barnhelm devalues notions of an ahistorical, decontextualized reason in favor of one that is "embodied," experiential, context-bound. Objective truth is by no means abandoned as a goal, but it emerges only as the result of an intersubjective process, one that gives rise to a level of awareness unachievable by the individual on his or her own. Learning occurs through experience, on the basis of an imaginative leap resulting from an actual confrontation with an alternative viewpoint, rather than through the assimilation of a fixed body of correct knowledge.

The epistemological model operative in the play, in other words, posits historical experience rather than abstract reason as the source of truth. As a site of competing perspectives, each of which is revealed at some point in the drama as inadequate, the urban environment fosters an awareness of the historical contingency of knowledge. In this regard, Minna von Barnhelm participates in the more general eighteenth-century acknowledgment of the historical variability of certain kinds of truth. Rather than calling for sensitivity vis-à-vis the evaluation of past ages, however, the play's perspectivism demonstrates the need to recognize the provisional character of the suppositions that guide individual behavior. This depiction of the city as a site of a practical insight that forces a revision of previously held assumptions is familiar from Nicolai's Sebaldus Nothanker, where the protagonist's entry into Berlin marks the abandonment, or at least the temporary repression, of his obsession with speculative philosophy. Lessing's endorsement of historical-empirical as opposed to abstract knowledge appears at various points in Minna von Barnhelm, but it is most strikingly represented in the conflict between Minna and Tellheim, each of whom can be seen as the representative of a particular epistemological position. 
Tellheim's principle of honor functions as an abstract ethical norm that operates independently of experience. However one interprets it from the outside, whether as the essence of a historically obsolete value system or as an appropriate response to historical conditions, within the context of the plot it operates ahistorically. Tellheim's honor admits of no compromise; it has become for him a kind of first principle that predetermines his response in any particular concrete situation. In the case of his meeting with the widow of his former captain Marloff, where he refuses to accept the repayment of a debt despite extreme need, his commitment appears in a positive light. In the case of his refusal of Werner's offer of financial assistance, it causes him to appear unnecessarily stubborn. In the case of his refusal of Minna, however, his rigid behavior borders on the inhumane. Tellheim's relations with the human world have become reified. His decisions and actions have lost any connection to experience, taking on the character of objective necessity generally associated with the immutable laws of nature. Unlike Lessing himself, who always insisted on the provisional validity of knowledge and placed the search for truth above all else, Tellheim believes that he has taken possession of it, and he behaves accordingly.

The potential inhumanity of an inflexible adherence to principle emerges as a theme in several of Lessing's plays; one need only think of the Partriarch in Nathan the Wise or the protagonist of Philotas. In Minna von Barnhelm, this inflexibility is opposed to the situation-specific ethics of Minna herself. In contrast to Tellheim's enslavement to an abstract ethical principle, Minna's decisions derive from her emotional, one could even say immediate physical, response to concrete situations. Whether triggered by her enthusiasm about finding Tellheim in Berlin, her sympathy for the gambler Riccaut, or her frustration with Tellheim's stubbornness, hers is an ad hoc ethics of spontaneity, driven by intuition but in harmony with reason nonetheless. As Georg Lukàcs writes of what he terms Minna's "wisdom," "it is not a theoretical superiority, just as it is not dead abstraction in the case of Nathan; it originates rather in a deep and deeply reflected life experience." ${ }^{69}$ This is not to say that Minna's judgment is flawless; her refusal in act 5 to end her deception before it spins out of control nearly leads to catastrophe. Nonetheless, her situational ethics, based on an unshakable confidence in the possibility of a happy and fulfilling life, appears in the play as decidedly superior to Tellheim's fatalistic rationalism.

Triggered by a historically concrete experience of sympathy, Tellheim's 
change of heart liberates him from the pessimistic fatalism that has convinced him of the impossibility of substantive historical change. This fatalism appears in various guises in the play: in his passivity upon being forced out of his room by the innkeeper, in his unwillingness to accept Werner's money as a means to improve his situation, and in his misanthropic laughter at the end of act 4. Perhaps its most striking manifestation is Tellheim's proclivity for ritualized, formulaic speech, which serves as a kind of linguistic marker of his position outside of history. A similar argument can be made in regard to his palpable fear of losing his resolve when actually forced to converse with Minna and his compulsive insistence that she read his letter, an allegedly incontrovertible treatise produced after a long period of rational deliberation. In his preference for the textual over the oral and his proclivity for sententious statements, with their alleged quality of timeless universality, Tellheim is linked to an ahistorical epistemology. The aesthetic experience occasioned by Minna's intrigue explodes this fatalism; it creates a situation that allows Tellheim to look to the future with renewed hope. The link between past and future that had been disrupted by the war is reestablished. Minna's pretended misery liberates Tellheim from a belief in the impossibility of positive change and reinserts him into a historical narrative with an open future.

The confrontation between competing perspectives in the urban context thus also gives rise to dialectical tensions that can serve as the motor for progress. Admittedly, Lessing appears in Minna von Barnhelm to be more interested in individual improvement than in any global teleology. But the complex model of social interaction depicted in the play, which gives rise to a learning process that cuts across class and gender boundaries, suggests that the improvement depicted here has implications on a more general level. It is important to recognize that this model represents knowledge as the result of spontaneous encounters within a network of individuals whose authority is basically equivalent rather than as something handed down to the ignorant from omniscient experts. Each of the players possesses a piece of the truth, but only by combining the parts can one gain a sense of the whole. Hans Blumenberg has written in a somewhat different context that precisely this disposition to participate in the generation of "transsubjective" knowledge serves as the precondition for the modern idea of progress. ${ }^{70}$

More difficult to reconcile with the claim of progress from within is the double deus ex machina that ends the play. Both the arrival of the letter 
from the king and the arrival of Minna's uncle can be seen as eschatological moments in the drama. As events that break into the autonomous urban space from the outside, they undermine the model of an authority that is immanent, contingent, and intersubjectively determined through interaction between equals. In a sense, the positive outcome of the play can be said to confirm Tellheim's fatalistic world view, except that the fatalism that seems appropriate in light of the final developments is of an optimistic rather than a pessimistic variety. The implication is that there was no need to worry, because divine providence was in control all along. One can perhaps argue that the authority of the absolutist order is called into question, inasmuch as the king's letter fails to resolve the conflict between the lovers, but the arrival of the Graf von Bruchsal clearly puts an end to the characters' experiment in self-regulation. Any endorsement of intersubjectively determined, historically contingent truth that has been articulated through the representation of the city would appear to be subordinate to the timeless validity of the patriarchal family order. This tension between a belief in the timeless truths of "nature" or reason and the recognition of the historical determinants of knowledge and behavior is, of course, central to Enlightenment thought, so it is not surprising that a similar tension should inform Minna von Barnhelm. That Lessing reproduces this tension in his work, moreover, does not detract from the fact that it is the city, as opposed to both the court and the country, that appears here as the space of this historical contingency. Indeed, perhaps the double reversal that caps the drama can be read as a final example of this contingency, as both Tellheim and Minna find themselves overtaken by historical events.

The urban perspectivism of Minna von Barnhelm has historical implications on a much more concrete level as well. The play does, after all, reflect on a specific historical occurrence - the Seven Years' War - and the confrontation between competing viewpoints that characterizes the play as a whole also characterizes the representation of this event. The war is at once a source of misery (for Marloff's widow), of opportunity (for Werner), and of vicarious pleasure and news (for Minna and Franziska) and a disruption of business as usual (for the innkeeper). In some cases it elicits multiple, seemingly contradictory interpretations from a single figure. So, for example, Minna heaves a "sigh against peace" in act 2, scene 1, lamenting the fact that Tellheim has only written her once since the end of the war. Furthermore, as becomes clear over the course of the play, the war made her relationship to 
Tellheim a reality in the first place, not just because it brought them together physically but also because it created the conditions in which Tellheim was able to reveal his generosity and thus win her admiration and love. And yet it is the culture of the military that fosters the obsession with honor and reputation at the root of Tellheim's inflexibility. Even more important, the financial and social chaos that characterizes the aftermath of war threatens to destroy any possibility of marital bliss for the two lovers.

One wonders to what extent Lessing conceived of Minna von Barnhelm as a kind of alternative to more one-dimensional, heroic, officially sanctioned accounts of the war, one that addressed (though not exclusively) its negative consequences for the individual. From a literary-historical perspective, the play's focus on the chaotic aftermath of the event certainly constitutes a departure from the panegyric war literature that had become modish in the period, from Gleim's War Songs to the various sermons given in commemoration of Friedrich II's final victory. ${ }^{71}$ And such a project would be in line with Lessing's own statements on the subject. In a letter to Johann Gotthelf Lindner from December 30, 1759, for example, he refers bitterly to the "disastrous war," which had been a source of great personal disappointment for him and a catastrophe for thousands of others. ${ }^{72}$ Perhaps the play can be seen as the "settling of accounts" with the Prussian king that Lessing ironically refers to in a letter to Ramler from June 18, 1757. Here he claims that he will simply wait until the onset of peace "to settle [the bill] with him in one way or another." ${ }^{73}$ Even Karl Lessing insists on the critical agenda of the play in his 1793 biography of his brother, claiming that the author wanted to call attention to the unjust treatment of the "free batallions" who lost their commissions after the end of the war despite valuable contributions to the Prussian war effort. ${ }^{74}$

As a demonstration of a critical historiography, then, the play can also be seen as part of the eighteenth-century turn toward history as a tool of social criticism. Whatever conclusion one comes to regarding the estatist character of Tellheim's honor, the drama clearly depicts the war from the standpoint of emerging middle-class values, excluding feats of military prowess and highlighting its impact on human relationships. Within this context, it is noteworthy that only the arrival of the Graf, the representative of the "middle-class" family, and not the letter from the king, the representative of the military aristocracy, leads to a final resolution of the conflict. Also central to the play's revisionist approach to the war is its obsession with eco- 
nomics. Lessing not only foregrounds the economic consequences of the conflict but also makes it clear that Minna's initial infatuation with Tellheim arose as a result of his financial generosity rather than his military heroism. In other words even the war itself is presented in the play in largely economic terms, and in this regard Lessing appears to share the interests of the other historians of his epoch. ${ }^{75}$

Finally, if we consider Lessing's critical reflections on the war together with the urban perspectivism that structures the drama, we can discern in Minna von Barnhelm a literary demonstration of another development in historical consciousness in the latter half of the eighteenth century, namely, the emergence of the concept of historical perspectivism as described at the beginning of this study. The pioneering figure in this context, it will be remembered, was Johann Martin Chladenius, whose concept of the "point of view" had an immediate impact on his contemporaries' views of how best to understand and represent the past. By the time Minna von Barnhelm appeared, this notion had found its way into the works of numerous professional historians who now insisted on the need to consider how one's own positionality as a historian and that of the historical witness impact any attempt to give an accurate account of the past. ${ }^{76}$ As is the case with Enlightenment discussions of perspectivism in general, one needs to remember that the recognition of different conceptions of history did not eliminate the possibility of historical truth as such. Rather, it led to an expanded role for the historian, who now had the task of producing history as a coherent narrative rather than simply recounting past events. ${ }^{77}$ The historian, in other words, attempts to achieve a kind of supraperspective through a cross-examination of sources.

Lessing's drama suggests that these concerns had an impact on literary practice as well. In fact, Minna von Barnhelm both illuminates the factors that shape an individual's historical perspective and, when viewed as a whole, can be seen as an attempt to achieve the supraperspective that emerges as the goal of historiography in the period. Although the play does not go so far as to thematize what Koselleck terms the "temporalization of historical perspective" - the notion that one's relationship to the past is conditioned both by one's subjectivity and one's own historical position - the characters' diverse reflections on the war and its aftermath certainly demonstrate the subjective lens that filters every depiction of past events. Furthermore, if considered in its entirety, the play actually instantiates Chladenius's 
historiographical ideal. In its depiction of collisions between opposing viewpoints, it offers something quite similar to a cross-examination of various witnesses to the war, the results of which combine to give the audience a more comprehensive understanding of its variegated impact. In this regard Minna von Barnhelm also offers an interesting commentary on the relationship between history and literature, suggesting an affinity between drama and good historical writing. Drama is, after all, a necessarily perspectival genre, one that requires, in Lessing's own words, that the author transport himself "from the point of view of the narrator into the true position of each individual person." ${ }^{78}$ As such, it lends itself to the representation of past events in all their perspectival complexity. And it may help foster a sensitivity to this complexity on the part of the audience or reader, who, like the historian, must evaluate the relative validity of the various individual positions in an attempt to come to a more complete understanding of a historical event.

Whether the inherent potential of drama is realized in a particular dramatic work, however, depends on the extent to which differing viewpoints are incorporated into the plot. If we consider Minna von Barnhelm's urban setting with this in mind, a link between the city and history again emerges. History is not necessarily made in the city. In the case of war, for example, the decisive battles may take place elsewhere. Because of its heterogeneity and inherent dynamism, however, the city would appear to provide the best vantage point from which to offer a complete picture (or acquire a complete understanding) of an object of historical inquiry, here the Seven Years' War. In this way as well then, Lessing's play suggests a connection between the urban context and what has come to be viewed as a key element in the emergence of a modern historical consciousness. The city can be seen as a training ground of sorts, not only for developing a sensitivity to perspective in general, but also to the specifically historical notion of perspective that begins to take shape in this period.

\section{Conclusion}

Minna von Barnhelm has long been recognized as innovative for bringing topics of immediate social and political relevance onto the German stage. As I have tried to point out in this chapter, however, it proves equally innovative 
in its engagement with elements of a modern urban culture that was increasingly becoming a topic of discussion in the period. One of the implications of this recognition is the need to rethink the claim found in scholarship on German travel literature, according to which eighteenth-century German intellectuals linked the city with liberation only in the case of foreign capitals. ${ }^{79}$ Lessing makes this connection with regard to Berlin, and, like the progressive foreign correspondents among his contemporaries, he largely dispenses with the Rousseau-inspired critique of civilization typical of some city texts and instead depicts such liberation in a positive light. Even if the threat of anarchy made possible by the nonregulated urban space does pose itself in the work, and even if Minna and Tellheim's experiment in independence ends with a reinsertion into a private-familial sphere subject to the authority of the patriarch, the emancipation that Minna experiences upon entering the city nonetheless constitutes the necessary precondition for her intrigue, which in turn provides the impetus for Tellheim's transformation. One of the most fascinating aspects of this representation of the city is the link it implies between the nonregulated urban space and aesthetic autonomy, a link that resonates with a number of interrelated eighteenth-century debates, from discussions of the philosophical autonomy of the aesthetic vis-à-vis reason to more specific reflections on the obsolete dramatic conventions of French classicism or the importance of an independent national theater.

An urban reading of Minna von Barnhelm also has significant consequences for our understanding the impact of urban experience on forms of literary practice in eighteenth-century Germany. The novel has long been considered the urban genre par excellence. Its natural penchant for the empirical over the abstract and the idealized, its narrative complexity, even its parvenu status as a literary genre have all been seen as factors contributing to its superiority as a medium for the representation of the complexities of modern urban life. ${ }^{80}$ If, however, the city in eighteenth-century Germany was conceived primarily in terms of sociability, as a site characterized by spontaneous forms of human interaction, then drama, as the most dialogical literary form, must be seen as a genre uniquely suited to mediating the urban experience. At the very least, conclusions like those of Volker Klotz, who claims that "in general, drama is not at home in the city," appear too hastily drawn. ${ }^{81}$ Particularly in the case of Minna von Barnhelm, the convergence of the urban setting and a remarkable increase in the level of social 
and epistemological complexity depicted suggests a symbiotic relationship between the city and a new kind of dramaturgy.

The potentially emancipatory impact of urban experience suggested by Minna von Barnhelm is hardly surprising when one considers Lessing's own biography. He did, after all, choose to spend much of his time in modern urban centers, not just Berlin but also Leipzig and Hamburg. His tortured early letters to his mother and father, in which he tries to defend his behavior in Leipzig and explain his decision to remain in Berlin despite their opposition, make it clear how much he himself valued the comparative freedom of the city. ${ }^{82}$ And in the letter to Lindner mentioned earlier he describes his plans to see Paris, London, and Rome, which had to be scrapped after the onset of the war, as "the most beautiful hope that I have yet had in my life." ${ }^{83}$ Clearly, Lessing associated the city with emancipation in his own experience. In light of this biographical context, it is perhaps surprising that Minna von Barnhelm constitutes something of an exception within his oeuvre. In his early dramatic works, the city is either absent or denigrated. In The Jews, for example, the protagonist remarks on the artificiality of the city, where everything is "dissembled, forced, and artificial." ${ }^{84}$ And neither Emilia Galotti (1772) nor Nathan the Wise (1779), the two plays that follow Minna von Barnhelm, is set in a contemporary urban location. Nonetheless, the city does continue to play an important role in these works, even if the progressive potential of the urban environment is no longer manifest to the same degree. In Emilia Galotti, the city lacks the autonomy it possesses in Minna von Barnhelm. Here the battle lines between the court and the home are more clearly drawn, and the city is crowded out by the confrontation between these two institutions. Yet a remnant of the notion of the city as a site of Mündigkeit remains in force. While the court exerts far more control over the urban space in this work than in Minna von Barnhelm, it is nonetheless the promise of a "city education" and the possibility of exposure to the world that convinces Claudia to remove her daughter from the country estate and raise her there. She takes this decision against the wishes of Emilia's father, Odoardo, whose own opinion of the city reproduces some of the standard antiurban clichés of Lessing's epoch. ${ }^{85}$ His view would seem to be confirmed by the tragic outcome of the drama, but recent interpretations have argued that it is precisely Emilia's lack of adequate exposure to the world outside of the family that makes the tragedy unavoidable. ${ }^{86}$ From 
this perspective, the drama appears as a warning against an overly sheltered existence in the patriarchal familial sphere, one that deprives Emilia of the life experience that would have allowed her to react to the advances of the prince with greater self-confidence and maturity. More city education, not less, might have made her less likely to fall into utter despair at the mere prospect of a stay at the house of Grimaldi.

Nathan the Wise can also be placed within an urban framework, which in this case bears some similarity to the one I have tried to construct for Minna von Barnhelm. Here as well the emphasis is on the recognition and overcoming of limited viewpoints, presented this time in the form of religious particularism. And here again money serves as the motor for the productive confrontations between perspectives. Moreover, the action takes place in Jerusalem, a setting that might even be seen as evocative of eighteenthcentury Berlin, also a city of diverse religious denominations, indeed, one famous for its religious tolerance. But the very fact that Lessing sets the drama in a distant foreign city and in the distant past suggests a shift in attitude visà-vis the contemporary urban context. If Nathan's Jerusalem evokes Berlin, it would seem to be a Berlin that no longer exists, or perhaps one that only ever existed as an ideal.

No doubt a variety of explanations can be found for these variations in Lessing's representation of the city, some of which - distinctions between or changes in generic conventions, for example - have a highly mediated relationship to evolving conceptions of urban life. Nonetheless, the shift I have touched on here does dovetail with Lessing's personal experience. Shortly after completing Minna von Barnhelm, he gave up on Berlin. Harboring no small degree of resentment toward a city that had disappointed his hopes for success and frustrated him with its smug self-portrait as a center of enlightenment, he turned to Hamburg, only to suffer disappointment once again. By the time he completed Nathan the Wise, his own years of urban detachment had long since ended, having been exchanged in 1770 for the more secure, though far less sociable atmosphere of the Wolfenbüttel library.

Lessing's apparent abandonment of the city as the site of emancipation also parallels an increase in skepticism on the part of his former Berlin associates. As we saw in the case of Nicolai, an unqualified celebration of the capital city in the 1750 sives way to a more equivocal evaluation of Berlin life in Sebaldus Nothanker. A change occurs on a more fundamental level in the case of Lessing's lifelong friend Moses Mendelssohn, whose attitude 
toward the urban category of sociability undergoes a significant transformation from his early to his late writings. An investigation of this category as it evolves in Mendelssohn's thought, and of its resonance in the late eighteenth-century urban context, helps reveal another facet of the city's impact on historical consciousness, namely, its imbrication with an incipient critique of modernity. Both Mendelssohn's late essays and a number of city texts from the same period reflect a growing fear that the very modern societal achievements that have made true cultivation possible threaten to deform that cultivation into a new barbarism. 


\section{Moses Mendelssohn and the Philosophy of the City}

\section{Introduction}

In a eulogy that appeared in the Berlinische Monatsschrift shortly after Moses Mendelssohn's death in 1786, the royal librarian and coeditor of the journal Johann Erich Biester offered the following description of the deceased: "He spoke (as one of his friends expressed it) with just as much ease and clarity about the existence of God as about a new silk pattern, and with as much precision and accuracy about the silk as about the existence of God." This brief remark, presumably intended to demonstrate the unity of Mendelssohn's essential character, captures both the essence of his appeal to eighteenth-century contemporaries as well as the philosophical ideal at the basis of this appeal. Of particular significance in this context is the characterization of Mendelssohn as an amateur philosopher, pursuing his metaphysical inquiries in addition to engaging in a more conventional occupation. Biester's description suggests a perfect harmonization of philosophical and professional pursuits. Speaking about the silk patterns and the existence of God appear as two points on a continuum rather than two distinct spheres of activity. The philosopher who comes into focus here thus not only writes about topics pertinent to life; he is himself a contributing member of society rather than a reclusive bibliomaniac. To borrow a phrase from fellow Berliner Johann Jakob Engel, he is a "philosopher for the world." ${ }^{2} \mathrm{He}$ is also a man of dialogue. The elision of any distinction between spoken and written discourse in the quotation - the author of the famous Phaedon "speaks" about God just as he speaks about silk patterns-places communication in the foreground, giving an impression of immediacy and personal contact. Philosophy takes shape in these lines as a discourse engaged with questions of the utmost importance and yet somehow rooted in quotidian experience.

Biester's characterization implies more than just a particular conception of philosophy, however. It also points to a more comprehensive ideal of 
individual cultivation that strives for the harmonization of social, commercial, and intellectual life, of knowledge and practical experience. This ideal not only provided the basis for the valorization of Mendelssohn by his contemporaries; it also played a crucial role in Mendelssohn's own writings. At the center of virtually all of his inquiries one finds a concern with the ultimate purpose of human life - "the vocation of man" (die Bestimmung des Menschen) - the realization of which requires a balanced development of all one's physical, emotional, intellectual, and spiritual capacities in the appropriate measure. Mendelssohn believes that such a development is made possible through social interaction and reaches its highest degree of perfection in a highly developed society. It is my contention that Mendelssohn's various articulations of this ideal can be adequately understood only against the backdrop of his experience in eighteenth-century Berlin. Moreover, and more significant for the question of historical consciousness, the concerns expressed in his late essays regarding the possibility of achieving this balance are equally indebted to the city, apprehended as the crystallization point for various modern phenomena that threaten to destroy the unity of experience. In short, the urban experience provides an important impetus for a dialectic of sociability that is a significant but neglected motif in Mendelssohn's late work, and which serves in turn as the basis for an incipient critique of modernity conceived in terms of fragmentation. In order to demonstrate the urban roots of this critique, however, it is first necessary to address the category of urban sociability more generally, especially as it pertains to eighteenthcentury conceptions of the self.

\section{Sociability and the City}

The eighteenth-century city is conceived first and foremost as a visual spectacle - in the case of Berlin, as an often troubling jumble of monumental architecture and dilapidated shanties, of fashionable residents out for a Sunday stroll passing beggars draped in rags. Indeed, if we are to believe some of the travel reports from the period, many of these fashionable residents are themselves little more than beggars in disguise. But the intense and often deceptive visual aspects of the urban environment are only part of the story. Commentators also represent the city as a space delimited by language, as the locus of unique forms of communication deriving from a particular frame- 
work of social interaction. In many cases, the freedom of communication found in the metropolis is also a source of anxiety. Zöllner's "Contribution," for example, touches on several of the more negative variants of the urban idiom. There is the impertinence that often characterizes exchanges between the lower classes and those of higher station, fostered by the confidence that the tradesman acquires through repeated business transactions with his superiors. Equally disturbing is the predilection of the big-city dweller for boasting, which Zöllner represents as an attempt to compensate for his failure to achieve the glory he had hoped for in the city. Most significant for Zöllner, however, is the pernicious gossip that circulates through urban social circles. While gossip figures prominently in small-town life as well, the speed with which novelties pass from mouth to mouth in the big city results in gross distortions. According to the author, "The most tasteless lies imaginable spread like wildfire, and people believe them." ${ }^{3}$ Zöllner's remarks on the language of the city offer another perspective on the eighteenth-century perception, addressed in the previous chapter, of the big city as a nonregulated space, one that challenges traditional social hierarchies and mechanisms of social control. The linguistic freedom of the city derives from and encourages new forms of social interaction less dependent on established notions of rank and status. The metropolis, in other words, serves as the locus of an unconstrained, sometimes uncontrollable sociability.

Zöllner represents this sociability in a rather negative light: he dismisses the frankness of the commoners as an unnatural "impertinence" (Naseweisheit) and the gossip of the more affluent as empty chatter at best, a source of dangerous prejudice at worst. Other eighteenth-century commentators are even more skeptical of urban society and its forms of social intercourse. In 1778 the Hannoverisches Magazin, a journal that printed a string of largely negative city-country articles in the late 1760 s and 1770s, published an essay entitled "Letter from a Newly Transplanted Big-City Dweller to the Dear Provincial He Left Behind." ${ }^{4}$ Written as a pseudodefense of urban life by a displaced country gentleman, the fictitious letter recycles all of the familiar clichés of eighteenth-century city criticism: urban luxury, excess, arrogance, laziness, and artificiality are opposed to the natural beauty and authentic friendship of country life. Even in its negativity, however, the essay still reveals the central role played by sociability and conversation in conceptions of urban life. The author writes: "Society and social intercourse are the characteristic prerogatives of large cities, and if anyone does not find pleasure in 
these and prefer them to all other things, he does not deserve to be a big-city dweller." 5

Negative depictions of urban sociability are easy to find in late eighteenthcentury journals, but sympathetic intellectuals also recognize the progressive potential of the more inclusive and less pre-scripted forms of communication that arise in the city. Even Zöllner contrasts the positive quality of the "unforced" (das Ungezwungene) that characterizes city language and city manners to the stiffness of the small town, claiming "stiff and provincial are thus nearly identical in meaning." ${ }^{6}$ Lessing is far more radical in this regard. One of the most fascinating aspects of Minna von Barnhelm is the way in which he grounds the positive outcome of the drama precisely in those categories of speech that Zöllner and others denigrate. Not only does Riccaut's "gossip" serve to reassure Minna and anticipate the happy resolution of the work's central conflict; it is precisely in those moments when the characters engage in spontaneous, face-to-face communication, often marked by the use of the informal terms schwatzen and plaudern, that they gain insight into their own prejudice and weakness. ${ }^{7}$ In contrast, the two most pronounced examples of overtly intentional language in the play, Tellheim's letter and the king's dispatch, both fail to achieve their intended aim.

Another positive representation of urban communication can be found in a lecture delivered in 1787 to the Silesian Economic Society by the philosopher and essayist Christian Garve. The lecture, entitled "On the Situation of Silesia at Different Points in Time, and on the Advantages of a Capital City over Provincial Cities," consists of two parts. ${ }^{8}$ In the first, Garve recounts what little is known about the history of the region, explains the various environmental and political factors that have impeded the development of a unified Silesian national character, and finally offers his endorsement of the recent integration of Silesia into the Prussian state. The second section of the lecture contains Garve's observations on the pros and cons of big-city life, observations inspired by a recent journal article containing an unfavorable comparison of the Silesians to the Berliners. Garve's representation of the city has much in common with those found in both Zöllner's "Contribution" and Gedike's letters. Briefly put, he argues that the social dynamic of a capital city results in a range and frequency of interaction that breaks down the barriers between estates. In a comment that could have been lifted directly from Zöllner's essay, he explains: "In all small towns one's birth, title, the reputation of one's office, in a word, one's rank will always be of 
supreme importance, in social life as well. In a large court city there are so many people of noble birth and holding titles, and these nobles are so used to seeing others of an even higher rank, that the distinctions of rank are necessarily somewhat less highly esteemed." 9 The advantages that Garve attributes to the uniquely urban mode of sociability are numerous. As the seat of government, the capital city attracts wealthy men of the world, who ensure that social exchange is both sophisticated and oriented toward practical knowledge. In addition, the possibility of advancing to the highest levels of civil service draws to the city the most talented of the provincial youths, who further contribute to the high level of social discourse as well as adding diversity to urban society. Finally, the concentration of wealth in the city, a phenomenon that more antiurban writers depict as the wellspring of urban degeneracy, is adduced by Garve as a foundation for the advancement of the arts and sciences. Those tasteful men of leisure who congregate in the city desire entertainment and education, and they are willing to support artists and scholars who can provide it. Indeed, for Garve, it is precisely the reduced concern with the conventions of rank and title that gives rise to this desire, apparently by freeing up intellectual energy for more meaningful pursuits. The close association of artists and the powerful in the big city benefits both groups: "This link between the worlds of the mighty and the learned gives the former more of an opportunity to acquire in-depth knowledge, and the latter more of an opportunity to refine their manners than either would have in a provincial city. And so both become in their own way more perfect in the court cities." 10

Garve's characterization of this symbiosis deserves special attention, because it is indebted to a model of cultivation at the heart of the German Enlightenment, the same model that informs Biester's eulogy. The perfection he refers to in the preceding quotation involves a harmonization of interior and exterior - that is, "knowledge" and "manners." Authentic, fully realized humanity requires that knowledge be coupled with refinement, with beauty of expression. The ideal that underlies his remarks is that of Bildung, the natural cultivation of both mind and manners that culminates in a perfect unity of personality, where both action and thought are expressive of a single essential character. Garve's comments in this context are important because they reveal the extent to which the big city was seen by some as the location where this ideal could best be achieved. 
These comments reintroduce the notion, common among advocates of metropolitan life in eighteenth-century Germany, of the city as a universalizing space. As we have seen, variants of this argument also appear in Zöllner's apprehensions regarding the urban craftsman, in Gedike's discussion of Berlin social life, in Nicolai's early reflections on drama as well as his later depiction of Berlin in Sebaldus Nothanker, and in Lessing's perspectival depiction of city life. In all of these writings the city appears as a space in which the individual, through the exposure to a diversity of experiences and individuals, that is, through the unconstrained sociability characteristic of urban life, becomes aware of the limits of his own subjectivity and, ideally, transcends them to become a more complete person. Gedike in particular offers a version of this narrative close to that of Garve. In his letters, he links Berlin's lack of a university to an increase in the availability and accessibility of knowledge, claiming: "And this city-long may it prosper! - has no real university, just as Athens had none in its prime. The sciences are not the business of a single estate here, they are the occupation of several individuals, and each of these individuals occupies himself with several of them." ${ }^{11}$ The author goes on to refute the objection that popularization leads to a reduction in scientific precision, and further insists that the predominance of nonprofessional scholars prevents pedantry, fosters intellectual open-mindedness, and even encourages a more appealing style:

On the contrary, must it not have the most beneficial consequences when men of business who, in the course of their investigations, occasionally come across matters that they find deserving of the attention of the general public, take pen in hand in order to speak of such things? Naturally one finds no bombast in their writings, no affected language, no youthful bravura, no vain pretensions, but rather manly virtue, seriousness, dignity, or, when the material demands a satirical spirit, always a refined, cosmopolitan tone and reasonable, civilized manners nonetheless. Naturally such authors are not out to lecture, but rather to present their opinions, as if to a polite society of enlightened minds, on matters that are important to them; they want to discuss these matters so that several minds become engaged with them, so that these materials enter into circulation and so that truth, the free spirit of investigation and general enlightenment ultimately profit therefrom. ${ }^{12}$ 
In Gedike, as in Garve, one finds an emphasis on the reciprocal relationship between urban sociability and the cultivation of the individual as totality. The absence of a university not only means that knowledge is more widely disseminated in the city, but also that it remains firmly rooted to the concerns of practical life. Gedike's businessmen pursue their investigations unsullied by the narrow strategic interests of professional scholars - "the petty envy of the scholars among themselves; the vile tricks that they use to displace one another or even to cause one another's downfall." ${ }^{13}$ Instead, both the will to knowledge and the desire to share this knowledge appear to stem from a commitment to the general good; their investigations are in the service of "general enlightenment." Gedike, in keeping with the spirit of the period, views the most valuable knowledge as the product and possession of the individual as human being pure and simple rather than a representative of a particular profession. Like Garve's metropolitans, then, Gedike's Berlin businessmen become more fully integrated individuals. They are knowledgeable, virtuous, and refined - men of the world who recognize the importance of ideas and whose intellectual contributions are characterized by a "refined cosmopolitan tone and reasonable, civilized manners."

Even for such urban advocates, however, metropolitan sociability is not without its risks. We have touched upon Gedike's reservations in earlier chapters. Garve, no doubt wary of offending his Silesian audience, dutifully follows his praise of the capital city with a discussion of its drawbacks. With regard to the progress of the arts and sciences, he points out the risk that attempts to make both more pleasing to worldly patrons will end in trivialization and dilution, in shallow scholarship and an art subservient to fashion. Garve claims that both great works of literature and those of philosophy ("investigative reason") are more likely to emerge at a certain distance from worldly concerns. The danger of the city lies in its distractions, which weaken the focus necessary to achieve real depth of thought, and in the temptation to put one's knowledge on display before it has had a chance to mature. In this respect, the provincial thinker is at a distinct advantage: "A good mind in a provincial city is sometimes like a flavorful and nutritious plant that grows in the desert. It may be a long time before its blossom and fruit provide any pleasure to anyone, but neither will anyone pluck it too early; it will not be disfigured by artifice. It quietly blossoms forth of its own accord, passes undisturbed through all of its natural stages of devel- 
opment, and comes in this way to produce the most perfect fruit of which it is capable." ${ }^{14}$ Garve is not alone in opposing big-city life to the highest examples of intellectual achievement. Zöllner argues in a similar direction when he claims: "A university in a large city will hardly produce scholars of the highest distinction." ${ }^{15}$ While diversity and frequency of social contact may lend the writings of urban intellectuals a certain aesthetic appeal - "a greater variety of ideas, a greater ease in composition, a greater precision with regard to the individual elements" - the frenetic pace of city life impedes concentration and the exposure to innumerable existing products of culture hinders true originality. ${ }^{16}$

Taken together, these representations of the advantages and disadvantages of metropolitan life indicate a striking ambivalence in evaluations of urban sociability and its impact on individual development. Not only as a site of visual dissimulation through fashion, but also in its role as the locus of diversion, idle talk, and social convention, the big city provides access only to contingent and superficial knowledge. It appears as the quintessential space of the exterior, where the desire to appear overwhelms any attempt to develop the authentic, interior values and knowledge that are seen as crucial to true cultivation. At the same time, however, big-city life is also seen as the basis for this very same cultivation. The urban experience helps break down social barriers; in the words of Zöllner, it fosters a critical acumen that allows the city dweller to recognize "man in all his forms and ornaments." ${ }^{17}$ From this perspective, it not only serves as a kind of anthropological training ground, where one acquires knowledge of the universal human nature shared by all, regardless of station, profession, or place of origin; it is also the place where expanded experience offers the individual the best opportunity to develop all of his human faculties without overdeveloping any of them. Garve's men of power become more knowledgeable in the city, whereas his artists become more sophisticated and worldly. Gedike's businessmen learn to balance science, sociability, and commerce. As a result, each of these groups manages to avoid the character deformations and extremes that stem from wholesale identification with a single activity, profession, or estate. As Gedike puts it, thanks to the intensity of contact in Berlin, "Everything is kept in check by everything else here." ${ }^{18}$ Rather than a place where interior and exterior become detached, the metropolis according to this narrative fosters their harmonious integration. 


\section{The Socrates of Berlin}

Gedike's description of the Berlin intellectual in his letters could have just as easily been written in praise of the city's resident metaphysician. Moses Mendelssohn was in fact a self-educated entrepreneur, having worked his way up from bookkeeper to partner in Isaak Bernhard's successful silk manufactory while publishing best-selling works on moral philosophy in his spare time. A Berlin resident since 1743, Mendelssohn was viewed by many of his contemporaries as the archetype of the cultivated and cosmopolitan intellectual. Admirers associated him with both the city and with public life, celebrating him as the Socrates of Berlin and sharing anecdotes about his walks in the Tiergarten and appearances in the Royal Theater, as well as about the lively debates that took place in his home. More significant than these outside evaluations for an understanding of the urban moment in his philosophy, however, is the central role played by the category of sociability in his works. Mendelssohn remained throughout his life one of Germany's most resolute champions of social intercourse as a source of practical knowledge and true cultivation. Assertions regarding the value of sociability and the civilizing process that makes sociability possible appear in several of his works, both those intended for German and for Jewish audiences. Whereas his early writings demonstrate an unequivocal enthusiasm for the achievements of contemporary society, however, his works from the 1780 s reveal an increasing recognition of what can be termed the dialectic of sociability. In this late period Mendelssohn appears to have acquired a heightened awareness of the way in which the very societal development that he saw as necessary for a complete unfolding of human capacities can, in certain circumstances, also sabotage that process. Mendelssohn's articulation of this dialectic resonates on multiple levels with the evaluations of metropolitan life written by his Berlin contemporaries in this period. This resonance suggests that Mendelssohn's philosophy, especially those later texts that address the threat posed to individual development by increasing societal complexity, can and should be read as a response to the ambiguities of modern urban experience.

In Mendelssohn's early writings, the defense of sociability often takes the form of a refutation of Rousseau, whose Discourse on Inequality he had translated in 1755 and 1756. In the 1756 Epistle to Herr Magister Lessing in Leipzig, for example, he praises Rousseau's eloquence but takes him to task for his un- 
reflective valorization of the state of nature. Mendelssohn argues that civilization, whatever its shortcomings, allows for the unfolding of new cognitive capacities, and this extension of our capacities constitutes our divine vocation as humans. The implication of his remarks is that we can develop fully as individuals only through interaction with others in an advanced society. Rousseau's mistake - one of many, according to the author - is to substitute the body for the entire self. Although it may be true that civilized humans are more delicate than "savages," their physical weakness is more than offset by increased refinement in the powers of the soul. He writes: "Is the soul such a lowly object that men should abandon all concern for nurturing it? Is it more suitable for them to strive for the agility of a dog or to strive for the divine insights of a Leibniz or a Newton? Which of these two capacities should give way to the other?"19 In Mendelssohn's opinion, Rousseau has reversed the hierarchy between body and spirit. Certainly the body should not to be neglected; moreover, the author admits that the evolution of new faculties brings with it new challenges: they may be overdeveloped, or misused, or other skills may be neglected. But to reject these faculties for this reason is to misunderstand the very purpose of human existence. Mendelssohn's role model is Socrates, to whom he attributes a perfect balance of physical and spiritual powers. Those who know Socrates only as philosopher and citizen of Athens, he writes, must become acquainted with Socrates the soldier, "a fearless warrior . . . who treads upon the ice with bare feet while his compatriots wrap themselves in furs." ${ }^{20}$

Mendelssohn's reflections in these passages constitute an early articulation of the much discussed German idea of self-cultivation or Bildung. His ideal is based on a holistic theory of individual development that includes both interior and exterior, the physical and the mental, sense and reason. Following Christian Wolff, he views the human being as comprising a hierarchical totality of faculties or Seelenkräfte, all of which must be developed in tandem and kept in proper balance with one another. Although, as the preceding reference to Newton and Leibniz suggests, rational insight occupies the highest position in this hierarchy, Mendelssohn also insists on the value of "innocent" sensuous pleasures: "Music, painting, delicious foods and drinks, as long as they are digestible, the magnificent works of nature and art, these are the generous gifts of our gracious father." ${ }^{21}$ For Mendelssohn, then, the potential for man's realization of his divine destiny is maximized in advanced societies, where the satisfaction of basic needs has en- 
abled the cultivation of more sophisticated pleasures, both intellectual and sensuous.

There is another important component to Mendelssohn's defense of sociability in this context, however. Full enjoyment of these pleasures and full development of these capacities are only possible on the basis of social interaction. Without friendship, he argues, the soul cannot be improved, leisure becomes an affliction, and we remain indifferent to all the pleasures of life. Even more fundamental is the human capacity for compassion or Mitleid, the one feeling that Rousseau grants to the savage and that drives the development of our faculties in the first place. Unlike Rousseau, Mendelssohn views compassion as derivative of love, which is itself grounded in an inborn desire for harmony and order. It is not, as Rousseau would have it, displeasure at the sight of suffering and a subsequent desire to help that brings individuals together, but rather pleasure in the perfections of others and a desire to foster and mimic those perfections. The innate drive for self-improvement thus motivates social contact, contact that in turn encourages further improvement. Individual and society are entwined in an inextricable dialectic. Summing up this position in another context, Mendelssohn writes: "Man is by nature social and will not achieve success without help from others of his kind; if he remains alone, his mental faculties and attributes will not pass from potentiality to actuality, and he will resemble the animals, and will perhaps not even achieve their merits." ${ }^{22}$ On the basis of these observations it becomes clear that the concept of sociability has a double valence for Mendelssohn, containing both a diachronic and a synchronic component. When he defends the "state of sociability" (Stand der Geselligkeit), he is defending both the cultural and intellectual achievements of advanced societies (diachronic) as well as the heightened level of intersubjectivity in these societies that enables such achievements (synchronic). This distinction is significant, because his later writings suggest that contemporary European society is threatened on both levels.

Mendelssohn's critique of Rousseau thus illustrates his defense of a modernity understood in terms of civilization, but it also reveals the extent to which he conceives civilization as a relative category, one whose content is identical regardless of the time period in human history to which it is applied. For the early as for the late Mendelssohn, there is no single, global historical metanarrative. He sees no fundamental qualitative distinction be- 
tween the Athenian context that gave rise to Socrates and the metropolitan culture of modern Europe that Rousseau attacks. Within a given society, however, he does assume a gradual process of evolution, and he clearly views modern Europe as representative of an advanced stage in a developmental paradigm that seems to have universal validity for individual cultures. At one point in the postscript to the essay he remarks that "all of our efforts to accustom a savage to our way of life must be fruitless if we fail to allow a series of fathers and children to gradually work their way up the ladder along which we have traveled in the course of so many centuries." ${ }^{23}$ In other words, Mendelssohn's early defense of sociability in the Epistle has an undeniable historical-philosophical component, and this conception of societal development remains with him in his later works.

This same basic attitude also shapes his arguments in Rhapsody, for example, published in 1771 as a supplement to the theory of mixed sentiments developed in the letters On Sentiments. Building in this context on his debate with Thomas Abbt regarding the vocation of man, Mendelssohn at one point addresses the criticism that his emphasis on an innate drive to perfection turns man into a creature of selfish desire. He dismisses this claim as ridiculous, inasmuch as the inclination to perfect one's own faculties always requires an element of community. He writes: "As if there could be a world in which a thinking being could isolate itself or as if a thinking creature that tears itself away from every bond and closes itself off within itself could also be perfect in itself, happy with itself!" ${ }^{24}$ Perfection in the sense of individual self-cultivation thus presupposes a social context; moreover, the project of self-cultivation itself exists in a symbiotic relationship with the improvement of the community: "We become more perfect, if everything that surrounds us is perfect; we become happier if we are able to make everything around us happy." 25

A more concrete endorsement of a specifically modern sociability can be found in an unpublished critique of Herder's Fragments on Recent German Literature, which Mendelssohn appears to have written in 1767 . Here he takes Herder to task for his primitivism, more specifically, for his suggestion that contemporary poets reintroduce the imagery of Norse and Celtic mythology in order to achieve a more powerful emotional impact. Mendelssohn exclaims: "What do we want literature (Poesie) to accomplish? To create a love for the crude and savage life?" ${ }^{26} \mathrm{He}$ then goes on to explain that the 
highest forms of beauty can never be achieved in "uncivilized (ungesittet) ages," because they require "the finest cultivation of manners, concepts, and expression." 27

Mendelssohn does not explicitly address the city in these texts, but there is every reason to think that his arguments were written with contemporary urban experience in mind. Perhaps most notably, his primary targetRousseau's critique of civilization - was itself conceived in opposition to the perceived decadence of urban life. The paradox of Rousseau's popularity, namely that his arguments against society were disseminated primarily through the institutions of urban sociability, was by no means lost on Mendelssohn. In an early satirical piece on the Discourse on Inequality from the moral weekly Der Chamäleon, his fictional mouthpiece refers with what can only be conscious irony to the fact that Rousseau's claims were being hotly debated in "all the coffeehouses" in Switzerland. ${ }^{28}$ Just as important as the metropolitan context of Rousseau's critique, however, is the fact that the highest achievements of civilization that Mendelssohn defends in these essays, as well as the benefits of social intercourse as a source of individual improvement, were clearly associated by his contemporaries with urban life. The writings of Gedike, Zöllner, Garve, Nicolai, and other commentators on the city make the connection repeatedly. To be sure, the notion of a sociability in the service of universally human values was one of the pillars of Enlightenment thought in general, and enlightened societies were not limited to the big city. Nonetheless, if we are to believe the aforementioned commentators, the level of social and geographical diversity necessary for the complete development of all one's faculties was only to be found in the capital city. It is also important to remember in this context that Mendelssohn's early writings defend sociability on a large scale, not merely in the form of the intimate friendships that are so celebrated in eighteenth-century literature and that are often depicted in opposition to society more broadly understood. On the contrary, Mendelssohn is interested in the highest levels of individual and societal cultivation, both of which his contemporaries explicitly link to the public life of the metropolis.

In Mendelssohn's case one also finds an important biographical factor that lends support to the idea of a link between the urban context and his remarks on sociability. Eighteenth-century Berlin was characterized by an unusually high degree of social and intellectual exchange between German and Jewish residents, especially in the period following the Seven Years' War. 
The factors that contributed to Berlin's unique status in this regard were complex, and they evolved over the course of the century. Nonetheless, one can discern a number of characteristics of the city that fostered such exchange, including the lack of an established urban patriciate, the absence in the Jewish community of a tradition of Talmudic learning, the importance of Jewish entrepreneurs for the mercantilist policies of Friedrich Wilhelm I and Friedrich II, and the prominence of Berlin as a center of medicine, the only university-level discipline to which Jews had access in eighteenth-century Germany. Interaction between Germans and Jews was also encouraged on a very concrete level by Berlin's lack of a Jewish ghetto; members of the Berlin community generally resided in Alt-Berlin, the old city center, a mixed-class neighborhood with approximately 22,00o residents in 1777. According to the statistics in Nicolai's Berlin book, between 3,000 and 3,500 of these residents were Jews. ${ }^{29}$ If Jewish self-understanding had long been linked to urban life through restrictions on land ownership and exclusion from traditional occupations, the circumstances that gave rise to Mendelssohn's attempt to construct a uniquely modern German Jewish identity were specific to Berlin.

Mendelssohn's own urban experience, in other words, certainly served as an enabling condition for his philosophical production. But I would argue that the impact extends to the level of content as well. Mendelssohn himself benefited significantly from the opportunities for exchange in the city. His celebrated friendship with Nicolai and Lessing offers the most obvious example, but he also participated as a guest in the activities of the Montagsklub (Monday Club), a learned society founded by the pastor Schultheß in 1749, and he was an active member of the Gelehrtes Kaffeehaus (Scholars' Coffeehouse), established by Johann Georg Müchler in 1755 as a combined reading room and lecture hall. In this early period he also joined the burgeoning ranks of the Berlin journalists, contributing a variety of mostly lighthearted epigrams, dialogues, and essays to Müchler's short-lived moral weekly Das Chamäleon, as well as founding the first modern Jewish journal, the Kohelet Mussar. His later years were marked by a more direct involvement in politics; he composed, for example, a summary of Jewish law for the Royal Ministry of Justice, which appeared in 1778 under the title Ritual Laws of the Jews. This period also saw the emergence of a new constellation of Berlin intellectuals with whom Mendelssohn came into contact, a generally more established group with closer ties to the Prussian state than the underemployed literati of the 1750 and 1760 s. $^{30}$ The common interest of these indi- 
viduals in state reform based on Enlightenment ideals led to the founding of the secret Berliner Mittwochsgesellschaft (Wednesday Society) in 1783, to which Mendelssohn belonged, as well as its public mouthpiece, the Berlinische Monatsschrift. Certainly Mendelssohn's involvement in these urban institutions must have contributed to his confidence in sociability as a source of progress, particularly in the early years, when the limited acceptance of Jews into Berlin intellectual circles seemed to indicate a new era of toleration in the city. ${ }^{31}$

In the writings composed in the context of the later phase of his Berlin social life, however, one can discern a shift in Mendelssohn's attitude toward sociability, and a greater suspicion of the relative modernity that he had so vigorously defended in the 1750s. A noteworthy example appears in one of Mendelssohn's last pieces of written work, a text that also draws the category of sociability more strongly into the urban orbit. In the brief 1784 essay entitled "The Division of Offices and Estates," he once again stresses the value of social intercourse, claiming that "tyrants seek to separate people, wise governments encourage all forms of union." ${ }^{32}$ Here he expresses his disagreement with a recent article in the Berlinische Monatsschrift that ridiculed the marksmen's guilds in Berlin and other German cities as obsolete. For Mendelssohn, these organizations have value in themselves, regardless of whether they fulfill some socially useful purpose. As long as an organization has no obvious negative impact on the general welfare, he claims, it should be allowed to exist, even if its members assemble for no other purpose than superficial amusement.

According to the author, such associations can serve an important compensatory function, bringing together individuals separated as a result of the necessary division of labor in a large state, giving them an opportunity to meet simply as human beings rather than as representatives of a particular estate or occupation. As he puts it: "That which has been separated from the one side by the interest of society may be brought back together from the other by the need for sociability." 33 Scholars have generally viewed Mendelssohn's remarks in this context as an elaboration of a distinction made in the better-known essay “On the Question: What Does ‘to Enlighten' Mean?” where he differentiates between the value of Enlightenment for the individual as human being pure and simple (Mensch) and as citizen (Bürger).$^{34}$ In fact, both essays point to a complex relationship between sociability, modernity, and the city that resurfaces in different guises in much of his writing 
from the 1780s. Under consideration in "The Division of Offices and Estates" is a quintessentially modern problem, namely, the destruction of the coherent totality of experience as a consequence of the division of labor that emerges in complex societies. The division of the "offices" proves necessary to the efficient functioning of the modern state, but it threatens to destroy the unity of human life and to reduce society to a collection of unrelated atoms. Thus the increased need for organizations that bring the "estates" together, organizations that can help counterbalance the aforementioned segregation.

The conception of modernity that underlies Mendelssohn's argument differs markedly from the one articulated in his critique of Rousseau. In this later essay the implication is that advanced societies necessitate a restriction of individual cultivation rather than encouraging it. The division of labor requires some to engage in repetitive tasks that enfeeble rather than stimulate their higher faculties. In a discussion of what he adduces as the three basic types of human productive activity, Mendelssohn writes: "Rarely will a craftsman who has learned to produce one part of a clock with ease be able to invent a new device of this kind or to improve the craft of clockmaking.... his viewpoint is too restricted for invention." ${ }^{35}$ Mendelssohn's remarks suggest his dissatisfaction with employment that reduces the complete human being to the exercise of a single capacity, and in this regard he anticipates the argument made ten years later by Schiller, whose On the Aesthetic Education of Man also characterizes the modern age as one of fragmentation: "Once the increase of empirical knowledge, and more exact modes of thought, made sharper divisions between the sciences inevitable, and once the increasingly complex machinery of state necessitated a more rigorous separation of ranks and occupations, then the inner unity of human nature was severed too, and a disastrous conflict set its harmonious powers at variance." ${ }^{36}$ In both cases the contemporary situation is criticized on the basis of an ideal that posits the human being as an integrated totality of faculties. It should be noted, however, that the modernity Mendelssohn addresses in his own text is, as was the case in his earlier discussion of Rousseau, only relative. Indeed, an important distinction between Schiller and Mendelssohn lies in the latter's apparent reluctance to acknowledge this problem as historically unique. He writes: "Men appear to have always been aware of the problems that arise from the division of offices; they have at all times been anxious to bring the estates together again through all kinds of associations - thus the fraterni- 
ties, orders, guilds, etc., in which the separated estates are brought back into contact with one another." 37

Mendelssohn seems to mischaracterize seriously traditional medieval and early-modern associations, which were more concerned with keeping the estates apart, with fostering a sense of community and identity within various corporate bodies than with bringing these bodies together. ${ }^{38}$ On the contrary, the credit for establishing new forms of sociability dedicated to the cultivation of a universal humanity is generally given to the eighteenth century. Indeed, the very distinction that Mendelssohn proposes in this essay, between "offices" and "estates," can itself be seen as a distinguishing characteristic of the emerging bureaucratic state. It would seem that Mendelssohn is engaging in a kind of backward rationalization here, projecting an ideal extrapolated from a contemporary mode of social interaction onto the past. This gesture, as we will see, reappears in other works from this late period.

Despite Mendelssohn's own reluctance to accept the historical specificity of the phenomenon he is addressing, the concerns expressed in the essay are clearly entwined with the experience of modernity. They also suggest a connection to the urban context out of which the essay originated. Not only does the author illustrate his points with the example of an urban tradesman; in addition, the argument about social complexity itself suggests a link to Berlin. Mendelssohn refers to the "large states in which the activity piles up," but it is in the capital cities of these states, as Christian Garve points out in his essay on big-city life, that the government, its ministries, and the important manufactories are located. As we have seen, the capital city in the eighteenth century is universally conceived - and, to a large degree, functions - as the state in microcosm. Nowhere was this more true than Berlin, which Friedrich Gedike characterizes as "an emblem of the Prussian monarchy." ${ }^{39}$ In short, Berlin in particular, and the big city in general, can be seen as the point of crystallization for the worrying trend that Mendelssohn addresses in his essay.

It is the point of crystallization for other negative trends as well, trends that threaten to undermine the balanced unfolding of individual capacities in more subtle but equally damaging ways. Not only in the more resolute condemnations of metropolitan life but also in Garve and Gedike one finds reference to the dangerous seductions of the city. Exposure to the wealth and power that have accumulated in the city, for example, can short-circuit the natural process of development, leading individuals to abandon the dif- 
ficult process of authentic cultivation in a quest for immediate affirmation and gratification. Garve articulates this risk for a specific group through the contrasting example of the provincial thinker, who, like a "nutritious plant that grows in a desert," is able to pass through all the natural stages of his evolution without any chance of disturbance from the outside. In contrast, metropolitan artists and intellectuals are in danger of being turned into mere impersonators before they find their own voices. In Gedike one finds expressions of a related but more general fear that exposure to the overwhelming opulence of the big city can result in a detachment of interior and exterior cultivation, as the unprepared individual sacrifices essence for mere appearance. In this case urban sociability is reduced to an opportunity for self-display and the satisfaction of vulgar pleasures, in the words of the newly minted metropolitan in the article from the Hannoverisches Magazin, to "eating, gambling, and shooting the breeze." 40

The fears expressed in both of these discussions reflect a concern with what can be termed the objectivity of culture, the fact that intellectual and cultural artifacts have a material permanence that transcends the individual life-span. The alleged problem is essentially one of uneven development between the individual and the species. Society as a whole evolves toward higher levels of luxury, knowledge, and cultivation, but the fruits of this evolution can deform the individual who is exposed to them before he has had the chance to progress through the natural stages of his own maturation. Civilization, in other words, makes the products of a long-term process of societal development available to all, even to individuals whose personal experience has not prepared them to assimilate these products into a balanced personality. The metropolis is significant in this regard because it contains civilization in microcosm and thus appears as the site where the individual is most threatened.

Reflections on the problem of uneven development appear at various points in Mendelssohn's late writings, especially those written in the period when Gedike and Zöllner were composing their respective texts on Berlin. In a 1782 letter to August Hennings, for example, he approaches the dilemma from a different direction, arguing that the most advanced societies are actually a threat to the maturation of the individual, because he will lack the adversity necessary for the development and exercise of his capacities. ${ }^{41} \mathrm{He}$ makes a similar claim in another text from the same period entitled $\mathrm{On}$ the Ideal Constitution, where he writes that if the fathers of a nation have 
struggled to achieve honor and success, then their children will be vulnerable to the decadence of pleasures enjoyed without personal achievement. ${ }^{42}$

A consideration of the specific problem of luxury and wealth can be found in a passage from one of Mendelssohn's lesser-known works, his translation of and commentary on the Pentateuch, which he completed in the 1770 and early 1780 s. In his discourse on the Book of Exodus he reiterates the familiar claim that human faculties can only realize their full potential in society, but here he also acknowledges that the same civilizing process that allows for this realization also gives rise to the dangers of luxury and excess. ${ }^{43}$ The developmental paradigm that Mendelssohn employs in this context, according to which society moves from a concern with the essentials of life (food, shelter) to comfort and utility (roads, tools) to culture in the narrow sense (literature, the arts), again suggests a connection between his arguments and the urban context. As we have seen, Gedike employs a similar framework in the historical section of his Berlin letters. Even more significantly, in Gedike as well as virtually all the other city commentators from the period, the big city serves as the focal point for reflections on the ambiguous consequences of this progression, the place where an abundance of wealth and leisure makes true civilization possible even as it threatens to tip that civilization over to decadence. Against this backdrop of an explicit linkage of such concerns with metropolitan life, Mendelssohn's comments suggest that his evolving theory of societal evolution, according to which modernity both enables total cultivation and puts it at risk, takes its inspiration from the urban context.

In addition, as with Mendelssohn's early defense of sociability, his comments also point to the specific situation of the Jewish community in late eighteenth-century Berlin. Prussian restrictions on Jewish residency meant that the community had always been affluent. During the Seven Years' War, however, the participation of Jewish entrepreneurs in Friedrich II's debasing of the coinage led to the acquisition of huge amounts of wealth. ${ }^{44}$ In the wake of the war, three prominent families - the Ephraims, the Itzigs, and the Isaac-Fliesses - emerged as the core of a new group of Jewish elites whose interest in acculturation marked a new phase in the evolution of the community. Their wealth triggered a modest drive toward modernization: they built elegant homes, collected art and built libraries, abandoned traditional dress for the newest European fashions, began to speak German more frequently, and became more interested in secular education. Coterminous with the 
life-style changes made by the modernizing Berlin Jews was the rise of the Haskala, with the new elites often serving as patrons for the impecunious Jewish intellectuals. Eventually the Jewish Enlightenment came to be identified more or less exclusively with the city. ${ }^{45}$

The benefits deriving from these changes were apparent to most educated Berlin Jews, who welcomed the relatively high level of interaction between German and Jewish residents in the city in this period. ${ }^{46}$ Moses Mendelssohn is not the only name that appears in the context of intellectual discussions and debates; one also finds references to prominent Jews like Aaron Gumpertz, who allegedly introduced Mendelssohn to Lessing; the entrepreneur David Friedländer; the Kantian philosopher Marcus Herz; and the renowned ichthyologist Marcus Elieser Bloch. Learned societies did occasionally include Jewish members, and by the early 1780 s the salon culture that was to play such a central role in the final decade of the century was already underway in the home of Marcus and Henriette Herz.

Beginning in the late 1770 s and early 1780 s, however, the most active period of the Jewish Enlightenment and the period during which Mendelssohn completed his Pentateuch commentary, one can discern an increasingly critical stance on the part of the intellectuals toward the wealthy elites. ${ }^{47}$ In a previously cited passage from his Berlin letters, Friedrich Gedike provides the outsider's perspective on the Berlin Jews that reveals an actual tension arising within the community itself: "To be sure, as is the case with all enlightened and affluent nations, luxury has begun to invade their ranks, and it may endanger their intellectual and moral, even their political development. . . . All of the sensuous pleasures, all of the luxuries of the capital city, all of the foolish fashions - often one sees the children of Israel lining up here to enjoy them as well; some of them are even abandoning the teachings of their fathers, merely in the hope of being better able to indulge their vanity among the Christians." ${ }^{48}$ While Gedike's remark suggests a troubling antiJewish bias, it should be noted that members of the Berlin Haskala voiced similar concerns. At the root of their fears is a model of individual and social development parallel to the one described by Mendelssohn in his Pentateuch translation.

The increase in the wealth of Berlin Jews following the war created unprecedented opportunities for self-improvement, as well as for improvement of the community as a whole. Because of the rapidity with which this increase occurred, however, critical commentators feared that enlightenment would 
degenerate into a superficial concern with the outward trappings of cultivation. The conception of enlightenment that undergirds these arguments is based on an organic model of development. In order for enlightenment to be authentic and resistant to corruption, it must necessarily proceed through a series of predetermined stages, during which the individual develops the strength of character required to resist the temptations to which a highly cultivated society gives rise. Briefly put, Jewish intellectuals feared that the windfall profits of the newly wealthy Jewish families would unnaturally accelerate the process of development, leading to an exaggerated concern with external cultivation and a corresponding neglect of the internal. Mendelssohn's former protégé Lazarus Bendavid states the case quite clearly in his 1793 essay Something on the Character of the Jews, where he presents the Prussian Jews as the vanguard of the entire nation: "The enlightenment of the Jews, which would have been accomplished by degrees, received a powerful upswing all of a sudden. Through it, enlightenment lost in strength what it seemed to gain in time. The unfortunate Seven Years' War broke out, in which a large portion of the Jews became rich, and one began the enlightenment among this people at the place where other peoples usually endwith the cultivation of the external at the expense of the internal." ${ }^{49}$ What these examples demonstrate is that a concern with the value and the inherent risks of both social intercourse and societal development, a concern central to much of Mendelssohn's philosophy, had a powerful resonance in the context of late eighteenth-century Berlin.

Scholars have tended to focus on the philosophical and theological origins of Mendelssohn's attitude toward sociability and cultivation, stressing his indebtedness to Leibnizian notions of perfectibility, or his adoption of Wolff's eudaimonism, or his dialogue with Maimonides and Spinoza. There are good reasons for such an approach. The influence of these philosophical predecessors on his theories is undeniable, and both Mendelssohn and his contemporaries tended to explain the evolution of his ideas in similar terms. In fact, one finds little in the reactions to Mendelssohn's works to suggest that his contemporaries made an explicit connection between his philosophy and the urban experience. This absence is hardly surprising, however, when one considers the nature of philosophical discourse in the eighteenth century, which focuses on the relations between particular theories rather than on the material preconditions of their origination. As soon as one shifts the focus from an abstract history of ideas and begins to evaluate his works 
against the backdrop of this social context, however, it becomes difficult to ignore their urban themes. The resonance of questions regarding sociability was particularly strong among the Berlin Jews, whose tentative steps toward modernization and assimilation had not only run up against legal barriers from without, but had also produced the first strains of tension between elites and intellectuals within the community, with the latter group expressing its fears regarding a trivialization of enlightenment. Mendelssohn's remarks on the dialectic of cultural development in his letters and in his Exodus commentary thus appear to owe much to the specific concerns of the Berlin Jewish community. At the same time, however, as numerous negative representations of urban life from the period demonstrate, these concerns can also be placed within the framework of a broader urban discourse on the potentially deformative effects of increasing affluence, one of the central themes in eighteenth-century commentaries on big-city life.

\section{Sociability and Historical Consciousness in Jerusalem}

An awareness of the constellation of sociability, modernity, and urban life that impacts Mendelssohn's thought in this period can open up new perspectives on his late work, especially as regards his understanding of historical change. Although scholarly interest in the philosopher's view of historical knowledge has increased in recent years, there is still a tendency to downplay the role of any coherent philosophy of history in his work..$^{50}$ Nonetheless, even though Mendelssohn explicitly rejects all philosophies of global human progress, he does possess a stadial theory of societal evolution, and his later works reflect his concern with the ambiguous impact of this evolution. Only when one views these later works together with Berlin texts from the 1780s, however, does it become possible to recognize these concerns for what they are. Jerusalem, Mendelssohn's penultimate major publication, offers a case in point. The work was conceived as a response to a pamphlet by August Cranz, who had challenged Mendelssohn to explain how the conception of Judaism articulated in his 1782 preface to Menasseh ben Israel's Vindiciae Judaeorum was really "Jewish" at all. Written in two-parts, Jerusalem first offers a sustained defense of religious tolerance on the basis of natural-law theory and then provides Mendelssohn's most extensive theoretical treatment of the Jewish faith. The work has been subjected to a great 
deal of interpretive scrutiny, with the majority of commentators concluding that Mendelssohn's attempt to reconcile Judaism and enlightenment, though admirable, fails to realize its aims. ${ }^{51}$ Rather than attempt a comprehensive analysis of Mendelssohn's arguments, I want to focus here on one aspect of the work that has been a source of some perplexity among interpreters. I am referring to Mendelssohn's discussion of the commandments in the second part of the essay and the critique of modern textuality that accompanies it.

In Jerusalem, the author offers a theory of Jewish ceremonial law that allows him to posit an equal opportunity of salvation among all faiths while justifying his adherence to Jewish religious practice and his belief in the unique vocation of the Jews. For Mendelssohn, the special character of Judaism, at least in its purest and most original form, lies in its exemplary reconciliation of theory and practice. ${ }^{52}$ Picking up on his argument from the Bible commentary, he claims that the Jewish ceremonial laws were intended to link religious knowledge to the activities of daily life, thereby avoiding the danger of idolatry he associates with textual representation. The ceremonial laws transformed truth into living knowledge; they helped maintain a sense of community; they fostered social intercourse among all members of the nation, regardless of station or occupation. As Mendelssohn remarks: "Thus teaching and life, wisdom and activity, speculation and sociability were most intimately connected; or rather, thus should it be, according to the initial plan and purpose of the lawgiver." 53

Mendelssohn's immediate aim in offering this elucidation of ancient Judaism is to support his two main claims: first, that Judaism has never attempted to coerce belief, only to prescribe certain behaviors; and, second, that no state has the right to coerce belief. By way of the former claim Mendelssohn recasts contemporary Judaism as a voluntary association that can be integrated into the modern state without any changes in Jewish practice. ${ }^{54}$ What proves most interesting in the context of this study, however, is the extent to which his characterization of ancient Judaism both reiterates the by now familiar emphasis on the value of sociability and suggests a historical displacement similar to the one found in "The Division of Offices and Estates." His representation of the Jewish past bears a striking resemblance to the eighteenth-century ideal of a knowledge dedicated to the cultivation of the whole person, an ideal that is linked by sympathetic contemporaries to the experience of an enlightened urban sociability. Mendelssohn represents the commandments as the perfect reconciliation of life and thought, 
theory and practice. In his words: "Religious and moral teachings were to be connected with everyday activities." 55 The performance of the ceremonial laws inspires reflection on the sacred truth at their foundation and leads the individual to seek the advice of other men of wisdom. The deeper knowledge that results increases the individual's sense of fulfillment in addition to strengthening his connection to the community as a whole.

Mendelssohn thus conceives the commandments as a source of practical rather than abstract theoretical knowledge, not practical in terms of instrumental utility but in the sense of being directed toward a life in harmony with the vocation of man. The discussion in Jerusalem is, of course, overtly religious; yet, from an epistemological standpoint, the state of affairs he describes is virtually identical to the secular ideal that appears in Gedike's Berlin letters. There as well, the will to know arises from an occupation with man as human being pure and simple rather than as the representative of a particular profession, while knowledge itself is refined and disseminated through social intercourse for the improvement of communal life. Moreover, Mendelssohn's valorization of the face-to-face interaction that characterized social life in ancient Judaism and his later denigration of textuality parallels similar claims made in support of big-city life in the period. Gedike, for example, bases the epistemological ideal he associates with Berlin on a model of oral presentation and discussion, one that entails a greater degree of immediacy, spontaneity, and dialogical intent than the written text in its traditional forms. Much has, of course, been made in recent scholarship, most notably in the works of Derrida, of the eighteenth century's predilection for the spoken word. Whatever the precise sources of this predilection, what is significant to the present argument is that a connection between the urban experience and a spontaneous, face-to-face, oral sociability appears in numerous contexts, not just Gedike's letters, but also Nicolai's early complaints about Germany's absent capital city and Lessing's complex representation of social interaction in Minna von Barnhelm. Even a resolutely antiurban text like the aforementioned "Letter from a Newly Transplanted Big-City Dweller" stresses the importance of conversation in the big city.

Mendelssohn, then, appears to construct his image of ancient Judaism with the help of an eighteenth-century urban ideal, albeit one that was only imperfectly realized in the actual city. What seems paradoxical in this regard is the fact that his own characterization of the eighteenth century places it in direct opposition to this ideal. Rather than an era of face-to-face sociability, 
Mendelssohn sees his age as one of isolation exacerbated by an overabundance of texts: "We teach and instruct one another only through writings; we learn to know nature and man only from writings. We work and relax, edify and amuse ourselves through overmuch writing. The preacher does not converse with his congregation; he reads or declaims to it in a written treatise. The professor reads his written lectures from the chair. Everything is the dead letter; the spirit of living conversation has vanished." ${ }^{56}$ Mendelssohn attributes this state of affairs to the invention of the printing press, thus failing to offer any detailed explanation of the mechanism through which human life comes to be dominated by textuality. His critique, however, can also be viewed within the framework of urban life, if we return our attention to the city's allegedly more threatening incarnation: not as a site of spontaneous sociability but as the condensation point for an expanding objective culture that threatens to interfere with a natural trajectory of individual development.

Mendelssohn's characterization of the problem points to its historicalphilosophical component. After lamenting the general decline in social contact, he writes: "Hoary age has lost its venerableness, for the beardless youth knows more from books than the old man knows from experience. Whether he understood it correctly or incorrectly does not matter; it is enough that he knows it, bears it upon his lips, and can talk about it more boldly than the honest old man who, perhaps, has the ideas rather than the words at his command." ${ }^{77}$ The dilemma here stems from the fact that knowledge objectified as text can be detached from the experience that gave rise to it and can be appropriated by those not ready to receive it. Whereas, as Mendelssohn points out in his characterization of ancient Judaism, the teacher can adapt his oral instruction to the level of development of his charges, the written work contains his thought in its most sophisticated form. For the author the work embodies the knowledge acquired through a lifetime of experience, but for the individual who ingests it prematurely it has no experiential connection. It degenerates into mere performance. Again we have a mismatch between the cultural surplus (here in the form of knowledge) that has evolved historically and the needs of specific individuals. In a society overwhelmed by texts, the individual acquisition of knowledge is no longer pegged to an organic progression through universal stages of human life. Wisdom in the traditional sense has become irrelevant, because the availability of information in textual form obliterates the value of experience. 
The concern with a devaluation of experience expressed here, the remarks on the fragmentation of experience in the "Division" essay, and the admonition against excessive luxury in the Exodus commentary constitute three prongs of an incipient critique of modernity that takes shape in Mendelssohn's late work. At the root of this critique is the by now familiar ideal of individual development that proceeds through a series of natural, predetermined stages, a development that in the best case gives rise to a total cultivation encompassing both interior and exterior. Each of the negative phenomena that Mendelssohn discusses entails a deformation of this development, either through disproportionate emphasis on one aspect of human nature (as with specialization) or through an unnatural acceleration of the process (as with excessive luxury and textuality). In all cases the fundamental problem can be described as a disjuncture between social and individual evolution. This disjuncture has its roots in the historical evolution of society and threatens to detach the interior from the exterior human world. The division of labor necessary for the efficient functioning of a highly developed society requires a restriction in the scope of individual activity that may hinder full development of the whole array of potential human faculties. With regard to excessive luxury, the cultural surplus made available through the civilizing process presents an irresistible temptation to individuals lacking the appropriate level of inner cultivation. As a result, rather than being reinvested to further the development of human capabilities in accordance with the destiny of man, it is squandered on superficialities. In the case of excessive textuality, the premature ingestion of knowledge without a corresponding level of life experience can cause knowledge to degenerate into a mere means of self-aggrandizement.

The basic problematic that underlies Mendelssohn's criticisms, namely, that an advanced level of societal development can put individual cultivation at risk, is at the heart of both Gedike's and Garve's anxieties regarding bigcity life. Especially the fear of an unnatural acceleration and deformation of the individual maturation process and its social consequences is a recurring theme in both their essays and in eighteenth-century city literature more generally. Garve, in the essay discussed previously, compares the urban artist or intellectual to a plant in danger of being "plucked too early." ${ }^{58}$ Gedike speaks of the diversity in Berlin, admitting that it has resulted in an enlightenment "brought to fruition prematurely." ${ }^{59}$ He employs a related image of deformation in his remarks on recent developments among the Berlin Jews: 
"Woe to us, should this mildew destroy all the hopeful blossoms before they have borne fruit!” ${ }^{60}$ And Friedrich Zöllner, to give one more example, describes the impact of the big city with the help of an anthropological framework almost identical to the one used by Mendelssohn. Zöllner writes: "In the big city the youth can speak of a thousand things - both good and bad which have never even reached the ears of a man who has grown old in a small town." 61

\section{Enlightenment, Modernity, Metropolis}

A final example of this problem of uneven development can be found in one of Mendelssohn's best-known late works - the essay on enlightenment that appeared in the Berlinische Monatsschrift in 1784. Here the author presents a conceptual model that makes little sense without the backdrop of his other writings from the period. He absorbs his earlier remarks on luxury in the Pentateuch translation and his comments on excessive textuality from Jerusalem into a theory of national "education" (Bildung), which, he claims, can be broken down into the constituent components of "enlightenment" and "culture." All three of these concepts describe what Mendelssohn terms "modifications of social life; effects of the hard work and efforts of human beings to improve their social condition." 62 Enlightenment pertains to the theoretical and culture to the practical sphere. As long as the two are kept in balance, a given nation can be described as having Bildung and can expect a high degree of happiness. Exaggeration of one or the other, however, can lead to disintegration.

Mendelssohn's arguments here, as in so many of his writings from this period, focus on the potential collision between individual and societal needs, and this collision is inextricable from historical-philosophical considerations. The tension is already indicated by the distinction he draws between the vocation of the individual as "human being" (Mensch) and as "citizen" (Bürger), a distinction that also echoes his comments on the needs of society versus the needs of humanity in the "Division" essay. According to the author, the level of enlightenment that is useful to the individual as human being may not always match the level appropriate to him in his concrete historical and social determinacy. He writes: "Certain truths which are useful to the human being as human being, can at times be harmful to him as 
citizen." ${ }^{63}$ The implication of this claim is that individual knowledge can be out of step with the needs of a particular form of social organization. In other words, as human being pure and simple, an individual can never suffer as a result of too much knowledge. As a representative of a particular estate and a particular occupation living in a specific social-historical context, however, this knowledge can indeed lead to a conflict between individual desires and the demands of one's station.

What this means for the author is that there may be times when access to knowledge must be restricted in order to avoid social instability, at least with regard to those kinds of knowledge he associates with the "extraessential vocations of the human being." As Mendelssohn argues in this context: "If human beings' essential vocations have been brought into conflict with their extra-essential vocations, if one is not permitted to disseminate certain useful truths that embellish humanity without thereby in any way tearing down the principles of religion and ethics inherent in human beings, then the virtue-loving man of enlightenment will proceed with caution and discretion, and prefer to indulge prejudice rather than drive away the truth that is so wound up with that prejudice." 64 Mendelssohn's conservatism on the question of popular enlightenment is worth noting, but more significant for our purposes is how it is entwined with concerns regarding the danger of knowledge ingested prematurely, the same danger that he addresses in the discussion of textuality in Jerusalem. Knowledge in and of itself can never be bad, rather, the problem arises from its inappropriateness to the developmental level of the individuals who have access to it. It is important to recognize the historical-philosophical aspect of Mendelssohn's argument here. The truth that he views as belonging to the "extra-essential" of man consists in those forms of knowledge and cultivation that emerge after a long process of societal evolution. For Mendelssohn, there can be no fundamental conflict between the essential and extra-essential vocations of man; the dilemma he refers to here can only arise as a result of an uneven historical development, one that leaves certain segments of society unprepared to appropriate the knowledge that is socially available. Once again, then, Mendelssohn is addressing the problem of objective culture, pointing out the way in which the availability of knowledge detached from experience can short-circuit the progression of the individual through the natural stages of his development. As the use of the term "embellish" (zierend) in particular suggests, certain levels of truth must be seen as ornamental. They can be pursued only after 
the proper foundation has been laid, lest they destroy the fragile balance of faculties that makes ethical behavior possible.

A related tension appears in Mendelssohn's discussion of the second central conceptual dichotomy of the essay, that between enlightenment and culture. He discusses both terms as they relate to the nation as a whole and to the individual, but it becomes clear as his argument progresses that enlightenment is a primarily individual affair, whereas culture is a social concern. Culture only becomes meaningful in a social context. Mendelssohn writes, for example, that in regard to culture there is no distinction between an individual's vocation as human being and as citizen: "In regard to culture, these considerations collapse into one another since all practical perfections have value merely in relation to the life of society. Hence, they must correspond solely and singularly to a human being's vocation as a member of society. The human being as human being is not in need of culture, but is in need of enlightenment." ${ }^{65}$ Ideally, enlightenment serves as a conceptual anchor for culture: "Enlightenment is related to culture as, generally, theory is related to practice; knowledge to ethics, criticism to virtuosity." ${ }^{66}$ Knowledge, in other words, whether of the true ("theory"), the beautiful ("virtuosity"), or the good ("ethics"), should always be immediately relevant to social practice, and this practice must in turn be subject to justification on the basis of theoretical reflection. One of the central implications of Mendelssohn's dialectic, then, is that enlightenment, understood as the acquisition of theoretical knowledge, must always be evaluated with regard to its social context. The progressive aspects of this argument have not been lost on interpreters, but one should not neglect the fact that what really drives his arguments is concern over the detachment of culture and enlightenment. If, as one commentator has put it, the central insight of the essay is that "enlightenment and culture determine one another reciprocally," then it is also crucial to recognize the anxiety at the root of this insight ${ }^{67}$ In practice, as Mendelssohn's list of examples makes clear, an effective balance is rarely achieved; instead, either theory ("enlightenment") or practice ("culture") becomes dominant. Too much enlightenment, according to Mendelssohn, leads to "hardheartedness," "egoism," "irreligion," and "anarchy," terms that suggest a hypertrophic individualism and a loss of social unity. A surfeit of culture, on the other hand, gives rise to "opulence," "hypocrisy," "weakness," "superstition," and "slavishness." In this case the terms indicate not only an 
intensification of sensuous affect, but also a loss of individual will, a subjugation of the rational self to stimuli of the external world. The crucial point here is that the very idea of too much enlightenment or culture only makes sense within the framework of a theory of societal evolution, one that recognizes that the availability of objectified social knowledge that has evolved over time may not correspond to the needs of individuals living at a given historical moment.

One can read the enlightenment essay as Mendelssohn's attempt to reconcile his lifelong belief in the value of sociability and cultivation with his increasing perception of their potentially damaging impact on certain individuals. By breaking down the idea of civilization into its component parts, he can argue for the inherent value of all cultural and intellectual achievements in theory, while simultaneously insisting that they may pose a threat to some individuals in practice. It is still the most advanced societies in which individuals have the best chance of developing all their capacities and thus fulfilling their divine vocation as human beings, but the pursuit of this goal now appears to be beyond the reach of certain social groups.

In familiar fashion, Mendelssohn presents his conceptual model as a historically unspecified framework that can explain, among other things, the rise and fall of nations. It appears, however, to owe a significant debt to the urban experience of late eighteenth-century Berlin, a location in which the balance Mendelssohn sees as crucial for authentic cultivation was considered by many to be at risk. The most convincing evidence for such an urban reading can be found in the city texts by Garve, Gedike, and Zöllner, which also appeared in the mid to late 1780 s, and which articulate this same risk on the basis of a theory of uneven development remarkably similar to the one employed by Mendelssohn. It is also worth noting the common concern with the lower classes, mentioned explicitly in Gedike and Zöllner and implied in Mendelssohn's remarks, on the need to limit enlightenment in cases where it might destroy existing moral and religious tenets. By viewing Mendelssohn's model here in combination with the criticisms in his other essays and the remarks of other Berlin intellectuals, one gains a sense of the extent to which the big city, viewed as the focal point of a material culture increasingly detached from an allegedly organic cycle of life, connects with an emerging critique of modernity. Indeed, the problem of a premature enlightenment, which occupies Mendelssohn and which Gedike, Garve, and Zöllner depict 
as rooted in the very structure of the metropolis, suggests that the enlightenment debate itself, at least for the Berlin participants, was to a large degree driven by the perceived ambivalences of contemporary urban life.

This contextualization of Mendelssohn thus helps illuminate the degree to which important elements in his philosophy can be linked to urban experience. Among these elements, I would argue, one must also include his alternative to the "disequilibrium" that threatens the present - an idealized mode of sociability that he locates in the Jewish past but that more likely has its origins in the eighteenth-century city. Somewhat surprising in this context is that Mendelssohn voiced his concerns at a time when the proximity of Berlin social life to this ideal, the integration of theory and practice, was as close as it had ever been. The new constellation of individuals that came to shape Berlin's intellectual life in the 1770 s and 1780 s, including Gedike and Zöllner as well as Johann Jakob Engel, Ernst Ferdinand Klein, Carl Gottlieb Svarez, Christian Gottlieb Selle, and Johann Erich Biester, were almost all officials of the Prussian state. The issues debated in secret in the Mittwochsgesellschaft and publicly in the Berlinische Monatsschrift thus had practical policy implications in a way that the earlier discussions of the Gelehrtes Kaffeehaus did not. Even Mendelssohn's own writings, including his introduction to the republication of Menasseh Ben Israel's treatise and Jerusalem in 1783 , take a decidedly practical and political turn in these years.

\section{Conclusion}

The interpenetration of sociability and an incipient critique of objective culture in Mendelssohn's late works suggests that the pheneomena of urban life helped inspire a discourse on modernity that was beginning to take shape in the period. Underlying Mendelssohn's various criticisms is a quintessentially modern concern: that knowledge and the totality of lived experience are becoming detached. This same fear, which later comes to be understood in terms of specialization and of culture as a "second nature," echoes through the works of nineteenth- and twentieth-century diagnosticians of modernity, from Nietzsche to Simmel and Weber. Mendelssohn's works, however, also reveal the contradictions of a late eighteenth-century consciousness caught between the desire to understand its own historical specificity on the one hand and the desire to subsume that specificity under a 
transhistorical theory of human nature on the other. An important distinction between Mendelssohn's reflections and those of his successors lies in his seeming unwillingness to acknowledge that the contemporary phenomena he addresses, whether positive or negative, are historically unique.

This unwillingness finds its most resolute expression in Mendelssohn's rejection of the idea of global progress, which he makes explicit in a critique of Lessing from the second part of Jerusalem. ${ }^{68}$ Against the theory of collective human evolution presented by Lessing in his 1780 treatise Education of the Human Race, Mendelssohn maintains that "individual man advances, but mankind continually fluctuates within fixed limits." ${ }^{69}$ His insistence on the primacy of the individual in this context can be seen as one more articulation of the ideal of personal cultivation that informs so much of his philosophy. The city, to the extent that one views it as the source of this ideal, as the locus of an experience of individual self-improvement on the basis of an enlightened sociability, would seem to be at odds with the development of an evolutionary historical consciousness. Urban cultivation appears as a transhistorical ideal, realizable and realized, according to Mendelssohn's interpretation of both Greek and Jewish antiquity, at different historical moments. The same claim holds for his contemporaries as well. The "world" that some eighteenth-century commentators equate with urban society, and the cosmopolitan outlook purported to result from immersion in it, are not viewed as modern in any absolute sense. Christian Garve, for example, introduces his remarks on city life with a reference to Cicero's claim that true urbanity can only be found in Rome. ${ }^{70}$ As a center of sociability, the city appears linked more to an archetypal or exemplary conception of history than a genetic one.

Precisely as a point of intersection between the archetypal and the genetic, however, the city helps inform conceptions of historical change in the period. The metropolis represents European civilization in microcosm. It serves as a kind of shorthand for the cultivation of late eighteenth-century Europe, and in this role it testifies to a long-term historical development toward ever increasing levels of wealth and refinement - to the progress of humankind. As the embodiment of "civilization" understood as a relative category, however, one opposed to the state of nature, the European capitals also lend themselves to comparisons with the great cities of antiquity. Johann Peter Süßmilch, it will be remembered, reflects in his Berlin treatise on the replacement of ancient powerhouses like Tyre, Carthage, and Rome 
with London, Paris, and Amsterdam (with Berlin presumably close behind). In the case of Berlin the preferred but by no means the only comparison is with Athens, as in Gedike's celebration of both cities' lack of a university. The troubling prospect that arises from these parallels is that Europe's ultimate fate will be the same as that of the ancient empires, whose demise is often traced back, following Rousseau, to the same degenerate obsession with luxury and pleasure that allegedly threatens the eighteenth-century capital city. The collision between two kinds of urban experience - of cultivated sociability on the one hand and the deformative impact of surplus production on the other-thus provides the basis for a conception of history that is at once linear and cyclical, a conception that helps structure several of Mendelssohn's late works. The development of individual cultures follows a linear, stadial trajectory from barbarism to cultivation, but, once achieved, this same cultivation threatens to turn back on itself and cause the entire process to begin again. Late eighteenth-century Berlin becomes a testing ground for efforts to gauge the probability of such a historical reversal.

The hopes and concerns that appear in Mendelssohn's late works continue to exercise the public in the decades following his death. In fact, it is the rise of Berlin salon culture at the end of the century that ultimately brings the perceived ambiguity of sociability to the attention of a wider audience and, at the same time, reveals the ill-fated convergence of these concerns with the first articulations of modern anti-Semitism. On the positive side, one finds texts like Friedrich Schleiermacher's Attempt at a Theory of Sociable Behavior, which appeared in the Berlinisches Archiv der Zeit und ihres Geschmacks in 1799. The essay was inspired by Schleiermacher's experiences in the salons of Henriette Herz, Rahel Levin, and others following his 1798 arrival in the city. ${ }^{71}$ In it he posits unconstrained sociability as the individual's most perfect realization of his own humanity, employing a rhetoric of holistic cultivation and social integration that evokes Mendelssohn and his Berlin contemporaries. Even as Schleiermacher was using the Berlin salons as the foundation for his own theory of Bildung, however, others were decrying them as the epitome of artificiality. This negative attitude already makes an appearance in Lazarus Bendavid's 1793 condemnation of a merely external enlightenment within the Berlin Jewish community, one driven by the windfall profits that followed the Seven Years' War. It receives a far more pernicious articulation, however, in Karl Wilhelm Grattenauer's vicious at- 
tack on the Jews, and on the salon women in particular, in a series of 1803 pamphlets that began with a treatise entitled Against the Jews.

As Deborah Hertz has pointed out, Grattenauer's antiassimilationist stance and protoracial arguments make him a strong candidate for the dubious distinction of being the first modern anti-Semite. ${ }^{72}$ His arguments, however, also turn on the notion of a "false" or superficial cultivation, the idea that the celebrated grace, charm, and accomplishment of the salonnières represent nothing more than external polish or "Appretur," undertaken for purely opportunistic reasons. Regardless of their achievements, according to Grattenauer, Jewish women will never be truly cultivated, because they are incapable of integrating their talents into a unified personality: "[They] possess all of the individual qualities that might allow them to lay claim to true charm, if it were possible to teach them the art of combining all of these individual qualities and presenting them as a complete image of beautiful femininity." 73 The emphasis on disunity here hearkens back to the fashion paradigm discussed in Chapter 2, with the addition of an ethnic component to the argument. It is not the city that is the problem here but the Jewish "national character." For Grattenauer, the metropolis remains the site of a personally enriching sociability, but Jews are excluded from making any contribution to or deriving any benefit from this sociability on the basis of an essentialized Jewish identity. These women, he claims, simply cannot acquire the "refined tact" that they lack, not in Paris, Berlin, Vienna, or anywhere else. ${ }^{74}$ The fact that Mendelssohn's complex and universal dialectic of sociability is replaced here by a crude, ahistorical identification of Jewishness and inauthenticity, and that this view exerted such a powerful influence around the turn of the century, forms a sobering postscript to this particular narrative of the city as a site of historical consciousness. 


\section{Conclusion: Metropolis, Hybridity, and Historical Consciousness}

In 1773, the same year in which the first volume of Friedrich Nicolai's Sebaldus Nothanker appeared, the engraver Johann David Schleuen completed a new map of Berlin. Along with the bird's-eye view of the urban landscape, the map also included miniature drawings of Berlin's most famous architectural landmarks and a short ode to the city, reprinted here in its entirety:

Diese Stadt, da Preußens Ruhm

Sich den Königs-Sitz erwählet, Hat des Glückes Eigentum

Ihr zum Braut-Schatz abgezählet.

Sie gleicht einer kleinen Welt,

Die der großen beste Schätze

Conzentriert beisammenhält.

Was Paris zum Wunder macht,

Ist auch in Berlin zu finden,

Und des Tibers stolze Pracht

Muß jetzt an der Spree verschwinden.

London sei so groß es will,

So darf ihm Berlin nicht weichen.

Denn kann's ihm nicht gänzlich gleichen,

So gebricht ihm doch nicht viel.

Hier ist Griechenlands Athen,

Hier sind Asiens Paläste,

Auf den meisten Gassen gehn

Weit entlegner Länder Gäste.

Hier ist ein berufner Thron,

Welchen Macht und Klugheit stützet 
Und der auf demselben sitzet

Ist ein weiser Salomon. ${ }^{1}$

This city, which the glory of Prussia

has chosen as its royal seat,

Has had the gifts of good fortune

paid out to her as a dowry.

She is like a world in miniature,

in which the best and greatest treasures

are concentrated together in one place.

That which makes Paris miraculous,

is also to be found in Berlin,

And the proud splendor of the Tiber

Must now fade before the Spree.

However large London may be,

Berlin need not give way.

For though she cannot quite measure up

She is still not far behind.

Here is Athens of ancient Greece,

Here are the palaces of Asia,

On most of the streets walk

Guests from far-away lands.

Here is an established throne,

which power and prudence sustain

And the one who sits upon it

Is a wise Solomon.

The poem is certainly no masterpiece, but it offers a snapshot of late eighteenth-century urban consciousness and can thus serve as a useful starting point for a recapitulation of some of the major themes of this study. The Berlin that takes shape in these lines exhibits a double ambiguity, one that is fundamental to the discourse on the city in the period. At issue here is an equivocation on two levels, that of the city's present identity as well as its relationship to history. A cursory reading of the poem might suggest a different conclusion, at least as regards Berlin's current status. The author begins and ends his ode with a reference to the throne, indicating a rather 
straightforward identification of Berlin with its function as capital of Prussia. This foregrounding of Prussia does indeed point to a key element in the eighteenth-century conception of the city. The centrality of both the court and state to representations of Berlin in this period can hardly be underestimated; all of the works considered in this study depict the city as inseparable from the "enlightened" absolutism of the Hohenzollerns. As we have seen, Friedrich Gedike expresses the metonymic relation between city and state with the greatest concision, referring to Berlin as "emblem of the Prussian monarchy." But this same association can be discerned in Lessing's Minna von Barnhelm, where the city appears as royal residence and headquarters for the Prussian army, in Nicolai's "topography of tolerance" in Sebaldus Nothanker, and in Mendelssohn's late essays, where the author appears to filter his reactions to urban phenomena through reflections on the development of state and nation.

Schleuen's poem, however, despite or perhaps even because of its panegyric ambitions, also leaves the reader with a sense of the hybrid character of Berlin. The marriage metaphor with which he begins underscores the city's independent identity even as it posits an insoluble connection with "the glory of Prussia." Following the description of the fortunate coupling is a list of Berlin's attractions. Only the palaces, however, suggest an immediate connection to the royal family and their activities, whereas the other attractions - the treasures (presumably cultural), the international visitors, Berlin's impressive size, and its role as a modern-day Athens - have at most an indirect relationship to Prussia. Indeed, the reference to the "established throne," inasmuch as it appears as the final item in this list, effectively absorbs the court, though not necessarily the state, into a more comprehensive urban framework. This conception of Berlin as an independent entity is strengthened by the comparison with Rome, Paris, and London, a gesture that detaches Berlin from the Prussian framework and places it in competition with a group of European metropolises too large and complex to identify with the expression of any single ruler.

What the poem suggests, and what the various works considered in this study confirm, is that the association of Berlin with Prussia and its king often forms the basis for an investigation of precisely those aspects of the city that exceed the conceptual framework of either state or court. The aforementioned discussion in Sebaldus Nothanker, to give just one example, reveals the autonomy of the urban space even as it endorses royal authority over 
the city. Even the distinction between state and court, carried out with varying degrees of consistency in eighteenth-century representations of Berlin, speaks to the city's autonomous role as a point of condensation for divergent and imperfectly understood processes of modernization. Particularly in its role as a capital city (Hauptstadt) rather than merely a court city (Residenzstadt), Berlin served as the locus of new, rationalized forms of economic production, an increasingly independent state bureaucracy staffed largely by the educated middle class, and, most important for the authors and works that have been the focus of this study, an emergent civil society. These new social, economic, and political frameworks coexisted alongside older ones, and the result was a sometimes inspiring, sometimes unsettling hybridity. In the words of one previously cited visitor, "Berlin is capital city, royal residence, manufacturing center, trading city, provincial city, village, and farm - all together within a single city wall." 2 The real significance of representations of late eighteenth-century Berlin lies in their explicit or implicit engagement with this hybridity, a hybridity that challenges commentators to develop new frameworks for conceptualizing the origins and implications of modern urban phenomena.

Although the references are subtle, one can discern in Schleuen's poem three separate strands of urban discourse that are crucial to the eighteenthcentury discussion of the city. Berlin is simultaneously the center of royal authority, the crystallization point for large-scale sociocultural phenomena, and the locus of a vibrant social and intellectual exchange. Schleuen only hints at this final aspect of the city. The eighteenth-century discourse on urban sociability echoes faintly in the reference to Athens, with its connotations of the polis and Socratic philosophy, as well as in the remark on Berlin's cosmopolitanism. By contrast, it is precisely the city's role as a center of social intercourse that comes to the fore in the works of Gedike, Nicolai, Lessing, and Mendelssohn. Here, as in the various other late eighteenthcentury essays on urban life, the big city emerges as a site of a spontaneous, unrestricted communication and interaction that challenges existing social hierarchies. In his early remarks on Germany's lack of a capital city, Nicolai connects this spontaneous sociability to the development of the universal perspective necessary for great art, and this notion of the universalizing impact of urban experience reappears in virtually all representations of the city in the period. Gedike writes of the diversity of opinions and experiences to which one is exposed in the city, claiming that this exposure helps one 
guard against both pedantry and provincialism. Lessing's Minna von Barnhelm offers what is perhaps the most intriguing articulation of this idea. Here the architecture of the drama itself suggests a model of nonregulated urban sociability as the basis for overcoming prejudice. In Lessing's work, Berlin appears as the locus of a multiperspectivity that fosters empathy even as it encourages the transcendence of perspective altogether.

Lessing's representation of Berlin also points to the eighteenth-century perception of the city as a space of practical education aimed at the creation of a unified personality, at the balanced development of human faculties. The reciprocal relativization of viewpoints that occurs through the various characters' interactions provides an example of the epistemological implications of urban sociability, which hinders extremism at the same time as it leads to higher levels of awareness. A variation on this same theme can be found in Nicolai's Sebaldus Nothanker, in which the author opposes the intersubjectivity of the urban experience to the isolation and narrowminded pedantry of university philosophy. And Gedike, in a similar vein, celebrates Berlin as home to the gentleman scholar, the well-integrated individual who combines knowledge, virtue, and refinement into a complete package. In this role as a kind of anthropological training ground, providing practical knowledge and insight into the universally human, the big city is entwined with an Enlightenment ideal of self-cultivation or Bildung.

This ideal finds its most extensive articulation in the works of Moses Mendelssohn, for whom urban sociability functions not only as a precondition of his own intellectual production but also as a category of philosophical inquiry. The discourse on sociability is, of course, widespread in the German Enlightenment. Nonetheless, as I have tried to show, Mendelssohn's position, indeed his very engagement with the topic, can only be fully understood against the backdrop of late eighteenth-century Berlin, which presented unique challenges and opportunities to members of a Jewish community in the early stages of modernization. What proves most interesting in this context is the dialectic of sociability addressed in Mendelssohn's late essays. The ideal of an organic unfolding of individual capacities at the foundation of his philosophy presupposes an advanced society for its full realization; yet, as these essays suggest, the required level of societal complexity also gives rise to phenomena - excessive luxury, a devaluation of experience, and increasing specialization - that threaten this process.

The dilemma that takes shape in Mendelssohn's late work anticipates 
nineteenth- and twentieth-century criticisms, voiced by intellectuals ranging from Marx to Simmel, of a reified modern culture that has become a second nature and threatens to distort the "natural" unfolding of individual capacities. If later thinkers clearly recognize the metropolis as the locus of this distortion, however, in the eighteenth century such a recognition is only beginning to take shape. In this context the question of Berlin's hybrid character emerges once again. Berlin's role as a site of practical knowledge and cultivated sociability has an ambiguous, at times even oppositional relationship to its other roles, whether as the seat of royal authority or the nucleus of a protomodern bureaucracy and capitalist economy. The image of Berlin reflected in the works of Gedike, Nicolai, Lessing, and Mendelssohn arises from a consideration of the interrelations between these various elements of the urban environment. The troubling question of whether these elements can be harmonized is at the root of these authors' concerns about their own present and its possible futures. The attempt to understand Berlin, in other words, is an attempt to grasp the heterogeneity of contemporary life as a totality and to divine its historical implications. In the case of Gedike and especially Nicolai, it also entails an effort to map the evolution of that heterogeneity.

The hybrid status of the city is thus crucial to its role in the development of historical consciousness in the period. But there is another variable that must be added to the equation. Returning to Schleuen's poem for a moment, one is struck by a second level of equivocation in his characterization of Berlin, pertaining in this case to the city's status as a historical entity. Schleuen's Berlin is both an archetypal space and a uniquely contemporary phenomenon. Much of his imagery and diction suggests a conception of the metropolis as an ahistorical category, defined by prodigious size, prodigious wealth, and cultural refinement. The identification of Berlin with ancient Athens, the comparison of Friedrich II to Solomon, even the archaic ring of the reference to Rome as "the proud splendor of the Tiber" points to a conception of the city that disavows historical specificity. At the same time, however, Berlin's historical dynamism figures prominently in the author's praise. Berlin's rise is linked to the rise of Prussia; moreover, in his comparisons with Rome and London, he indicates the city's recent and still only partial achievement of metropolitan status, giving a sense of Berlin as part of a process of historical development.

The particular character of the reference to London also reveals the way 
in which historical specificity even seeps into the poem's apparently archetypal imagery. An eighteenth-century discussion of the advantages and disadvantages of unrestricted urban growth, in which critics regularly adduced London as an example, was in full swing in Germany at this time. It is difficult to imagine a contemporary reader confronting this remark without making a connection. Thus, through its invocation of the size of the metropolis, the poem participates in both a venerable literary tradition and in a contemporary cultural debate. A similarly dual resonance seems likely for the references to urban wealth as well-the "splendor" of Rome and Asia's "palaces" - especially when one considers the widespread concern with the degenerative effects of excessive luxury in the period and the identification of the metropolis as the center of such excess.

Schleuen's poem thus reveals the extent to which the big city, although it continues to be viewed in terms of ahistorical archetypes in the eighteenth century, simultaneously offers an occasion for calling these archetypes into question. The role of the metropolis in fostering an awareness of historical specificity can be seen in all the works under consideration in this study. Gedike's initial letter points explicitly to the traces of earlier epochs that can be discerned in the urban topography. Nicolai's Sebaldus Nothanker depicts the city as a site of confrontation between historical and ahistorical epistemologies, when, at the beginning of the Berlin section of the novel, Sebaldus unsuccessfully exhorts his Pietist companion to view the city in a historical rather than biblical context. A similar metropolitan challenge to ahistorical thinking, albeit a more subtle one, is operative in Lessing's Minna von Barnhelm, where it is incorporated into the structure of the drama. Lessing's investigation of the nonregulated urban space suggests several interesting connections between Berlin and eighteenth-century historical consciousness, but one of the most significant involves the role of urban experience in fostering an awareness of the historical contingency of truth. Tellheim's change of heart entails a renunciation of the abstract rationalism embodied in his concept of honor in favor of a more intersubjective, experiential model of knowledge.

The full complexity of the relation between urban experience and late eighteenth-century historical thought, however, is best captured by Mendelssohn's philosophy, specifically by his theory of sociability. As a space of cultivation, the big city is at once detached from and entwined with a sensitivity to historical change. The urban ideal of the cultivated individual, in 
possession of a practical knowledge of man and the world, is conceived as a model with universal validity. By the same token, however, the achievement of such cultivation always presupposes a process of historical development, inasmuch as true aesthetic and moral refinement is only possible in an advanced society. Thus Mendelssohn's dialectic, though only implicitly linked to the urban experience, nonetheless offers a compelling indication of the city's historical-theoretical ambiguity. As the microcosmic embodiment of an advanced society, the metropolis is simultaneously a universal and a historically determined space.

The real uniqueness of eighteenth-century Berlin lies in this historicaltheoretical dualism. The city not only fosters a sensitivity to historical specificity through its status as a crucible of modernity; to the extent that it is conceived as an archetypal and universalizing space, its representation also elicits attempts to reinscribe modern developments into an ahistorical framework. Eighteenth-century representations of Berlin both recognize its historical singularity and try to frame that singularity in terms of universal categories, whether in the obvious sense of taking recourse to literary convention in representing city life, or in the sense of fitting urban phenomena into allegedly universal theories of human nature and cultural development. An oscillation between the ahistorical universal and the historical particular, together with an effort to reconcile the two, characterizes all of the city texts investigated in this study. This oscillation demarcates the interpretive challenge presented by Berlin in the period. The point is not simply that the city encourages a recognition of the difference between past, present, and future, but that it also encourages the development of conceptual frameworks to theorize that difference. Herein lies Berlin's significance for an emerging hermeneutics of historicity.

This study was undertaken in order to illustrate the significance of the late eighteenth-century metropolis, especially Berlin, for the historical consciousness of the German Enlightenment. The value of such an approach lies primarily in the scope and inclusivity it entails. To the extent that the changes in historical consciousness in this period occur on a general societal level, any attempt to grasp them must necessarily consider a broader range of texts than those that are explicitly historiographical. Moreover, the focus on eighteenth-century Berlin and the sociocultural phenomena associated with it reveals the degree to which historical consciousness encompasses more that just representations of the past or the theoretical discourse surrounding 
those representations. On the contrary, I would argue that historical consciousness in the German Enlightenment can be best grasped through an investigation of representations of the eighteenth-century present. In the case of Berlin, because the city is recognized as the result of a process of historical development, these representations always entail a theory of how that present is entwined with its past and its future. It is the perceived relation between the elements in this triad rather than the conception of any specific element that best approximates the historical consciousness of the epoch.

The results of this investigation suggest that late eighteenth-century historical consciousness in Germany was characterized by an even greater degree of complexity than is generally indicated in the scholarship on this topic. This insight stems in part from a recognition of the variation among genres. An analysis of literary, philosophical, and journalistic sources reveals the extent to which the elements of historical consciousness embedded in a given text are shaped by the generic tradition in which that text participates. In other words, it is not only the representations of the city itself that are "pretextualized" by literary convention but also the historical-theoretical content of those representations. Not surprisingly, for example, one finds a greater emphasis on the archetypal in Schleuen's poem than in Gedike's letters on the city. Historical consciousness, in other words, is at least partly contingent upon the medium through which it is articulated.

One can, however, also point to a more substantive complexity. The nineteenth-century characterization of the Enlightenment as an "unhistorical age" relied on an opposition between an ahistorical rationalism perceived by nineteenth-century intellectuals and their own emphasis on historical process and the uniqueness of historical periods. An analysis of eighteenth-century representations of Berlin, however, reveals that these two paradigms often coexisted in the period, even within a single work. The city appears as both a machine and an evolving organism, both a site of historically unique opportunities and an archetypal space circumscribed by the operation of rational natural laws and the limits of human nature. Discussions of Berlin reflect a historical consciousness that is "modern," if one associates the term modern with attempts to understand historical change in evolutionary and causal terms. This evolution, however, is often reinscribed into an exemplary framework, employed in order to demonstrate a universal truth about the human condition, or incorporated into a cyclical theory 
of cultural development. To the extent that it uncovers this tension, the investigation of late eighteenth-century Berlin also illuminates one of the fundamental philosophical dilemmas of an Enlightenment struggling to negotiate between universalist aspirations and a recognition of its own historical singularity. 



\section{NOTES}

\section{CHAPTER 1}

1. Ernst Cassirer, The Philosophy of the Enlightenment, trans. Fritz C. Koelln and James P. Pettegrove (Princeton: Princeton University Press, 1951), 197; originally published as Die Philosophie der Aufklärung (Tübingen: J. C. B. Mohr, 1932).

2. Otto Brunner, Werner Conze, and Reinhart Koselleck, Geschichtliche Grundbegriffe: Historisches Lexikon zur politisch-sozialen Sprache in Deutschland, 8 vols. (Stuttgart: E. Klett, 1972-97). Although Koselleck edited the Geschichtliche Grundbegriffe together with Brunner and Conze, he is the one who has come to be associated most closely with conceptual history as a historical subdiscipline.

3. Among the most important authors and texts in this context are Peter Hanns Reill, The German Enlightenment and the Rise of Historicism (Berkeley: University of California Press, 1975); Reinhart Koselleck, Zeitschichten: Studien zur Historik (Frankfurt am Main: Suhrkamp, 200o) and Vergangene Zukunft: Zur Semantik geschichtlicher Zeiten (Frankfurt am Main: Suhrkamp, 1979); and Horst Walter Blanke, Historiographiegeschichte als Historik (Stuttgart-Bad Cannstatt: Frommann-Holzboog, 1991). Also significant for the discussion are a number of essay collections, most notably Wolfgang Küttler, Jörn Rüsen, and Ernst Schulin, eds., Geschichtsdiskurs, vol. 2, Anfänge modernen historischen Denkens (Frankfurt am Main: Fischer, 1994), and Hans Erich Bödeker et al., eds., Aufklärung und Geschichte: Studien zur deutschen Geschichtswissenschaft im 18. Jahrhundert (Göttingen: Vandenhoeck \& Ruprecht, 1986).

4. René Descartes, Discourse on the Method of Rightly Conducting One's Reason and Seeking Truth in the Sciences, in The Philosophical Writings of Descartes, trans. Robert Stoothoff (Cambridge: Cambridge University Press, 1985), 116.

5. Friedrich Wilhelm Taube, "Gedanken über die Verschönerung der Städte, mit einer historischen Nachricht, wie seit 1763 die vornehmsten Hauptstädte in Europa sich allmählig verbessert und verschönert haben," Deutsches Museum 2 (1776): 632-33.

6. Ibid., 641.

7. Ibid., 637.

8. For a discussion of this conception of the city, especially as it relates to conceptions of the human body in the period, see Richard Sennet, Flesh and Stone: The Body and the City in Western Civilization (New York: Norton, 1994), 255-81. 
9. See, for example, Silvio Vietta's discussion in Die literarische Moderne (Stuttgart: Metzler, 1992), 273-82.

10. Thorsten Sadowsky, "Gehen Sta(d)t Fahren. Anmerkungen zur urbanen Praxis des Fußgängers in der Reiseliteratur um 180o," in Wanderzwang - Wanderlust: Formen der Raum- und Sozialerfahrung zwischen Aufklärung und Frühindustrialisierung, ed. Wolfgang Albrecht and Hans-Joachim Kertscher (Tübingen: Max Niemeyer, 1999), 64.

11. Jean-Jaques Rousseau, Politics and the Arts: Letter to M. d'Alembert on the Theater, trans. Allan Bloom (Glencoe, Ill.: Free Press, 1960), 58-59.

12. The letter was written on August 18, 1756. Rousseau, The Indispensable Rousseau, compiled and presented by John Hope Mason (London: Quartet Books, 1979), 112-19.

13. N. J. H. Dent, A Rousseau Dictionary (Oxford: Blackwell, 1992), 46-49 (s.v. "Civilization").

14. For more on Rousseau's impact on urban discourse in eighteenth-century Germany, see Conrad Wiedemann, “'Supplement seines Daseins'?: Zu den kulturund identitätsgeschichtlichen Voraussetzungen deutscher Schriftstellerreisen nach Rom-Paris-London seit Winckelmann," in Rom-Paris-London: Erfahrung und Selbsterfahrung deutscher Schriftsteller und Künstler in den fremden Metropolen, ed. Conrad Wiedemann (Stuttgart: J. B. Metzler, 1988), 1-20.

15. "Über die Erzeugung und Erziehung in Berlin," Allerneueste Mannigfaltigkeiten 1 (1782): 148.

16. Ibid., 160.

17. Koselleck, "Moderne Sozialgeschichte und historische Zeiten," in Zeitschichten, 327.

18. Cassirer, Enlightenment, 198-99.

19. Friedrich Schiller writes: "The discoveries made by our European navigators in distant seas and on faraway coasts offer us a drama that is as edifying as it is entertaining. They show us peoples in the most various stages of cultivation encamped around us, just as children of different ages stand around an adult and remind him through their example of what he himself once was and where he began." Friedrich Schiller, "Was heißt und zu welchem Ende studiert man Universalgeschichte," in Schillers Werke: Nationalausgabe, ed. Lieselotte Blumenthal and Benno von Wiese, vol. 17 (Weimar: Herman Böhlaus Nachfolger, 1962), 364.

20. I would like to thank W. Daniel Wilson for bringing these particular examples to my attention.

21. On the relation between historical events and temporal structures, see Koselleck, "Moderne Sozialgeschichte und historische Zeiten," 327-31.

22. For a comprehensive study of their contribution, see Reill, Rise of Historicism.

23. Hans Erich Bödeker, "Die Entstehung des modernen historischen Denkens als soziohistorischer Prozeß. Ein Essay," in Küttler, Rüsen, and Schulin, Geschichtsdiskurs, 309. 
24. Rudolf Vierhaus, "Historisches Interesse im 18. Jahrhundert," in Bödeker et al., Aufklärung und Geschichte: Studien zur deutschen Geschichtswissenschaft im 18. Jahrhundert, 268.

25. Ibid., 269.

26. Ibid., 272.

27. Ibid., 274.

28. Blanke, Historiographiegeschichte als Historik, 115.

29. Ibid., 117.

30. This criticism comes despite the fact that Koselleck has insisted from the beginning on the need to evaluate concepts within their contexts; see, for example, Koselleck, "Begriffsgeschichte und Sozialgeschichte," in Historische Semantik und Begriffsgeschichte, ed. Reinhart Koselleck (Stuttgart: Klett-Cotta, 1978), 19-36. Conceptual history has also been criticized for other reasons, such as its lack of an adequate concept of "the concept," but these criticisms are not of immediate relevance for the argument I am trying to formulate here.

31. Both James J. Sheehan and Clemens Knobloch have pointed out that conceptual history often resembles a traditional history of ideas, with the "concept" simply taking the place of the idea. See Sheehan, "Begriffsgeschichte: Theory and Practice," Journal of Modern History 50, no. 2 (1978): 312-19, and Clemens Knobloch, "Überlegungen zur Theorie der Begriffsgeschichte aus Sprach- und Kommunikationswissenschaftlicher Sicht," Archiv für Begriffsgeschichte 35 (1992): 7-24. On the issue of social reality, see Jörn Rüsen's review of Historische Semantik und Begriffsgeschichte in Journal of Modern History 54, no. 2 (1982): 326-28.

32. For the arguments that follow, I am indebted to a number of sources. The two most important are Koselleck, Vergangene Zukunft, and Küttler, Rüsen, and Schulin, Geschichtsdiskurs.

33. Koselleck, "Vergangene Zukunft der frühen Neuzeit," in Vergangene Zukunft, 19.

34. Bödeker, "Entstehung des modernen historischen Denkens," 295.

35. [Gottlob David Hartmann], "Über das Ideal einer Geschichte," in Theoretiker der deutchen Aufklärungshistorie, ed. Horst Walter Blanke and Dirk Fleischer, vol. 2 (Stuttgart-Bad Cannstatt: Frommann-Holzboog, 1990), 689; originally appeared in Teutscher Merkur 6 (1774): 195-213.

36. Koselleck, "Historia Magistra Vitae: Über die Auflösung des Topos im Horizont neuzeitlich bewegter Geschichte," in Vergangene Zukunft, 50.

37. Schiller, "Was heißt und $\mathrm{zu}$ welchem Ende studiert man Universalgeschichte," 373; Johann Jacob Engel, "Über Handlung, Gespräch und Erzählung," in Blanke and Fischer, Theoretiker der deutschen Aufklärungshistorie, 2:602; originally appeared in Neue Bibliothek der schönen Wissenschaften und der freyen Künste 16 (1774): 177-256.

38. Frederick, king of Prussia, De la littératur allemande, ed. Christoph Gutknecht and Peter Kerner (Hamburg: Helmut Buske, 1969), 51-52.

39. Koselleck, "Historia Magistra Vitae," 51. 
40. Reill, Rise of Historicism, 53.

41. Koselleck, "Historia Magistra Vitae," 48.

42. Jürgen Habermas, "Aus der Geschichte lernen?" in Die Normalität einer Berliner Republik (Frankfurt am Main: Suhrkamp, 1995), 10-11.

43. Johann Gottfried Herder, Auch eine Philosophie der Geschichte zur Bildung der Menschheit, in Sämtliche Werke, ed. Bernhard Suphan, vol. 5 (1891; reprint, Hildesheim: Georg Olms, 1967), 489-90.

44. Friedrich Nicolai, Beschreibung einer Reise durch Deutschland und die Schweiz im Jahre 1781, nebst Bemerkungen über Gelehrsamkeit, Industrie, Religion und Sitten, vol. 7 (Berlin, 1786), 45-46.

45. Koselleck, "Standortbindung und Zeitlichkeit: Ein Beitrag zur historiographischen Erschließung der geschichtlichen Welt," in Vergangene Zukunft, 17888.

46. Ibid., 183-84.

47. Ibid., 184-86.

48. Johann Martin Chladenius, Einleitung zur richtigen Auslegung vernünftiger Reden und Schriften, ed. Lutz Geldsetzer (Düsseldorf: Stern Verlag Janssen, 1969), 195.

49. Koselleck, "Standortbindung und Zeitlichkeit," 186.

50. Ibid., 187.

51. Ibid., 189.

52. Johann Christoph Gatterer, "Abhandlung vom Standort und Gesichtspunct des Geschichtsschreibers oder der teutsche Livius," in Blanke and Fleischer, Theoretiker der deutschen Aufklärungshistorie, 2:453-54; originally appeared in Allgemeine historische Bibliothek 5 (1768): 3-29.

53. Koselleck, "Standortbindung und Zeitlichkeit," 189.

54. Ibid.

55. Quoted in ibid., 191.

56. Ibid., 191-95.

57. Friedrich Nicolai, Einige Bemerkungen über den Ursprung und die Geschichte der Rosenkreuzer und Freymaurer, in Gesammelte Werke, ed. Bernhard Fabian and Marie-Luise Spieckermann, vol. 5 (Hildesheim: Georg Olms, 1988), 27.

58. In this study, I use the term "middle class" in virtually all instances where the German equivalent would be "bürgerlich." While "bourgeois" makes a more elegant adjective, it suggests a level of economic and political power that was lacking among the nonnoble German elites in the eighteenth century. It should also be noted that some of those who shared the values and interests of the educated middle class, which consisted largely of bureaucrats, professors, tutors and teachers, authors and editors, clergymen, and some merchants, were themselves of noble birth.

59. Bödeker, "Entstehung des modernen historischen Denkens," 305.

6o. Horst Möller, Aufklärung in Preussen: Der Verleger, Publizist und Geschichtsschreiber Friedrich Nicolai (Berlin: Colloquium, 1974), 479. 
61. Reill, Rise of Historicism, 44.

62. Blanke, Historiographiegeschichte als Historik, 122-23.

63. Ibid., 123.

64. Ibid., 152.

65. Bödeker, "Entstehung des modernen historischen Denkens," 305.

66. Ibid., 306.

67. Schiller, "Was heißt und zu welchem Ende studiert man Universalgeschichte," 367.

68. Thomas Abbt, "Von dem verschiedenen Gebrauch der alten Geschichte," Wöchentliche Hallische Anzeigen (1760): 181.

69. See, for example, Horst Möller, Vernunft und Kritik: Deutsche Aufklärung im 17. und 18. Jahrhundert (Frankfurt am Main: Suhrkamp, 1986), 71-109.

70. Bödeker, "Entstehung des modernen historischen Denkens," 298.

71. Frederick, king of Prussia, De la littératur allemande, 70, 72.

72. It is interesting to note that Johann Heinrich Gottlob von Justi, in a 1764 essay on the city, defines the big city as one that has a population of at least 100,000. Justi, “Die große Stadt in verschiedenen Verhältnissen betrachtet, insonderheit von den besten Maaßregeln sie mit Abgaben zu belegen, und ihr einen wohlfeilen Preiß der Lebensmittel zu verschaffen," in Gesammelte Politische und Finanz-Schriften, vol. 3 (1764; reprint, Aalen: Scientia Verlag, 1970), 451.

73. Statistics are taken from Heinz Schilling, Die Stadt in der frühen Neuzeit (Munich: R. Oldenbourg, 1993), 11-12. According to Schilling, in 1750 Berlin had approximately 90,000 residents, Hamburg 75,000, and Vienna 175,000. In 1800 Berlin had grown to 150,000 , Hamburg to 100,000 , and Vienna to 231,000 . Other sources diverge slightly from these numbers. Helga Schulz, for example, gives a population of 126,661 for Berlin in 1755. See Schulz, Berlin 1650-180o: Sozialgeschichte einer Residenz (Berlin: Akademie-Verlag, 1987), 172. And Deborah Hertz writes that Berlin had a population of 172,000 residents by the end of the eighteenth century. See Hertz, Jewish High Society in Old Regime Berlin (New Haven: Yale University Press, 1988), 26.

74. [Friedrich Gedike], Über Berlin: Briefe "Von einem Fremden" in der Berlinischen Monatsschrift 1783-1785, ed. Harald Scholtz (Berlin: Colloquium, 1987), 11.

75. Deborah Hertz claims that Berlin's population increased sixfold between 1700 and 1800 . Hertz, Jewish High Society, 26.

76. Schulz, Berlin 1650-180o, 188-94.

77. The treastise was originally presented as a lecture to the Royal Academy of Sciences in Berlin in 1749. Johann Peter Süßmilch, Abhandlung von dem schnellen Wachsthum der königlichen Residentz Berlin, in Die königliche Residenz Berlin und die Mark Brandenburg im 18. Jahrhundert: Schriften und Briefe, ed. Jürgen Wilke (Berlin: Akademie-Verlag, 1994), 15-48.

78. For an overview of Vienna and the German Enlightenment, see Engelhard Weigl, Schauplätze der deutschen Aufklärung: Ein Städterundgang (Reinbek bei Hamburg: Rowohlt, 1997), 210-29. 
79. In a 1783 article on big-city life Johann Friedrich Zöllner creates a special category for the free imperial cities (Reichsstädte), which are defined in his opinion by their historical stasis: "In the free imperial cities politics requires that everything remain as far as possible as it has always been, because every innovation threatens the heart of the form of government." [Zöllner], "Beitrag zur Charakteristik der großen Städte und des Großstädters," Lesebuch für alle Stände 4 (1783): 108-9.

80. This cliché appears to have first been made popular by Madame de Staël in 1813. In De l'Allemagne, de Staël describes Berlin as follows: "The capital of Prussia resembles Prussia itself; its edifices and institutions are of a single generation and no more, because a single man has created them." Anne Germaine de Staël, De l'Allemagne, ed. Jean de Pange and Simone Balayé (Paris: Hacette, 1958), 236.

81. Schilling, Die Stadt, 51-56. Lewis Mumford propounds a similar view in his classic work, The City in History (New York: Harcourt, Brace \& World, 1961), esp. 345-56. For Mumford, the emergence of the large capital cities of the baroque era marks the end of municipal autonomy and the beginning of soulless bureaucracy.

82. Schilling, Die Stadt, 54-55.

83. This took place in Berlin in 1738. Sadowsky, "Gehen Sta(d)t Fahren," 83.

84. [Gedike], Über Berlin, 9.

85. Johann Heinrich Zedler, ed., Grosses vollständiges Universallexicon, s.v. "Stadt," vol. 39 (Leipzig: Zedler, 1744), 768.

86. Rousseau offers the classic formulation of this idea in his Emile: "All capitals resemble one another. All peoples are mixed together in them, and all morals are confounded. It is not to capitals that one must go to study nations. Paris and London are but the same city in my eyes." Rousseau, Emile, or, On Education, trans. Allan Bloom (New York: Basic Books, 1979), 468.

87. See Schilling, Die Stadt, 20-37.

88. Quoted in ibid., 59.

89. Hertz, Jewish High Society, 26-27.

90. For a discussion of these developments, see Wilhelm Treue, Wirtschaftsgeschichte der Neuzeit (Stuttgart: Alfred Kröner, 1966), 165-79, and Felix Escher, "Die brandenburgisch-preußische Residenz und Hauptstadt Berlin im 17. und 18. Jahrhundert," in Geschichte Berlins, ed. Wolfgang Ribbe (Munich: C. H. Beck, 1987), 374-76.

91. Christof Dipper, Deutsche Geschichte 1648-1789 (Frankfurt am Main: Suhrkamp, 1991), 76-81.

92. Ibid., 211.

93. Schilling, Die Stadt, 46.

94. Johann Wolfgang Goethe, Sämtliche Werke, Briefe Tagebücher und Gespräche, ed. Karl Eibl et al., sec. II, vol. 1 (Frankfurt am Main: Deutscher Klassiker Verlag, 1997), 68.

95. Kant writes: "But only a ruler who is himself enlightened and has no fear 
of phantoms, yet who likewise has at hand a well-disciplined and numerous army to guarantee public security, may say what no republic would dare to say: Argue as much as you like and about whatever you like, but obey!" Immanuel Kant, "An Answer to the Question: 'What is Enlightenment?'" in Political Writings, 2d, enlarged ed., ed. Hans Reiss, trans. H. B. Nisbet (Cambridge: Cambridge University Press, 1991), 59.

96. This politicization is discussed in Bödeker, "Journals and Public Opinion: The Politicization of the German Enlightenment in the Second Half of the Eighteenth Century," in The Transformation of Political Culture: England and Germany in the Late Eighteenth Century, ed. Eckhart Hellmuth (London: Oxford University Press, 1990), 423-45.

97. Treue, Wirtschaftsgeschichte, 186-90.

98. Escher, "Die brandenburgisch-preußische Residenz," 376-82.

99. Hertz, Jewish High Society, 27-28 and 44-47.

100. Hertz remarks that unlike the older powerful cities of the early modern period, which usually had one primary economic function and thus one homogenous group of elites, Berlin had a mix of officials, financiers, and intellectuals. See ibid., 27-28.

101. Ibid., 25 .

102. Justi, "Die große Stadt," 469.

103. Ibid., 470-71.

104. Erich Kleinschmidt, "Die ungeliebte Stadt: Umrisse einer Verweigerung in der deutschen Literatur des 18. Jahrhunderts," LiLi 48 (1982): 29-49.

105. Wiedemann, "'Supplement eines Daseins'?," 10-11.

106. This argument has also been made by Sadowsky, "Gehen Sta(d)t Fahren," 65-66.

107. Justi, "Die große Stadt," 463.

108. Christian Garve, "Bruchstücke zu der Untersuchung über den Verfall der kleinen Städte, dessen Ursachen, und die Mittel, ihm abzuhelfen," in Gesammelte Werke, ed. Kurt Wölfel, section 1, vol. 4, part 1 (1796 and 180o; reprint, Hildesheim: Georg Olms, 1985), 373-444.

109. [Gedike], Über Berlin, 13.

110. Ludwig Hölty, "Das Landleben," in Gesammelte Werke und Briefe, ed. Walter Hettche (Göttingen: Wallstein, 1998), 219-20; Johann Georg Schlosser, Katechismus der Sittenlehre für das Landvolk, ed. Holger Böning and Reinhart Siegert (Stuttgart-Bad Cannstatt: Frommann-Holzboog, 1998), 97-98.

111. In the case of valorizations such as Hölty's, the situation is not as straightforward, because poetic celebrations of country life participate in long-standing rhetorical traditions whose precise connection to social developments must be established. Nonetheless, in light of the concerns expressed regarding the growth of cities in the period, it also seems reasonable to view these literary representations as at least in part a reaction to the increased interest in urban life. Wiede- 
mann makes a similar point about the dialectical relationship between city and country but claims that Germany's lack of a genuine metropolitan culture meant that such reactions had more to do with a national identity conceived in terms of provincialism than with any domestic urban challenge. See Wiedemann, "'Supplement eines Daseins'?," 5.

\section{CHAPTER 2}

1. [Karl Heinrich Krögen], Freie Bemerkungen über Berlin, Leipzig, Prag (Leipzig: Gustav Kiepenheuer, 1986), 5. The book appeared originally without indicating either the author or the publisher. According to the information on publication provided in the reprint, however, the author has been identified as the bookseller Karl Heinrich Krögen.

2. "Ein Wort über die vielen antiberlinischen Schriften in unseren Tagen," Berlinische Monatsschrift 2 (1785): 311-35.

3. As mentioned in Chapter 1, Johann Heinrich Gottlob von Justi suggests a cutoff of 100,000 residents for the definition of a "big city," and there is little in the travel literature from the period to suggest that even another several hundred thousand residents makes for a qualitative difference in the eyes of eighteenthcentury commentators. While size is certainly a topic of discussion in writings on the city, the phenomena understood as characteristic of big-city life, both positive and negative, do not appear to vary significantly between large and very large cities.

4. "Briefe eines Reisenden aus Berlin," Teutscher Merkur, no. 4 (1787): 61.

5. Translations: Modefieber, "fashion fever"; Modeleichtsinn, "weakness for fashions"; Modegespräch, "fashionable conversation"; Modeliteratur, "fashionable literature."

6. Daniel L. Purdy, The Tyranny of Elegance: Consumer Cosmopolitanism in the Era of Goethe (Baltimore: Johns Hopkins University Press, 1998).

7. Ibid., 229.

8. Ibid., 233.

9. Purdy does remark that "Mode" and "modern" are already associated in the period. He quotes the definition of "modern" from Adelung's 1775 Grammatischkritisches Wörterbuch: "that which accords with the newest morals, the newest taste, the newest fashion, in contrast to the antique or outdated." Quoted in ibid., 53 (his translation). His primary interests lie elsewhere, however, so he does not pursue this facet of the discourse on fashion.

10. Purdy oversimplifies a bit, I think, in his identification of German critiques of fashion and luxury with the tradition of Latin Stoicism. While there can be no doubt that Latin writers like Seneca and Cicero were crucial for the German discussion, one also needs to consider how this critique is appropriated by more 
temporally proximate interlocutors like Montesquieu and, even more important, Rousseau.

11. Johann Heinrich Zedler, ed., Grosses vollständiges Universallexikon, s.v. "Mode," vol. 21 (Leipzig and Halle: Zedler, 1739), 702.

12. Ibid., 704 .

13. Ibid., 708.

14. Ibid., 707 .

15. Ibid., 705 .

16. Ibid., 710.

17. Quoted in Purdy, The Tyranny of Elegance, 55 (his translation).

18. Ibid., 55. Purdy cites an example from Die Zeitung für die elegante Welt, in which the "fashion" of having one's children innoculated against cowpox is lauded.

19. [Friedrich Gedike], Über Berlin: Briefe "Von einem Fremden" in der Berlinischen Monatsschrift 1783-1785, ed. Harald Scholtz (Berlin: Colloquium, 1987), $10-11$.

20. Baron de Montesquieu, The Spirit of the Laws, ed. Franz Neumann and trans. Thomas Nugent (New York: Hafner Publishing, 1966), 95.

21. Ibid., 96-97. See also Purdy, The Tyranny of Elegance, 51-53.

22. [Johann Friedrich Zöllner], "Beitrag zur Charakteristik der großen Städte und des Großstädters," Lesebuch für alle Stände 4 (1783): 120.

23. [Krögen], Freie Bemerkungen, 29.

24. [F. Schulz], "Kleine Wanderungen durch Teutschland, in Briefen eines Hypochondristen an den Doctor $\mathrm{K}^{\star}$," Teutscher Merkur, no. 2 (1785): 121.

25. Ibid., 124.

26. Ibid., 121.

27. Ibid., 65. Deborah Hertz quotes a similar example from the 1788 Schattenriss von Berlin. According to this text, much that appears impressive is merely "poverty covered with a sparkling varnish." Quoted in Hertz, Jewish High Society in Old Regime Berlin (New Haven: Yale University Press, 1988), 24.

28. "Briefe eines Reisenden aus Berlin," 65.

29. See, for example, Uwe Hentschel, "Die Reiseliteratur am Ausgang des 18. Jahrhunderts: Vom Gelehrten Bericht zur Literarischen Beschreibung," Internationales Archiv für Sozialgeschichte der deutschen Literatur 16, no. 2 (1991): 51-83.

30. At least when viewed from an eighteenth-century perspective. Twentyfirst-century readers might find it difficult to share these authors' enthusiasm for Berlin's criminalization of begging.

31. [Krögen], Freie Bemerkungen, 12.

32. Johann Peter Süßmilch, Abhandlung von dem schnellen Wachsthum der königlichen Residentz Berlin, in Die königliche Residenz Berlin und die Mark Brandenburg im 18. Jahrhundert: Schriften und Briefe, ed. Jürgen Wilke (Berlin: Akademie Verlag, 1994), 38. 
33. Ibid.

34. Ibid.

35. [Gedike], Über Berlin, 5 .

36. Ibid., 7 .

37. Ibid.

38. Ibid.

39. Ibid., 8 .

40. Ibid., 20.

41. For a detailed, if unsympathetic discussion of Dohm's arguments, see Paul Lawrence Rose, German Question/Jewish Question: Revolutionary Antisemitism from Kant to Wagner (Princeton: Princeton University Press, 1990), 70-79.

42. [Gedike], Über Berlin, 146-47; see also the editor's footnote on that page. In contrast, Dohm writes: "This cowardly tendency toward ritualism and a focus on trivialities which has now insinuated itself into the Jewish religion will no doubt disappear again, just as soon as the Jews are granted a wider sphere of influence and, as accepted members of society, are able to make its interests their own. They will then adapt their religious constitution and laws accordingly; they will return to the freer and more noble Mosaic constitution of ancient times, and will no doubt find in their Talmud the authority to apply this constitution, and to elucidate it, in a manner appropriate to the changed times and circumstances." Christian Wilhelm von Dohm, Über die bürgerliche Verbesserung der Juden (1781; reprint, 2 vols. in 1, Hildesheim: Georg Olms, 1973), 143-44.

43. [Gedike], Über Berlin, 144.

44. Ibid., 141.

45. Friedrich Schiller, "Was heißt und zu welchem Ende studiert man Universalgeschichte," in Schillers Werke: Nationalausgabe, ed. Lieselotte Blumenthal and Benno von Wiese, vol. 17 (Weimar: Herman Böhlaus Nachfolger, 1962), 366.

46. It is worth noting that Dohm adopts a similar view, insisting at various points in his text that the current condition of the Jews is unacceptable in an enlightened age. He writes, for example, of the government discrimination against the Jews: "This policy is a vestige of the barbarism of past centuries, a consequence of the fanatical religious hatred, which, unworthy as it is of the enlightenment that characterizes our age, should have been eliminated by this enlightenment long ago." Dohm, Verbesserung, 39.

47. [Gedike], Über Berlin, 144.

48. Ibid., 145 .

49. Ibid., 146.

50. I return to these developments in my discussion of Mendelssohn. Steven Lowenstein, The Berlin Jewish Community: Enlightenment, Family, and Crisis, 1770-1830 (Oxford: Oxford University Press, 1994), 25-32.

51. Johann Heinrich Gottlieb von Justi, "Die große Stadt in verschiedenen Verhältnissen betrachtet, insonderheit von den besten Maaßregeln sie mit Abgaben zu belegen, und ihr einen wohlfeilen Preiß der Lebensmittel zu verschaffen," in 
Gesammelte Politische und Finanz-Schriften, vol. 3 (1764; reprint, Aalen: Scientia Verlag, 1970), 464.

52. [Gedike], Über Berlin, 146.

53. Süßmilch, Abhandlung, 37-38.

54. [Gedike], Über Berlin, 15.

55. Ibid., 146.

56. [Zöllner], "Beitrag," 104.

57. Justi, "Die große Stadt," 474.

58. [Gedike], Über Berlin, 155.

59. Ibid.

6o. See Purdy, The Tyranny of Elegance, 52-53.

61. [Gedike], Über Berlin, 155.

62. Ibid.

\section{CHAPTER 3}

1. For a recent discussion, see Peter Fritzsche, Reading Berlin, 1900 (Cambridge, Mass.: Harvard University Press, 1996), 1-11.

2. Ibid., 22-24.

3. Ibid., 27-29.

4. Ibid., 29.

5. Fredric Jameson, "Postmodernism and Consumer Society," in The Cultural Turn: Selected Writings on the Postmodern, 1983-1998 (London: Verso, 1998), 20.

6. Georg Heym, "Der Gott der Stadt," in Menschheitsdämmerung: Symphonie jüngster Dichtung, ed. Kurt Pinthus (Berlin: Ernst Rowohlt, 1922), 6-7; Siegfried Kraucauer, "Farewell to the Linden Arcade," in The Mass Ornament: Weimar Essays, trans. and ed. Thomas Y. Levin (Cambridge, Mass.: Harvard University Press, 1995), 337-42.

7. Horst Möller, Aufklärung in Preussen: Der Verleger, Publizist und Geschichtsschreiber Friedrich Nicolai (Berlin: Colloquium, 1974). Another important milestone in the rehabilitation of Nicolai was the publication of an essay collection in commemoration of the 25oth anniversary of his birth. Bernhard Fabian, ed., Friedrich Nicolai, 1733-1811: Essays zum 250. Geburtstag (Berlin: Nicolaische Verlagsbuchhandlung, 1983).

8. Most recently, Pamela Selwyn has published a meticulous investigation of Nicolai's life as a bookseller and publisher in the period, which also sheds new light on the nature of the book trade in eighteenth-century Germany. Pamela Selwyn, Everyday Life in the German Book Trade: Friedrich Nicolai as Bookseller and Publisher in the Age of Enlightenment, 1750-1810 (University Park: Pennsylvania State University Press, 2000).

9. One exception is Erich Kleinschmidt, who, however, ends his brief discussion of Nicolai's novel Sebaldus Nothanker with the claim that the city is not really 
the focus of the author's interest. Erich Kleinschmidt, "Die ungeliebte Stadt: Umrisse einer Verweigerung in der deutschen Literatur des 18. Jahrhunderts," LiLi 48 (1982): 29-49.

10. Ibid., 39.

11. The scope and influence of Nicolai's publishing activities together with his outspoken criticism of other parts of Germany played no small part in generating the negative representations of Berlin that become increasingly prevalent toward the end of the century. The seemingly disproportionate influence of the Berliners in cultural debates raised the hackles of various contemporaries, who accused Nicolai and his Berlin cronies of exercising a kind of cultural despotism.

12. Nicolai's remarks were likely inspired by Montesquieu, who argued that the capital city was the driving force behind a coherent national identity. On Montesquieu and the city, see Conrad Wiedemann, "'Supplement seines Daseins'?: $\mathrm{Zu}$ den kultur- und identitätsgeschichtlichen Voraussetzungen deutscher Schriftstellerreisen nach Rom - Paris - London seit Winckelmann," in Rom-ParisLondon: Erfahrung und Selbsterfahrung deutscher Schriftsteller und Künstler in den fremden Metropolen, ed. Conrad Wiedemann (Stuttgart: J. B. Metzler, 1988), 6.

13. Selwyn also addresses Nicolai's arguments in these letters, but she does not pursue the author's valorization of the metropolis.

14. Friedrich Nicolai, Briefe über den jetzigen Zustand der schönen Wissenschaften in Deutschland, in Sämtliche Werke, Briefe, Dokumente, ed. P. M. Mitchell et al., vol. 4 (Berlin: Peter Lang, 1995), 157.

15. Nicolai, Das Leben und die Meinungen des Herrn Magister Sebaldus Nothanker, in Gesammelte Werke, ed. Berhard Fabian and Marie-Luise Spieckermann, vol. 3 (Hildesheim: Georg Olms, 1988), 75.

16. Ibid., 121.

17. Goethe, despite his general celebration of German cultural diversity, offers an argument very similar to Nicolai's in his 1795 essay "Literary Sansculottism." Here he claims that Germany's lack of a "centerpoint for the cultivation of social life" is the reason for its failure to produce "classical" works. Voicing his opposition to the French Revolution, however, he also remarks, "We would not wish for the upheavals that could prepare the way for classical works in Germany." Johann Wolfgang Goethe, "Literarischer Sanscülottismus," in Sämtliche Werke, Briefe, Tagebücher und Gespräche, ed. Friedmar Apel et al., sec. I, vol. 18 (Frankfurt am Main: Deutscher Klassiker Verlag, 1998), 321.

18. Nicolai, Briefe, die neueste Litteratur betreffend, in Sämtliche Werke, 4:174.

19. Ibid.

20. [Johann Friedrich Zöllner], "Beitrag zur Charakteristik der großen Städte und des Großstädters," Lesebuch für alle Stände 4 (1783): 104.

21. Ibid., 106.

22. Hans Erich Bödeker, "Reisebeschreibungen im historischen Diskurs der Aufklärung," in Aufklärung und Geschichte: Studien zur deutschen Geschichtswis- 
senschaft im 18. Jahrhundert, ed. Hans Erich Bödeker et al. (Göttingen: Vandenhoeck \& Ruprecht, 1986), 295.

23. According to Peter Hanns Reill, these three models were all popular at the beginning of the eighteenth century. See Reill, The German Enlightenment and the Rise of Historicism (Berkeley: University of California Press, 1975), 127-31.

24. Ibid., 160-62.

25. Nicolai, Beschreibung der königlichen Residenzstädte Berlin und Potsdam und aller daselbst befindlicher Merkwürdigkeiten (Berlin, 1779), III.

26. Nicolai, Sämtliche Werke, 8:13.

27. The phrase is borrowed from Fritzsche.

28. Biester and Gedike were also the editors of the Berlinische Monatsschrift.

29. Nicolai, Sämtliche Werke, 8:12.

30. Ibid., 13 .

31. Nicolai utilized a similar framework in his eleven volume Beschreibung einer Reise durch Deutschland und die Schweiz im Jahre 1781. For a discussion of this work, see Wolgang Martens, "Ein Bürger auf Reisen," in Fabian, Friedrich Nicolai, 1733-1811, 99-123.

32. Hartmut Kugler, Die Vorstellung der Stadt in der Literatur des deutschen Mittelalters (Munich: Artemis, 1986), 17-37.

33. Heinrich Schmidt, Die deutschen Stadtchroniken als Spiegel des bürgerlichen Selbstverständnisses im Spätmittelalter (Göttingen:Vandenhoek \& Ruprecht, 1958), 111-27. The history of city chronicles constitutes a field of inquiry unto itself. The preceding remarks are intended only to cast the historical specificity of Nicolai's approach to Berlin into greater relief.

34. Nicolai, Sämtliche Werke, 8:53.

35. The occasionally panegyric tone of the essay may also be a result of the material conditions of its production. Such an exhaustive history of Berlin was only made possible through the benevolence of Friedrich II, who granted Nicolai permission to use materials in the royal archives.

36. Möller, Aufklärung in Preussen, 327.

37. Ibid., 509.

38. This view of temporal change is distinguished from both Christian historiography and philosophies of historical progress in Reinhart Koselleck's essay, "Vergangene Zukunft der frühen Neuzeit," in Vergangene Zukunft: Zur Semantik geschichtlicher Zeiten (Frankfurt am Main: Suhrkamp, 1979), 17-37.

39. In addition to his essays on Berlin proper, Süßmilch published a treatise in 1741 entitled Die göttliche Ordnung in den Veränderungen des menschlichen Geschlechts. In this essay he developed the statistical method for evaluating church birth and death lists that Nicolai also used. See Möller, Aufklärung in Preussen, 326.

40. Nicolai, Sämtliche Werke, 8:49.

41. Nicolai, Beschreibung (1779), III-IV. 
42. See also Horst Möller, "Friedrich Nicolai als Historiker," in Fabian, Friedrich Nicolai, 1733-1811, 139-73.

43. Nicolai, Gesammelte Werke, 3:20. All page references refer to the second volume of the novel, unless otherwise noted.

44. Ibid., 21.

45. Reill, Rise of Historicism, 9.

46. Nicolai, Gesammelte Werke, 3:21.

47. Ibid., 30.

48. Reill, Rise of Historicism, 9. Reill describes this model as follows: "Accordingly, the history of the mankind was divided into four periods, each dominated by a world monarchy. The last of the monarchies was usually said to begin with Christ's crucifixion and resurrection."

49. Möller, Aufklärung in Preussen, 489.

50. Nicolai, Gesammelte Werke, 3:26 (first volume).

51. By the 1780 s, Nicolai's description appears to have achieved paradigmatic status. The author of "Little Excursions through Germany, in Letters from a Hypochondriac to Doctor $\mathrm{K}^{\star}$," for example, writes: "I wouldn't know how to describe the Tiergarten more suitably than N. has done it in Sebaldus Nothanker." [F. Schulz], "Kleine Wanderungen durch Teutschland, in Briefen eines Hypochondristen an den Doctor $\mathrm{K}^{\star}$," Teutscher Merkur, no. 2 (1785): 58.

52. Nicolai, Gesammelte Werke, 3:24-25.

53. Two of the best known examples are the protagonist's enraptured description of Wahlheim in Goethe's Werther and the scene "Outside the Town Wall" in his Faust.

54. Karl Philipp Moritz, Anton Reiser: A Psychological Novel, trans. John R. Russell (Columbia, S.C.: Camden House, 1996), 31.

55. Ibid.

56. Koselleck, "Vergangene Zukunft der frühen Neuzeit," 34.

57. Nicolai, Gesammelte Werke, 3:46.

58. Wilhelm Kühlmann has written an exhaustive analysis of the critique of pedantry as it emerges in the late Renaissance and evolves through the seventeenth century. He also offers a brief overview of its continued significance for the project of enlightenment in the eighteenth century. See Kühlmann, Gelehrtenrepublik und Fürstenstaat: Entwicklung und Kritik des deutschen Späthumanismus in der Literatur des Barokzeitalters (Tübingen: Max Niemeyer, 1982), esp. 455-73.

59. [Friedrich Gedike], Über Berlin: Briefe "Von einem Fremden" in der Berlinischen Monatsschrift 1783-1785, ed. Harald Scholtz (Berlin: Colloquium, 1987), 80.

6o. Nicolai, Gesammelte Werke, 3:46.

61. Ibid., 71.

62. Ibid., 76-78.

63. Reill, Rise of Historicism, 100-126.

64. One finds support for an urban reading of this disparity in Zöllner's discussion of the metropolis in his "Contribution." In a description of the impact 
of big-city life on both artists and artisans, he adduces a greater appreciation for small differences as one consequence of the exposure to a multiplicity of ideas and experiences. According to Zöllner, "a greater variety of ideas, a greater ease in composition, a greater precision with regard to the individual elements is the consequence of more frequent observation." Zöllner, "Beitrag," 105.

65. Nicolai, Gesammelte Werke, 3:94.

66. Ibid., 99.

67. Daniel Purdy, The Tyranny of Elegance: Consumer Cosmopolitanism in the Era of Goethe (Baltimore: Johns Hopkins University Press, 1998), 220-22.

68. See Walter Benjamin, "On Some Motifs in Baudelaire," in Illuminations, ed. Hannah Arendt, trans. Harry Zohn (New York: Schocken, 1968), 155-94.

69. Kleinschmidt, "Die ungeliebte Stadt," 45.

\section{CHAPTER 4}

1. Gotthold Ephraim Lessing, Werke und Briefe, ed. Wilfried Barner et al., vol. 11.1 (Frankfurt am Main: Deutscher Klassiker Verlag, 1987), 622.

2. Ibid.

3. Paul Rilla, Lessing und sein Zeitalter (Berlin: Aufbau-Verlag, 1981), 30-31.

4. Ibid., 141-43.

5. Joachim Dyck, Minna von Barnhelm, oder: Die Kosten des Glücks (Berlin: Verlag Klaus Wagenbach, 1981).

6. Riccaut also proves significant in that he offers one of the only explicit topographical references in the play, albeit one that requires a bit of deciphering. At the beginning of act 4 , he refers to the "Kriegsminister," "in der lange Straß," "auf die breite Platz." Given that the War Department, one of six departments in the Generaldirektorium, was housed in the Royal Palace, it would appear that the square in question here is the Schloßplatz. If so, then the "long street" is most likely Unter den Linden. It is also possible, however, that Riccaut's ignorance of things German extends even to topography. He may actually be referring to the Ober-Krieges- und Domainenrechenkammer, which was located not on the "breite Platz," but next to it, on the "breite Straße," just at the corner, interestingly enough, of the "Lange Brücke." For locations, see Friedrich Nicolai, Beschreibung der königlichen Residenzstädte Berlin und Potsdam, in Sämtliche Werke, Briefe, Dokumente, ed. P. M. Mitchell et al., vol. 8 (Berlin: Peter Lang, 1995), 22938.

7. Lessing, Minna von Barnhelm, in Werke und Briefe, vol. 6, act 1, scene 2, 14 .

8. [Friedrich Gedike], Über Berlin: Briefe "Von einem Fremden" in der Berlinischen Monatsschrift 1783-1785, ed. Harald Scholtz (Berlin: Colloquium, 1987), 102.

9. Unless otherwise noted, all translations from Lessing's plays are taken from Gotthold Ephraim Lessing, Nathan the Wise, Minna von Barnhelm, and Other 
Plays and Writings, ed. Peter Demetz (New York: Continuum, 1991); act 2, scene 1, 15 (translation amended); act 1, scene 12, 13 (translation amended).

10. Sebaldus Nothanker, it will be remembered, arrives in the Berlin Tiergarten at three o'clock as well.

11. Lessing, Minna von Barnhelm, act 5, scene 13, 72 .

12. Recent interpretations of the play have insisted that Tellheim's refusal reflects his understanding that the accusation of corruption has made marriage a legal impossibility. See Günther Saße, "Zum Verhältnis von Liebe und Recht in Lessings Minna von Barnhelm," in Die Ordnung der Gefühle: Das Drama der Liebesheirat im 18. Jahrhundert (Darmstadt: Wissenschaftliche Buchgesellschaft, 1996), $161-83$.

13. [Gedike], Über Berlin, 15.

14. [Friedrich Zöllner], "Beitrag zur Charakteristik der großen Städte und des Großstädters," Lesebuch für alle Stände 4 (1783): 109.

15. Ibid., 109.

16. Ibid., 111.

17. Ibid., 107-8.

18. Georg Simmel, "The Metropolis and Mental Life," in Rethinking Architecture, ed. Neal Leach (London: Routledge, 1997), 74 (translation amended).

19. Nicolai's Sebaldus Nothanker offers another example. Written between 1773 and 1776 , it already articulates many of the concerns about changes in the city that become a staple of 178 os travel literature. In addition, as we saw in Chapter 3 , Nicolai's description of the Tiergarten in the novel had achieved exemplary status by the end of the century.

20. Siegfried Kracauer makes this same argument in regard to the twentiethcentury hotel lobby in his study of the detective novel, written between 1922 and 1925 but not published until after his death. Siegfried Kracauer, "The Hotel Lobby," in The Mass Ornament: Weimar Essays, ed. and trans. Thomas Y. Levin (Cambridge, Mass.: Harvard University Press), 173-85.

21. Lessing, Minna von Barnhelm, act 2, scene 2, 18 .

22. Ibid., act 4, scene 6, 56 (translation amended).

23. Ibid., act 2, scene 2,19 .

24. This topic has been addressed primarily in regard to the nineteenth century. See, for example, Elke Fredericksen, "Blick in die Ferne: Zur Reiseliteratur von Frauen," in Frauen Literatur Geschichte: Schreibende Frauen vom Mittelalter bis zur Gegenwart, ed. Hiltrud Gnüg and Renate Möhrmann (Stuttgart: Metzler, 1985), 104-22.

25. [Ludwig Friedrich Günther von Göckingk], "Briefe eines Reisenden an den Drost von LB," Deutsches Museum 2 (1779): 273.

26. Lessing, Minna von Barnhelm, act 2, scene 2, 19.

27. For examples of the former, see Dyck, Minna von Barnhelm, as well as Wilfried Barner et al., Lessing: Epoche-Werk-Wirkung (Munich: C. H. Beck, 1987), 248-81. 
28. Hans-Georg Werner, Text und Dichtung: Analyse und Interpretation (Berlin: Aufbau Verlag, 1984), 51.

29. Lessing, Minna von Barnhelm, act 5, scene 2, 60 .

30. The arguments that follow are indebted to the excellent analysis contained in Monika Fick, Lessing Handbuch: Leben - Werk - Wirkung (Stuttgart: Metzler, 2000), 253-56.

31. Lessing, Minna von Barnhelm, act 4, scene 6, 55 .

32. Ibid., 56.

33. Peter Michelsen, "Die Verbergung der Kunst: Über die Exposition in Lessings Minna von Barnhelm," Jahrbuch der deutschen Schillergesellschaft 17 (1973): 252.

34. Lessing, Minna von Barnhelm, act 5, scene 5, 63.

35. G. E. Lessing, Moses Mendelssohn, and Friedrich Nicolai, Briefwechsel über das Trauerspiel, ed. Jochen Schulte-Sasse (Munich: Winkler, 1972), 55.

36. Wolfgang Albrecht, Gotthold Ephraim Lessing (Stuttgart: J. B. Metzler, 1997), 58.

37. Lessing, Minna von Barnhelm, act 2, scene 9, 26.

38. Ibid., act 5, scene 9, 66.

39. Ibid., 68.

40. Walter Hinck, "Lessings Minna-Anmut und Geist: Kleine KomödienChronik zur Emanzipation der Frau," in Festschrift für Rainer Gruenter, ed. Bernhard Fabian (Heidelberg: C. Winter, 1978), 298.

41. Werner, Text und Dichtung, 59.

42. Georg Lukács, "Minna von Barnhelm," in Wege der Forschung: Gotthold Ephraim Lessing, ed. Gerhard Bauer and Sybille Bauer (Darmstadt: Wissenschaftliche Buchgesellschaft, 1968), 431.

43. Karoline Herder, for example, took offense at the active involvement of the maid-in-waiting, the soldier, and the innkeeper in the love story. In a letter from September 1770 her husband quotes her as saying: "That the lady's maid, the soldier and the innkeeper get themselves involved in a situation as delicate as that of love does not please me at all!" Lessing, Werke und Briefe, 6:827.

44. Lessing, Minna von Barnhelm, act 2, scene 1, 16.

45. Ibid., act 4, scene 3, 50 (emphasis added).

46. For an overview of the eighteenth-century debate regarding perspectivism in antiquity, both in its Pan-European context and as it relates to Lessing's work in particular, see Hinrich Seeba, "Der wahre Standort einer jeden Person: Lessings Beitrag zum historischen Perspektivismus," in Nation und Gelehrtenrepublik: Lessing im europäischen Zusammenhang, ed. Wilfried Barner and Albert M. Reh (Detroit: Wayne State University Press, 1984), 193-214.

47. See, for example, Volker Nölle, Subjektivität und Wirklichkeit in Lessings dramatischem und theologischem Werk (Berlin: Erich Schmidt, 1977), and Joachim Desch, "Vernünfteln wider die Vernunft: Zu Lessings Begriff eines konsequenten Rationalismus," in Humanität und Dialog: Lessing und Mendelsohn in neuer Sicht, 
ed. Erhard Bahr, Edward P. Harris, and Laurence G. Lyon (Detroit: Wayne State University Press, 1982), 133.

48. Friedrich Nicolai, Über meine gelehrte Bildung, über meine Kenntniß der kritischen Philosophie und meine Schriften dieselbe betreffend, und über die Herren Kant, J. B. Erhard und Fichte, in Gesammelte Werke, ed. Bernhard Fabian and Marie-Luise Spieckermann, vol. 1.2 (Hildesheim: Georg Olms, 1997), 41-42.

49. Nölle, Subjektivität und Wirklichkeit, 12.

50. Lessing, Werke und Briefe, 6:813.

51. Ibid., 819 .

52. Ibid., 821.

53. Ibid., 847 .

54. Ibid., $829,816,820$.

55. As I mentioned in Chapter 3, this understanding of the capital city was widespread in the eighteenth century and is most memorably advanced in Montesquieu's writings.

56. Ruth Glatzer, ed., Berliner Leben 1648-1806: Erinnerungen und Berichte (Berlin: Rütten \& Loening, 1956), 208.

57. [F. Schulz], "Kleine Wanderungen durch Teutschland, in Briefen eines Hypochondristen an den Doctor K*," Teutscher Merkur, no. 2 (1785): 75.

58. [Göckingk], "Breife eines Reisenden," 274.

59. [Gedike], Über Berlin, 50.

6o. [Zöllner], "Beitrag," 109.

61. Ibid., 108.

62. Ibid., 107.

63. See Simmel, "The Metropolis and Mental Life," 118.

64. Hinrich C. Seeba, Die Liebe zur Sache: Öffentliches und privates Interesse in Lessings Dramen (Tübingen: Niemeyer, 1973), 81.

65. Dyck, Minna von Barnhelm, 8.

66. Mark Lehrer, "Lessing's Economic Comedy," Seminar 20, no. 2 (1984): 79.

67. This does appear to be the case with regard to the innkeeper, but he is presented so as to suggest that character is prior to context; in other words, his essentially selfish nature simply manifests itself in his relationship to money, rather than stemming from it.

68. Lehrer, "Lessing's Economic Comedy," 84.

69. Lukács, "Minna von Barnhelm," 441-42.

70. Hans Blumenberg, "Progress Exposed as Fate?" in Rethinking the Subject: An Anthology of Contemporary European Social Thought, ed. James D. Faubion (Boulder: Westview Press, 1995), 94. Blumenberg makes this particular claim in reference to the development of scientific method.

71. Barner et al., Lessing: Epoche-Werk-Wirkung, 256.

72. Lessing, Werke und Briefe, 11.1:338. Lessing had been forced by the war to cut short a European tour undertaken as a travel companion to Christian Gottfried Winckler. 
73. Ibid., 215.

74. Karl Lessing, G. E. Lessings Leben, ed. Otto F. Lachmann (Leipzig: Reclam, 1886), 138.

75. In his survey of the Enlightenment, Panajotis Kondylis writes of the "unparalleled attention granted to economic factors in history." Kondylis, Die Aufklärung im Rahmen der neuzeitlichen Rationalismus (Munich: Deutscher Taschenbuch Verlag, 1986), 425.

76. Reinhardt Koselleck, "Standortbindung und Zeitlichkeit: Ein Beitrag zur historischen Erschließung der geschichtlichen Welt," in Vergangene Zukunft: Zur Semantik geschichtlicher Zeiten (Frankfurt am Main: Suhrkamp, 1979), 189.

77. Ibid., 187-88.

78. Quoted in Seeba, "Der wahre Standort einer jeden Person," 200. Seeba makes a similar argument about the relationship between drama and history in his essay.

79. Conrad Wiedemann, for example, speaks of the opposition "German provincialism - foreign urbanism" in his introductory lecture to a symposium on the experience of German intellectuals in foreign capitals. Conrad Wiedemann, "Einleitendes Referat," in Rom-Paris-London: Erfahrung und Selbsterfahrung deutscher Schriftsteller und Künstler in den fremden Metropolen, ed. Conrad Wiedemann (Stuttgart: J. B. Metzler, 1988), 22.

8o. Volker Klotz, Die erzählte Stadt (Munich: Carl Hanser, 1969), 16-20.

81. Ibid., 13.

82. See, for example, the letter to his mother from January 20,1749 , and to his father from April 10, 1749. Lessing, Werke und Briefe, 11.1:14-19, 19-23.

83. Ibid., 338.

84. Lessing, The Jews, act 1, scene 6, 146.

85. He remarks: "You might renew my old suspicion:- that it was more the excitement and diversion of the world, more the nearness to the court than the necessity of giving her a proper education, that made you stay in the city with her" (act 2, scene 4, 91).

86. See, for example, Saße, "Zum Verhältnis von Liebe und Familie in Lessings Emilia Galotti," 139-60. Saße writes: "Thus Emilia receives two messages as a result of being sequestered from the world: one says beware of the world, because it is depraved; and the other says beware of the world, because you are seducible. When she no longer experiences her father as protector, the lesson of her education comes into force - that without the protective space of the family as constituted by the father, she is helpless to resist the temptations of the world" (153).

\section{CHAPTER 5}

1. Johann Erich Biester, "Zum Andenken Moses Mendelssohns," in Moses Mendelssohn, Gesammelte Schriften: Jubiläumsausgabe, ed. Alexander Altmann 
et al., vol. 24 (Stuttgart-Bad Cannstatt: Friedrich Frommann, 1998), 21 (hereafter GSJ).

2. Der Philosoph für die Welt was the title of a journal published by Engel in three volumes that appeared in 1775, 1777, and 1800 . Mendelssohn contributed two essays to the first volume.

3. [Johann Friedrich Zöllner], "Beitrag zur Charakteristik der großen Städte und des Großstädters," Lesebuch für alle Stände 4 (1783): 121.

4. The articles in Hannoverisches Magazin include the following: "Schreiben an einen Freund, von den Vorzügen des Landlebens vor dem Stadtleben," 2 (1764): 29-32; "Schreiben eines Frauenzimmers vom Lande an ihre Freundin in der Stadt," 2 (1764): 65-72; J. Steuart, "Von großen Städten und von Städten überhaupt," 5 (1767): 1543-52 (originally in English); "Betrachtungen über den Geschmack am Landleben," 6 (1768): 737-46 (originally in French); "Damalis, oder der Sieg des Landlebens," 8 (1770): 433-42; "Die Sitten in der Stadt: Nach einer Satyre des Juvenals," 8 (1770): 1073-82; "Schreiben eines neuverpflanzten Großstädters an seinen zurückgelassenen lieben Kleinstädter," 16 (1778): 98-122.

5. "Schreiben eines neuverpflanzten Großstädters an seinen zurückgelassenen lieben Kleinstädter," Hannoverisches Magazin 16 (1778): 105.

6. Zöllner, "Beitrag," 108.

7. Both terms mean roughly "to chat" or "to shoot the breeze."

8. Christian Garve, "Über die Lage Schlesiens in verschiedenen Zeitpuncten, und über die Vorzüge einer Hauptstadt vor Provizialstädten," in Gesammelte Werke, ed. Kurt Wölfel, sec. 1, vol. 4, part 1 (1796 and 180o; reprint, Hildesheim: Georg Olms, 1985), 229-62. In 1793 he also published an article entitled, "Bruchstücke zu der Untersuchung über den Verfall der kleinen Städte, dessen Ursachen, und die Mittel, ihm abzuhelfen," which includes additional material on the relationship between the rise of the capital cities and the progress of civilization. See ibid., 373-444.

9. Ibid., 257. Garve uses the term "court city" or Residenzstadt synonymously with "capital city" in this essay.

10. Ibid., 258.

11. [Friedrich Gedike], Über Berlin: Briefe "Von einem Fremden" in der Berlinischen Monatsschrift 1783-1785, ed. Harald Scholtz (Berlin: Colloquium, 1987), 79.

12. Ibid., 82.

13. Ibid., 80 .

14. Garve, "Über die Lage Schlesiens," 258-59.

15. Zöllner, "Beitrag," 106.

16. Ibid., 105.

17. Ibid., 109.

18. [Gedike], Über Berlin, 80. Original: "Alles schleift sich hier aneinander $\mathrm{ab} \ldots .$.

19. Mendelssohn, Sendschreiben an den Herrn Magister Lessing in Leipzig, in GSJ, 2:89. 
20. Ibid., 95.

21. Ibid., 91.

22. Quoted in David Sorkin, Moses Mendelssohn and the Religious Enlightenment (Berkeley: University of California, 1996), 61. The passage is from his commentary to Genesis 2:18. The translation from the Hebrew is Sorkin's.

23. Mendelssohn, GSJ, 2:103.

24. Mendelssohn, Rhapsody or Additions to the Letters on Sentiments, in Philosophical Writings, ed. and trans. Daniel O. Dahlstrom (Cambridge: Cambridge University Press, 1997) 151.

25. Ibid., 152.

26. Mendelssohn, GSJ, 5.2:308.

27. Ibid.

28. Mendelssohn, "Betrachtung über die Ungleichheit und Geselligkeit der Menschen; nebst einem neuen Plan, die Menschengesichter vernünftig und sittlich zu machen," in GSJ, 2:137.

29. Steven Lowenstein, The Berlin Jewish Community: Enlightenment, Family, and Crisis, 1770-1830 (Oxford: Oxford University Press, 1994), 16.

30. Ursula Goldenbaum, "Der 'Berolinismus': Die preußische Hauptstadt als ein Zentrum geistiger Kommunikation in Deutschland," in Aufklärung in Berlin, ed. Wolfgang Förster (Berlin: Akademie-Verlag, 1989), 350-52.

31. Despite continued repression on the state level. Friedrich II's restrictive edict of 1750 had formalized the social stratification of the Berlin Jews into six categories, ranging from those with a coveted "general privilege" to the private employees who were only allowed to stay in the city for the duration of their employment. See Alexander Altmann, Moses Mendelssohn: A Biographical Study (University: University of Alabama Press, 1973), 16-17.

32. Mendelssohn, "Sonderung der Ämter und Stände," in GSJ, 6.1:150.

33. Ibid., 151-52.

34. Fritz Bamberger, "Einleitung," in GSJ, XXXIII.

35. Ibid., 152.

36. Friedrich Schiller, On the Aesthetic Education of Man in a Series of Letters, ed. and trans. Elizabeth M. Wilkinson and L. A. Willoughby (Oxford: Clarendon Press, 1967), 33. It is tempting to see in Schiller's essay a repression of Mendelssohn's influence. In addition to the thematic overlap, the author also remarks: "I no longer recall which of the ancient or modern philosophers it was who remarked that the nobler a thing is, the more repulsive it is when it decays, but we shall find that it is no less true in the moral sphere." It was in fact Mendelssohn who had made the remark most recently, in his essay on enlightenment, where he attributes its origin to an unnamed "Hebrew author" (27).

37. Mendelssohn, GSJ, 6.1:150.

38. See, for example, Richard van Dülmen's remark on the role of the estates: "The individual could not choose his estate, he was born into it: his life was thereby controlled and regimented with respect to both the private and the professional 
spheres. Individual needs were made subordinate to collective norms. The estates were not simply professional organizations; they were tightly knit communities that extensively regulated the religious and familial as well as the economic aspects of life. They excluded economic expansion just as much as they excluded communication among different groups." Dülmen, Die Gesellschaft der Aufklärer (Frankfurt am Main: Fischer, 1986), 13-14.

39. [Gedike], Über Berlin, 9.

40. "Schreiben eines neuverpflanzten Großstädters," 105.

41. Mendelssohn, GSJ, 13:65-66. For a discussion of this passage, see Altmann, Moses Mendelssohn, 538-42.

42. Mendelssohn, "Über die beste Staatsverfassung," in GSJ, 6.1:145.

43. Mendelssohn, GSJ, 16:403-7. For a discussion of this passage, see Sorkin, Moses Mendelssohn, 61. I would like to thank both David Sorkin and Amir Banbaji for helping me to understand these remarks.

44. Lowenstein, Berlin Jewish Community, 26-27.

45. Ibid., 33 .

46. "Relatively" is the key term here. Berlin Jews still faced animosity from a large part of the general population in Berlin and were still subjected to severe legal restrictions; Mendelssohn, for example, was unable to obtain a guarantee that his wife and children would retain their residency rights after his death. Substantive reform of the legal status of Berlin Jews was not seriously considered until after the death of Friedrich II, and full emancipation occurred only in 1812. On this point, see ibid., esp. 69-103.

47. Ibid., 68 .

48. [Gedike], Über Berlin, 146.

49. Lazarus Bendavid, Etwas zur Charakteristik der Juden (Leipzig, 1793), 34-35. The translation is from Lowenstein, Berlin Jewish Community, 2o9n (amended).

50. Two of the more recent examples of this interest are Amos Funkenstein, Perceptions of Jewish History (Berkeley: University of California Press, 1993), in particular the chapter entitled "The Threshold of Modernity," and Eduard Breuer, "Of Miracles and Events Past: Mendelssohn on History," Jewish History 9, no. 2 (1995): 27-52.

51. Allan Arkush, Moses Mendelssohn and the Enlightenment (Albany: State University of New York Press, 1994), xiv-xv.

52. My summary of Mendelssohn's arguments in Jerusalem is indebted to the discussion contained in Sorkin, Moses Mendelssohn, 127-46. For another discussion, see Arnold Eisen, "Divine Legislation as 'Ceremonial Script': Mendelssohn on the Commandments," AJS Review 15, no. 2 (1990): 239-67.

53. Mendelssohn, Jerusalem, trans. Allan Arkush (Hanover, N.H.: University Press of New England, 1983), 119-20.

54. Sorkin, Moses Mendelssohn, 134-35.

55. Mendelssohn, Jerusalem, 118. 
56. Ibid., 103.

57. Ibid., 103-4.

58. Garve, "Über die Lage Schlesiens," 258-59.

59. [Gedike], Über Berlin, 15.

6o. Ibid., 146.

61. Zöllner, "Beitrag," 104-5.

62. Mendelssohn, “On the Question: What Does 'to Enlighten' Mean?, in Philosophical Writings, 313 .

63. Ibid., 315.

64. Ibid., 316.

65. Ibid., 314 .

66. Ibid.

67. Willi Goetschel, "Moses Mendelssohn und das Projekt der Aufklärung," Germanic Review 71, no. 3 (1996): 171.

68. It should be noted that Mendelssohn does accept that certain fields of inquiry exhibit a steady increase in the quantity and quality of knowledge available, most notably philosophy.

69. Mendelssohn, Jerusalem, 97.

70. Garve, "Über die Lage Schlesiens," 251.

71. See the commentary to the essay in Friedrich Schleiermacher, Schriften, ed. Andreas Arndt (Frankfurt am Main: Deutscher Klassiker Verlag, 1996), 1139.

72. Deborah Hertz, Jewish High Society in Old Regime Berlin (New Haven: Yale University Press, 1988), 261. Grattenauer's pamphlets were quite popular and went through several printings. They also generated a variety of published responses from both Jews and gentiles.

73. Karl Friedrich Wilhelm Grattenauer, Erster Nachtrag zu seiner Erklärung über seine Schrift: Wider die Juden (Berlin: Johann Wilhelm Schmidt, 1803), 50.

74. Ibid., 52.

\section{CONCLUSION}

1. Quoted in Heinz Knobloch, Herr Moses in Berlin (Frankfurt am Main: Fischer, 1997), 254-55.

2. [F. Schulz], "Kleine Wanderungen durch Teutschland, in Briefen eines Hypochondristen an den Doctor $\mathrm{K}^{\star}$," Teutscher Merkur 2 (1785): 75. 



\section{WORKS CITED}

\section{EIGHTEENTH-CENTURY SOURCES}

Abbt, Thomas. "Von dem verschiedenen Gebrauch der alten Geschichte." Wöchentliche Hallische Anzeigen (1760): 177-87, 193-203.

"Betrachtungen über den Geschmack am Landleben." Hannoverisches Magazin 6 (1768): 737-46 (originally in French).

"Briefe eines Reisenden aus Berlin." Teutscher Merkur, no. 4 (1787): 57-82, 135-52; no. 1 (1788): 93-106.

Chladenius, Johann Martin. Allgemeine Geschichtswissenschaft. 1752. Reprint, with a foreword by Reinhart Koselleck and an introduction by Christoph Friedrich. Vienna: Böhlau, 1985.

- Einleitung zur richtigen Auslegung vernünftiger Reden und Schriften. 1742. Reprint, with an introduction by Lutz Geldsetzer. Düsseldorf: Stern Verlag Janssen, 1969.

“Damalis, oder der Sieg des Landlebens." Hannoverisches Magazin 8 (1770): 433-42.

"Die Sitten der Stadt: Nach einer Satyre des Juvenals." Hannoverisches Magazin 8 (1770): 1073-82.

Dohm, Christian Wilhelm von. Über die bürgerliche Verbesserung der Juden. 1781. Reprint, 2 vols. in 1, Hildesheim: Georg Olms, 1973.

"Ein Wort über die vielen antiberlinischen Schriften in unseren Tagen." Berlinische Monatsschrift 2 (1785): 311-35.

Engel, Johann Jacob. "Über Handlung, Gespräch und Erzählung.” Neue Bibliothek der schönen Wissenschaften und der freyen Künste 16 (1774): 177256. Excerpt reprinted in Theoretiker der deutschen Aufklärungshistorie, edited by Horst Walter Blanke and Dirk Fleischer, 2:599-604. Stuttgart-Bad Cannsstatt: Frommann-Holzboog, 1990.

Frederick, King of Prussia. De la littératur allemande. Edited by Christoph Gutknecht and Peter Kerner. Hamburg: Helmut Buske, 1969.

Garve, Christian. Gesammelte Werke. Edited by Kurt Wölfel. Sec. 1, vol. 4, part 1. 1796 and 180o. Reprint, Hildesheim: Georg Olms, 1985.

Gatterer, Johann Christoph. "Abhandlung vom Standort und Gesichtspunct des Geschichtsschreibers oder der teutsche Livius.” In Allgemeine Historische Bibliothek 5 (1768): 3-29. Reprinted in Theoretiker der deutchen 
Aufklärungshistorie, edited by Horst Walter Blanke and Dirk Fleischer, 2:452-66. Stuttgart-Bad Cannstatt: Frommann-Holzboog, 1990.

[Gedike, Friedrich]. Über Berlin: Briefe "Von einem Fremden" in der Berlinischen Monatsschrift 1783-1785. Edited by Harald Scholtz. Berlin: Colloquium Verlag, 1987.

Glatzer, Ruth, ed. Berliner Leben 1648-1806: Erinnerungen und Berichte. Berlin: Rütten \& Loening, 1956.

[Göckingk, Ludwig Friedrich Günther von]. "Briefe eines Reisenden an den Drost von LB." Deutsches Museum 2 (1779): 267-79.

Goethe, Johann Wolfgang. Sämtliche Werke, Briefe, Tagebücher und Gespräche. Edited by Dieter Borchmeyer et al. 40 vols. Frankfurt am Main: Deutscher Klassiker Verlag, 1985-99.

Grattenauer, Karl Friedrich Wilhelm. Erster Nachtrag zu seiner Erklärung über seine Schrift: Wider die Juden. Berlin: Johann Wilhelm Schmidt, 1803.

[Hartmann, Gottlob David]. "Über das Ideal einer Geschichte.” Teutscher Merkur 6 (1774): 195-213. Reprinted in Theoretiker der deutschen Aufklärungshistorie, edited by Horst Walter Blanke and Dirk Fleischer, 2:688-97. Stuttgart-Bad Cannstatt: Frommann-Holzboog, 1990. 688-697.

Herder, Johann Gottfried. Auch eine Philosophie der Geschichte zur Bildung der Menschheit. In Sämtliche Werke, edited by Bernhard Suphan, vol. 5. 1891. Reprint, Hildesheim: Georg Olms, 1967.

Hölty, Ludwig. "Das Landleben." In Gesammelte Werke und Briefe, edited by Walter Hettche, 220-21. Göttingen: Wallstein, 1998.

Justi, Johann Heinrich Gottlob von. "Die große Stadt in verschiedenen Verhältnissen betrachtet, insonderheit von den besten Maaßregeln sie mit Abgaben zu belegen, und ihr einen wohlfeilen Preiß der Lebensmittel zu verschaffen." In Gesammelte Politische und Finanz-Schriften, 3:449-538. 1764. Reprint, Aalen: Scientia Verlag, 1970.

Kant, Immanuel. "An Answer to the Question: 'What Is Enlightenment?' " In Political Writings, edited by Hans Reiss and translated by H. B. Nisbet. 2d, enlarged ed. Cambridge: Cambridge University Press, 1991.

[Krögen, Karl Heinrich]. Freie Bemerkungen über Berlin, Leipzig, Prag. Leipzig: Gustav Kiepenheuer Verlag, 1986.

Lessing, Gotthold Ephraim. Nathan the Wise, Minna von Barnhelm, and Other Plays and Writings. Edited by Peter Demetz. New York: Continuum, 1991.

- Werke und Briefe. Edited by Wilfried Barner et al. 12 vols. Frankfurt am Main: Deutscher Klassiker Verlag, 1987.

Lessing, Gotthold Ephraim, Moses Mendelssohn, and Friedrich Nicolai. Briefwechsel über das Trauerspiel. Edited by Jochen Schulte-Sasse. Munich: Winkler, 1972.

Mendelssohn, Moses. Gesammelte Schriften: Jubiläumsausgabe. Edited by Alexander Altmann et al. 27 vols. to date. Stuttgart-Bad Cannstatt: Frommann-Holzboog, 1971-. 
Jerusalem. Translated by Allan Arkush. Hanover, N.H.: University Press of New England, 1983.

- Philosophical Writings. Edited and translated by Daniel O. Dahlstrom. Cambridge: Cambridge University Press, 1997.

Montesquieu, Baron de. The Spirit of the Laws. Edited by Franz Neumann and translated by Thomas Nugent. New York: Hafner Publishing Company, 1966.

Moritz, Karl Philipp. Anton Reiser: A Psychological Novel. Translated by John R. Russell. Columbia, S.C.: Camden House, 1996.

Nicolai, Friedrich. Beschreibung der königlichen Residenzstädte Berlin und Potsdam und aller daselbst befindlicher Merkwürdigkeiten. Berlin, 1779.

- Beschreibung einer Reise durch Deutschland und die Schweiz im Jahre 1781, nebst Bemerkungen über Gelehrsamkeit, Industrie, Religion und Sitten. Vol. 7. Berlin, 1786.

- Gesammelte Werke. Edited by Bernhard Fabian and Marie-Luise Spieckermann. 20 vols. Hildesheim: Georg Olms, 1985-99.

—. Sämtliche Werke, Briefe, Dokumente. Edited by P. M. Mitchell et al. 4 vols. to date. Berlin: Peter Lang, 1991.

Rousseau, Jean-Jaques. Emile, or, On Education. Translated by Allan Bloom.

New York: Basic Books, 1979.

- Politics and the Arts: Letter to M. d'Alembert on the Theater. Translated by Allan Bloom. Glencoe, Ill.: Free Press, 1960.

- The Indespensable Rousseau. Compiled and presented by John Hope Mason. London: Quartet Books, 1979.

Schiller, Friedrich. On the Aesthetic Education of Man in a Series of Letters.

Edited and translated by Elizabeth M. Wilkinson and L. A. Willoughby. Oxford: Clarendon Press, 1967.

—. "Was heißt und zu welchem Ende studiert man Universalgeschichte." In Schillers Werke: Nationalausgabe, edited by Lieselotte Blumenthal and Benno von Wiese, 17:359-76. Weimar: Hermann Böhlaus Nachfolger, 1962. Schleiermacher, Friedrich. "Versuch einer Theorie des geselligen Betragens." In Schriften, edited by Andreas Arndt, 65-91. Frankfurt am Main: Deutscher Klassiker Verlag, 1996.

Schlosser, Johann Georg. Katechismus der Sittenlehre für das Landvolk. Edited by Holger Böning and Reinhart Siegert. Stuttgart-Bad Cannstatt: Frommann-Holzboog, 1998.

"Schreiben an einen Freund, von den Vorzügen des Landlebens vor dem Stadtleben." Hannoverisches Magazin 2 (1764): 29-32.

"Schreiben eines Frauenzimmers vom Lande an ihre Freundin in der Stadt." Hannoverisches Magazin 2 (1764): 65-72.

"Schreiben eines neuverpflanzten Großstädters an seinen zurückgelassenen lieben Kleinstädter." Hannoverisches Magazin 16 (1778): 98-122.

[Schulz, F.]. "Kleine Wanderungen durch Teutschland, in Briefen eines 
Hypochondristen an den Doctor K*." Teutscher Merkur, no. 2 (1785): 54-76, 121-42.

Staël, Anne Germaine de. De l'Allemangne. Edited by Jean de Pange and Simone Balayé. Paris: Hacette, 1958.

Steuart, J. "Von großen Städten und von Städten überhaupt." Hannoverisches Magazin 5 (1767): 1543-53 (originally in English).

Süßmilch, Johann Peter. Die göttliche Ordnung in den Veränderung des menschlichen Geschlechts. Berlin: Verlag Daniel August Gohls, 1742.

- Abhandlung von den schnellen Wachsthum der Königlichen Residentz Berlin. In Die königliche Residenz Berlin und die Mark Brandenburg im 18. Jahrhundert: Schriften und Briefe. Edited by Jürgen Wilke. Berlin: Akademie Verlag, 1994.

Taube, Friedrich Wilhelm. “Gedanken über die Verschönerung der Städte, mit einer historischen Nachricht, wie seit 1763 die vornehmsten Hauptstädte in Europa sich allmählig verbessert und verschönert haben.” Deutsches Museum 2 (1776): 625-49.

"Über die Erzeugung und Erziehung in Berlin." Allerneueste Mannigfaltigkeiten 1 (1782): 145-6o.

Zedler, Johann Heinrich, ed. Grosses vollständiges Universallexikon. Lepzig: Zedler, 1732-50.

[Zöllner, Johann Friedrich]. "Beitrag zur Charakteristik der großen Städte und des Großstädters.” Lesebuch für alle Stände 4 (1783): 101-26.

\section{SECONDARY LITERATURE/OTHER SOURCES}

Albrecht, Wolfgang. Gotthold Ephraim Lessing. Stuttgart: J. B. Metzler, 1997. Altmann, Alexander. Moses Mendelssohn: A Biographical Study. University: University of Alabama Press, 1973.

Arkush, Allan. Moses Mendelssohn and the Enlightenment. Albany: State University of New York Press, 1994.

Barner, Wilfried, et al. Lessing: Epoche-Werk-Wirkung. Munich: C. H. Beck, 1987.

Benjamin, Walter. “On Some Motifs in Baudelaire." In Illuminations, edited by Hannah Arendt and translated by Harry Zohn, 155-200. New York: Schocken, 1968.

Blanke, Horst Walter. Historiographiegeschichte als Historik. Stuttgart-Bad Cannstatt: Frommann-Holzboog, 1991.

Blumenberg, Hans. "Progress Exposed as Fate?" In Rethinking the Subject: An Anthology of Contemporary European Social Thought, edited by James D. Faubion, 90-97. Boulder: Westview Press, 1995.

Bödeker, Hans Erich. "Die Entstehung des modernen historischen Denkens als sozialhistorischer Prozeß. Ein Essay.” In Geschichtsdiskurs, edited by 
Wolfgang Küttler, Jörn Rüsen, and Ernst Schulin, vol. 2, Anfänge modernen historischen Denkens, 295-319. Frankfurt am Main: Fischer, 1994. "Journals and Public Opinion: The Politicization of the German Enlightenment in the Second Half of the Eighteenth Century." In The Transformation of Political Culture: England and Germany in the Late Eighteenth Century, edited by Eckhart Hellmuth, 423-45. London: Oxford University Press, 1990.

. "Reisebeschreibungen im historischen Diskurs der Aufklärung." In Aufklärung und Geschichte: Studien zur deutschen Geschichtswissenschaft im 18. Jahrhundert, edited by Hans Erich Bödecker et al., 276-98. Göttingen: Vandenhoeck \& Ruprecht, 1986.

Bödeker, Hans Erich, et al., eds. Aufklärung und Geschichte: Studien zur deutschen Geschichtswissenschaft im 18. Jahrhundert. Göttingen: Vandenhoeck \& Ruprecht, 1986.

Breuer, Eduard. "Of Miracles and Events Past: Mendelssohn on History.” Jewish History 9, no. 2 (1995): 27-52.

Brunner, Otto, Werner Conze, and Reinhart Koselleck. Geschichtliche Grundbegriffe: Historisches Lexikon zur politisch-sozialen Sprache in Deutschland. 8 vols. Stuttgart: E. Klett, 1972-97.

Cassirer, Ernst. The Philosophy of the Enlightenment. Translated by Fritz C. A. Koelln and James P. Pettegrove. Princeton: Princeton University Press, 1951. Originally published as Die Philosophie der Aufklärung (Tübingen: J. C. B. Mohr, 1932).

Dent, N. J. H. A Rousseau Dictionary. Oxford: Blackwell, 1992.

Descartes, René. Discourse on the Method of Rightly Conducting One's Reason and Seeking Truth in the Sciences. In The Philosophical Writings of Descartes, translated by Robert Stoothoff, 111-51. Cambridge: Cambridge University Press, 1985.

Desch, Joachim. "Vernünfteln wider die Vernunft: Zu Lessings Begriff eines konsequenten Rationalismus." In Humanität und Dialog: Lessing und Mendelssohn in neuer Sicht, edited by Erhard Bahr, Edward P. Harris, and Laurence G. Lyon, 133-41. Detroit: Wayne State University Press, 1982.

Dipper, Christof. Deutsche Geschichte 1648-1789. Frankfurt am Main: Suhrkamp, 1991.

Dülmen, Richard van. Die Gesellschaft der Aufklärer. Frankfurt am Main: Fischer, 1986.

Dyck, Joachim, ed. Minna von Barnhelm oder: Die Kosten des Glücks. Berlin: Verlag Klaus Wagenbach, 1981.

Eisen, Arnold. 'Divine Legislation as 'Ceremonial Script': Mendelssohn on the Commandments." AJS Review 15, no. 2 (1990): 239-67.

Escher, Felix. "Die brandenburgisch-preußische Residenz und Hauptstadt Berlin im 17. und 18. Jahrhundert." In Geschichte Berlins, edited by Wolfgang Ribbe, 344-403. Munich: C. H. Beck, 1987. 
Fabian, Bernhard, ed. Friedrich Nicolai, 1733-1811: Essays zum 250. Geburtstag. Berlin: Nicolaische Verlagsbuchhandlung, 1983.

Fick, Monika. Lessing Handbuch: Leben-Werk-Wirkung. Stuttgart: Metzler, 2000.

Fredericksen, Elke. "Blick in die Ferne: Zur Reiseliteratur von Frauen.” In Frauen Literatur Geschichte: Schreibende Frauen vom Mittelalter bis zur Gegenwart, edited by Hiltrud Gnüg and Renate Möhrmann, 104-22. Stuttgart: Metzler, 1985.

Fritzsche, Peter. Reading Berlin, 1900. Cambridge, Mass.: Harvard University Press, 1996.

Funkenstein, Amos. Perceptions of Jewish History. Berkeley: University of California Press, 1993.

Goetschel, Willi. "Moses Mendelssohn und das Projekt der Aufklärung." Germanic Review 71, no. 3 (1996): 163-75.

Goldenbaum, Ursula. “Der 'Berolinismus': Die preußische Hauptstadt als ein Zentrum geistiger Kommunikation in Deutschland." In Aufklärung in Berlin, edited by Wolfgang Förster, 339-62. Berlin: Akademie-Verlag, 1989.

Habermas, Jürgen. “Aus der Geschichte lernen?” In Die Normalität einer Berliner Republik, 9-18. Frankfurt am Main: Suhrkamp, 1995.

Hentschel, Uwe. "Die Reiseliteratur am Ausgang des 18. Jahrhunderts: Vom Gelehrten Bericht zur Literarischen Beschreibung." Internationales Archiv für Sozialgeschichte der deutschen Literatur 16, no. 2 (1991): 51-83.

Hertz, Deborah. Jewish High Society in Old Regime Berlin. New Haven: Yale University Press, 1988.

Heym, Georg. "Der Gott der Stadt.” In Menschheitsdämmerung: Symphonie jüngster Dichtung, edited by Kurt Pinthus, 6-7. Berlin: Ernst Rowohlt, 1922.

Hinck, Walter. "Lessings Minna-Anmut und Geist: Kleine Komödien-Chronik zur Emanzipation der Frau.” In Festschrift für Rainer Gruenter, edited by Bernhard Fabian, 9-25. Heidelberg: C. Winter, 1978.

Jameson, Fredric. "Postmodernism and Consumer Society." In The Cultural Turn: Selected Writings on the Postmodern, 1983-1998, 1-20. London: Verso, 1998.

Kleinschmidt, Erich. "Die ungeliebte Stadt: Umrisse einer Verweigerung in der deutschen Literatur des 18. Jahrhunderts." LiLi 48 (1982): 29-49.

Klotz, Volker. Die Erzählte Stadt. Munich: Carl Hanser Verlag, 1969.

Knobloch, Clemens. "Überlegungen zur Theorie der Begriffsgeschichte aus Sprach- und Kommunikationswissenschaftlicher Sicht." Archiv für Begriffsgeschichte 35 (1992): 7-24.

Knobloch, Heinz. Herr Moses in Berlin. Frankfurt am Main: Fischer, 1996.

Kondylis, Panajotis. Die Aufklärung im Rahmen der neuzeitlichen Rationalismus. Munich: Deutscher Taschenbuch Verlag, 1986.

Koselleck, Reinhart. "Begriffsgeschichte und Sozialgeschichte." In Historische 
Semantik und Begriffsgeschichte, edited by Reinhart Koselleck, 19-36. Stuttgart: Klett-Cotta, 1978.

—. Vergangene Zukunft: Zur Semantik geschichtlicher Zeiten. Frankfurt am Main: Suhrkamp, 1979.

. Zeitschichten: Studien zur Historik. Frankfurt am Main: Suhrkamp, 2000.

Kracauer, Siegfried. The Mass Ornament: Weimar Essays. Edited and translated by Thomas Y. Levin. Cambridge, Mass.: Harvard University Press, 1995.

Kühlmann, Wilhelm. Gelehrtenrepublik und Fürstenstaat: Entwicklung und Kritik des deutschen Späthumanismus in der Literatur des Barockzeitalters. Tübingen: Max Niemeyer, 1982.

Kugler, Hartmut. Die Vorstellung der Stadt in der Literatur des deutschen Mittelalters. Munich: Artemis, 1986.

Küttler, Wolfgang, Jörn Rüsen, and Ernst Schulin, eds. Geschichtsdiskurs. Vol. 2, Anfänge modernen historischen Denkens. Frankfurt am Main: Fischer, 1994.

Lehrer, Mark. "Lessing's Economic Comedy." Seminar 20, no. 2 (1984): 79-94.

Lessing, Karl. G. E. Lessings Leben. Edited by Otto F. Lachmann. Leipzig: Reclam, 1886.

Lowenstein, Steven M. The Berlin Jewish Community: Enlightenment, Family and Crisis, 1770-1830. Oxford: Oxford University Press, 1994.

Lukács, Georg. “Minna von Barnhelm.” In Wege der Forschung: Gotthold Ephraim Lessing, edited by Gerhard Bauer and Sibylle Bauer, 427-47. Darmstadt: Wissenschaftliche Buchgesellschaft, 1968.

Martens, Wolfgang. “Ein Bürger auf Reisen.” In Friedrich Nicolai, 1733-1811: Essays zum 250. Geburtstag, edited by Bernhard Fabian, 99-123. Berlin: Nicolaische Verlagsbuchhandlung, 1983.

Michelsen, Peter. "Die Verbergung der Kunst: Über die Exposition in Lessings Minna von Barnhelm." Jahrbuch der deutschen Schillergesellschaft 17 (1973): 192-252.

Möller, Horst. Aufklärung in Preussen: Der Verleger, Publizist und Geschichtsschreiber Friedrich Nicolai. Berlin: Colloquium, 1974.

—_. "Friedrich Nicolai als Historiker." In Friedrich Nicolai, 1733-1811: Essays zum 250. Geburtstag, edited by Bernhard Fabian, 139-73. Berlin: Nicolaische Verlagsbuchhandlung, 1983.

- Vernunft und Kritik: Deutsche Aufklärung im 17. und 18. Jahrhundert. Frankfurt am Main: Suhrkamp, 1986.

Mumford, Lewis. The City in History. New York: Harcourt, Brace \& World, Inc., 1961.

Nölle, Volker. Subjektivität und Wirklichkeit in Lessings dramatischem und theologischem Werk. Berlin: Erich Schmidt, 1977.

Purdy, Daniel L. The Tyranny of Elegance: Consumer Cosmopolitanism in the Era of Goethe. Baltimore: Johns Hopkins University Press, 1998. 
Reill, Peter Hanns. The German Enlightenment and the Rise of Historicism. Berkeley: University of California Press, 1975.

Rilla, Paul. Lessing und sein Zeitalter. Berlin: Aufbau-Verlag, 1981.

Rose, Paul Lawrence. German Question/Jewish Question: Revolutionary Antisemitism from Kant to Wagner. Princeton: Princeton University Press, 1990.

Rüsen, Jörg. Review of Historische Semantik und Begriffsgeschichte, edited by Reinhart Koselleck. Journal of Modern History 54, no. 2 (1982): 326-28.

Sadowsky, Thorsten. "Gehen Sta(d)t Fahren. Anmerkungen Zur urbanen Praxis des Fußgängers in der Reiseliteratur des 18. Jahrhunderts.” In Wanderzwang - Wanderlust: Formen der Raum- und Sozialerfahrung zwischen Aufklärung und Frühindustrialisierung, edited by Wolfgang Albrecht and Hans-Joachim Kertscher, 61-90. Tübingen: Max Niemeyer, 1999.

Saße, Günther. Die Ordnung der Gefühle: Das Drama der Liebesheirat im 18. Jahrhundert. Darmstadt: Wissenschaftliche Buchgesellschaft, 1996.

Schilling, Heinz. Die Stadt in der frühen Neuzeit. Munich: R. Oldenbourg, 1993.

Schmidt, Heinrich. Die deutschen Stadtchroniken als Spiegel des bürgerlichen Selbstverständnisses im Spätmittelalter. Goettingen: Vandenhoeck \& Ruprecht, 1958.

Schulz, Helga. Berlin 1650-180o: Sozialgeschichte einer Residenz. Berlin: Akademie-Verlag, 1987.

Seeba, Hinrich C. Die Liebe zur Sache: Öffentliches und privates Interesse in Lessings Dramen. Tübingen: Niemeyer, 1973.

_. "Der wahre Standort einer jeden Person: Lessings Beitrag zum historischen Perspektivismus." In Nation und Gelehrtenrepublik: Lessing im europäischen Zusammenhang, edited by Wilfried Barner and Albert M. Reh, 193-214. Detroit: Wayne State University Press, 1984.

Selwyn, Pamela. Everyday Life in the German Book Trade: Friedrich Nicolai as Bookseller and Publisher in the Age of Enlightenment, 1750-1810. University Park: Pennsylvania State University Press, 2000.

Sennet, Richard. Flesh and Stone: The Body and the City in Western Civilization. New York: Norton, 1994.

Sheehan, James J. "Begriffsgeschichte: Theory and Practice." Journal of Modern History 50, no. 2 (1978): 312-19.

Simmel, Georg. “The Metropolis and Mental Life.” In Rethinking Architecture, edited by Neal Leach, 69-85. London: Routledge, 1997.

Sorkin, David. Moses Mendelssohn and the Religious Enlightenment. Berkeley: University of California Press, 1996.

Treue, Wilhelm. Wirtschaftsgeschichte der Neuzeit. Stuttgart: Alfred Kröner, 1966.

Vierhaus, Rudolf. "Historisches Interesse im 18. Jahrhundert.” In Aufklärung und Geschichte: Studien zur deutschen Geschichtswissenschaft im 18. 
Jahrhundert, edited by Hans Erich Bödeker et al., 264-75. Göttingen: Vandenhoeck \& Ruprecht, 1986.

Vietta, Silvio. Die literarische Moderne. Stuttgart: Metzler, 1992.

Weigl, Engelhard. Schauplätze der deutschen Aufklärung: Ein Städterundgang. Reinbek bei Hamburg: Rowohlt, 1997.

Werner, Hans-Georg. Text und Dichtung: Analyse und Interpretation. Berlin: Aufbau-Verlag, 1984.

Wiedemann, Conrad. "Einleitendes Referat." In Rom-Paris-London:

Erfahrung und Selbsterfahrung deutscher Schriftsteller und Künstler in den fremden Metropolen, edited by Conrad Wiedemann, 21-29. Stuttgart: J. B. Metzler, 1987.

. “'Supplement seines Daseins'?: Zu den kultur- und identitätsgeschichtlichen Voraussetzungen deutscher Schriftstellerreisen nach Rom-Paris-London seit Winckelmann." In Rom-Paris-London: Erfahrung und Selbsterfahrung deutscher Schriftsteller und Künstler in den fremden Metropolen, edited by Conrad Wiedemann, 1-20. Stuttgart: J. B. Metzler, 1987. 



\section{N D E X}

Abbt, Thomas, 21

Absolutism: impact on development of cities, 26-27, 29-31

Beauty, urban, 3, 38, 85-86

Bendavid, Lazarus: Something on the Character of the Jews, 152

Benjamin, Walter, 94-95

Berlin: dynamism of, 13, 25, 2829; compared with other cities, 24-25, 26, 38, 85, 98, 168, 171, 184 (n. 3); population and rapid growth of, 24-25, 26, 37, 51, 74, 181 (n. 73); modernity of, 26, 31, 169; historical-theoretical complexity of, $28,50,51-63,65-66,85-88,95$, 171-73; as territorial capital, $28-$ 29, 49, 83, 148, 168-69, 182 (n. 8o); reputation for tolerance of, 29-30, 45, 90-91, 97-98; economic conditions in, 30; social heterogeneity of, 31, 45, 59, 99, 101-2, 118, 145, 183 (n. 100); as center of enlightenment, 34, 89-91, 95, 98; 1780 s controversy over, 37-38, 39; beauty of, $38,85-86$; and fashion, 46-47, $48,61,92-94$; and idea of progress, 48-49, 52-59, 77-79, 84, 90; impact of Hohenzollerns on, 52-54, 7778 ; as site of temporal acceleration, 60-63; and development of models of historical causation, $63,77-81$, 84, 91-94, 95; as text, 75-76; as epistemological problem, 83-85; women in, 106; and perspectivism,
117-19; and sociability, 118, 169. See also City

Berlin Enlightenment: as urban phenomenon, 34, 45

Berliners: as degenerate, 6; unstable identity of, 27-28; role of in improvement of their city, 52, 53

Berlinische Monatsschrift, 9, 37, 146

Berlin Jewish community, 25; and emancipation, 54-55, 197 (n. 31), 198 (n. 46); perceived as case of arrested development, 54-57; impact of wealth on, 56-57, 58, 150, 152; social integration of, 144-45; and modernization, 150-52, 153; K. W. F. Grattenauer's attack on, 164-65

Bertuch, Friedrich, 44

Bestimmung des Menschen, 133, 155

Biester, Johann Erich, 44, 132

Bildung, 136, 141, 158, 164, 170

Blanke, Horst Walter, 11-12

Bloch, Ernst, 7

Blumenberg, Hans, 123, 194 (n. 70)

Bödeker, Hans Erich, 22, 72

Cassirer, Ernst, 1, 7

Causation, historical, 15; competing models of, 22, 80; fashion and, 39, $61-62,92-94$; refinement of theories of, 72-73; materialist versus idealist theories of, 91-92; See also Berlin; City

Chladenius, Johann Martin, 11, 17-18, 126-27 
City: historical versus rationally planned, 2-4, 51-52; as indicator of progress, 4, 48-49, 52-53, 72, 84, 98; as embodiment of civilization, 5-6, 8, 49, 150, 163-64; negative views of, 5-6, 32-34; historicaltheoretical complexity of, 7-8, 23-24, 35, 50, 62-63, 87; biblical representations of, 8, 32, 83, 103; as territorial capital, 8, 26-27, 49, $67-72,148,188$ (n. 12); competing definitions of, 28; versus country, 33-34, 88, 183-84 (n. 111); concerns about growth of, 34; and fashion, 45-46; and development of models of historical causation, 53, 56-57, $63,66,72,73,77,78,79-81,90-$ 91, 95; as universalizing space, 54 , 69, 71-72, 96, 113, 116, 135-36, 137; as site of luxury consumption, 57; as unnatural, 59-60; and development of individual, 60, 70-71, 157-58, 161; eighteenth- versus twentieth-century conceptions of, 64-65, 94-96; and sociability, $68,69,71,89,100,103,104,134-$ 36, 169-70 (See also Sociability, urban); as middle-class space, 71; and autonomy of individual, 96, 97-99, 101-3, 104-7, 109-10, 111-13, 134; as site of premature enlightenment, 101-2, 148-49; and perspectivism, 117, 120-21, 127; and genre, 128, 183 (n. 111); and forms of communication, 134, 155. See also Berlin

City chronicles, 76-77, 189 (n. 33)

Conceptual history, 1, 12, 179 (nn. 30, 31)

Consciousness, historical, 1, 9-10, 25-26, 31; complexity of, 7, 23, 17475; and global exploration, 8, 23; sources of evidence for, 12-13, 23, 51, 173-74; and stadial theory of development, 52; and individual versus social time scales, 60 ; in city chronicles, 76-77; and genre, 174 Culture, objectivity of, 149, 156, 159, 162

Descartes, René, 2-3, 5, 6, 25

Dohm, Christian Wilhelm: On the Civic Improvement of the Jews, 54, 186 (nn. 42, 46)

Drama: capital city and, 69-70, 116; as urban genre, 128-29

Dülmen, Richard van, 197-98 (n. 38)

Dyck, Joachim, 99, 100, 119

Engel, Johann Jakob, 15, 132, 196 (n. 2) Enlightenment, premature, 101-2, $152,157-58,161-62$

Enlightenment debate: urban origins of, 45; as debate about modernity, 87

Fashion: as historical-theoretical category, 39, 40, 42-44, 61, 92-94; and identity, 39-40, 93; as source of corruption, 40-42, 46-47; and city, 45-46

François, Etienne, 28

Frederick (king of Prussia): on historiography, 15, 23; and tolerance, 30; and Berlin Enlightenment, 34; as "middle-class" king, 53

Fritzsche, Peter, 65

Garve, Christian, 34, 44; "On the Situation of Silesia at Different Points in Time and on the Advantages of a Capital City over Provincial Cities," 135-36, 138-39, $148-49,163$ 
Gatterer, Johann Christoph, 10, 11, 18 Gedike, Friedrich, 32, 37, 38; life and activities of, 9, 44-45; on growth of Berlin, 24-25, 51-54; on Berlin and Prussia, 27, 168; unstable definition of Berliners, 27-28; on urban overcrowding, 34; On Berlin (letters), 35, 45, 50-51; on Berlin Jewish community, 55-57, 58, 59, 151; on foreigners in Berlin, 59, 101-2; on fashion and luxury in Berlin, $61-63,148-49$; on lack of a university in Berlin, 89, 137-38; on Berlin social life, 118, 155, 169-70, 171

Gender: and fashion, 61; in Minna von Barnhelm, 105-6, 112-13

Geschichte: as collective singular, 14-15 Geschichtsphilosophie, 12, 16, 21; relation of to Enlightenment historiography, 11; Mendelssohn's critique of, 163

Goethe, Johann Wolfgang, 30, 89, 117, 188 (n. 17)

Gossip, 102-3, 134

Göttingen: as center of historical studies, 10, 11

Grattenauer, Karl Wilhelm Friedrich, 164-65

Habermas, Jürgen, 16

Hamburg, 24, 25, 26

Hartmann, Gottlob David, 14

Haskala, 150, 151

Hegel, Georg Wilhelm Friedrich, 11, 16

Herder, Johann Gottfried, 11, 16

Hertz, Deborah, 31, 165, 185 (n. 22)

Hinck, Walter, 114

Historia magistra vitae, 16, 20-21, 23

History: linear versus cyclical conceptions of, $7,8,78-79,164$; as academic discipline, 10-12; popular interest in, 10-12, 80; Christian view of, 13-14, 19, 21-22, 82-83, 84; temporalization of, $13-16,66,87$; and literary narrative, 15-16, 18; didactic function of, 16, 20-21, 23; and perspectivism, 17-19, 126-27; as tool of middle-class emancipation, 19-22, 125-26; supraindividual factors in, 22, 79, 84-85. See also Fashion

Hölty, Ludwig Christoph Heinrich: "Country Life," 34

Jews. See Berlin Jewish community Judaism: Mendelssohn's defense of, 153-55

Justi, Johann Heinrich Gottlob von, $32-33,34,57-58,60$

Kant, Immanuel, 11; "An Answer to the Question: What is Enlightenment?"” 30, 68, 182-83 (n. 95); and idea of progress, 91

Kleinschmidt, Erich, 33, 66-67, 9596, 187-88 (n. 9)

Klotz, Volker, 128

Koselleck, Reinhart, 1, 42; on temporalization of history, 14, 15, 43; on historical perspectivism, 17, 18-19, 126; on idea of an open future, 62

Kracauer, Siegfried, 192 (n. 20)

La Mettrie, Julian Offray de, 30 Lessing, Gotthold Ephraim: ambivalence toward Berlin, 9, 97-98; and Geschichtsphilosophie, 11, 16; views on religion, 19, 97; Minna von Barnhelm, 35, 99-101, 103-30; Correspondence on Tragedy, 109; Emilia Galotti, 111, 129-30, 195 (n. 86); as dialectical thinker, 115-16; views 
on Seven Years' War, 125-26; The Jews, 129; views on city life, 129, 130; Nathan der Weise, 129-30

London, 3, 24-25, 33, 49, 68

Lukàcs, Georg, 114, 122

Luxury, 8, 22, 172; Roman critique of, 40, 184-85 (n. 10); voluntary renunciation of, 45-46; concentration of in city, 57-58; as indicator of social decline, 61-62; Mendelssohn's views on, 150

Mandeville, Bernard, 45, 46

Mendelssohn, Moses, 35, 47; life in Berlin, 9, 144-46; urban context of works, 35, 152-53, 161-62, 170; views on sociability, 35, 131, 14042, 143-46, 161, 162, 170, 172-73; and Berlin Jewish community, 56; reception of, 132-33, 140; critique of Rousseau, 140-42, 144; Epistle to Herr Magister Lessing in Leipzig, 140-43; views on history, 142-43, 147-48, 153, 163; Rhapsody, 143; "On the Question: What Does 'to Enlighten' Mean?,' 146, 15861; "The Division of Offices and Estates," 146-47, 154; on tension between individual and societal development, 149-50, 158-61; "On the Ideal Constitution," 149-50; translation of Pentateuch, 150; Jerusalem, 153-58, 163; defense of Jewish ceremonial law, 155-56; on textuality and modernity, 156-57

Michelsen, Peter, 108-9

Minna von Barnhelm, 35; urban references in, 99-100, 104-5, 191 (n. 6); representation of city as nonregulated space in, 103-7, 109-10, $112-13,128$; gendered reading of, 105-6, 112-13; and perspectivism,
$107,114-15,119-21,123-24$; theme of Tellheim's honor in, 107-9, 12223; public versus private sphere in, 110-11; contemporary reviews of, 117, 193 (n. 43); representation of money in, 119; as critical historiography, 125-27; representation of language in, 135

Mittwochsgesellschaft, 9, 146, 162

Modernity: eighteenth-century discourse on, 97-98, 142-43, 147-48, $157-58,162-63$

Möller, Horst, 66

Money: as vehicle of characterization, 119-21

Montagsklub, 145

Montesquieu, Baron de, 45-46, 188 (n. 12)

Moritz, Karl Philipp, 86-87

Möser, Justus, 11, 19, 27

Mumford, Lewis, 182 (n. 81)

Mündigkeit, 112

Nicolai, Friedrich, 35, 37; life and reception of, 9, 30, 66-67, 187 (nn. 7, 8), 188 (n. 11); as historian, 11, 16, 19, 73-74, 77-78, 81; Description of a Journal through Germany and Switzerland, 16; as advocate of Berlin, 32, 38, 66-67, 75; Sebaldus Nothanker, 35, 68-69, 81-95, 121, 168, 170, 172, 192 (n. 19); Letters on the Current State of the Fine Sciences in Germany, 67-68; on Germany's lack of a national capital, 67-71, 116, 169; Allgemeine Deutsche Bibliothek, 68; Letters concerning the Most Recent Literature, 69-71, 74, 116; views on Hohenzollerns, 71, 77, 78, 84, 90-91, 189 (n. 35); Description of the Royal Court Cities Berlin and Potsdam, 
74-81; on history of Berlin, 76-

81 ; views on historical causation, 77-80, 84-85, 91-94; on fashion, 92-94; relationship to Lessing, 97-98, 115-16

Nölle, Volker, 116

Non-simultaneity, 7, 23, 51, 52, 56

Novel: as urban genre, 128

Paris, 3, 33, 49, 68; Rousseau's views on, 5; compared with Berlin, 24-25, 26

Perspectivism: in Minna von Barnhelm, 107, 114-15, 119-21, 123-24; city as site of, 113, 116, 130; Lessing as advocate of, 115-16; and Berlin, 117-19; money as vehicle of, 119-21; and Seven Years' War, 124-25

Perspectivism, historical, 17-18, 19, 124-27

Philosopher: eighteenth-century ideal of, 132-33

Planck, Gottlieb Jakob, 18

Progress, 7, 24; concept of in flux, 13; and temporalization of history, 16; opposed to fashion, 39, 43-44; dialectic of, 58-59, 60, 62, 150, 164; in Minna von Barnhelm, 123. See also Berlin; City

Provincialism: Germany's alleged, 68-70, 71, 195 (n. 79)

Public sphere: literary, 11; textual versus actual, 68-69; city as, 72, 110; versus private sphere in Minna von Barnhelm, 110-11

Purdy, Daniel, 39, 40, 44, 45, 93, 184 (nn. 9, 10)

Reill, Peter Hanns, 16, 72, 190 (n.48)

Rilla, Paul, 98

Roman Empire, 62

Rome, 26, 33, 49
Rousseau, Jean-Jacques, 5-7, 60, 62, 182 (n. 86). See also Mendelssohn, Moses

Salon culture, 151, 164-65

Schiller, Friedrich: lecture on universal history, $15,21,23,48,50,178$ (n. 19); influenced by Mendelssohn, 179 (n. 36)

Schleiermacher, Friedrich: Attempt at a Theory of Sociable Behavior, 164

Schleuen, Johann David, 166-69, $171-72$

Schlosser, Johann Georg, 34

Schlözer, August Ludwig, 10, 11, 20

Seeba, Hinrich C., 119

Selwyn, Pamela, 187 (n. 8)

Seven Years' War, 99; impact on Berlin Jewish community, 57, 152; and financial crisis in Prussia, 100, 119; differing views on, 124-25

Simmel, Georg, 46, 64, 70, 103, 120

Sociability: dialectic of, 133, 140. See also Mendelssohn, Moses

Sociability, urban: and cultural refinement, 68; and drama, 69-70, 128 ; and development of a universal perspective, 69-71, 118-19, 137-38, 139, 169-70; and temporal cyclicality, 85-87; as opposed to university life, 89 ; as source of practical knowledge, 89-90, 113, 121; as challenge to social hierarchies, 102-3, 134, 135-36, 139, 169; unregulated character of, 103, 104, 118, 134; and gender, 106-7; and idea of progress, 123; and language, 133-34, 139; impact of on development of the individual, 136-39, $148-49,164-65,170-71$; oral character of, 155. See also Mendelssohn, Moses 
Spittler, Ludwig Timotheus, 10, 11

Süßmilch, Johann Peter, 25, 49, 58,

$$
\text { 72, 163-64, } 189 \text { (n. 39) }
$$

Taube, Friedrich Wilhelm, 3, 4, 6, 7, 51

Textuality: Mendelssohn's critique of, 156-57

Travel: emancipatory effects of, 104, 106

Travel literature, $38,48,54,128$

Universalism: as basis for understanding history, 21-22, 78; nationalism as foundation for, 117; and Enlightenment historicism, 174-75. See also City; Sociability

Vienna, 3, 24, 25, 26, 28, 98 Vierhaus, Rudolf, 10-13, 23 Voltaire, 5
Werner, Hans Georg, 114

Wiedemann, Conrad, 33, 183-84

$$
\text { (n. 11), } 195 \text { (n. 79) }
$$

Wolff, Christian, 141

Zedler, Johann Heinrich, 28, 40

Zöllner, Johann Friedrich: "A Contribution to a Characterization of the Big City and the Big City Dweller," 46; on fashion in the city, 46; on premature aging in the city, 59, 158; on dangers of city life, 60; on impact of city life on intellectual achievement, 70-71, 139, 190-91 (n. 64); on forms of urban communication, 102-3, 134; on sociability, 118-19; on free imperial cities, 182

(n. 79) 

